\author{
Universidade de São Paulo \\ Instituto de Física
}

\title{
Caracterização de propriedades mecânicas da região cortical de fibras capilares humanas com mapeamento multiparamétrico por Microscopia de Força Atômica
}

\author{
Raissa Lima de Oblitas
}

Orientadora: Prof ${ }^{a}$. Dr ${ }^{a}$. Maria Cecília B. S. Salvadori

Tese de doutorado apresentada ao Instituto de Física da Universidade de São Paulo, como requisito parcial para a obtenção do título de Doutora em Ciências.

Banca Examinadora:

Prof ${ }^{\mathrm{a}}$. Dr ${ }^{\mathrm{a}}$ Maria Cecília B. S. Salvadori - Orientadora (IFUSP)

Prof ${ }^{a}$. Dr ${ }^{\mathrm{a}}$ Marcia Carvalho de Abreu Fantini (IFUSP)

Prof $^{a}$. Dr ${ }^{\mathrm{a}}$ Denise Freitas Siqueira Petri (IQUSP)

Prof. Dr. Antonio Carlos da Cunha Migliano (IEAv - DCTA)

Prof. Dr. Demétrio Jackson dos Santos (UFABC) 
FICHA CATALOGRÁFICA

Preparada pelo Serviço de Biblioteca e Informação do Instituto de Física da Universidade de São Paulo

\section{Oblitas, Raissa Lima de}

Caracterização de propriedades mecânicas da região cortical de fibras capilares humanas com mapeamento multiparamétrico por Microscopia de Força Atômica. São Paulo, 2021.

Tese (Doutorado) - Universidade de São Paulo. Instituto de Física. Depto. de Física Aplicada.

Orientador: Profa ${ }^{\text {. Dra }}{ }^{\mathrm{a}}$. Maria Cecília Barbosa da Silveira Salvadori

Área de Concentração: Física Aplicada

Unitermos: 1. Fibras naturais; 2. Microscópio de Força Atômica; 3. Elasticidade 


\title{
University of São Paulo \\ Physics Institute
}

\section{Mechanical properties characterization of human hair fibers cortex region by multiparametric Atomic Force Microscopy mapping}

\author{
Raissa Lima de Oblitas
}

Supervisor: Prof. Dr. Maria Cecília B. S. Salvadori

Thesis submitted to the Physics Institute of the University of São Paulo in partial fulfillment of the requirements for the degree of Doctor of Science.

Examining Committee:

Prof. Dr. Maria Cecília B. S. Salvadori - Supervisor (IFUSP)

Prof. Dr. Marcia Carvalho de Abreu Fantini (IFUSP)

Prof. Dr. Denise Freitas Siqueira Petri (IQUSP)

Prof. Dr. Antonio Carlos da Cunha Migliano (IEAv - DCTA)

Prof. Dr. Demétrio Jackson dos Santos (UFABC) 
Este trabalho também é dedicado àqueles que lhes possa ser útil, que sonharam ou sonham em trabalhar com algo que apaixone e que exerça uma função social. 


\section{Agradecimentos}

Aos meus pais, Teresinha e Adolfo. Vocês me deram o tempo da vida e a alegria de vivê-lo. Fizeram também ser possível meus estudos e me apoiaram, sempre. Mesmo em momentos difíceis, não me deixaram desistir e me deram razões para persistir. Obrigada! Ao meu irmão, Yuri. Obrigada pelo infindável companheirismo de sua amizade. À irmã, que adotei pra mim, Mariana Yelena. Obrigada pela amizade e pelos inúmeros textos corrigidos. Ao tio, que adotei pra mim, Walter. Obrigada pela amizade.

Aos amigos que fizeram de toda essa trajetória, desde a graduação, um aprendizado acadêmico e pessoal. Em especial, agradeço ao Baldi - Roberto Baldijão -, Xavito - Rivaldo Xavier -, Adolfo Forti, Andre Luis Santana e à Prof ${ }^{\mathrm{a}}$ Ana Regina Black. Ao CEFISMA - Centro Acadêmico do Instituto de Física da USP -, que representa uma instituição de luta, com a qual tive a feliz oportunidade de aprender e participar.

Aos professores Clara de Almeida e Rodrigo Prioli, pela amabilidade e disponibilidade, com os quais tive a feliz oportunidade de ter aula.

À toda equipe do Laboratório de Filmes Finos (LFF-IFUSP), em especial à Prof ${ }^{\text {a }}$ Cecília Salvadori, sempre me impulsionando em novas jornadas e me orientando de forma muito criteriosa e crítica. Também pelo depósito de sua confiança e por batalhar comigo pelos próximos passos. Aos companheiros de laboratório e café: Filipe, Leonardo, Roman, Robinson e Wagner. Em especial à Fernanda, sanando minhas muitas e enormes dúvidas e problemas, contribuindo nas diversas discussões, também tornando os dias de trabalho muito mais agradáveis. Obrigada! À amiga Natália, por sua amizade e carinho. Obrigada! À amiga Nataly, pelas longas conversas, risadas e tudo que se preza de uma amizade. Obrigada!

À empresa Chemyunion, pelo suporte financeiro e colaboração neste trabalho. Em especial, ao Wagner Magalhães, que abraçou este projeto de colaboração. Ao Flávio Camargo, por sua amabilidade, seu aporte nas discussões e sua disponibilidade. Ao Marcos Rossan e Andrew Camillo pela colaboração nas discussões.

À CAPES, FAPESP, CNPq e FINEP pelo financiamento de diversos equipamentos utilizados. O presente trabalho também foi realizado com apoio da Coordenação de Aperfeiçoamento de Pessoal de Nível Superior - Brasil (CAPES) - Código de Financiamento 001, através de suporte financeiro concedido inicialmente.

Muito obrigada! 
"... Como um velho boiadeiro, levando a boiada Eu vou tocando os dias pela longa estrada, eu vou.

Estrada eu sou. Conhecer as manhas e as manhãs, o sabor das massas e das maçãs ..."

(Almir Sater e Renato Teixeira, Tocando em Frente) 


\section{Resumo}

Este trabalho apresenta a utilização de Microscopia de Força Atômica (AFM: Atomic Force Microscopy) para a avaliação da eficácia de um ativo cosmético, na melhora das propriedades mecânicas de fibras capilares humanas. Para isso, foram caracterizadas fibras sem e com danos químicos (grupo virgem e controle, respectivamente), causados pelo processo de descoloração. Para as amostras danificadas quimicamente, foi aplicado o produto sem e com ativo cosmético (grupo placebo e ativo). As fibras foram embebidas em resina epóxi e cortes foram realizados por ultramicrotomia, para observação das seções transversais por Microscopia Eletrônica de Transmissão (TEM). A superfície do bloco de resina, proveniente do corte, com seção transversal da fibra capilar exposta, foi utilizada para a caracterização por AFM. As propriedades mecânicas da seção transversal das fibras foram caracterizadas por AFM, no modo Force Volume (FV-AFM). No modo FV-AFM, registra-se uma curva força-distância (FC) em cada ponto da varredura, obtendo uma matriz 2D de FCs associada à imagem topográfica. Para cada FC foram obtidos dados de força de adesão entre a sonda e a amostra, deformação máxima da amostra pela sonda e módulo de Young $(E)$. Os dados da fibra e da resina foram obtidos simultaneamente em um mapa, com a finalidade de ter os dados da resina como referência, de forma a garantir uma comparação coerente entre os grupos das fibras. Para comparação dos grupos das fibras, foram realizadas avaliações estatísticas utilizando o método ANOVA (Analysis of Variance), considerando nível de significância $\alpha=5 \%$. Foi encontrado que o grupo controle mostrou um decréscimo estatisticamente significante no logaritmo natural do módulo de Young $(\ln (E))$ em relação ao grupo de fibras virgens e que o grupo ativo apresentou aumento de $(\ln (E))$ em relação ao grupo controle e em relação ao grupo placebo. Os resultados demonstraram a degradação das fibras do grupo controle, corroborando com a análise realizada por TEM; e a aplicação do produto com ativo foi eficaz na melhora do módulo de Young da fibra danificada. Também encontramos uma diminuição radial de $\ln (E)$ ao longo da seção transversal da fibra do grupo ativo, o que é compatível com o resultado obtido pela análise de Confocal Raman Spectroscopy, o qual apresentou variação da permeação do ativo ao longo da profundidade. Vale ressaltar que o módulo de Young também foi determinado por Tensile Tester, no qual não foi possível verificar diferenças estatisticamente significantes entre os grupos, evidenciando a vantagem da análise por FV-AFM. Também foi encontrado a prevalência de diminuição de $\ln (E)$ para maiores forças de adesão entre a ponta e a amostra, por meio da análise do coeficiente de correlação de Pearson $r$. Esse resultado pode corroborar com a presença de estruturas adesivas diferenciadas (Cell Membrane Complex - CMC com baixo teor de cistina), que apresentam baixo módulo de Young.

Palavras-chaves: fibra capilar; região cortical; curva de força; propriedades mecânicas. 


\section{Abstract}

In this work, by use of Atomic Force Microscopy, we show the evaluation of the effectiveness of a cosmetic active improving the mechanical properties of human hair fibers. For this, we characterized human hair fibers without and with chemical damage (virgin and control group, respectively) caused by bleaching process, using Atomic Force Microscopy (AFM). For chemically damaged samples, product without and with cosmetic active (placebo and active group, respectively) was applied. The fibers were embedded in epoxy resin and cuts were made by ultramicrotomy, for observing cross-sections by Transmission Electron Microscopy (TEM). The resin block surface from the cut with exposed hair fiber cross-section, was used for the characterization by AFM. Mechanical properties of the fibers cross-section surface were characterized by AFM, in Force Volume (FV-AFM) mode. FV-AFM records a force-distance curve (FC) at each point of the scan, obtaining a $2 \mathrm{D}$ matrix of FCs associated with topographic images. For each FC, it was obtained adhesion force between probe and sample, maximum sample deformation by the probe and Young's modulus $(E)$ data. The fiber and resin data were obtained simultaneously in a map for the purpose of having the resin data as a reference, to ensure a coherent comparison between the fibers groups. To compare the fibers groups, statistical evaluations were performed using the ANOVA (Analysis of Variance) method, considering the significance level $\alpha=5 \%$. We found that the control group, showed a statistically significant decrease in the natural logarithm of Young's modulus $(\ln (E))$ concerning the virgin fibers group and, the active group presented an increase of $(\ln (E))$, concerning the control group and placebo group. Our results demonstrated the fiber degradation of the control group, corroborating with TEM analysis; and the application of the product with active was effective in improving the Young's modulus of the damaged fiber. We also found a radial decrease of $\ln (E)$ along the cross-section of the active group fiber, which is compatible with the results obtained by Confocal Raman Spectroscopy analysis, that presented variation of the active permeation along the depth. It is worth mentioning that the Young's modulus was also determined by Tensile Tester, in which it was not possible to verify statistically significant differences between the groups, evidencing the advantage of the FV-AFM analysis. We also found the prevalence of decrease of $\ln (E)$ for higher adhesion force between tip and sample, using Pearson's correlation coefficient analysis $r$. This result may corroborate with the presence of differentiated adhesive structures (Cell Membrane Complex - CMC with low cystine contents), which have low Young's modulus.

Key-words: hair fiber; cortex region; force curve; mechanical properties. 


\section{Lista de ilustrações}

Figura 1.1 - Desenho esquemático da fibra capilar, mostrando (a) a borda de um corte transversal, detalhando a estrutura sublamelar da cutícula e (b) micro e nanoestruturas $[1] \ldots \ldots$. . . . . . . . . . . . . . . . . . . . . . . 19

Figura 1.2 - Subestruturas do córtex, onde cada "cone"corresponde a uma ampliação maior, evidenciando estruturas menores $[2]$. . . . . . . . . . .

Figura 2.1 - Gráfico da força de interação entre a sonda e a superfície da amostra em AFM, dada pelo potencial de Lennard-Jones, apresentando os três modos de operação: modo não-contato; modo de contato intermitente; e modo contato. . . . . . . . . . . . . . . . . . . . 23

Figura 2.2 - Desenho esquemático do Microscópio de Força Atômica (AFM). . . . . 24

Figura 2.3 - Curva de força (FC) típica durante aproximação e distanciamento entre ponta e superfície da amostra [3]. . . . . . . . . . . . . . .

Figura 2.4 - Curva de força-distância (FD) em função da profundidade de indentação $\delta$ para materiais com comportamento (a) idealmente elástico e (b) com comportamento elasto-plástico, dada uma força máxima configurada (trigger) [4] - adaptada. . . . . . . . . . . . . . . .

Figura 2.5 - Posições do sistema quando (a) a ponta está afastada da superfície, (b) a ponta está próxima à superfície e (c) a ponta está indentando a superfície. . . . . . . . . . . . . . . . . . 27

Figura 2.6 - Modelo de contato mecânico, apresentando as grandezas $F, R$ e $a$. . . . 28

Figura 2.7 - Razão entre a força de adesão entre ponta e amostra $F_{a d}$ e a força máxima exercida pela ponta sobre a amostra $F_{\text {max }}$, para cada amostra. As amostras são identificadas pela letra correspondente ao seu grupo (V: Virgem; C: Controle; P: Placebo; A: Ativo), seguida do número da fibra (1 a 8). As especificações das amostras são apresentadas na seção 2.4 (Tab. 2.2). . . . . . . . . . . . . . . . . . . . . .

Figura 2.8 - a) Curvas cruas da amostra de interesse; b) obtenção da constante deflection sensitivity; c-d) passos para obtenção da curva força-distância(FD)

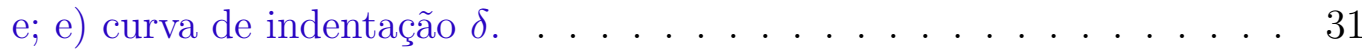

Figura 2.9 - Exemplo de ajuste concatenado de curvas de ressonância do cantilever, considerando o comportamento de um oscilador harmônico forçado amortecido.

Figura 2.10-Exemplo de parabolóide elíptico ajustado a partir do software OriginPro®. 33 
Figura 2.11-Média do $\ln \left(\right.$ deformação máxima) $\left(\ln \left(\delta_{\max }\right)\right)$ da amostra pela ponta obtida a partir dos mapas de cada fibra. Note que a média (linha contínua vermelha) é $\ln \left(\delta_{\max }\right)=2,3 \rightarrow \delta_{\max }=10 \mathrm{~nm}$. As fibras são identificadas pela letra correspondente ao seu grupo (V: Virgem; C: Controle; P: Placebo; A: Ativo), seguida do número da fibra (1 a 8). . . 34

Figura 2.12-Exemplo de curva de tensão-deformação (stress-strain curve) obtida a partir de Tensile Tester, evidenciando regiões de deformação elástica e deformação plástica. . . . . . . . . . . . . . . . . . 35

Figura 2.13-Obtenção de cortes ultrafinos por ultramicrotomia. . . . . . . . . . . . 38

Figura 2.14-Exemplo de imagem por Microscopia Óptica de superfície, obtida por ultramicrotomia, de seção transversal de fibra capilar embebida em resina (top view) (amostra correspondente à imagem da Fig. 2.17a). . .

Figura 2.15-Imagens AFM - modo tapping de seções transversais de fibras capilares, pertencentes ao grupo virgem. . . . . . . . . . . . . . . . .

Figura 2.16-Imagens AFM - modo tapping de seções transversais de fibras capilares, pertencentes ao grupo controle. . . . . . . . . . . . . . . . . . 40

Figura 2.17-Imagens AFM - modo tapping de seções transversais de fibras capilares, pertencentes ao grupo placebo. . . . . . . . . . . . . . . . 40

Figura 2.18-Imagens AFM - modo tapping de seções transversais de fibras capilares, pertencentes ao grupo ativo. . . . . . . . . . . . . . . . . . . . 41

Figura 2.19-Geometria do cantilever retangular, com comprimento $L_{c}$ e largura $w_{c}$, medidos a partir de imagem de Microscopia Óptica. . . . . . . . . . . .

Figura 3.1 - Exemplo do mapeamento multiparamétrico por FV-AFM de seção transversal de fibra capilar, embebida por resina epoxy (região circundante), com dados de altura (z) (em escala de cinza), logaritmo natural do módulo de Young $(\ln (E))$ (em tons de azul), força de adesão entre ponta e amostra $\left(F_{a d}\right)$ (em tons de verde) e deformação máxima da amostra pela ponta $(\delta)$ (em tons de vermelho). . . . . . . . . . . . 45

Figura 3.2 - Fibras pertencentes ao grupo virgem. . . . . . . . . . . . . . 46

Figura 3.3 - Fibras pertencentes ao grupo controle. . . . . . . . . . . . . . . 47

Figura 3.4 - Fibras pertencentes ao grupo placebo. . . . . . . . . . . . . . . . 48

Figura 3.5 - Fibras pertencentes ao grupo ativo. . . . . . . . . . . . . . . . . 49

Figura 3.6 - Exemplos de gráficos de $\ln (E)$ em função da distância à borda da fibra, apresentando o coeficiente de correlação de Pearson $r$, com força de relação linear muito fraca (gráfico superior) e força de relação linear moderada (gráfico inferior) . . . . . . . . . . . . . . 5 50

Figura 3.7 - Gráficos dos dados do logaritmo natural do módulo de Young em função da distância à borda da fibra, para os valores correspondentes às fibras pertencentes às mechas do grupo virgem. . . . . . . . . . . . . . 
Figura 3.8 - Gráficos dos dados do logaritmo natural do módulo de Young em função da distância à borda da fibra, para os valores correspondentes às fibras pertencentes às mechas do grupo controle. . . . . . . . . . . . . . 51

Figura 3.9 - Gráficos dos dados do logaritmo natural do módulo de Young em função da distância à borda da fibra, para os valores correspondentes às fibras pertencentes às mechas do grupo placebo. . . . . . . . . . . . . . . 52

Figura 3.10-Gráficos dos dados do logaritmo natural do módulo de Young em função da distância à borda da fibra, para os valores correspondentes às fibras pertencentes às mechas do grupo ativo. . . . . . . . . . . . . . . . . . 52

Figura 3.11-Coeficiente de correlação de Pearson $r$ do logaritmo natural do módulo de Young com a distância à borda da fibra, apresentando nível de força de relação linear. . . . . . . . . . . . . . . . . . . . .

Figura 3.12-Perfis traçados ao longo da seção transversal da fibra A4, pertencente ao grupo ativo, no mapa do ln (E) [Fig. 3.12a], mostrando relação do $\ln (E)$ em função da distância à borda, ajustados por função sigmóide [Fig. 3.12b] . . . . . . . . . . . . . . . . . 54

Figura 3.13-Média das medidas do perfil de permeação em unidades arbitrárias (a.u) das fibras capilares tratadas (preto - grupo ativo) ou não (vermelho grupo controle) com ativo cosmético composto de fibroína, em diferentes profundidades. A intensidade da distribuição espacial da fibroína é representada como cores escuras para o grupo tratado [5]. Reprodução da imagem autorizada pelos autores. . . . . . . . . . . . . .

Figura 3.14-Exemplo de gráfico de $\ln (E)$ em função da força de adesão entre ponta e amostra $F_{a d}$, apresentando o coeficiente de correlação de Pearson $r . \quad 55$

Figura 3.15-Gráficos dos dados do logaritmo natural do módulo de Young em função da distância à borda da fibra, para os valores correspondentes às fibras pertencentes às mechas do grupo virgem. . . . . . . . . . . . . . . 56

Figura 3.16-Gráficos dos dados do logaritmo natural do módulo de Young em função da distância à borda da fibra, para os valores correspondentes às fibras pertencentes às mechas do grupo controle. . . . . . . . . . . . .

Figura 3.17-Gráficos dos dados do logaritmo natural do módulo de Young em função da distância à borda da fibra, para os valores correspondentes às fibras pertencentes às mechas do grupo placebo. . . . . . . . . . . . . . 57

Figura 3.18-Gráficos dos dados do logaritmo natural do módulo de Young em função da distância à borda da fibra, para os valores correspondentes às fibras pertencentes às mechas do grupo ativo. . . . . . . . . . . . . 57

Figura 3.19-Coeficiente de correlação de Pearson $r$ do $\ln$ (módulo de Young) com a força de adesão. . . . . . . . . . . . . . . . . . . 5 58 
Figura 3.20-Médias e histograma dessas médias com ajuste gaussiano do $\ln (E)$ obtido para cada amostra de resina [Fig. 3.20a], em função dos cantilevers utilizados para coleta dos dados [Fig. 3.20b] e em função do tempo transcorrido após cura da resina, no qual foi realizado a coleta do respectivo dado, agrupado por lote, de preparações realizadas em diferentes dias [Fig. 3.20c]. A linha contínua azul indica a média $(\bar{\mu})$ obtida do ajuste e as linhas tracejadas azuis indicam os limites superiores e inferiores considerando 3 desvios-padrão $(\sigma) \ldots \ldots \ldots$. . . . . .

Figura 3.21-(a) Média do $\ln (E)$ obtido para a resina, em função da velocidade de avanço/retração da ponta em direção à amostra e (b) média do $\ln (E)$ em função da taxa de coleta das curvas de força (ramp rate). . . . . . .

Figura 3.22-(a) Média do $\ln (E)$ obtido para cada amostra, na região da resina, em função da umidade relativa (a) e da temperatura (b), medidas no ambiente da coleta dos dados. . . . . . . . . . . . . . . . . . .

Figura 3.23-(a) Médias do $\ln (E)$ e respectivos desvios-padrão de dados, obtidos de ajustes gaussianos, provenientes da região da fibra, reunidos conforme grupo de tratamento: virgem, controle, placebo e ativo. Cada ponto, neste caso, representa a média e seu respectivo desvio-padrão, de $\ln (E)$ tomados nos mapas, sendo cada mapa correspondente a uma fibra, apresentado na Fig. A.1 (Apêndice A). (b) Diagrama de caixa (box plot) dos dados citados, reunidos por grupo de tratamento. . . . . . . .

Figura 3.24-Diferença padronizada das médias, a partir do método paramétrico ANOVA, empregando o teste de comparação múltipla de Tukey, do $\ln (E)$ dos dados da região das fibras, reunidos por grupo de tratamento. A coloração vermelha denota diferença estatisticamente significante entre o par de grupos e a coloração preta denota diferença não estatisticamente significante, considerando nível de significância $\alpha=0.05$ (5\%) . . . . .

Figura 3.25-(a) $\ln (E)$ de dados obtidos por Tensile Tester, reunidos conforme grupo de tratamento: virgem, controle, placebo e ativo. Cada ponto, neste caso, representa um valor tomado em uma medida, correspondente a uma fibra. (b) Diagrama de caixa (box plot) dos dados citados, reunidos por grupo de tratamento. . . . . . . . . . . . . . . .

Figura 3.26-Diferença padronizada das médias, a partir do método paramétrico ANOVA, empregando o teste de comparação múltipla de Tukey, do $\ln (E)$ dos dados das fibras, reunidos por grupo de tratamento, obtidos por Tensile Tester. A coloração preta denota diferença não estatisticamente significante, considerando nível de significância $\alpha=0.05$ (5\%) . . . . .

Figura 3.27-Razão entre o ln(módulo de Young (Pa)) de medidas obtidas por FVAFM e de medidas obtidas por Tensile Tester. . . . . . . . . . . . 
Figura 3.28-Médias da força de adesão entre ponta e amostra de dados provenientes da região da fibra, reunidos conforme grupo de tratamento: virgem, controle, placebo e ativo. a) Média e desvio padrão obtidos do ajuste gaussiano, de histogramas apresentados na Fig. A.2 (Apêndice A). b) Diagrama de caixa (box plot) dos dados reunidos por grupo de tratamento. 67

Figura 3.29-Diferença das médias, a partir do método paramétrico ANOVA, empregando o teste de comparação múltipla de Tukey, da força de adesão entre ponta e amostra, dos dados da região das fibras, reunidos por grupo de tratamento. A coloração vermelha denota diferença estatisticamente significante entre o par de grupos, considerando nível de significância $\alpha$ $=0.05(5 \%)$.

Figura 3.30-Gráficos de força de adesão em função da temperatura, umidade relativa, velocidade de retração/avanço da ponta e ramp rate para as fibras pertencentes ao: a) grupo virgem, b) grupo controle, c) grupo placebo e d) grupo ativo.

Figura 3.31-Gráficos de força de adesão em função da temperatura, umidade relativa, velocidade de retração/avanço da ponta e ramp rate para as fibras pertencentes grupo virgem, controle, placebo e ativo, diferenciando-se por cores, conforme legenda. . . . . . . . . . . . . . .

Figura 3.32-Micrografias por TEM, de seções transversais de $80 \mathrm{~nm}$ de espessura, de fibra capilar sem danos químicos (virgem), com diferentes procedimento de coloração (staining) por: a) sem e b) com $\mathrm{OsO}_{4}$, evidenciando o córtex, ambas com coloração por $\mathrm{C}_{12} \mathrm{H}_{10} \mathrm{O}_{14} \mathrm{~Pb}_{3} ;$ c) sem e d) com $\mathrm{OsO}_{4}$, evidenciando também a cutícula, ambas com coloração por $\mathrm{C}_{12} \mathrm{H}_{10} \mathrm{O}_{14} \mathrm{~Pb}_{3}$. As setas apontam para os grânulos de melanina e Complexo da Membrana Celular (CMC). Magnificação original M = 15.000x. . . . . . . . . . . . . . . . . .

Figura 3.33-Micrografias por TEM, de cortes transversais de $80 \mathrm{~nm}$ de espessura, de fibras capilares pertencentes ao (a) grupo virgem (sem danos químicos) e (b) controle (com danos químicos). . . . . . . . . . . . . . 73

Figura 3.34-Micrografias por TEM, de cortes transversais de $80 \mathrm{~nm}$ de espessura, de fibras capilares pertencentes aos grupos virgem [Figs. 3.34a e 3.34b] e controle [Figs. 3.34c e 3.34d], mostrando as cutículas [Figs. 3.34a e 3.34c] e evidenciando o córtex [Figs. 3.34b e 3.34d] . . . . . . . . . . . 74

Figura 5.1- Micrografias por SEM de grid recoberto por filme de parlódio para suporte de cortes ultrafinos de seções transversais de fibras capilares humanas. . . . . . . . . . . . . . . . . . . 
Figura A.1-Histogramas dos dados do logaritmo natural do módulo de Young, para os valores correspondentes às fibras pertencentes às mechas dos grupos: virgem [Fig. A.1a], controle [Fig. A.1b], placebo [Fig. A.1c] e ativo [Fig. A.1d]. . . . . . . . . . . . . . . . 89

Figura A.2-Histogramas dos dados da adesão entre ponta e amostra, para os valores correspondentes às fibras pertencentes às mechas dos grupos: virgem [Fig. A.2a], controle [Fig. A.2b], placebo [Fig. A.2c] e ativo [Fig. A.2d]. 91

Figura A.3-Histogramas dos dados do logaritmo natural da deformação máxima da amostra pela indentação da ponta, para os valores correspondentes às fibras pertencentes às mechas dos grupos: virgem [Fig. A.3a], controle [Fig. A.3b], placebo [Fig. A.3c] e ativo [Fig. A.3d] . . . . . . . . . . . 93

Figura A.1-Desenho esquemático do diagrama de caixa (box plot), indicando as estatísticas representadas de um conjunto de dados. . . . . . . . . . . . 95

Figura A.2-Exemplo de distribuição F. . . . . . . . . . . . . . . . . . . . . . . 97 


\section{Lista de tabelas}

Tabela 2.1 - Parâmetros obtidos para cada cantilever. . . . . . . . . . . . . . . 34

Tabela 2.2 - Especificação das fibras capilares. . . . . . . . . . . . . . . 36

Tabela 2.3 - Valores de rugosidade $R_{R M S}$ (Root Mean Square) (nm) obtidos a partir das imagens de AFM, apresentadas nas Figuras 2.15, 2.16, 2.17 e 2.18. Para cada grupo, é calculado o valor médio $R_{R M S}^{-}$e o respectivo erro da média. As fibras são identificadas pela letra correspondente ao seu grupo (V: Virgem; C: Controle; P: Placebo; A: Ativo), seguida do

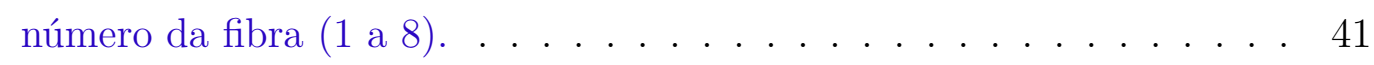

Tabela 3.1 - Média e respectivos desvios-padrão da média do $\ln (E)$ para cada grupo de tratamento: virgem, controle, placebo e ativo; sendo a quantidade de dados de 6214 para cada grupo. . . . . . . . . . . . . . . . . 63

Tabela 3.2 - Média e respectivos desvios-padrão da média do $\ln (E)$ para as fibras, obtidos por Tensile Tester, para cada grupo de tratamento: virgem, controle, placebo e ativo. . . . . . . . . . . . . . 65

Tabela 3.3 - Média e respectivos desvios-padrão da média da força de adesão entre ponta e amostra, para cada grupo de tratamento: virgem, controle, placebo e ativo; sendo a quantidade de dados de 7128 para cada grupo. 67 


\section{Lista de abreviaturas e siglas}

$\begin{array}{ll}\text { AFM } & \text { Atomic Force Microscopy / Microscope - Microscopia / Microscópio de } \\ & \text { Força Atômica } \\ \text { FV-AFM } & \text { Force Volume - Atomic Force Microscopy } \\ \text { TEM } & \text { Transmission Electron Microscopy - Microscopia Eletrônica de Trans- } \\ & \text { missão } \\ \text { CMC } & \text { Cell Membrane Complex - Complexo da Membrana Celular } \\ \text { CAGR } & \text { Compound Annual Growth Rate } \\ \text { SPM } & \text { Scanning Probe Microscopy } \\ \text { RMS } & \text { Root Mean Square } \\ \text { FC } & \text { Force Curve } \\ \text { FD } & \text { Force-Distance curve } \\ \text { ANOVA } & \text { Analysis of Variance }\end{array}$




\section{Lista de símbolos}

$F_{a d} \quad$ Força de adesão entre ponta e amostra

$\delta_{\max } \quad$ Deformação máxima da amostra devido à indentação da ponta

E Módulo de Young / Módulo elástico

$\ln \quad$ Logarítmo natural

$\mathrm{R}_{R M S} \quad$ Rugosidade quadrática média (root mean square)

Z Posição vertical do scanner piezoelétrico (piezo position)

z $\quad$ Altura / Posição vertical do scanner piezoelétrico no momento em que é alcançada a força máxima (trigger), correspondendo à altura na imagem topográfica

Força

D Distância entre ponta e superfície

$d_{c} \quad$ deflexão do cantiléver

$\delta \quad$ Deformação da amostra devido à indentação da ponta

$k_{s} \quad$ Constante elástica da amostra (sample)

$k_{c} \quad$ Constante elástica do cantilever

a Raio de contato

$E_{\text {total }} \quad$ Ver Eq. 2.3

$E_{s} \quad$ Módulo de Young da amostra (sample $) \rightarrow E$

$E_{c} \quad$ Módulo de Young do cantilever

$\nu_{s} \quad$ Razão de Poisson da amostra $($ sample $) \rightarrow \nu$

$\nu_{c} \quad$ Razão de Poisson do cantilever

$R \quad$ Raio da ponta

$F_{\max } \quad$ Força máxima exercida pela ponta sobre a amostra

$\rho_{f} \quad$ Densidade do fluido nas quais as medidas são realizadas 


\begin{tabular}{|c|c|}
\hline$\nu_{f}$ & Viscosidade do fluido nas quais as medidas são realizadas \\
\hline$L_{c}$ & Comprimento do cantilever \\
\hline$w_{c}$ & Largura do cantilever \\
\hline$f_{0}$ & Frequência de ressonância do cantilever \\
\hline$Q$ & Fator de qualidade da oscilação do cantiléver \\
\hline$\Gamma_{i}$ & $\begin{array}{l}\text { Componente imaginária da função hidrodinâmica } \Gamma(R e) \text {, sendo } R e \text { o } \\
\text { número de Reynolds }\end{array}$ \\
\hline$V$ & Volume de um parabolóide elíptico $\rightarrow$ volume de uma calota esférica \\
\hline$a_{a d j}$ & $\begin{array}{l}\text { Parâmetro ajustado para um parabolóide elíptico } z-z_{0}=-\left(\frac{x-x_{0}}{a_{\text {adj }}}\right)^{2}+ \\
\left(\frac{y-y_{0}}{b_{a d j}}\right)^{2}\end{array}$ \\
\hline$b_{\text {adj }}$ & $\begin{array}{l}\text { Parâmetro ajustado para um parabolóide elíptico } z-z_{0}=-\left(\frac{x-x_{0}}{a_{\text {adj }}}\right)^{2}+ \\
\left(\frac{y-y_{0}}{b_{a d j}}\right)^{2}\end{array}$ \\
\hline$L$ & Comprimento da amostra de interesse \\
\hline$\Delta$ & Variação do comprimento $L$ da amostra de interesse \\
\hline$\sigma_{T T}$ & Tensão (Stress) \\
\hline$\epsilon_{T T}$ & Deformação (Strain) \\
\hline$A$ & Área da seção transversal da amostra \\
\hline$R^{2}$ & Coeficiente de determinação \\
\hline$r$ & Coeficiente de correlação de Pearson \\
\hline $\bar{\mu}$ & Média dos dados \\
\hline$\sigma$ & Desvio-padrão dos dados \\
\hline$\alpha$ & Nível de significância \\
\hline $\mathrm{C}_{12} \mathrm{H}_{10} \mathrm{O}_{14} \mathrm{~Pb}_{3}$ & 3 Citrato de chumbo \\
\hline $\mathrm{OsO}_{4}$ & Tetróxido de ósmio \\
\hline
\end{tabular}




\section{Sumário}

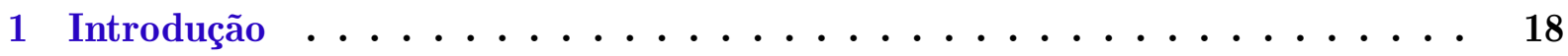

1.1 Indústria cosmética . . . . . . . . . . . . . . . . . . . . . . . . 18

1.1.1 Avaliação da eficácia de produtos cosméticos . . . . . . . . . . . . 18

1.2 Fibra capilar humana . . . . . . . . . . . . . . . . . . . . . . . . . . . . 19

1.2.1 Dano químico por descoloração . . . . . . . . . . . . . . 20

1.3 Caracterização de propriedades mecânicas . . . . . . . . . . . . . . . . 21

2 Materiais e Métodos . . . . . . . . . . . . . . . . 23

2.1 Microscopia de Força Atômica . . . . . . . . . . . . . . . . . . . . . 23

2.1.1 Espectroscopia de força . . . . . . . . . . . . . . 25

2.1.1.1 Região de indentação . . . . . . . . . . . . . . 26

2.1.2 Obtenção da curva de força-distância (FD) a partir da FC . . . . . 30

2.1.3 Determinação da constante elástica do cantilever $k_{c} \ldots \ldots$. . . . . 31

2.1.4 Determinação do raio da ponta $R \ldots$. . . . . . . . . . 32

2.2 Tensile Tester. . . . . . . . . . . . . . . . . . 34

2.3 Microscopia Eletrônica de Transmissão . . . . . . . . . . . . . . . . . . 35

2.4 Preparação e avaliação das amostras . . . . . . . . . . . . . . 36

2.4.1 Preparação para Microscopia Eletrônica de Transmissão . . . . . . 37

2.4 .2 Ultramicrotomia . . . . . . . . . . . . . . . . . . 37

2.4.3 Preparação para Microscopia de Força Atômica . . . . . . . . . . . 38

2.4.4 Force Volume-AFM . . . . . . . . . . . . . . . . . . 42

3 Resultados e Discussão . . . . . . . . . . . . . . . . . . 44

3.1 Force Volume-AFM . . . . . . . . . . . . . . . . . . . . 44

3.1 .1 Dados referentes à resina . . . . . . . . . . . . . . . . 59

3.1 .2 Dados referentes às fibras . . . . . . . . . . . . . . . 62

3.2 Microscopia Eletrônica de Transmissão . . . . . . . . . . . . . . . . . . . . 72

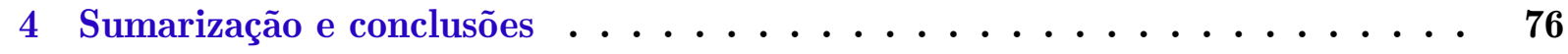

5 Perspectivas futuras ........................ 78

5.1 Microscopia Eletrônica de Transmissão . . . . . . . . . . . . . . . . . 78

5.2 Force Volume-AFM . . . . . . . . . . . . . . . . . . . . . . . 79

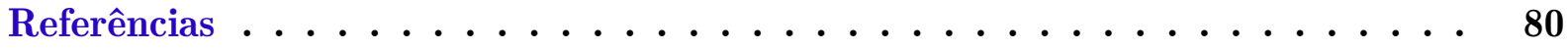

Apêndices $\quad 86$

APÊNDICE A Histogramas .................... 87 
ANEXO A Métricas estatísticas................ 95

A.1 Diagrama de caixa $($ box plot $) \ldots \ldots \ldots \ldots \ldots \ldots \ldots \ldots$

A.2 Coeficiente de determinação $R^{2} \ldots \ldots \ldots \ldots \ldots \ldots$

A.3 Coeficiente de correlação de Pearson $r$. . . . . . . . . . . . . 96

A.4 Analysis of Variance (ANOVA) . . . . . . . . . . . . . . . 96 


\section{Introdução}

Fibras capilares humanas são compósitos biológicos de relevante interesse, principalmente para a tricologia, ciência forense [6-8] e indústria cosmética.

\subsection{Indústria cosmética}

Na indústria cosmética, os produtos são desenvolvidos tanto para manutenção e higiene, quanto para mudanças provisórias e permanentes. O mercado cosmético tem se expandido, agregando novas demandas e assimilando novos perfis. Produtos que proporcionam sensação de bem-estar, tratando a pele e o cabelo, minimizando efeitos do envelhecimento precoce e também que protegem dos danos sofridos pelo sol e poluição, elevam a auto-estima e a aparência, o que pode ser relacionada com sucesso pessoal e

profissional [9]. A região Ásia-Pacífico domina o mercado de cuidados com o cabelo, sendo que o mercado de crescimento mais rápido é a América Latina. O mercado global tem uma previsão de crescimento a um CAGR (Compound Annual Growth Rate) de 3,35\% no período de 2020-2025 [10], sendo que para o mesmo período, a previsão para o Brasil é de 3,52\% [11]. Em 2021, o tamanho global deste mercado alcançou cerca de US\$ 95 bilhões, com previsão para 2025 de US\$ 105 bilhões [12].

\subsubsection{Avaliação da eficácia de produtos cosméticos}

No processo de desenvolvimento de princípios ativos para os cuidados dos cabelos, após a elaboração das formulações, normalmente são realizadas caracterizações macroscópicas de propriedades das fibras capilares para a comprovação da eficácia dos ativos [13]. Ensaios mecânicos são essenciais nesta etapa, convencionalmente realizando-se testes de tensão, torção e flexão, além de ensaios de tração e fadiga, o qual avalia a elasticidade e resistência à ruptura; Breakage Test que consiste em pentear uma mecha de cabelo manualmente ou por dispositivo automatizado e contar ou medir a massa de cabelo que se quebraram; Combing que consiste em medir a força necessária para deslizar um pente sobre uma mecha de cabelo; além de análises qualitativas, feitas através de comparações visuais e sensoriais de mechas para avaliação de aspectos em questão, como maciez e frizz [14-16]. Para melhor compreensão dos danos sofridos pelas fibras capilares em decorrência de tratamentos ou danos por agentes externos, como também para avaliação do desempenho de ativos cosméticos, técnicas sofisticadas têm sido utilizadas, representando um desafio permanente a busca por testes adequados e confiáveis para a avaliação das fibras capilares $[17,18]$. 


\section{$1.2 \quad$ Fibra capilar humana}

Uma fibra capilar humana [Fig. 1.1], é um compósito micro e nanoestruturado, composto principalmente pela proteína queratina (entre $65 \%$ e $95 \%$ ) (fibra $\alpha$-queratinosa) [19]. A proteína queratina é formada por cerca de 20 aminoácidos, que conectam-se por ligações químicas, chamadas de ligações polipeptídicas, formando cadeias polipeptídicas. As configurações espaciais das cadeias polipeptídicas encontradas para a proteína queratina é a $\alpha$-queratina ( $\alpha$-helix) (forma predominante nas fibras capilares) e a $\beta$-queratina ( $\beta$ sheet). Na região interna das fibras, ligações e/ou pontes laterais que conectam as cadeias polipeptídicas são responsáveis pelas mudanças temporárias e permanentes dos cabelos, como quando o molhamos, secamos, relaxamos ou ondulamos os cabelos. Essas ligações e/ou pontes são: ponte de hidrogênio, salina e dissulfeto. As pontes de hidrogênio são facilmente rompidas pela água ou calor, sendo responsáveis por mudanças temporárias do cabelo. As pontes salinas podem ser facilmente rompidas por soluções que diferem do pH fisiológico da fibra. Já as pontes dissulfeto não se quebram quando expostas ao calor ou à água, sendo formadas pela união do enxofre de dois aminoácidos cisteína, gerando a cistina [19]. O distinto conteúdo de cistina das subestruturas da fibra capilar produz efeito significante nas propriedades físicas, possuindo alta relevância nas propriedades mecânicas.

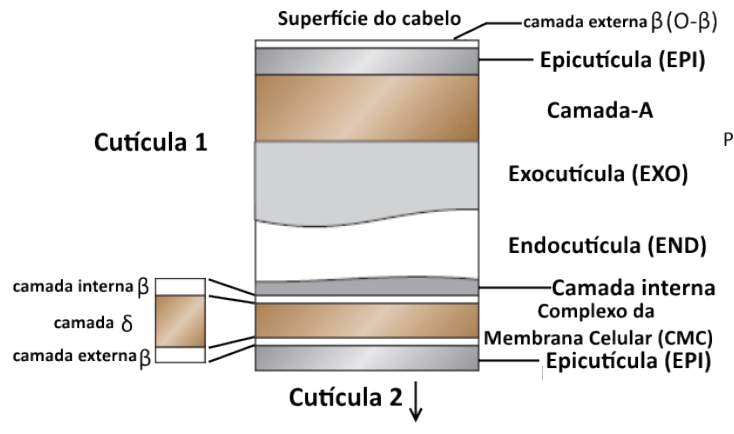

(a)

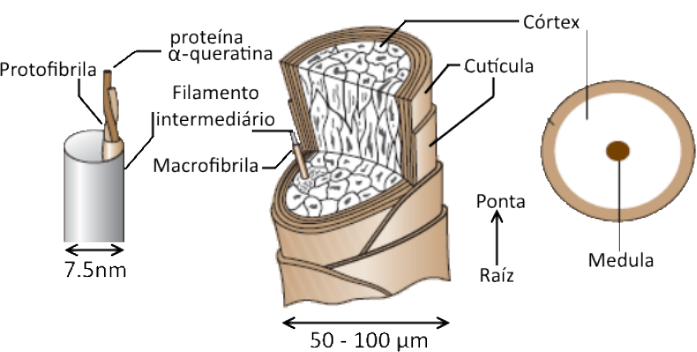

(b)

Figura 1.1 - Desenho esquemático da fibra capilar, mostrando (a) a borda de um corte transversal, detalhando a estrutura sublamelar da cutícula e (b) micro e nanoestruturas [1].

A fibra capilar possui de 6 a 8 camadas externas sobrepostas, de estruturas chamadas cutículas [Fig. 1.1a], às quais são hidrofóbicas quando saudáveis, conferindo proteção às estruturas internas: o córtex e a medula. A medula é uma região de estruturas porosas próxima ao centro, presente normalmente em fibras mais espessas. O córtex é uma região com diâmetro de cerca de $80 \mu \mathrm{m}$, subestruturado por microfibras, filamentos intermediários e macrofibrilas, alinhadas paralelamente ao eixo da fibra capilar [Fig. 1.1b], o qual define características mecânicas em macroescala do cabelo, como resistência mecânica e elasticidade [20,21].

Mais especificamente, o córtex é constituído por células corticais e material de 
ligação intercelular, denominado Complexo da Membrana Celular (CMC: Cell Membrane Complex, também presente, em menor quantidade, na região cuticular) [Fig. 1.2]. As células corticais possuem geralmente de 1 a $6 \mu \mathrm{m}$ de espessura e $100 \mu \mathrm{m}$ de comprimento, alinhadas paralelamente ao eixo da fibra e é o constituinte majoritário do córtex. As células corticais são compostas por macrofibrilas, que são conectadas por material intermacrofibrilar, remanescente citoplasmático e grânulos de melanina. O grânulo de melanina é responsável pela coloração das fibras, conforme seu tamanho e quantidade e tipo de melanina presente. A macrofibrila (com diâmetro entre 0,1 e $0,4 \mu \mathrm{m}$ ) é subestruturada por filamentos intermediários (com diâmetro de aproximadamente 7,5 nm, com baixo conteúdo de cistina $\approx 6 \%$ ), e pela matriz, rica em cistina $(\approx 21 \%)$. O CMC, também presente nas cutículas, consiste de membranas celulares e material adesivo que une as células corticais e consiste primariamente de proteína não-queratinosa e tem baixo conteúdo de cistina $(\approx$ $2 \%)$.

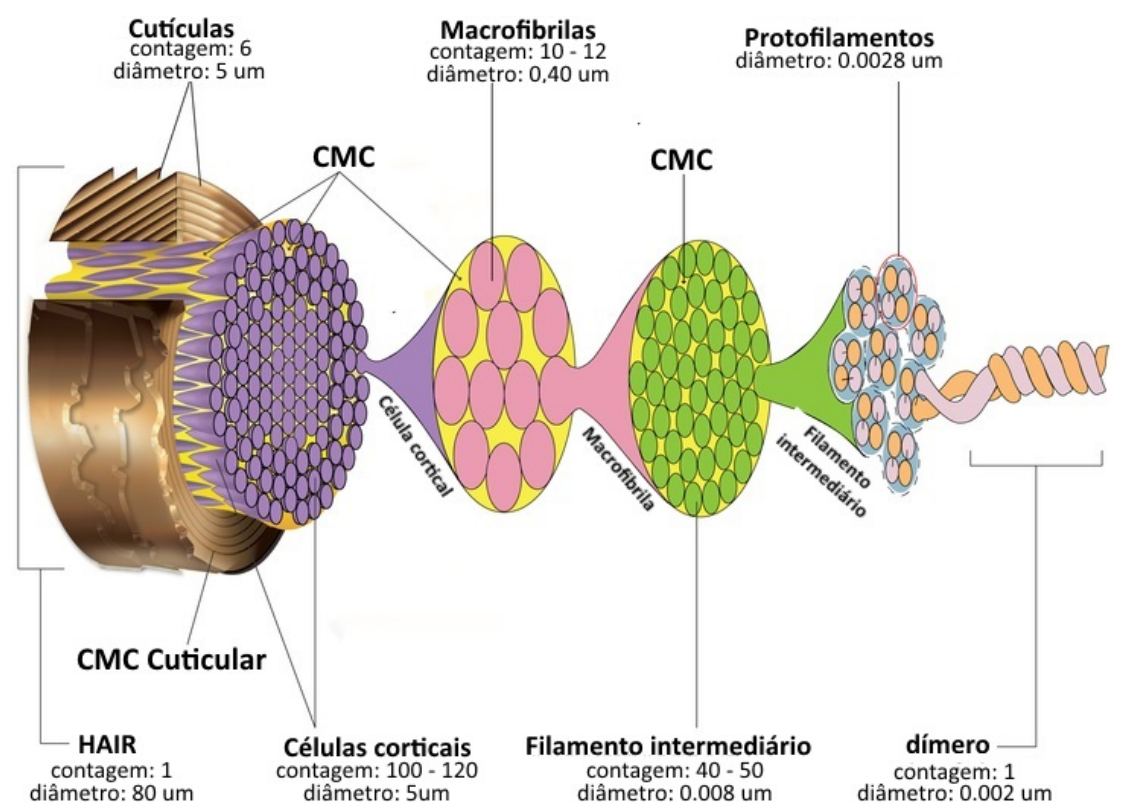

Figura 1.2 - Subestruturas do córtex, onde cada "cone"corresponde a uma ampliação maior, evidenciando estruturas menores [2].

\subsubsection{Dano químico por descoloração}

As fibras capilares humanas estão sujeitas a diversos tipos de danos mecânicos e/ou químicos, podendo-se danificar severamente a integridade das estruturas devido à exposição a altas temperaturas, radiação UV e tratamentos químicos, como ondulação ou alisamento permanente e descoloração. O processo de descoloração das fibras é muito comum, pois é realizado principalmente como etapa anterior à aplicação de tintura.

A descoloração das fibras capilares $[17,21]$ se dá a partir da aplicação de agentes oxidantes, sendo utilizado principalmente o peróxido de hidrogênio e sais de persulfato. A descoloração ocorre devido à reação dos agentes oxidantes com os grânulos de melanina, 
degradando e/ou solubilizando as estruturas, tornando a cor da pigmentação difusa. Apesar da reação do peróxido de hidrogênio ocorrer preferencialmente com os grânulos de melanina e menos com a queratina [22], o agente não é totalmente seletivo, provocando danos colaterais em outras estruturas. O processo de descoloração provoca, principalmente, a oxidação da cistina, gerando ácido cisteico, sendo que a quebra do aminoácido cistina ocorre principalmente pela quebra de pontes dissulfeto. Os danos causados pelos processos oxidativos se refletem nas características químicas, estruturais e mecânicas [23].

\subsection{Caracterização de propriedades mecânicas}

Usualmente, as propriedades mecânicas de fibras capilares humanas são determinadas macroscopicamente. Contudo, os dados obtidos de caracterizações macroscópicas não revelam a complexa ultraestrutura existente nas fibras capilares [24,25]. Para avaliações em nanoescala, propõe-se utilizar Microscopia de Força Atômica (AFM: Atomic Force Microscopy) [26], que é parte de uma família de microscopia de varredura por sonda (SPM: Scanning Probe Microscopy). Diversas aplicações e grande desenvolvimento tem sido concebido para esta técnica e a possibilidade de operá-la em temperatura e pressão ambiente, além de permitir imageamento de amostras inclusive em meio líquido, fez desta técnica uma poderosa ferramenta para caracterização de sistemas biológicos [27]. Na caracterização de propriedades de fibras capilares por AFM são reportadas principalmente análise de cutículas [1,28-32]. O primeiro estudo que relaciona medidas de nanoindentação [33] e Microscopia Eletrônica de Transmissão (TEM: Transmission Electron Microscopy), de seções transversais de fibras biológicas (lã), foi realizado por Parbhu, Bryson e Lal, 1999 [34]. Este trabalho relata medidas locais de elasticidade, associadas a imageamento de ultraestruturas por TEM. Kitano et al., 2009 [35] também relata investigação de mudanças nas propriedades de elasticidade de subestruturas a partir de AFM, considerando fibras capilares humanas, causadas por danos químicos, avaliando efeito reparador de agentes condicionantes.

Neste trabalho, investigou-se nanoscopicamente propriedades mecânicas (nanomecânicas) de fibras capilares humanas. Foram avaliadas amostras de material danificado quimicamente e/ou fisicamente, em processo de descoloração, com e sem tratamento por ativo cosmético, por processos controlados. Através da análise nanoscópica das fibras capilares, avaliou-se a contribuição das estruturas para a alteração das propriedades mecânicas. A caracterização de propriedades mecânicas das estruturas foram realizadas por AFM, no modo de imageamento multiparamétrico Force Volume (FV-AFM). Esta técnica é uma variação de AFM, que registra uma curva de força a cada ponto da varredura. A partir do processamento de cada curva, obteve-se para cada ponto da varredura informações de propriedades mecânicas da superfície em escala nanométrica, sendo elas: módulo elástico (módulo de Young), força máxima de adesão entre a sonda de AFM e a amostra e defor- 
mação máxima da amostra pela sonda, sendo todos esses parâmetros associados à imagem topográfica. Os resultados obtidos foram correlacionados com medidas macroscópicas de propriedades mecânicas das fibras capilares humanas, por medidas tomadas em ensaios de tração (Tensile Tester).

Vale ressaltar que a investigação de propriedades mecânicas em nano/microescala de fibras capilares humanas pode, não apenas desempenhar um papel interessante no desenvolvimento de ativos cosméticos, mas também na área da indústria têxtil. Para confecção de tecidos têxteis, são utilizadas fibras biológicas que possuem, em alguns aspectos, muitas semelhanças com as fibras capilares humanas e também se baseiam em propriedades mecânicas para análise da qualidade das fibras e dos tecidos. De fato, muito do conhecimento utilizado sobre fibras capilares humanas resultaram de pesquisas realizadas primeiramente em outros tipos de fibras biológicas, principalmente a lã.

Nesta tese, no Capítulo 2 constam brevemente os princípios teóricos das técnicas utilizadas para preparação das amostras, assim como caracterização topográfica por AFM e propriedades mecânicas por FV-AFM (a partir do emprego de modelo específico para a análise de curvas de força) e morfologia por TEM. Ao longo do Capítulo 2 também são descritos os procedimentos e parâmetros experimentais adotados, bem como análise prévia das amostras para verificação da qualidade das superfícies das amostras. No Capítulo 3 são apresentados os resultados obtidos, a partir das técnicas descritas. Dados os resultados encontrados, são apresentadas as conclusões e sumarização no Capítulo 4, embasando as perspectivas futuras de continuidade do trabalho, apresentadas no Capítulo 5. 


\section{Materiais e Métodos}

Neste capítulo são apresentadas brevemente as técnicas e métodos utilizados, dando ênfase para Microscopia de Força Atômica (AFM: Atomic Force Microscopy), técnica de maior interesse para o desenvolvimento deste trabalho.

\subsection{Microscopia de Força Atômica}

SPM (Scanning Probe Microscopy) é um tipo de microscopia na qual uma sonda varre a superfície da amostra e através do monitoramento de algum tipo de interação física, gera imagens tridimensionais. No caso de AFM [36,37], parte da família do SPM, capaz de investigar superfícies condutoras e isolantes, a força entre os átomos de uma sonda e da amostra é monitorada e pode operar em três regimes de interação: força repulsiva, atrativa ou em regime intermediário. Cada regime corresponde a um modo de operação do microscópio, sendo o regime de força repulsiva chamado de modo de contato; força atrativa o modo de não contato; e o regime intermediário o modo de contato intermitente (tapping mode) [Fig. 2.1]. A Fig. 2.1 apresenta a força de interação entre a sonda e a superfície, dada pelo potencial de Lennard-Jones, com os intervalos referentes aos três modos de operação. O nível de sensibilidade dessa microscopia é capaz de detectar na escala vertical deslocamentos da ordem de frações de nm e forças da ordem de pN.

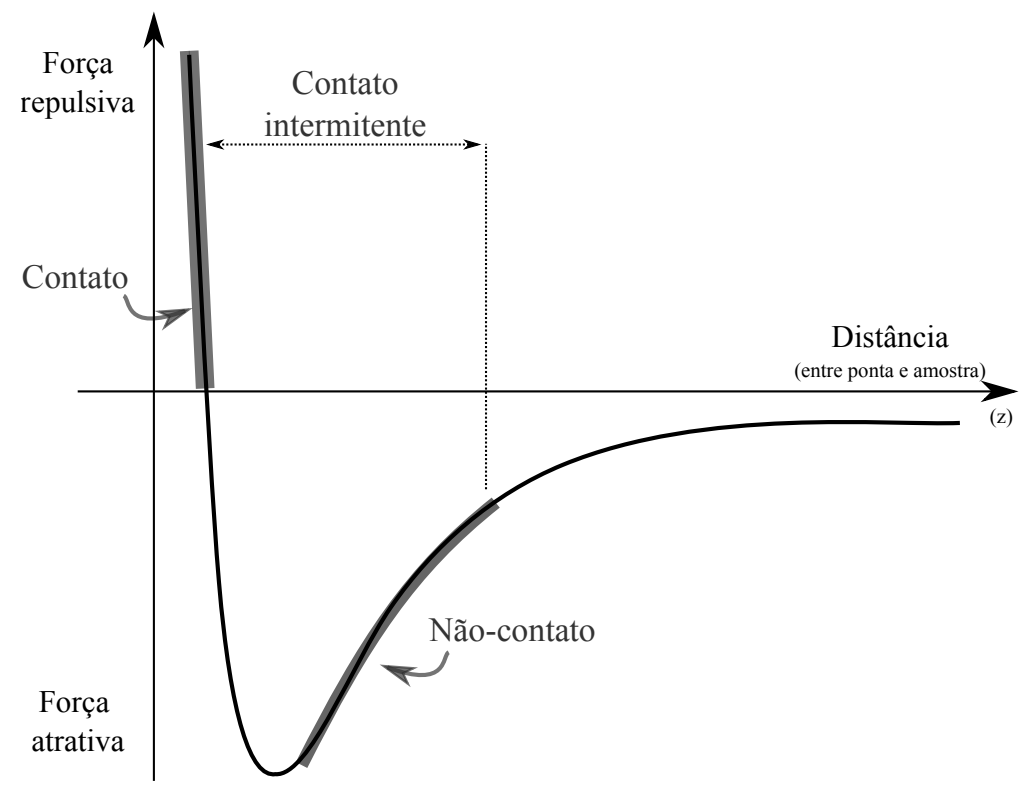

Figura 2.1 - Gráfico da força de interação entre a sonda e a superfície da amostra em AFM, dada pelo potencial de Lennard-Jones, apresentando os três modos de operação: modo não-contato; modo de contato intermitente; e modo contato. 
No caso específico de AFM [Fig. 2.2] no modo de contato intermitente (tapping), a sonda consiste de um cantilever com uma ponta muito afiada em sua extremidade, oscilando próximo ou em sua frequência de ressonância, varrendo a amostra através do deslocamento em seu plano $(\mathrm{x}, \mathrm{y})$. A varredura é realizada por um scanner de material piezoelétrico, o qual apresenta uma expansão ou contração controlada devido à aplicação de uma tensão elétrica. Durante a varredura, a ponta toca a superfície da amostra próxima à máxima amplitude de oscilação do cantilever. Um sistema óptico, onde um feixe de laser é refletido na extremidade do cantilever e chega a um fotodetector, permite o monitoramento da amplitude de oscilação do cantilever, que é o parâmetro mantido constante neste modo de operação. Assim, durante a varredura, quando a ponta encontra uma altura diferente, a amplitude de oscilação do cantilever é alterada e, então, o microscópio realiza uma correção vertical (normal à superfície) através da movimentação do scanner, até o RMS (Root Mean Square) da amplitude de oscilação retornar ao valor previamente definido (parâmetro a ser mantido constante). Com as informações destas correções em altura e das coordenadas $(\mathrm{x}, \mathrm{y})$ de cada ponto da varredura, a imagem topográfica é obtida.

Já no modo de contato, a ponta mantém contato constante com a superfície da amostra. Neste caso, o sistema óptico monitora a deflexão do cantilever, que é o parâmetro a ser mantido constante neste modo de operação. Quando a ponta se depara com uma altura diferente, a deflexão do cantilever é alterada, e então o microscópio realiza a correção vertical. Assim, de forma similar ao modo de contato intermitente, coletando as informações desta correção, a imagem topográfica é obtida.

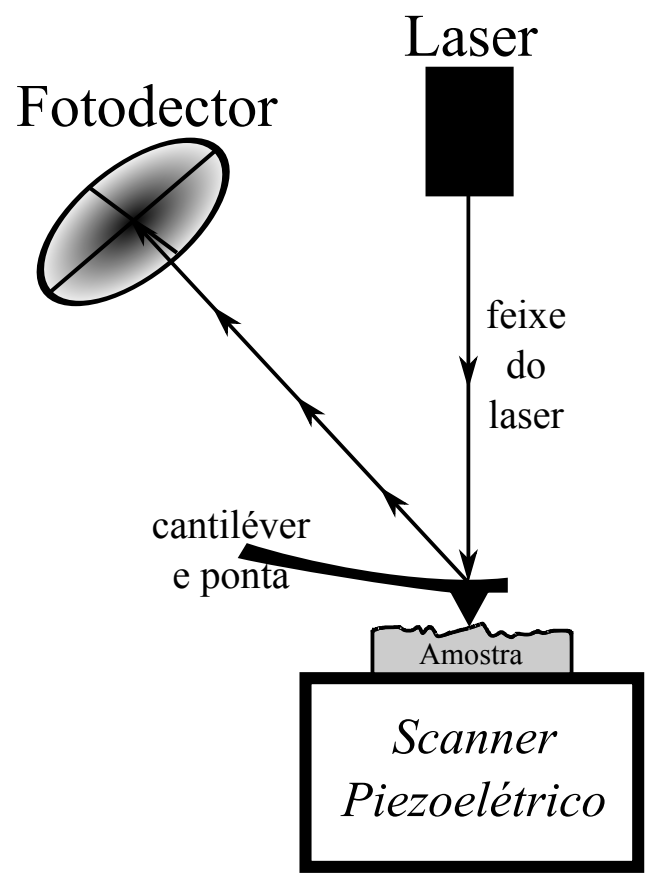

Figura 2.2 - Desenho esquemático do Microscópio de Força Atômica (AFM). 


\subsubsection{Espectroscopia de força}

Quando operado no modo FV-AFM [38], uma curva de força (FC: Force Curve) é registrada em cada ponto da varredura, correspondendo à interação local entre a ponta e a superfície da amostra. Uma FC representa a força aplicada na ponta conforme se aproxima (approach) e se distancia (retract) verticalmente (em $Z$ ) de um ponto na superfície da amostra. Uma deflexão máxima é pré-estabelecida pelo usuário, correspondendo a uma força máxima a ser aplicada em cada ponto (x,y) (trigger). Quando a força máxima é atingida, o sistema registra a posição vertical $(Z)$ do scanner, que corresponde à altura desse pixel $(z)$, e então o scanner inicia a retração. Assim, FV-AFM associa cada coordenada $(\mathrm{x}, \mathrm{y})$ com uma altura $z$, fornecendo a topografia, e com uma curva de força, que permite a obtenção de propriedades mecânicas da superfície da amostra.

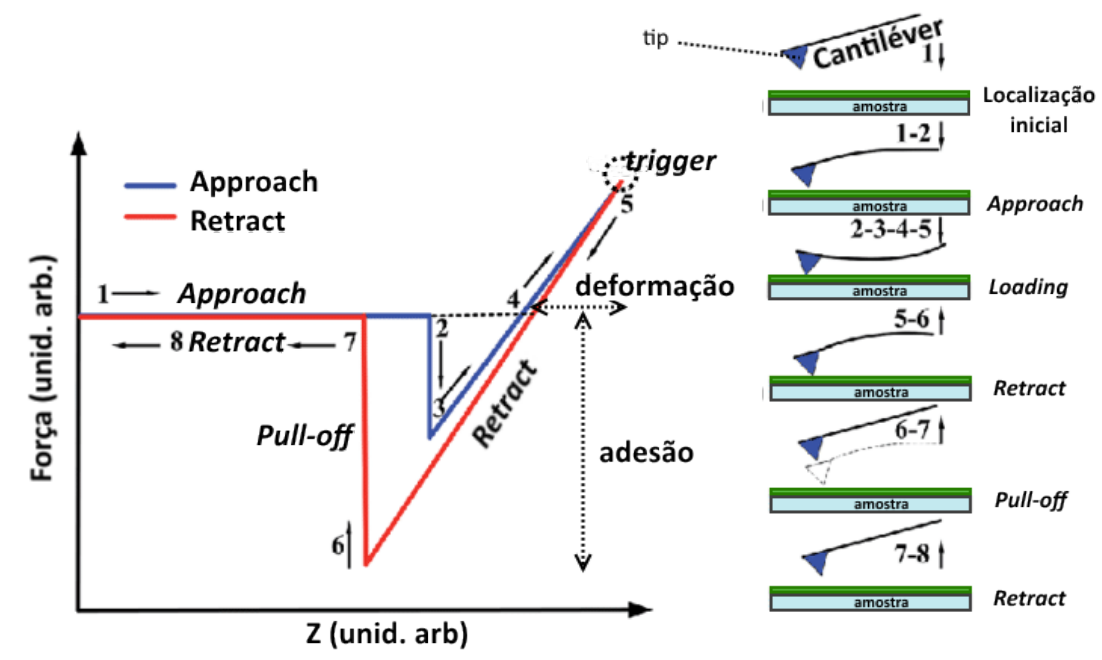

Figura 2.3 - Curva de força (FC) típica durante aproximação e distanciamento entre ponta e superfície da amostra [3].

Conforme apresentado na Fig. 2.3, quando a ponta está muito distante da superfície da amostra (1), existe pouca ou nenhuma força agindo sobre a ponta. Quando a ponta se aproxima da superfície (approach - curva azul), o cantilever sofre uma força atrativa na direção da superfície (1-2), que corresponde normalmente à força de van der Waals. Na sequência, a ponta prossegue na aproximação e a força cresce até seu valor máximo configurado pelo usuário (trigger) (2-3-4-5). No momento em que é alcançado o trigger, é registrado o valor relativo de $Z$ que corresponderá à altura da amostra nesse pixel (z). Então a ponta inicia o processo de afastamento (retract - curva vermelha) (5-6-7-8), diminuindo a força exercida sobre a superfície até atingir a força de adesão máxima $F_{a d}$ (6-7) entre ponta e amostra. Assim que a ponta se desprende da superfície, apenas forças de longo alcance atuam, correspondendo a uma força muito pequena ou nula (7-8) [4]. 


\subsubsection{Região de indentação}

Com uma calibração prévia, a partir da análise da FC na região de deformação da amostra [Fig. 2.3], podemos obter o gráfico da força em função da penetração (indentação) da ponta na amostra, chamada de curva de força-distância (FD: Force-Distance curve) como será descrito na próxima seção. Obtendo esse gráfico (força em função da indentação), é possível aferir sobre o comportamento elasto-plástico da amostra de interesse e obter o módulo elástico (módulo de Young) do local.

Se o material é idealmente elástico, não há histerese entre as curvas de aproximação e retração da ponta na região de indentação, ou seja, as curvas se sobrepõem [Fig. 2.4(a)]. Se o material é idealmente plástico, ele sofre uma deformação após o pressionamento da ponta contra a superfície durante a aproximação, não retornando a sua forma original na retração da ponta, mesmo com o decréscimo da força exercida pela ponta no local. Para a maioria dos materiais, está presente um comportamento misto, onde a curva de descarga (retract) fica abaixo da curva de carga (approach) (elástico e plástico) [Fig. 2.4(b)].

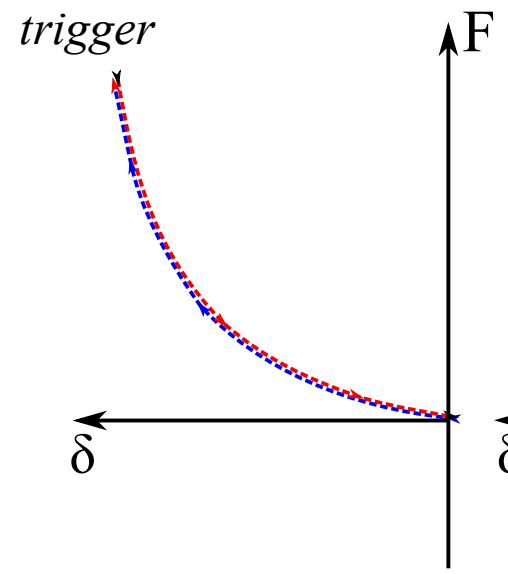

(a)

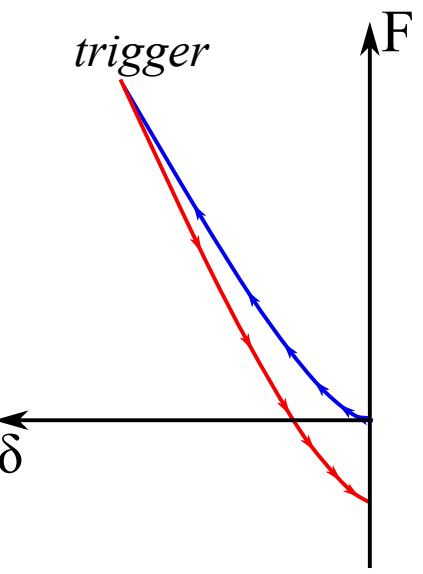

(b)

Figura 2.4 - Curva de força-distância (FD) em função da profundidade de indentação $\delta$ para materiais com comportamento (a) idealmente elástico e (b) com comportamento elasto-plástico, dada uma força máxima configurada (trigger) [4] - adaptada.

Uma das propriedades mecânicas importantes de um material é seu módulo elástico $E$, também chamado de módulo de Young. Essa grandeza equivale à razão entre a tensão aplicada e a correspondente deformação do material em regime elástico, a qual se relaciona com a rigidez do material.

Para obtenção do módulo de Young, é necessário modelar a dependência da indentação $\delta$ da ponta na amostra, considerando uma força $F$ exercida sobre a amostra.

A posição do scanner piezoelétrico ( $Z$-piezo position) é o movimento controlado pelo sistema, de forma a aproximar ou afastar a ponta da superfície da amostra, contribuindo 
para a distância $D$ entre ponta e superfície [Fig. 2.5(a)]. Quando a ponta está próxima à superfície da amostra, seja na trajetória de aproximação ou retração da ponta, ocorre a deflexão do cantilever $d_{c}$ devido a: forças atrativas de longo alcance (que inclui a força de van der Waals, força de capilaridade, etc...) [Fig. 2.5(b)]; e forças repulsivas de curto alcance [Fig. 2.5(c)], que ocorre no regime de contato, onde a ponta indenta a amostra, podendo causar uma deformação $\delta$. As grandezas $Z, D, d_{c}$ e $\delta$ obedecem a Eq. 2.1:

$$
Z=D-d_{c}-\delta
$$

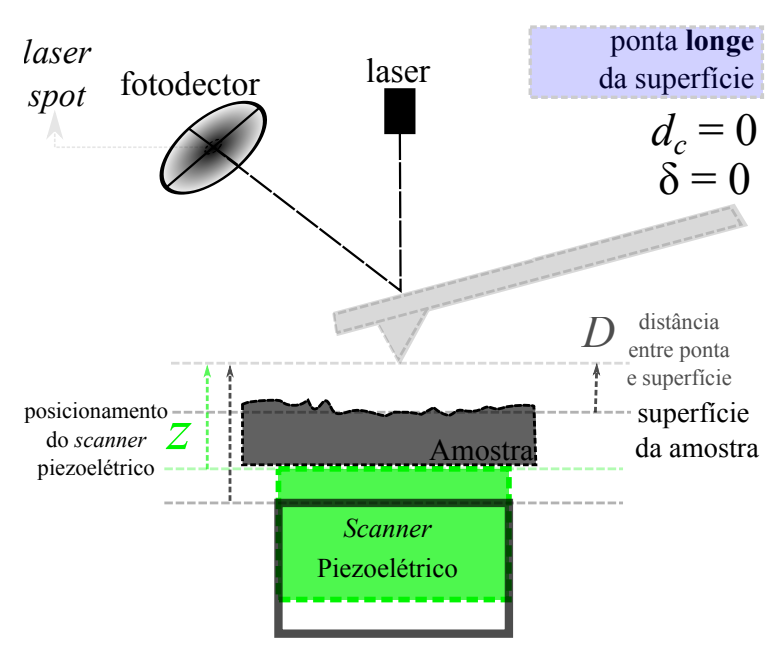

(a)

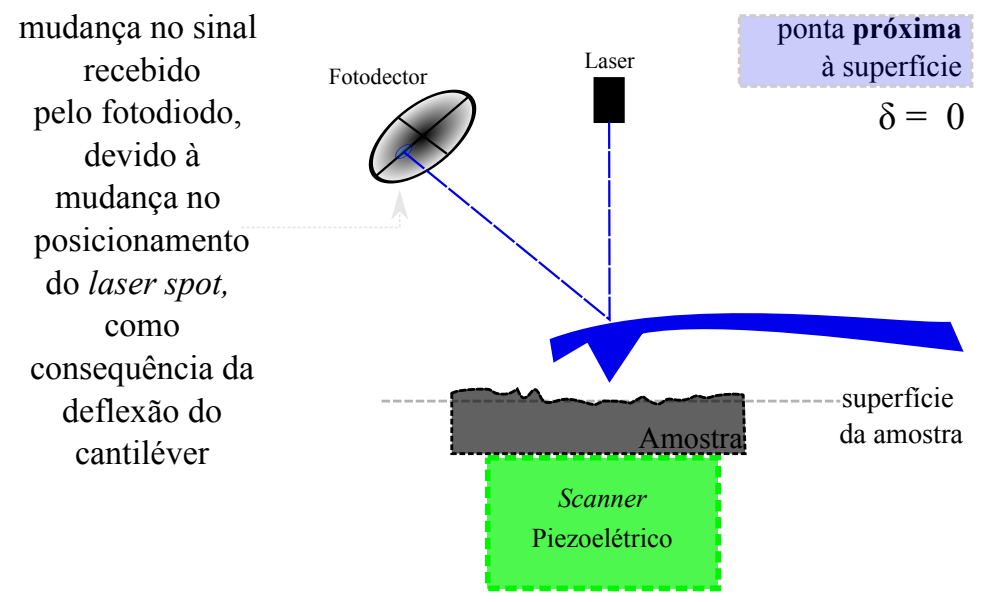

(b)

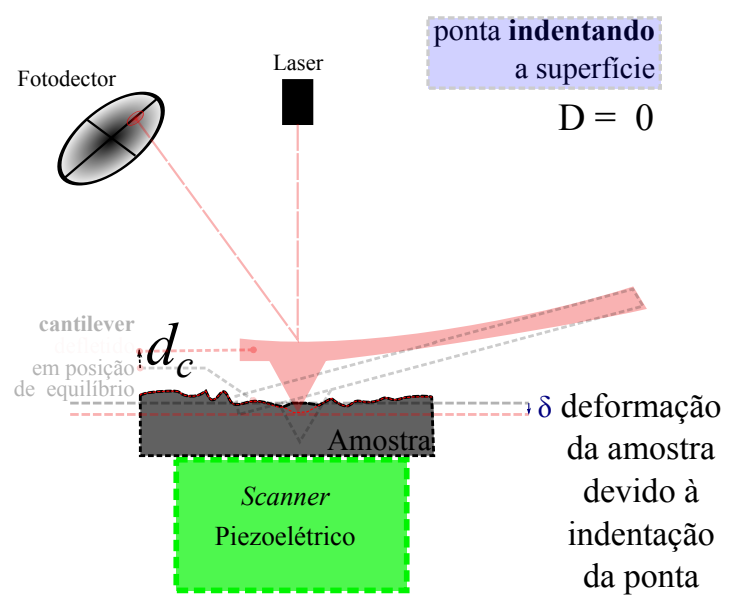

(c)

Figura 2.5 - Posições do sistema quando (a) a ponta está afastada da superfície, (b) a ponta está próxima à superfície e (c) a ponta está indentando a superfície.

De fato, após a ponta tocar uma amostra que não ofereça resistência alguma à penetração, não ocorrerá deflexão do cantilever e $Z=-\delta$, que é o esperado; para o caso de uma amostra que seja impenetrável, $\delta=0$ e $Z=-d_{c}$, pois ocorrerá apenas a deflexão do cantilever. Assim, em um caso onde ocorra penetração e deflexão do cantilever, onde $D=0$, a equação $Z=-d_{c}-\delta$ deve ser usada. Assumindo que a amostra e o cantilever se 
comportam como materiais elásticos, no regime de equilíbrio tem-se $k_{s} \delta=k_{c} d_{c}$, sendo $k_{s}$ e $k_{c}$ a constante elástico da amostra e do cantilever, respectivamente, que substituindo na Eq. 2.1, para eliminação de $\delta$ tem-se:

$$
k_{c} d_{c}=-\frac{k_{c} k_{s}}{k_{c}+k_{s}} Z
$$

Há diversas teorias que descrevem a relação entre a força aplicada $F=k_{c} d_{c}$ e o raio de contato $a$ (entre ponta e amostra) ou a deformação $\delta$. A constante elástica da amostra $k_{s}$ depende do raio de contato $a$, das razões de Poisson $\nu$ e dos módulos elásticos $E$, da amostra e do cantilever, conforme a relação [4]:

$$
k_{s}=\frac{3}{2} a E_{\text {total }} \quad \text { com } \quad \frac{1}{E_{\text {total }}}=\frac{3}{4}\left(\frac{1-\nu_{s}^{2}}{E_{s}}+\frac{1-\nu_{c}^{2}}{E_{c}}\right)
$$

sendo os índices $s$ de parâmetros pertencentes à amostra e os índices $c$ pertencentes ao cantilever. No caso em que $E_{c}>E_{s}$ (quando a deformação da ponta é desprezível), $E_{\text {total }} \approx \frac{4}{3} \frac{E s}{\left(1-\nu_{s}^{2}\right)}$, a Eq. 2.3 pode ser aproximada por:

$$
k_{s}=2 a\left(\frac{E_{s}}{1-\nu_{s}^{2}}\right) .
$$

Por simplicidade, no que se segue, adota-se a notação $E$ para $E_{s}$ e $\nu$ para $\nu_{s}$.

Quando a força de adesão $F_{a d}$ é desprezível em relação à carga máxima e quando $a$ é muito menor que o raio da ponta $R$ (pequenas indentações $(\delta<<R) \rightarrow \frac{\delta}{R}<0.1$ [39]), vale a teoria desenvolvida por Hertz, 1881 [40].

No entanto, neste trabalho, as deformações sofridas pelas amostras não podem ser desprezadas e portanto, a teoria de Hertz não é aplicável, pois não é possível considerar pequenas indentações. Sendo assim, utilizou-se o modelo proposto por Sneddon, 1965 [41], o qual é uma generalização do modelo de Hertz. Neste caso, a obtenção da relação entre a profundidade de indentação $\delta$ e a carga aplicada $F$ é dada em termos de integrais de uma função que descreve uma ponta de perfil arbitrário com simetria axial, rotacionada sobre o eixo z, resultando em um sólido de revolução. Considera-se

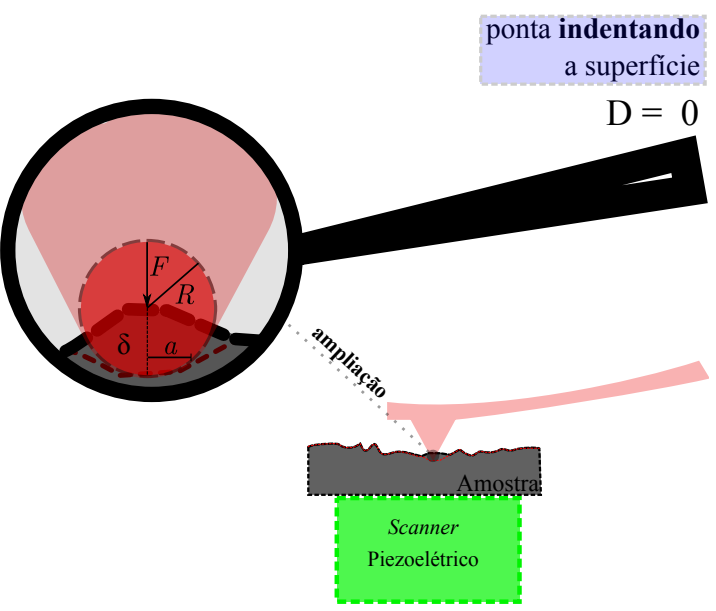

Figura 2.6 - Modelo de contato mecânico, apresentando as gran$\operatorname{dezas} F, R$ e $a$. que a profundidade de indentação $\delta$ produz um círculo de contato na superfície com raio de contato $a$ [Fig. 2.6]. Para o caso específico de uma ponta esférica, a deformação elástica é dada por uma equação transcendental que pode ser computada numericamente $[4,42]$ 
[Eq. 2.5]:

$$
F=\frac{E}{1-\nu^{2}}\left(\frac{R^{2}+a^{2}}{2} \ln \frac{R+a}{R-a}-a R\right) \quad \text { e } \quad \delta=\frac{a}{2} \ln \frac{R+a}{R-a} .
$$

Os parâmetros $\nu$ e $R$ são especificados previamente e o módulo elástico da amostra $E$ é calculado a partir da Eq. 2.5.

Considerando que a força de adesão $F_{a d}$ deve ser desprezível em relação à carga máxima $F_{\text {max }}$, tanto para o modelo de Hertz quanto para o modelo de Sneddon, foi avaliada a razão $\frac{F_{a d}}{F_{\max }}$. A Fig 2.7 apresenta a razão $\frac{F_{a d}}{F_{\max }}$ para cada amostra. As amostras são identificadas pela letra correspondente ao seu grupo (V: Virgem; C: Controle; P: Placebo; A: Ativo), seguida do número da fibra (1 a 8).

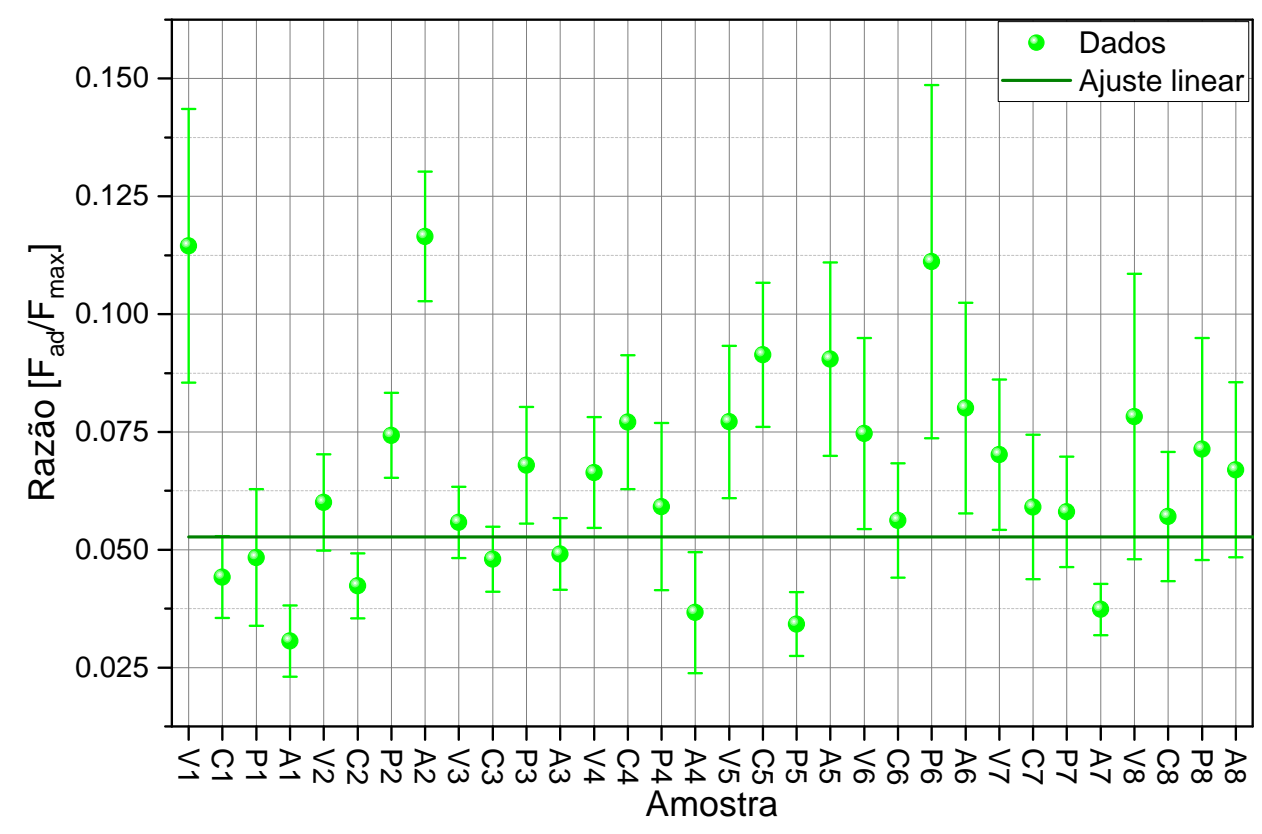

Figura 2.7 - Razão entre a força de adesão entre ponta e amostra $F_{a d}$ e a força máxima exercida pela ponta sobre a amostra $F_{\max }$, para cada amostra. As amostras são identificadas pela letra correspondente ao seu grupo (V: Virgem; C: Controle; P: Placebo; A: Ativo), seguida do número da fibra (1 a 8). As especificações das amostras são apresentadas na seção 2.4 (Tab. 2.2).

A partir dos dados apresentados na Fig. 2.7, verificou-se que todas as razões são menores que 10\%, em até 3 desvios-padrão, sendo que, em média, a força de adesão representa $\approx 5 \%$ da força máxima exercida pela ponta sobre a amostra, tornando-se adequado o emprego do modelo de Sneddon [4]. 


\subsubsection{Obtenção da curva de força-distância (FD) a partir da FC}

A calibração que será aqui descrita é realizada no modo de curva de força (FVAFM). Os dados coletados a cada ponto da varredura correspondem ao sinal do laser recebido pelo fotodiodo $d_{c}$ (deflection) (em Volts) em função do tempo (em s) ou da posição do scanner $Z$ (em nm) [Fig. 2.8(a)]. Para que seja obtida $d_{c}$ em nm, é tomada uma curva em uma amostra com $k_{s}>>k_{c}$ (amostra rígida em relação ao cantilever). A partir da consideração de que a amostra não se deforma, a relação mostrada na Eq. 2.1 para a região de contato $(D=0)$ torna-se $d_{c}=-Z$, como já discutido anteriormente. Então, o ajuste linear na região de contato em uma amostra de $k_{s}$ muito maior que $k_{c}$ [Fig. 2.8(b)], resulta na constante para conversão de $d_{c}$ de $\mathrm{V}$ para $\mathrm{nm}$, chamada de deflection sensitivity. A conversão é aplicada, obtendo-se a curva $d_{c}(\mathrm{~nm}) \times Z(\mathrm{~nm})$ [Fig. 2.8(c)]. Determinando-se $k_{c}$ (subseção 2.1.3), pode-se converter a deflexão de nm para força $(\mathrm{nN})$ [Fig. 2.8(d)]. Finalmente, para a região de contato, pode-se converter $Z$ em $\delta$ através da Eq. 2.1 [Fig. 2.8(e)] [43].
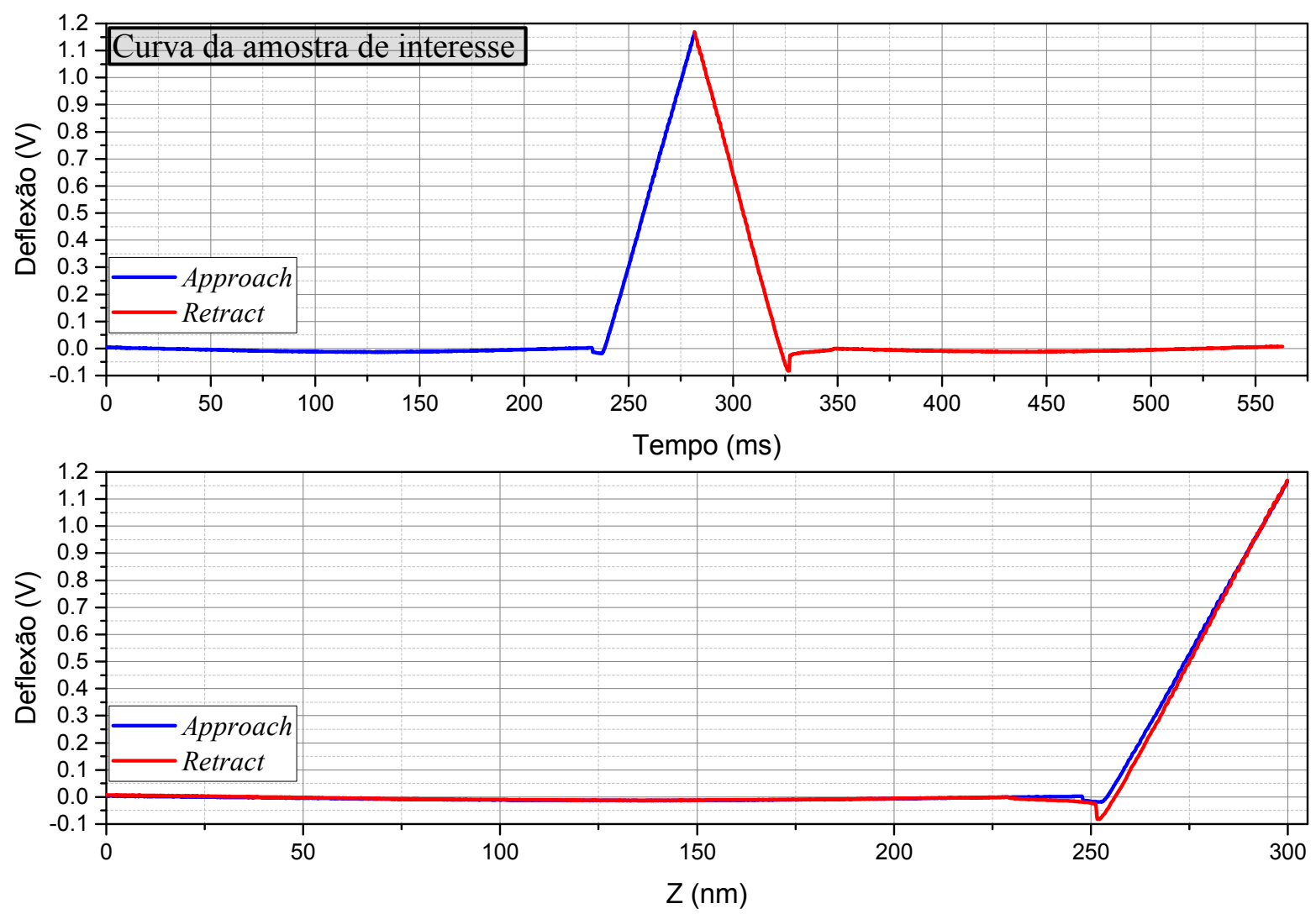

(a) 


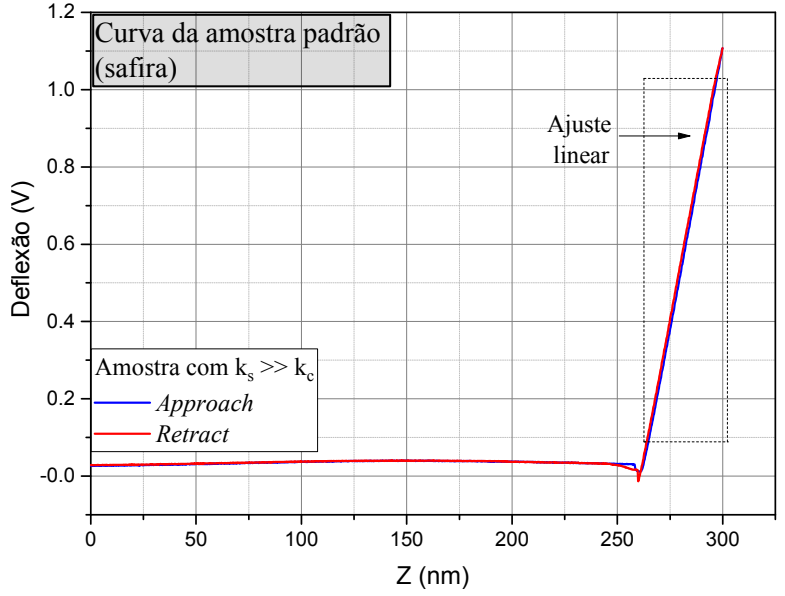

(b)

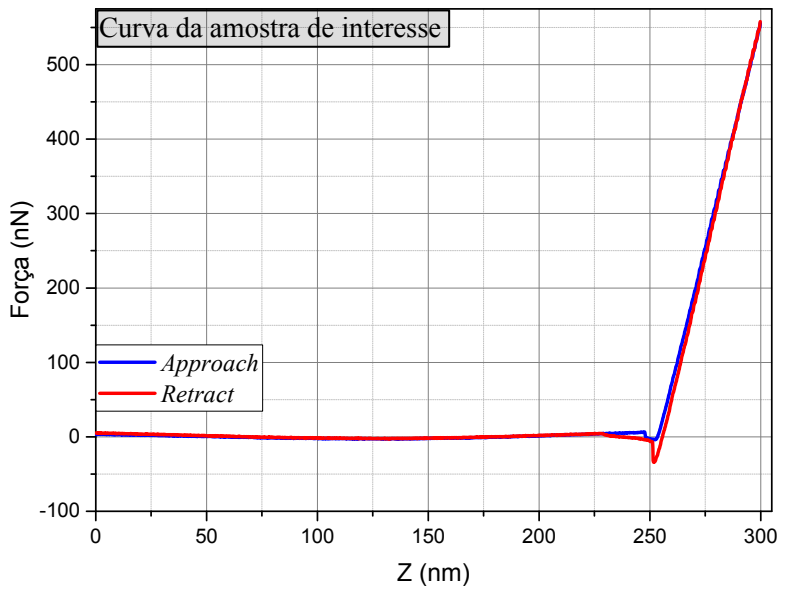

(d)

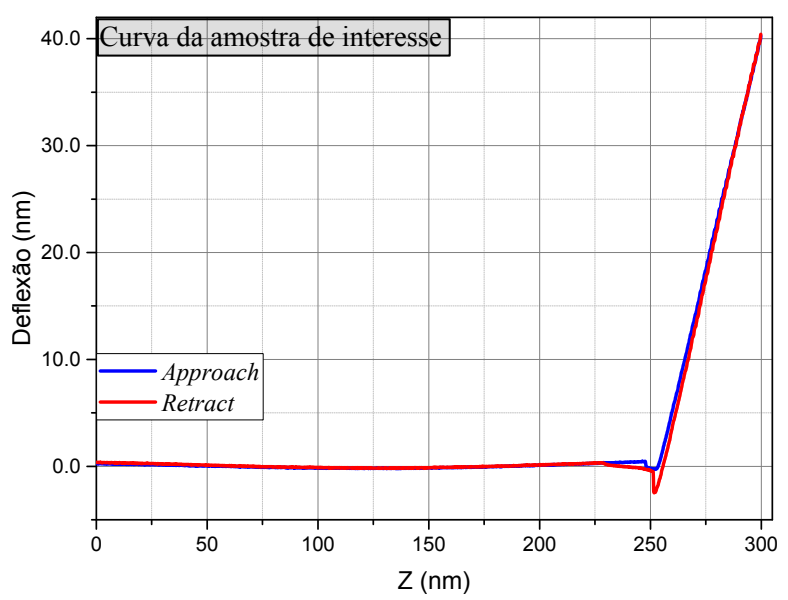

(c)

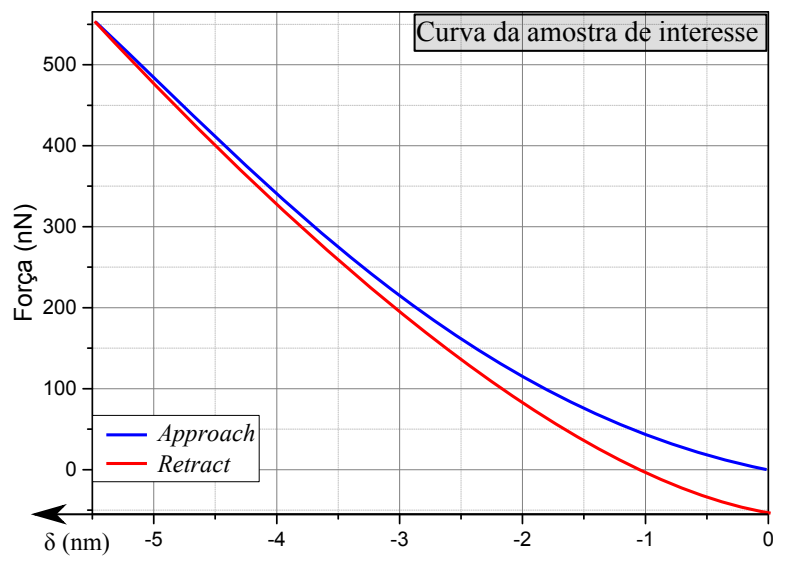

(e)

Figura 2.8 - a) Curvas cruas da amostra de interesse; b) obtenção da constante deflection sensitivity; c-d) passos para obtenção da curva força-distância(FD) e; e) curva de indentação $\delta$.

\subsubsection{Determinação da constante elástica do cantilever $k_{c}$}

Para obtenção de uma FD é necessário conhecer a constante elástica do cantilever $k_{c}$. Diversos métodos estão disponíveis para a determinação de $k_{c}$, cada qual com seus fatores limitantes, vantagens e desvantagens [44]. Para este estudo, foi utilizado o método de Sader $[45,46]$. Este método requer medição da frequência de ressonância do cantilever, o seu fator de qualidade e as suas dimensões. Especificamente, para um cantilever retangular, vale a equação:

$$
k_{c}=7,5246 \rho_{f} w_{c}^{2} L_{c} Q f_{0}^{2} \Gamma_{i}(R e),
$$

sendo $\rho_{f}$ a densidade do fluido na qual as medições são realizadas, $L_{c}$ o comprimento e $w_{c}$ a largura do cantílever, $f_{0}$ a frequência de ressonância e $Q$ o fator de qualidade de oscilação do cantilever (relacionado à razão de amortecimento do cantilever) e $\Gamma_{i}$ a componente imaginária da função hidrodinâmica $\Gamma$, que é função do número de Reynolds $R e$. 
Os parâmetros $f_{0}$ e $Q$ são medidos a partir de um gráfico da amplitude de oscilação do cantilever em função da frequência. Um transdutor atua no suporte do cantilever (tip holder) aplicando uma força oscilatória de frequência ajustável $f$, à qual o cantilever responde como um oscilador harmônico forçado amortecido, devido à resistência do seu material [37].

Quando a frequência $f \approx f_{0}$, a amplitude na região do pico da ressonância é ajustado por:

$$
A=A_{0}+\frac{A_{1} f_{0}^{4}}{\left(f^{2}-f_{0}\right)^{2}+\left(\frac{f f_{0}}{Q}\right)^{2}}
$$

sendo $A_{0}$ o ruído branco da linha de base e $A_{1}$ a amplitude na frequência de ressonância [44].

Na Fig. 2.9 é mostrado um exemplo de ajuste realizado para obtenção de $f_{0}$ e $Q$, considerando o comportamento do cantilever como um oscilador harmônico forçado amortecido.

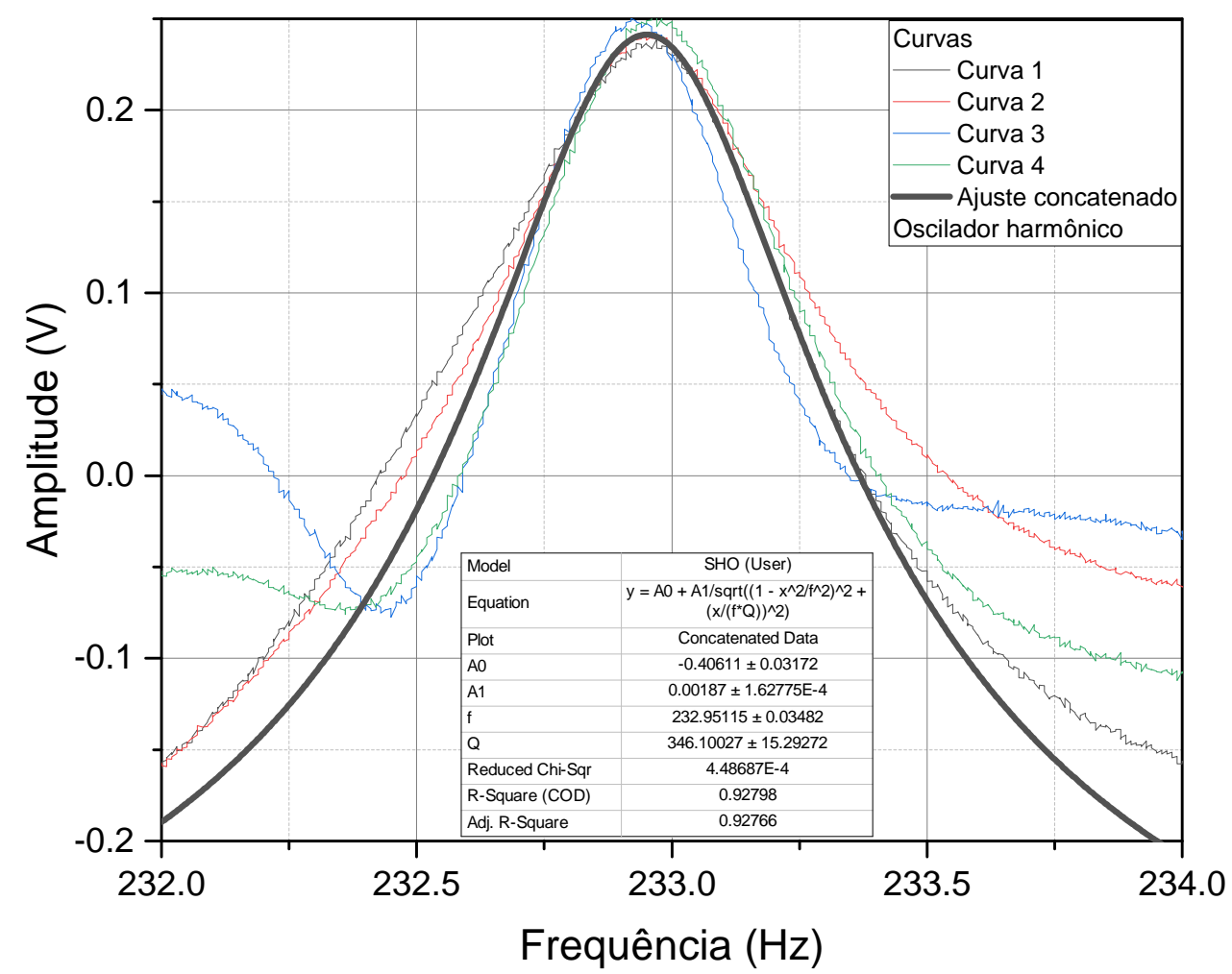

Figura 2.9 - Exemplo de ajuste concatenado de curvas de ressonância do cantilever, considerando o comportamento de um oscilador harmônico forçado amortecido.

\subsubsection{Determinação do raio da ponta $R$}

Para determinação do raio da ponta $R$, inicialmente obtém-se uma imagem da ponta por AFM, utilizando uma amostra padrão de titânio rugoso (RS-15M Bruker PFQNM SMKit). A ideia geral para isso é utilizar estruturas (da amostra) mais afiladas do que a 
própria ponta para que a ponta seja imageada repetidamente ao longo da varredura da amostra. O software, então, identifica o padrão repetitivo e identifica a imagem da ponta, gerando um arquivo com sua imagem.

Nesta imagem, é realizado ajuste da superfície considerando um parabolóide elíptico

$$
z-z_{0}=-\left(\frac{x-x_{0}}{a_{a d j}}\right)^{2}+\left(\frac{y-y_{0}}{b_{a d j}}\right)^{2} .
$$

Um parabolóide elíptico limitado pelo plano $z=z_{0}-\delta_{\max }$, onde $\delta_{\max }$ é a média da deformação máxima ocorrida nas medidas das fibras capilares, tem volume $V=\frac{\pi}{2} a b \delta_{\text {max }}^{2}$. O raio $R$ é obtido, então, considerando o volume de uma calota esférica $V\left(R, \delta_{\max }\right)$ :

$$
R=\frac{1}{3}\left(\frac{3}{\pi} \frac{V}{\delta_{\max }^{2}}+\delta_{\max }\right)
$$

Na Fig. 2.10 é mostrado um exemplo de ajuste de superfície realizado para a ponta do cantilever T231019 [Tab. 2.1]. Os ajustes foram realizados com dados $z_{0}-\delta_{\max } \leq z \leq z_{0}$. O valor $\delta_{\max }$ foi estimado a partir da média de $\delta_{\max }$ sofrida pelas fibras, conforme Fig. 2.11. Sendo assim, a partir dos valores $a_{a d j}$ e $b_{a d j}$ obtidos dos ajustes de superfície e tomando $\delta_{\max }=10 \mathrm{~nm}$, obtém-se o raio da ponta pertencente a cada cantilever.

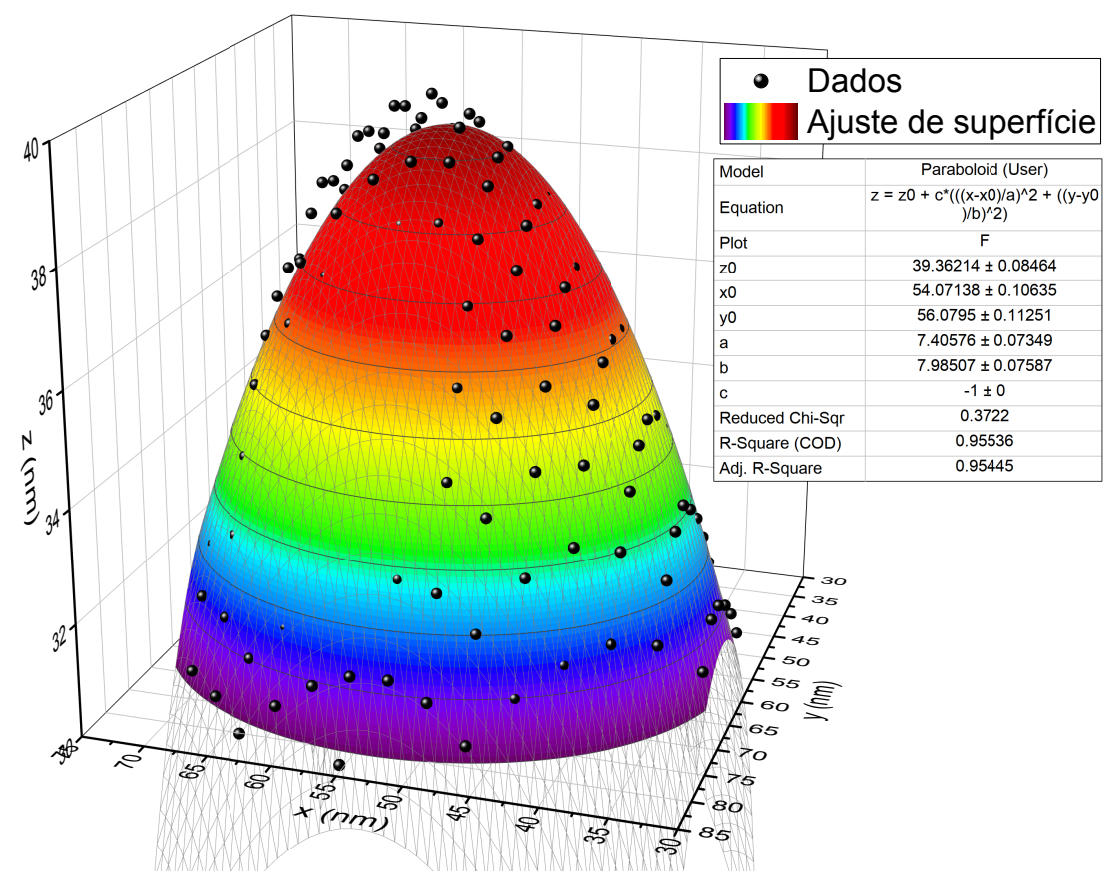

Figura 2.10 - Exemplo de parabolóide elíptico ajustado a partir do software OriginPro®. 


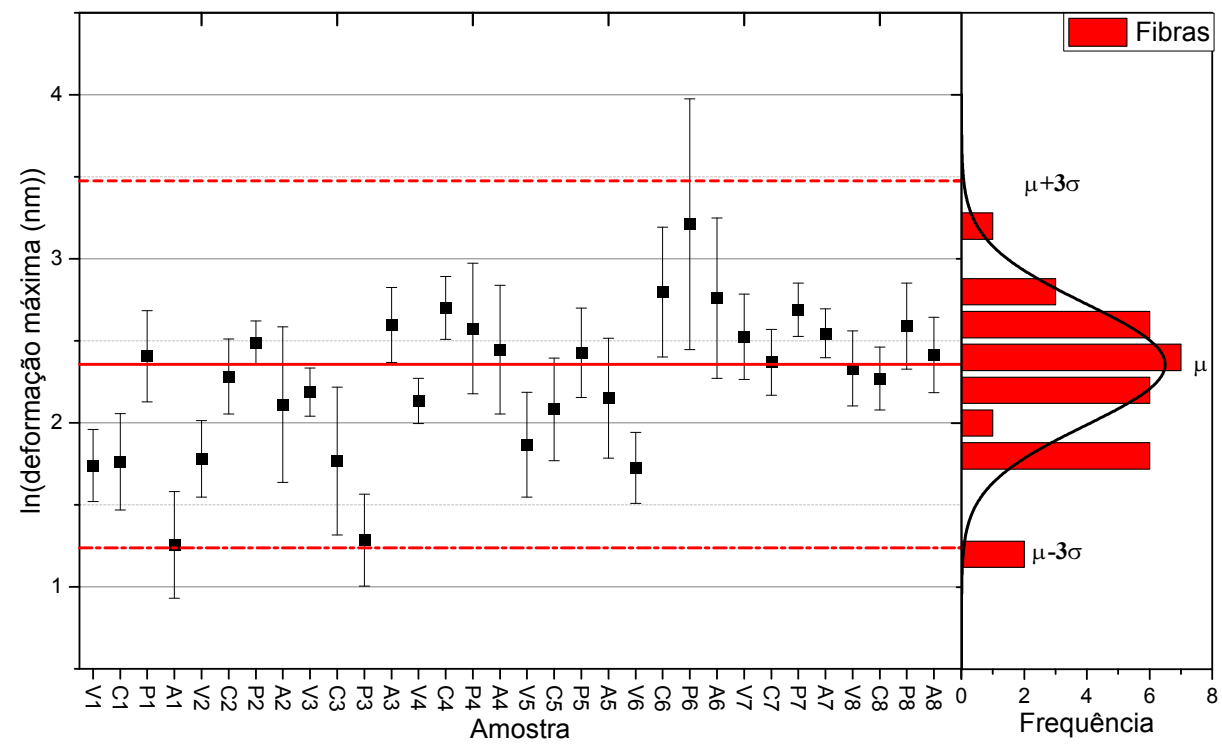

Figura 2.11 - Média do $\ln ($ deformação máxima $)\left(\ln \left(\delta_{\max }\right)\right)$ da amostra pela ponta obtida a partir dos mapas de cada fibra. Note que a média (linha contínua vermelha) é $\ln \left(\delta_{\max }\right)=2,3 \rightarrow \delta_{\max }=10 \mathrm{~nm}$. As fibras são identificadas pela letra correspondente ao seu grupo (V: Virgem; C: Controle; P: Placebo; A: Ativo), seguida do número da fibra (1 a 8).

Na Tab. 2.1 são apresentados os parâmetros relevantes para cada cantilever. A determinação do $k_{c}$ foi realizada considerando static stiffness [46].

Tabela 2.1 - Parâmetros obtidos para cada cantilever.

\begin{tabular}{|c|c|c|c|c|c|c|}
\hline Cantilever & $\begin{array}{c}k_{c} \\
(\mathbf{N} / \mathbf{m})\end{array}$ & $\begin{array}{c}\text { raio da ponta } \\
(\mathbf{n m})\end{array}$ & $\begin{array}{c}f_{0} \\
(\mathbf{k H z})\end{array}$ & $\mathbf{Q}$ & $\begin{array}{c}L_{c} \\
\boldsymbol{\mu m}\end{array}$ & $\begin{array}{c}w_{c} \\
\boldsymbol{\mu m}\end{array}$ \\
\hline $\mathbf{0 1 1 1 1 8}$ & 10.1 & 33 & 233.7 & 250 & 133 & 32 \\
\hline $\mathbf{1 2 1 1 1 8}$ & 18.5 & 45 & 235.8 & 491 & 132 & 31 \\
\hline $\mathbf{2 1 1 2 1 8 1}$ & 12.4 & 48 & 231.8 & 303 & 134 & 33 \\
\hline $\mathbf{2 1 1 2 1 8 2}$ & 12.7 & 30 & 227.3 & 330 & 135 & 31 \\
\hline $\mathbf{2 7 0 5 1 9}$ & 19.8 & 35 & 236.0 & 453 & 137 & 33 \\
\hline $\mathbf{0 2 0 7 1 9 A}$ & 17.1 & 10 & 223.0 & 374 & 148 & 35 \\
\hline $\mathbf{0 2 0 7 1 9 B}$ & 18.5 & 30 & 246.8 & 344 & 138 & 38 \\
\hline $\mathbf{T 2 3 1 0 1 9}$ & 13.7 & 57 & 233.0 & 346 & 134 & 31 \\
\hline $\mathbf{T 1 9 0 2 2 0}$ & 17.8 & 68 & 234.0 & 336 & 133 & 35 \\
\hline
\end{tabular}

\subsection{Tensile Tester}

Um dispositivo de ensaio de tração (Tensile Tester) é um equipamento que permite obtenção de propriedades mecânicas da amostra de interesse. O ensaio consiste em aplicar à amostra de interesse uma força $F$ de tração e registrar sua resposta à tensão, que é a variação $\Delta$ do seu comprimento $L$, até a ruptura. A partir dos dados coletados, é obtida uma curva do tensão (stress $\sigma_{T T}=\frac{F}{A}$ ) em função da deformação $\left(\operatorname{strain} \epsilon_{T T}=\frac{\Delta L}{L}\right.$ ), sendo 
$A$ a área da seção transversal da amostra [Fig. 2.12]. Do ensaio, pode-se obter diretamente informações como a resistência à ruptura, o alongamento máximo e a resistência à tração final. A partir da curva $\sigma_{T T}$ em função de $\epsilon_{T T}$, pode-se calcular, principalmente, o módulo de Young e a dureza (hardness).

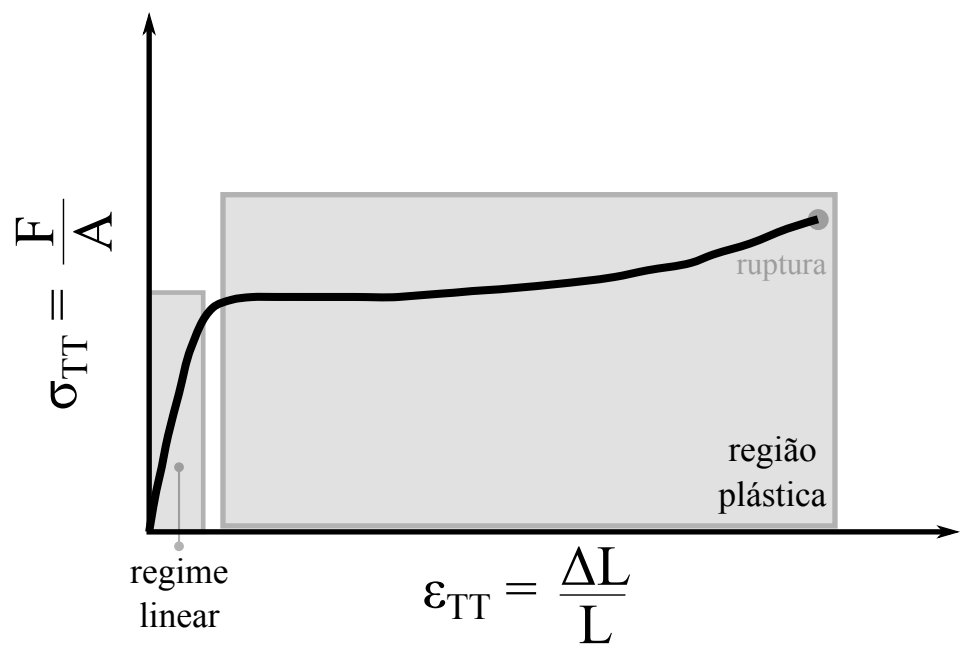

Figura 2.12 - Exemplo de curva de tensão-deformação (stress-strain curve) obtida a partir de Tensile Tester, evidenciando regiões de deformação elástica e deformação plástica.

Para obtenção do módulo de Young de fibras capilares humanas a partir de Tensile Tester, foi utilizado o equipamento automatizado DIA-STRON MTT680, no laboratório da empresa Chemyunion LTDA. As amostras, sendo 17 fibras por grupo, foram preparadas usando o bloco de crimpagem padrão e a prensa. Anteriormente ao ensaio de tração, foi realizada uma avaliação das propriedades dimensionais das fibras, utilizando o equipamento DIA-STRON FDAS770. A partir dos valores de área da seção transversal, foram obtidos o módulo de Young para cada fibra.

\subsection{Microscopia Eletrônica de Transmissão}

Um Microscópio Eletrônico de Transmissão (TEM: Transmission Electron Microscope) [47] é constituído basicamente por um sistema de iluminação, lente objetiva, porta-amostra e um sistema de registro de imagem. As lentes, nesse caso, são eletromagnéticas. O sistema de iluminação compreende uma fonte de elétrons, o qual forma um feixe em alto vácuo a partir de emissão termoiônica ou emissão por campo, que é acelerado em direção a lentes condensadoras, que têm por principal objetivo demagnificar o diâmetro do feixe e colimá-lo. O feixe incide na amostra e, a partir do espalhamento dos elétrons que atravessam a amostra, forma-se a imagem pela lente objetiva. O registro de imagem é realizado por CCD sensível a elétrons. 
O alto poder de resolução espacial desta microscopia é devido à radiação do sistema de iluminação ser elétrons. Considerando o critério de Rayleigh, um elétron viajando com $100 \mathrm{keV}$ de energia, que é a ordem de grandeza da tensão aceleradora utilizada (100 kV), teoricamente a menor distância resolvida seria de aproximadamente 5 pm, que é muito menor que o diâmetro de um átomo. Porém, as aberrações das lentes são severas e limitam essa resolução. Aberturas também são colocadas no sistema para reduzir as aberrações, permitindo poder de resolução espacial de fração de nanometro.

Como a formação das imagens é dada por elétrons transmitidos, a técnica não possui sensibilidade em profundidade e requer que as amostras tenham espessuras menores que $100 \mathrm{~nm}$. A diferença em intensidade na distribuição espacial dos elétrons espalhados em diferentes pontos da amostra gera contraste nas imagens, dando informações morfológicas.

As micrografias foram realizadas no Laboratório de Biologia Celular da Faculdade de Medicina da USP , utilizando o microscópio eletrônico de transmissão JEOL 1010, com tensão aceleradora de $80 \mathrm{kV}$, sendo o registro realizado por uma câmera CCD Bioscan 782, de $1 \mathrm{k} \times 1 \mathrm{k}$ pixels.

\subsection{Preparação e avaliação das amostras}

As amostras estudadas correspondem a fibras capilares humanas de mechas padronizadas de cabelo caucasiano (International Hair Importers). As amostras do grupo virgem correspondem a fibras sem danos químicos e sem aplicação de produto cosmético. As amostras do grupo controle, placebo e ativo correspondem a fibras, que sofreram danos químicos por descoloração (3 ciclos) e foram tratados conforme Tab. 2.2:

Tabela 2.2 - Especificação das fibras capilares.

\begin{tabular}{|l|l|}
\hline Grupo & Especificação \\
\hline \hline Virgem & Sem danos químicos e sem aplicação de produto. \\
\hline Controle & Danificada quimicamente ${ }^{1 *}$ e sem aplicação de produto. \\
\hline Placebo & Danificada quimicamente ${ }^{1 *}$ com aplicação de produto ${ }^{2}$ Sem ativo cosmético (placebo). \\
\hline Ativo & Danificada quimicamente ${ }^{1 *}$ e com aplicação de produto ${ }^{2}$ com ativo cosmético ${ }^{3 *}$ \\
\hline 1* Dano químico por descoloração (bleaching) a partir de aplicação de peróxido de hidrogênio e \\
persulfatos (3 ciclos). \\
2* Produto cosmético composto por: Water, Sodium Laureth Sulfate, Citric Acid, Cocamidopropyl \\
Betaine, Cocamide DEA, Sodium Chloride, Xylityl Sesquicaprylate e Disodium EDTA (Shampoo); \\
Water, Cetearyl Alcohol, Cetyl Alcohol, Glycerin, Cetrimonium Chloride, Xylityl Sesquicaprylate, \\
Lactic Acid, Stearamidopropyl Dimethylamine e Disodium EDTA (Condicionador). \\
3* Ativo cosmético composto de água, Polyquaternium- 7, Fibroin ${ }^{1}$, Hidroxypropyl Starch Phosphate, \\
Glycerin e Guar Hydroxypropyltrimonium Chloride.
\end{tabular}

1 Fibroína (proteína da seda): principal componente do ativo. 


\subsubsection{Preparação para Microscopia Eletrônica de Transmissão}

A dificuldade desta técnica reside principalmente na preparação da amostra, pela necessidade de obtenção de cortes ultrafinos ( $\lesssim 100 \mathrm{~nm})$, que geralmente envolvem processos de fixação e inclusão do material, assim como coloração ${ }^{2}$ (staining) das amostras utilizando elementos pesados, para contrastação, a fim de evidenciar as estruturas de interesse. Dada a necessidade indicada pela literatura da utilização de materiais altamente tóxicos para fixação e/ou coloração ${ }^{2}$ [48-57], foi estabelecido protocolo para completa preparação das amostras para observação por TEM $[48,55]$ :

1. Inclusão em resina epoxy STRUERS Specifix-20 de segmento de cerca de $1 \mathrm{~cm}$ da fibra capilar, obtida a partir de $10 \mathrm{~cm}$ de distância da raíz do couro cabeludo, sem procedimento de fixação;

2. Cura da resina com fibra incluída em temperatura ambiente, por 72 horas;

3. Desbastamento da resina até a primeira exposição da fibra capilar, a partir do ultramicrótomo LEICA EM UC7, utilizando faca de vidro;

4. Coloração (staining) do bloco de resina com fibra capilar já exposta à superfície, em ambiente escuro por 1 hora com tetróxido de ósmio 1\%, diluído em solução fisiológica ( $\mathrm{NaCl}$, sacarose e água destilada) e posterior lavagem com água deionizada (2 banhos);

5. Coloração (staining) em ambiente escuro por 4 horas com acetato de uranila $1 \%$ e posterior lavagem com água deionizada;

6. Desidratação via vácuo (dessecador) para remoção de resíduos;

7. Corte de seções de $\approx 80 \mathrm{~nm}$ de espessura, a partir de ultramicrotomia, sobre água deionizada e coleta em grid para observação por TEM (subseção 2.4.2);

8. Coloração (staining) dos cortes no grid por 2 min com acetato de uranila $1 \%$ e 1 min com citrato de chumbo $0,2 \%$, enxaguado com água ultrapura a cada passo da coloração (etapa realizada no Laboratório de Biologia Celular da Faculdade de Medicina da USP);

\subsubsection{Ultramicrotomia}

Para obtenção dos cortes ultrafinos, foi utilizado o ultramicrótomo, equipamento provido de navalhas de vidro ou diamante, onde um braço móvel desloca a amostra para realização do corte. O equipamento possui capacidade de passos entre $30 \mathrm{~nm}$ e $15 \mu \mathrm{m}$, que

2 Coloração (staining) neste contexto deve ser entendido como introdução de elementos pesados na amostra, o que gera contraste perante o espalhamento do feixe eletrônico ao atravessar a amostra. 
corresponde à espessura do corte. Normalmente, os cortes ultrafinos são depositados em um pequeno compartimento contendo água em um nível muito próximo à lâmina de corte [Fig. 2.13]. Então os cortes flutuantes na superfície da água são coletados e posicionados em grid para observação por TEM.

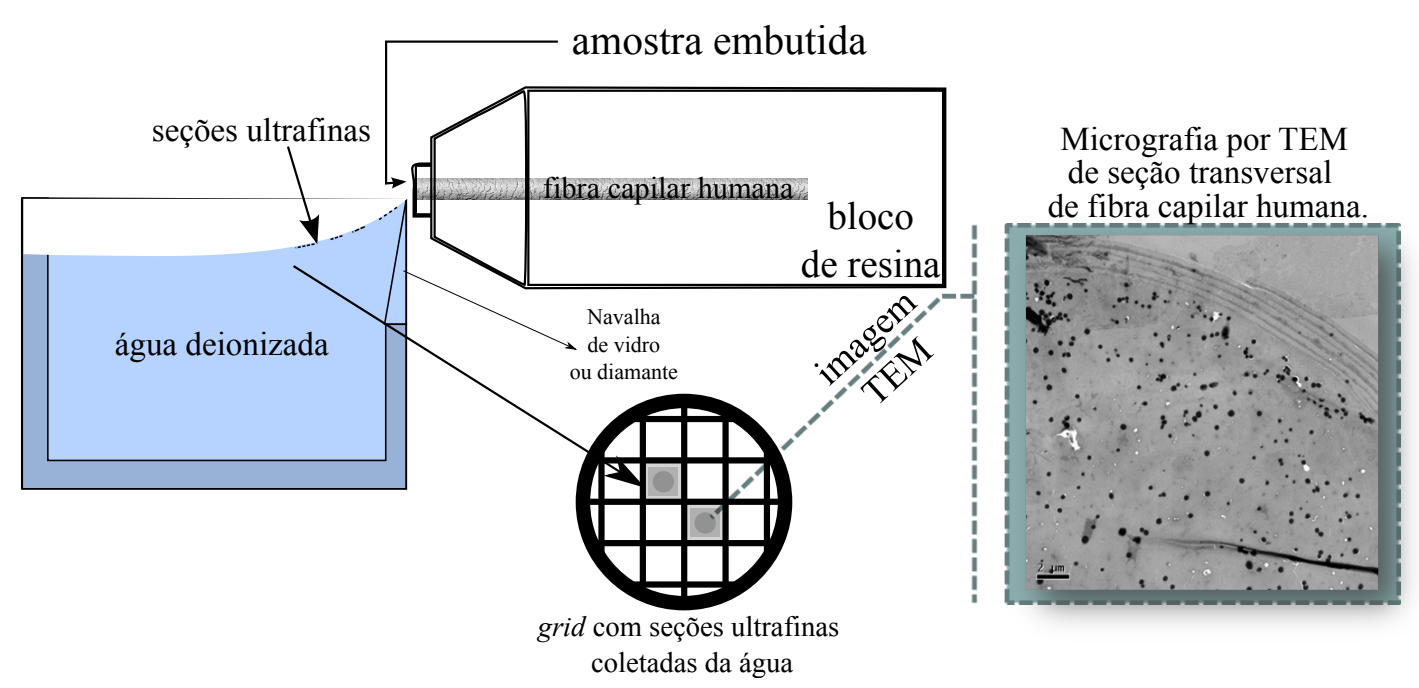

Figura 2.13 - Obtenção de cortes ultrafinos por ultramicrotomia.

\subsubsection{Preparação para Microscopia de Força Atômica}

Uma forma interessante de preparar a amostra para AFM é utilizar a superfície do bulk proveniente dos cortes ultrafinos realizados no ultramicrótomo. Neste caso, o bulk se trata do bloco de resina com seção transversal da fibra capilar exposta, por corte realizado por faca de diamante. A superfície deste bulk permite a caracterização de propriedades mecânicas de estruturas internas por AFM, pois expõe a região do córtex, com superfície de baixa rugosidade. Vale ressaltar que a análise por AFM do bulk é feita anteriormente ao procedimento de coloração (staining) do bloco (subseção 2.4 .1 - procedimento 4).

Para avaliar a qualidade das superfícies, foram tomadas imagens topográficas da superfície dos bulks pelo Microscópio de Força Atômica BRUKER MultiMode 8, no modo tapping, de 512 x 512 pixels, para averiguar a rugosidade. Na Fig. 2.14 é mostrado uma imagem de Microscopia Óptica como exemplo de superfície obtida. Com a finalidade de obter a rugosidade das amostras devido principalmente ao processo de corte, foram obtidos valores de rugosidade $R_{R M S}$ (rugosidade Root Mean Square) das imagens ${ }^{3}$. Nesta análise, foram desconsideradas as regiões medulares, por serem altamente porosas, o que provocaria grande influência no cálculo devido a uma estrutura intrínseca das amostras. Para o cálculo, também foi desconsiderada a região da resina. Nas Figs. 2.15, 2.16, 2.17 e 2.18 são apresentadas as imagens das quais foram calculadas a $R_{R M S}$ [Tab. 2.3], obtidas de regiões das fibras, ou seja, desconsiderando regiões da resina, e também as regiões

\footnotetext{
3 As imagens foram processadas com Plane Fit em XY de $3^{\text {a }}$ ordem.
} 
medulares. As fibras são identificadas pela letra correspondente ao seu grupo (V: Virgem; C: Controle; P: Placebo; A: Ativo), seguida do número da fibra (1 a 8).

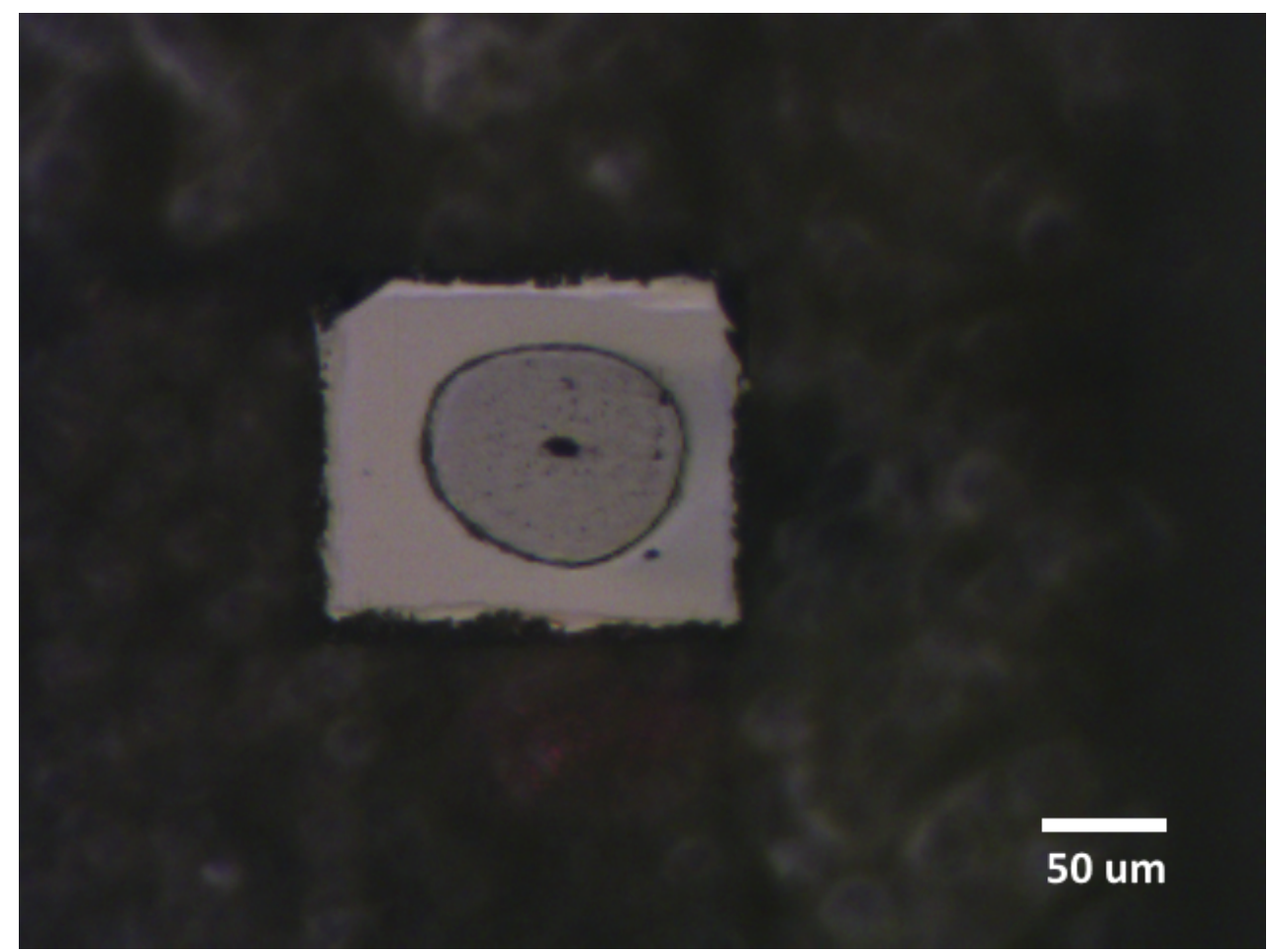

Figura 2.14 - Exemplo de imagem por Microscopia Óptica de superfície, obtida por ultramicrotomia, de seção transversal de fibra capilar embebida em resina (top view) (amostra correspondente à imagem da Fig. 2.17a).

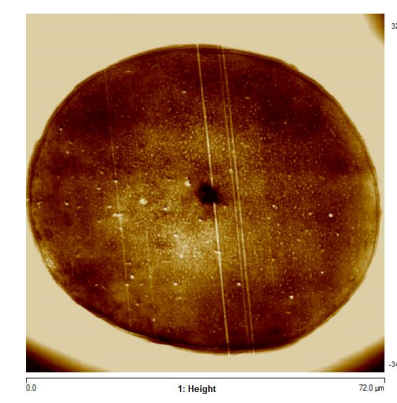

(a) Amostra V1.

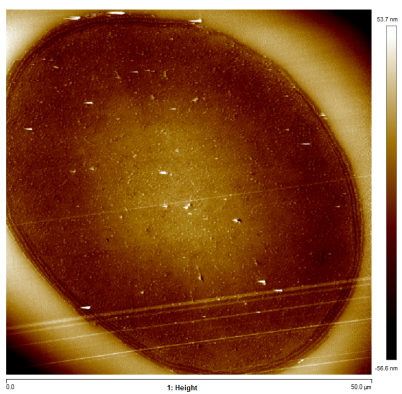

(e) Amostra V5.

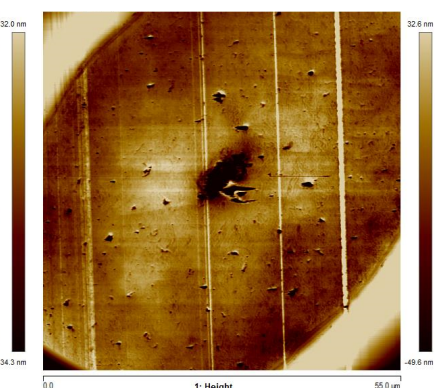

(b) Amostra V2.

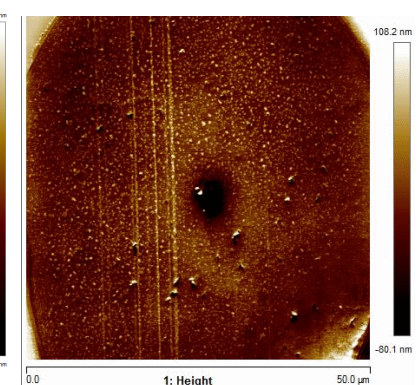

(f) Amostra V6.

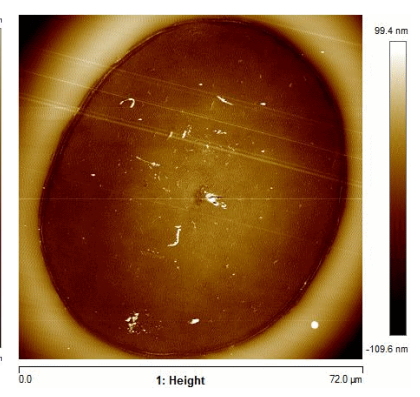

(c) Amostra V3.

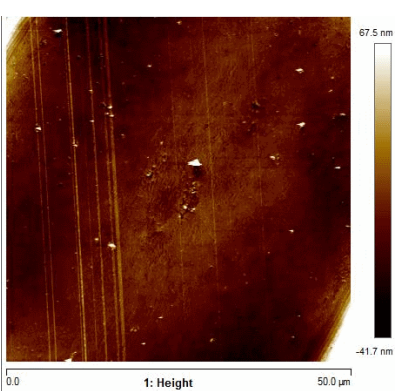

(g) Amostra V7.

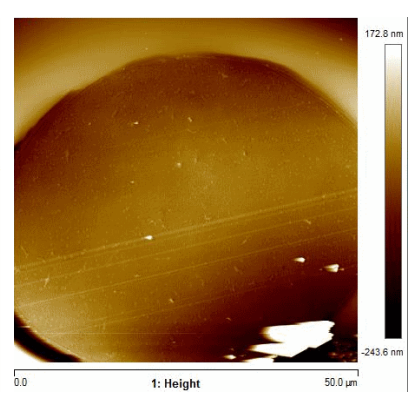

(d) Amostra V4.

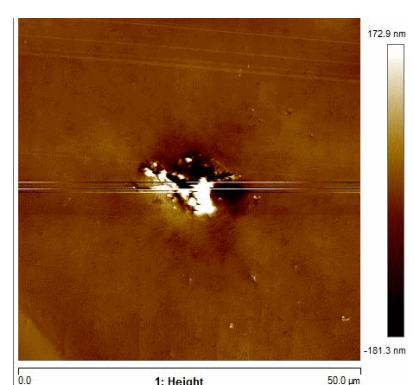

(h) Amostra V8.

Figura 2.15 - Imagens AFM - modo tapping de seções transversais de fibras capilares, pertencentes ao grupo virgem. 


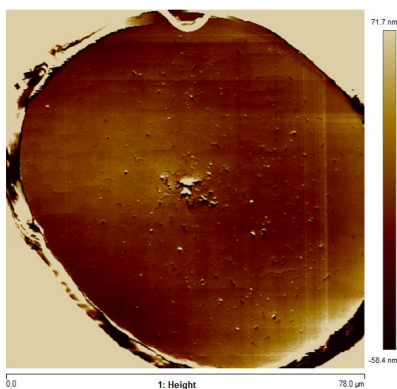

(a) Amostra C1.

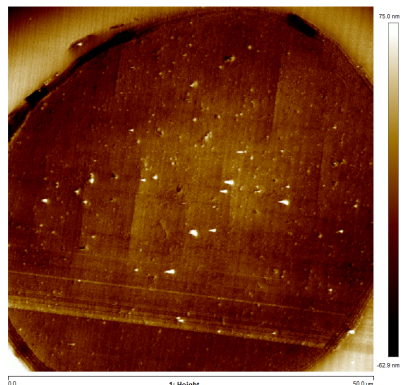

(e) Amostra C5.

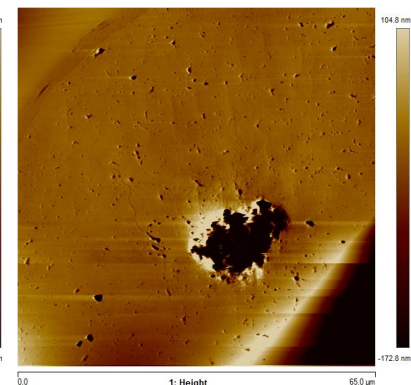

(b) Amostra C2.

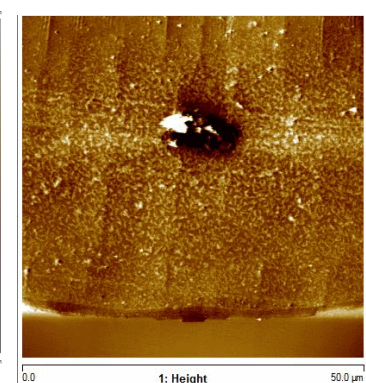

(f) Amostra C6.

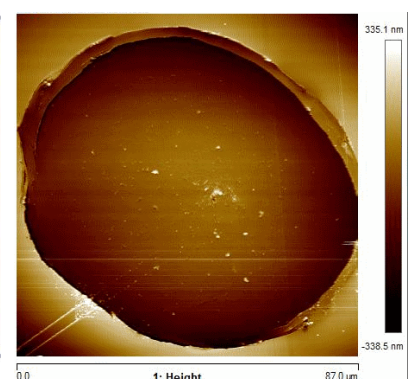

(c) Amostra C3.

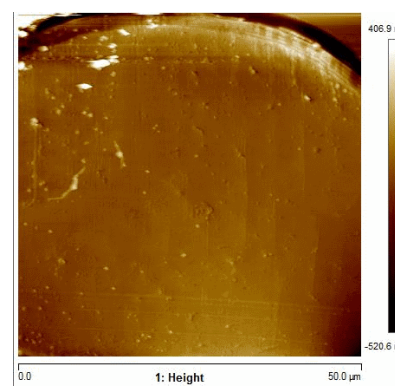

(g) Amostra C7.

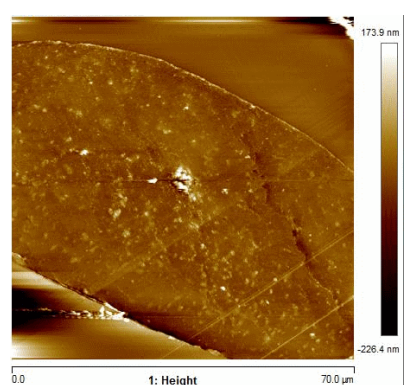

(d) Amostra C4.

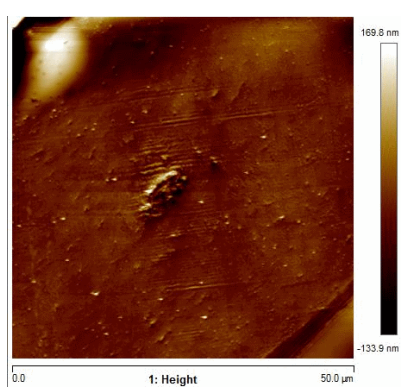

(h) Amostra C8.

Figura 2.16 - Imagens AFM - modo tapping de seções transversais de fibras capilares, pertencentes ao grupo controle.

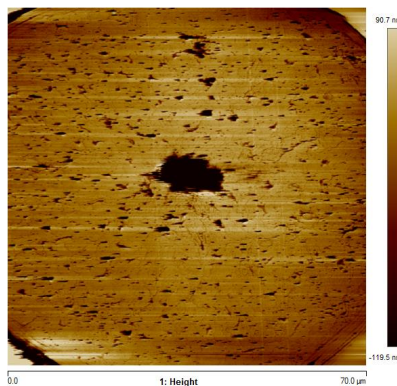

(a) Amostra P1.

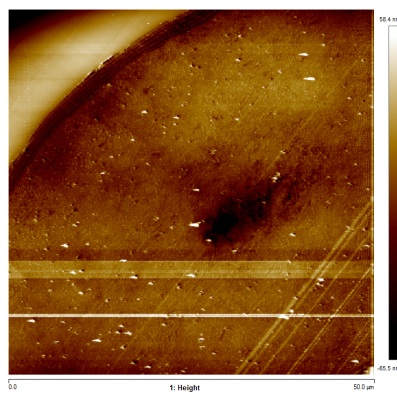

(e) Amostra P5.

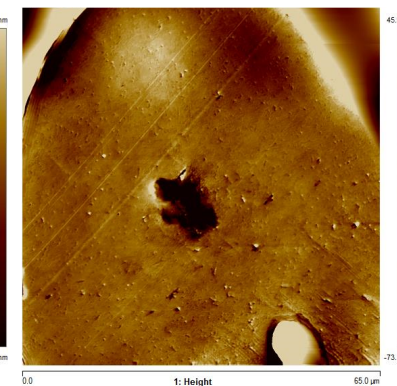

(b) Amostra P2.

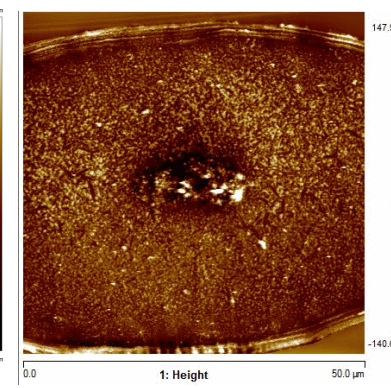

(f) Amostra P6.

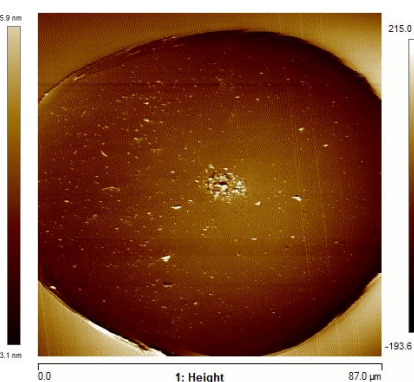

(c) Amostra P3.

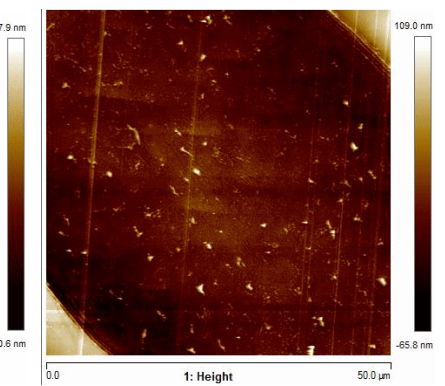

(g) Amostra P7.

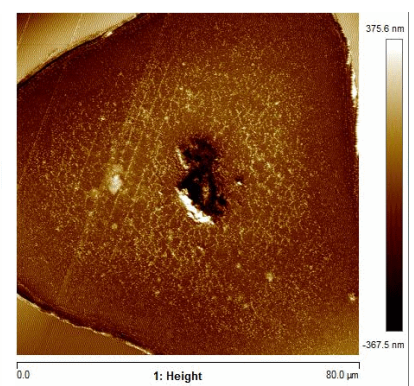

(d) Amostra P4.

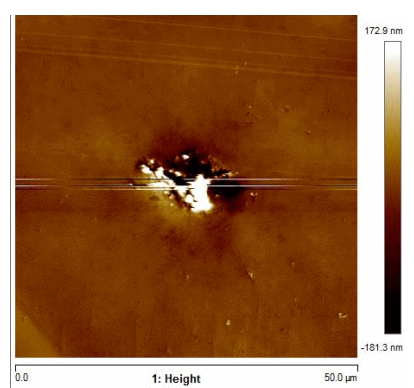

(h) Amostra P8.

Figura 2.17 - Imagens AFM - modo tapping de seções transversais de fibras capilares, pertencentes ao grupo placebo. 


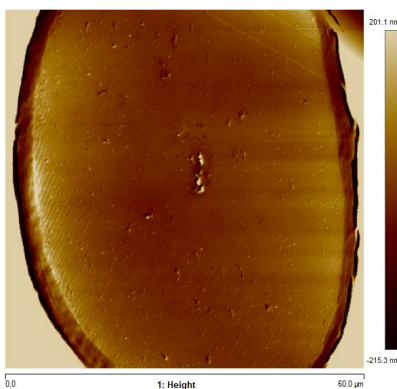

(a) Amostra A1.

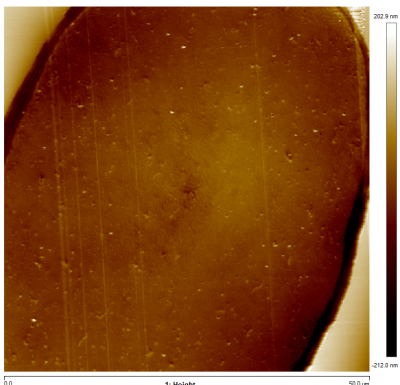

(e) Amostra A5.

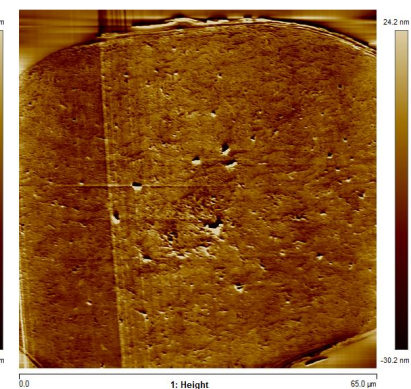

(b) Amostra A2.

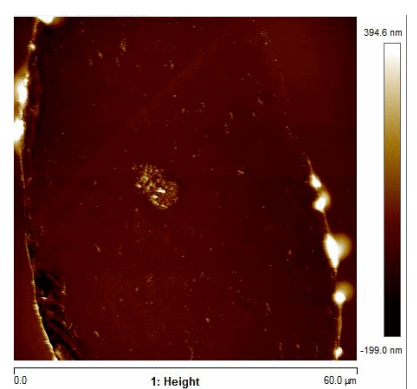

(c) Amostra A3.

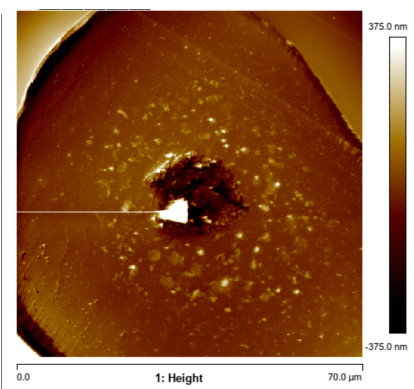

(d) Amostra A4.

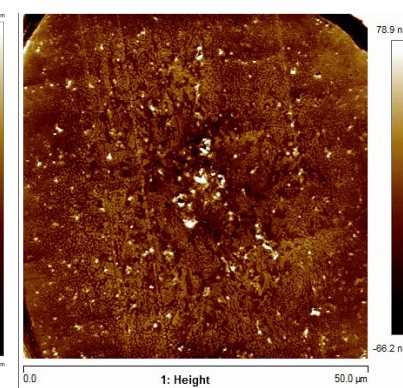

(f) Amostra A6.

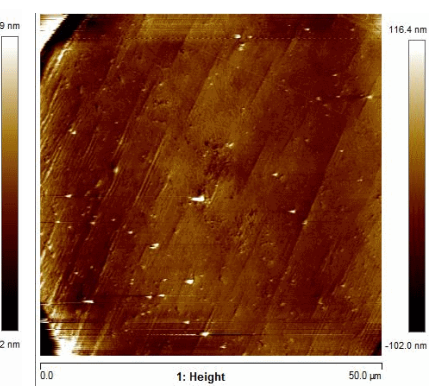

(g) Amostra A7.

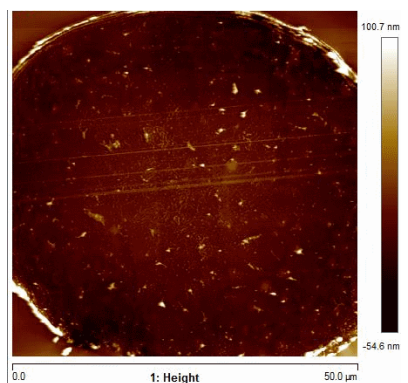

(h) Amostra A8.

Figura 2.18 - Imagens AFM - modo tapping de seções transversais de fibras capilares, pertencentes ao grupo ativo.

Os valores $R_{R M S}$ e respectiva incerteza, apresentados na Tab. 2.3, foram obtidos a partir do ajuste da Height-Height Correlation Function (HHCF) unidimensional para cada amostra, utilizando o software Gwyddion v2.59 [58,59]. Os valores apresentados de $R_{R M S}^{-}$para cada grupo correspondem a média ponderada pelo inverso do desvio padrão quadrático [60].

Tabela 2.3 - Valores de rugosidade $R_{R M S}$ (Root Mean Square) (nm) obtidos a partir das imagens de AFM, apresentadas nas Figuras 2.15, 2.16, 2.17 e 2.18. Para cada grupo, é calculado o valor médio $R_{R M S}$ e o respectivo erro da média. As fibras são identificadas pela letra correspondente ao seu grupo (V: Virgem; C: Controle; P: Placebo; A: Ativo), seguida do número da fibra (1 a 8).

\begin{tabular}{|c|c|c|c|c|c|c|c|c|}
\hline & \multicolumn{8}{|c|}{$R_{R M S}$} \\
\hline & V1 & $5,74 \pm 0,04$ & C1 & $7,83 \pm 0,06$ & P1 & $31,03 \pm 0,27$ & A1 & $9,03 \pm 0,04$ \\
\hline & V2 & $9,09 \pm 0,09$ & $\mathrm{C} 2$ & $14,80 \pm 0,22$ & P2 & $4,616 \pm 0,016$ & A2 & $7,01 \pm 0,05$ \\
\hline & V3 & $5,63 \pm 0,11$ & C3 & $10,30 \pm 0,18$ & P3 & $11,18 \pm 0,12$ & A3 & $9,3 \pm 0,12$ \\
\hline & $\mathrm{V4}$ & $4,09 \pm 0,06$ & $\mathrm{C4}$ & $15,74 \pm 0,26$ & $\mathrm{P} 4$ & $51,6 \pm 0,4$ & A4 & $29,3 \pm 0,3$ \\
\hline & V5 & $4,413 \pm 0,010$ & C5 & $7,880 \pm 0,022$ & $\mathrm{P} 5$ & $6,688 \pm 0,016$ & A5 & $7,86 \pm 0,03$ \\
\hline & V6 & $16,7 \pm 0,6$ & C6 & $20,9 \pm 0,5$ & P6 & $28,06 \pm 0,13$ & A6 & $15,04 \pm 0,07$ \\
\hline & V7 & $5,44 \pm 0,04$ & $\mathrm{C} 7$ & $17,8 \pm 0,7$ & P7 & $5,94 \pm 0,03$ & A7 & $8,70 \pm 0,20$ \\
\hline & V8 & $3,93 \pm 0,06$ & C8 & $9,86 \pm 0,12$ & P8 & $8,914 \pm 0,017$ & A8 & $7,98 \pm 0,08$ \\
\hline$R_{R M S}$ & \multicolumn{2}{|c|}{$4,60 \pm 0,25$} & \multicolumn{2}{|r|}{$8,1 \pm 0,4$} & \multicolumn{2}{|r|}{$6,8 \pm 1,0$} & \multicolumn{2}{|c|}{$8,6 \pm 0,8$} \\
\hline
\end{tabular}

A partir dos dados apresentados na Tab. 2.3, obteve-se a média da rugosidade RMS de todas as superfícies avaliadas, resultando em $R_{R M S}^{-}=6,2 \pm 0,4 \mathrm{~nm}$. Portanto, 
verifica-se que, tanto as médias para cada grupo de amostra, quanto a média de todas as amostras, são menores que $\delta_{\max }^{-}$(subseção 2.1.4), considerando-se superfícies adequadas para avaliação de propriedades mecânicas por curvas de força [43].

\subsubsection{Force Volume - AFM}

A cada início de experimento, dado pela montagem do cantilever no tip holder e alinhamento do laser, foi tomada uma curva de $d c \times Z$ para obtenção do deflection sensitivity em amostra de alta rigidez em relação ao cantilever $\left(k_{s}>>k_{c}\right)$ : safira Sapphire15M BRUKER PFQNM-SMKit, limpa previamente por esfregamento mecânico com algodão embebido em álcool isopropílico e jato de nitrogênio para remoção de excessos.

As medidas foram realizadas em ar, utilizando cantilevers retangulares NANOSENSORS PPP-NCH-W, com medidas de comprimento $L_{c}$ e largura $w_{c}$ obtidas por Microscopia Óptica [Fig. 2.19], frequência de ressonância $f_{0}$ e fator de qualidade $Q$ a partir da obtenção do gráfico de amplitude em função da frequência de oscilação do cantilever pelo modo Tune cantilever, disponível no Microscópio de Força Atômica BRUKER MultiMode 8. A partir destes parâmetros, a constante elástica do cantilever $k_{c}$ foi calculada pelo método de Sader [45], considerando a densidade $\rho_{f}=1,18$ $\mathrm{kg} / \mathrm{m}^{3}$ e viscosidade do fluido $\nu_{f}=1,86 \times 10^{-5} \mathrm{~kg} / \mathrm{m} / \mathrm{s}$ (ar), pelo aplicativo disponível em <http://www.ampc.ms.unimelb.edu.au/afm/calibration.html> [46].

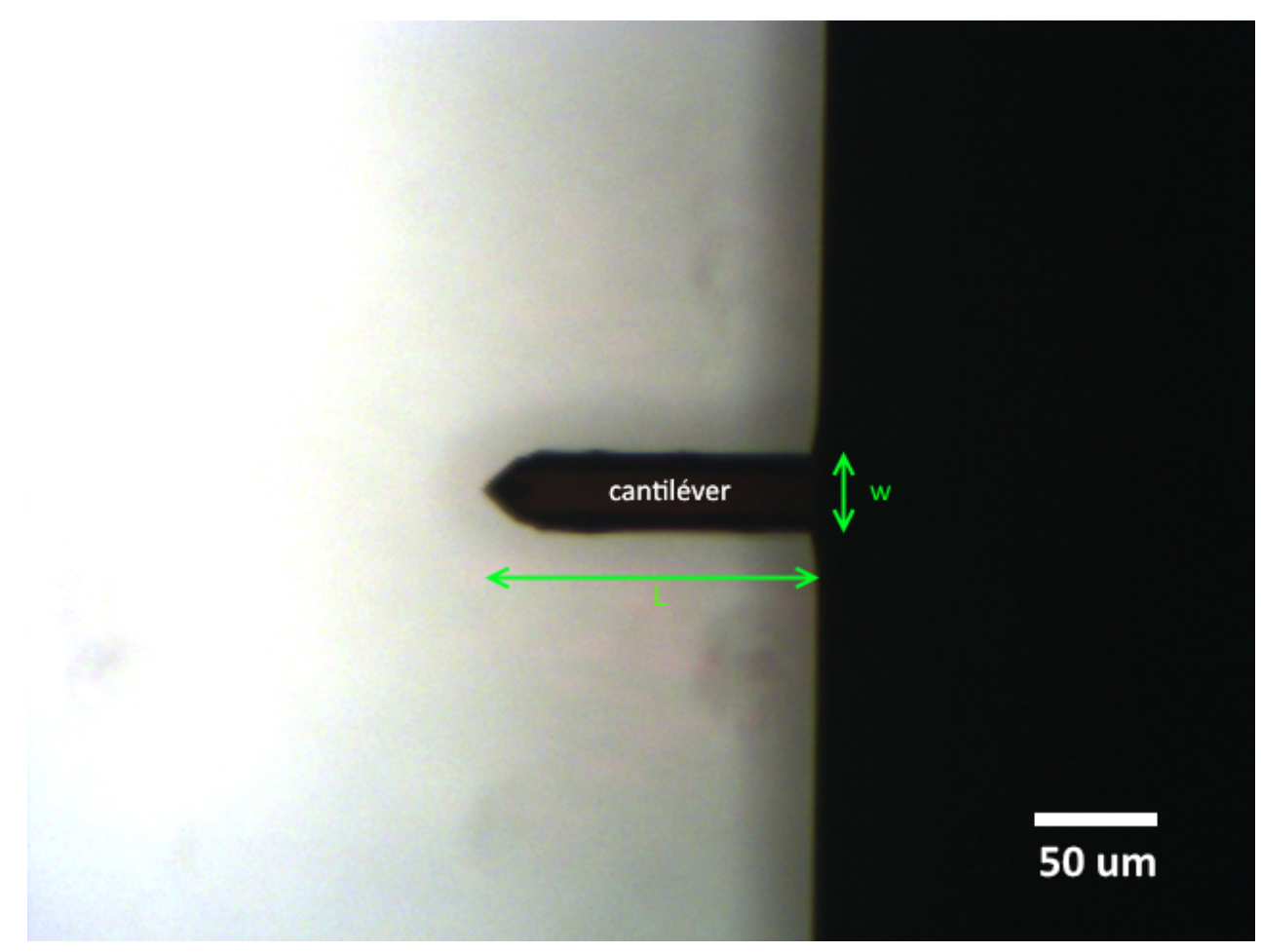

Figura 2.19 - Geometria do cantilever retangular, com comprimento $L_{c}$ e largura $w_{c}$, medidos a partir de imagem de Microscopia Óptica. 
O mapeamento por FV-AFM foi realizado na mesma região onde foram tomadas as imagens topográficas no modo tapping [Figs. 2.15, 2.16, 2.17 e 2.18], com trigger = $40 \mathrm{~nm}$ para obtenção das curvas (64x64 pontos) [61]. Devido ao possível desgaste sofrido pelas pontas após diversas indentações, foram utilizadas pontas distintas. Conforme procedimento descrito na subseção 2.1.3, obteve-se os parâmetros para cada cantilever.

Para obtenção dos valores de propriedades mecânicas (módulo elástico, deformação máxima da amostra pela ponta e adesão máxima entre ponta e amostra), os dados foram processados pelo software Atomic J v1.8 [62]. Foi realizado ajuste das curvas de aproximação, considerando o modelo de Sneddon na região de contato (subseção 2.1.1.1) para pontas esféricas, aproximadas por um parabolóide do raio $R$ medido. Para as amostras, foi considerado a razão de Poisson $\nu=0,38$, conforme encontrado em [63]. 


\section{Resultados e Discussão}

\subsection{Force Volume - AFM}

Na Fig. 3.1 é mostrado o mapeamento multiparamétrico de propriedades mecânicas (módulo de Young, força máxima de adesão entre ponta e superfície da amostra e deformação máxima da amostra pela indentação da ponta) por FV-AFM, associado à imagem topográfica ${ }^{1}$, de seção transversal da fibra capilar embutida em resina. Os mapas obtidos de todas as amostras pertencentes aos grupos virgem, controle, placebo e ativo são apresentados, respectivamente, nas Figs. 3.2, 3.3, 3.4 e $3.5^{2}$. Nos mapas, estão contidas regiões tanto da fibra, quanto da resina, a qual foi utilizada para embebimento da amostra. Os valores pertencentes à fibra foram analisados separadamente dos valores pertencentes à resina (região circundante), sendo selecionados a partir da visualização do mapa topográfico, onde é possível identificar a borda da fibra. Tanto para os dados das fibras quanto da resina, foram considerados apenas valores provenientes de curvas com estatística $R^{2} \geq 0.95^{3}$, de forma a desconsiderar dados espúrios.

Para os parâmetros módulo de Young e deformação máxima da amostra pela indentação da ponta, foi considerado que os dados seguem uma distribuição lognormal, pois estas grandezas não admitem valores negativos. Portanto, para análise dos parâmetros módulo de Young e deformação, foi tomado o logaritmo natural dos dados.

1 As imagens de topografia foram processadas utilizando Plane Fit em XY de $3^{\text {a }}$ ordem.

2 Na versão digital deste documento, que pode ser obtida em < https://www.teses.usp.br/>, as figuras podem ser ampliadas com alta resolução.

3 Coeficiente de determinação $R^{2}$ (seção A.2). 

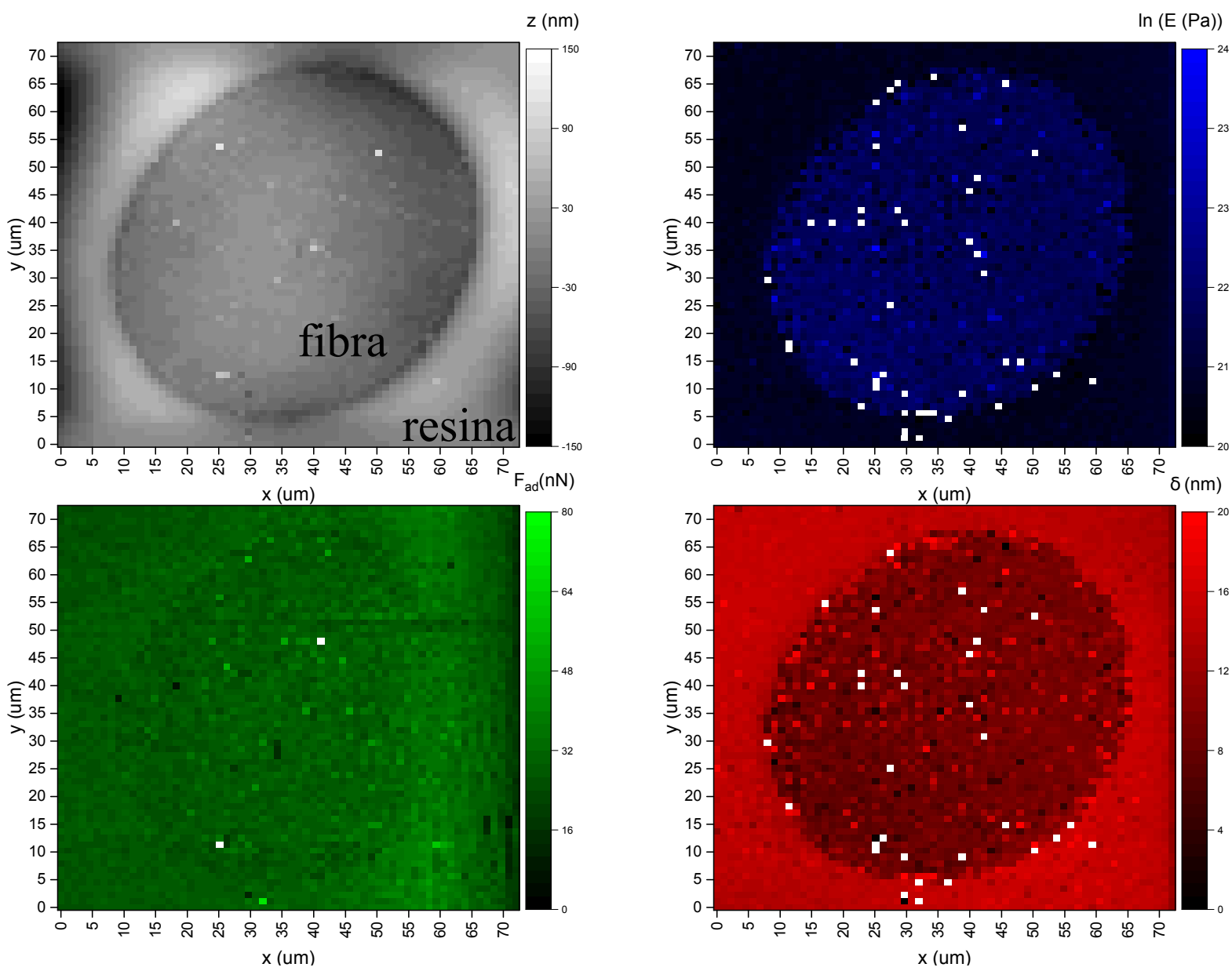

Figura 3.1 - Exemplo do mapeamento multiparamétrico por FV-AFM de seção transversal de fibra capilar, embebida por resina epoxy (região circundante), com dados de altura (z) (em escala de cinza), logaritmo natural do módulo de Young $(\ln (E))$ (em tons de azul), força de adesão entre ponta e amostra $\left(F_{a d}\right)(\mathrm{em}$ tons de verde) e deformação máxima da amostra pela ponta $(\delta)$ (em tons de vermelho).

A seguir, são apresentados os mapas obtidos de todas as amostras pertencentes aos grupos virgem, controle, placebo e ativo, respectivamente, nas Figs. 3.2, 3.3, 3.4 e 3.5, com amplitude de varredura (scan size) de 50-87 $\mu \mathrm{m}$. 

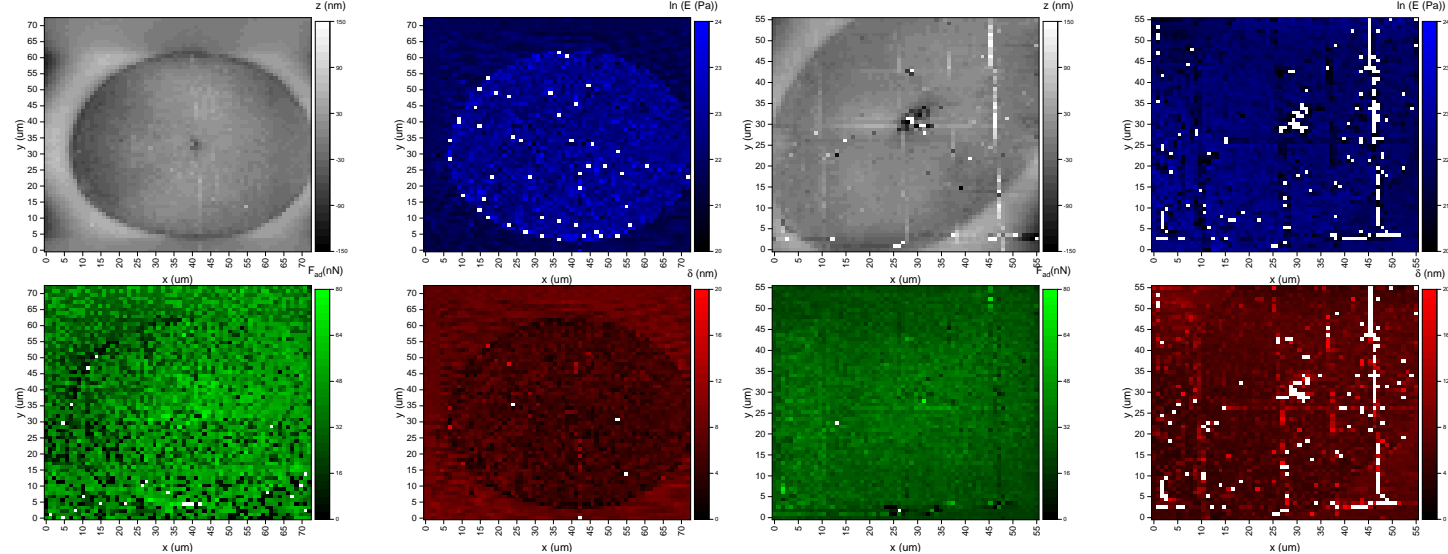

(a) Amostra V1.
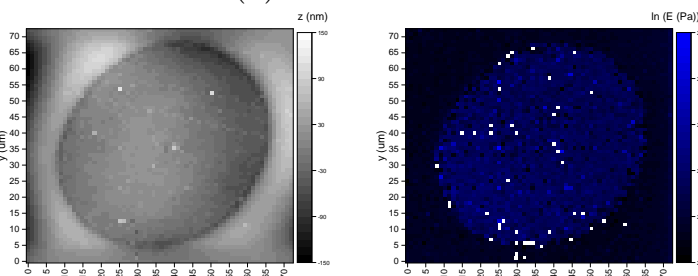

(b) Amostra V2.
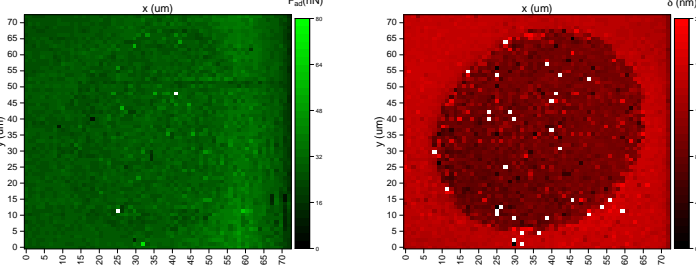

(c) Amostra V3.
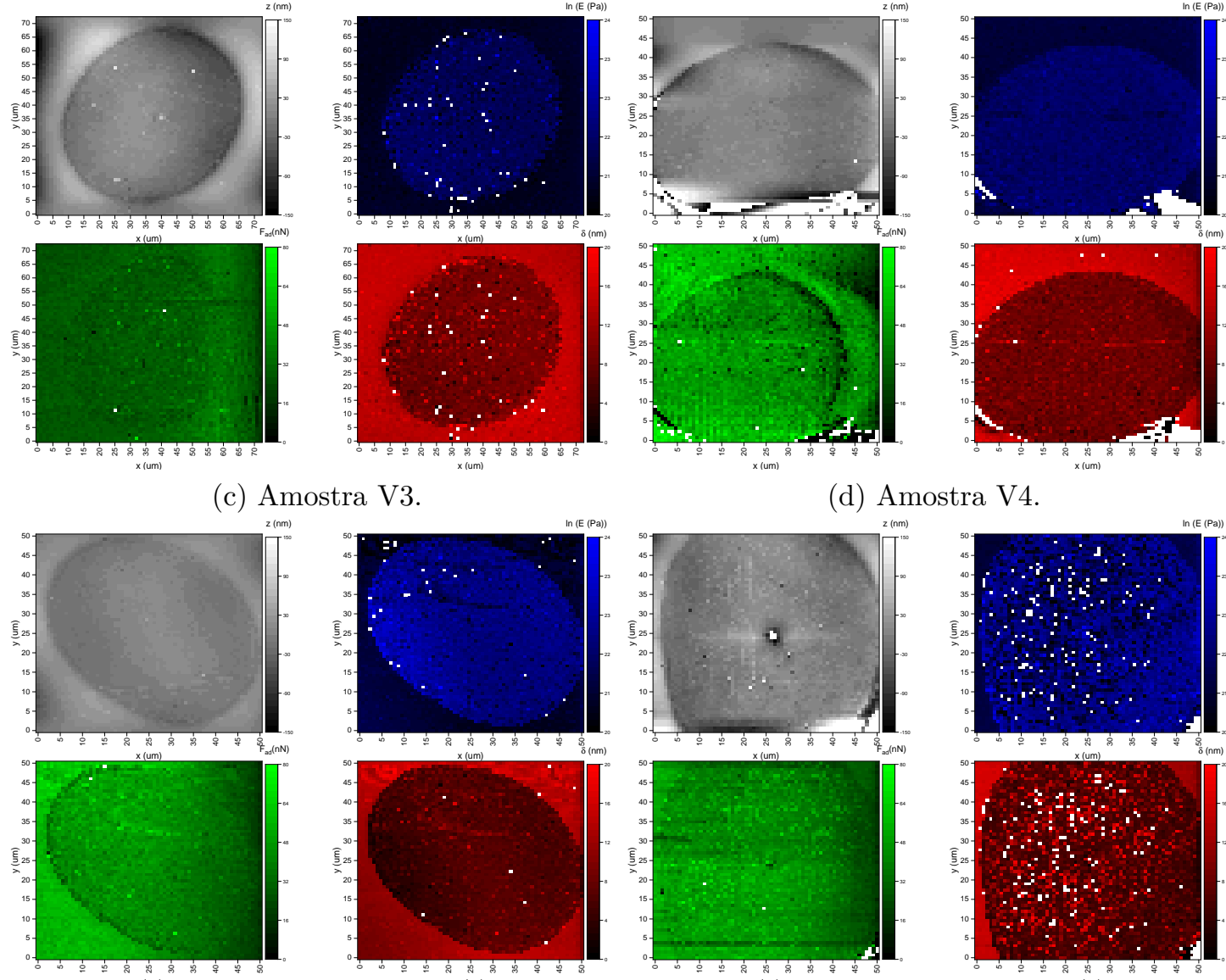

(e) Amostra V5.
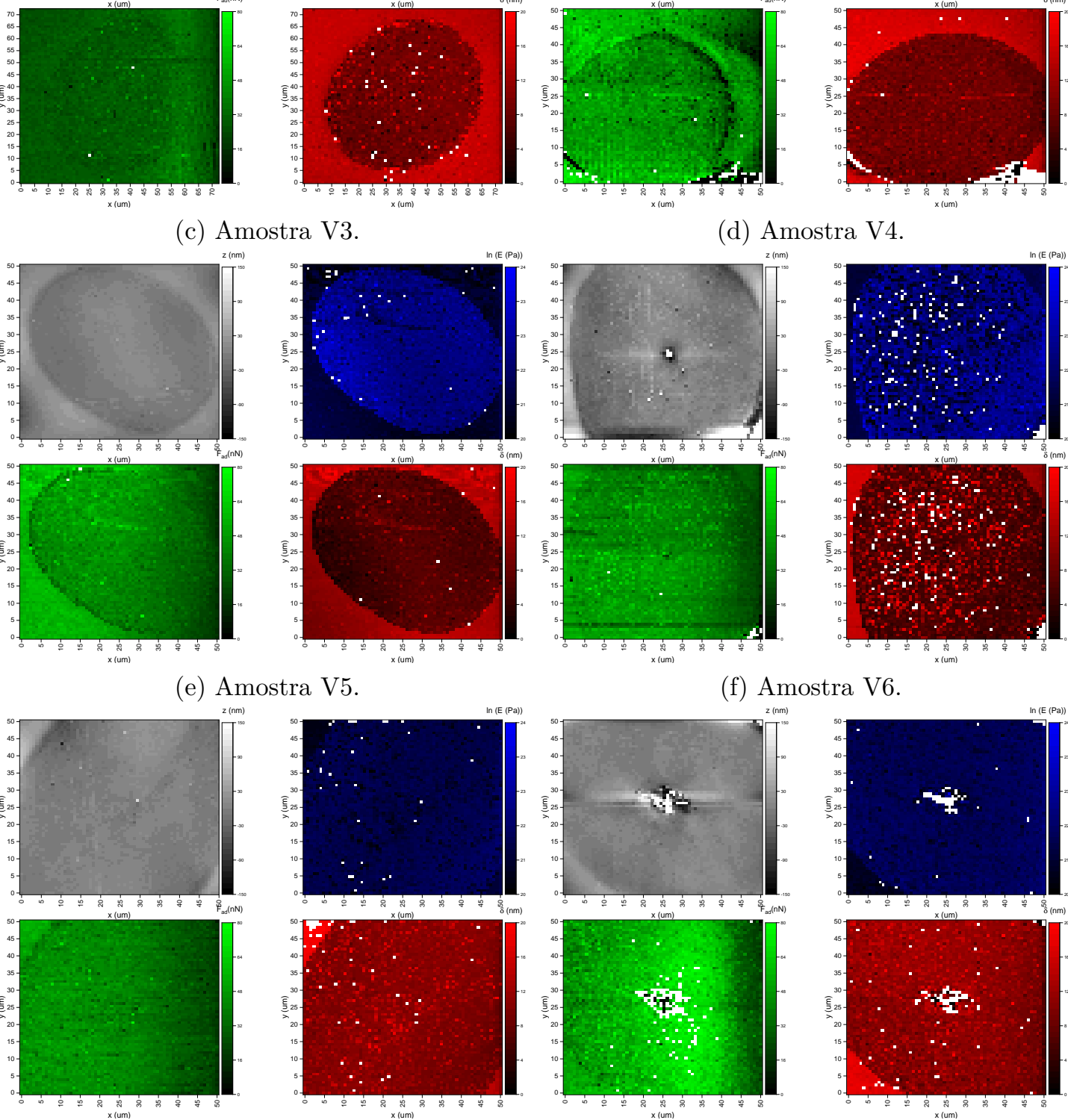

(d) Amostra V4.
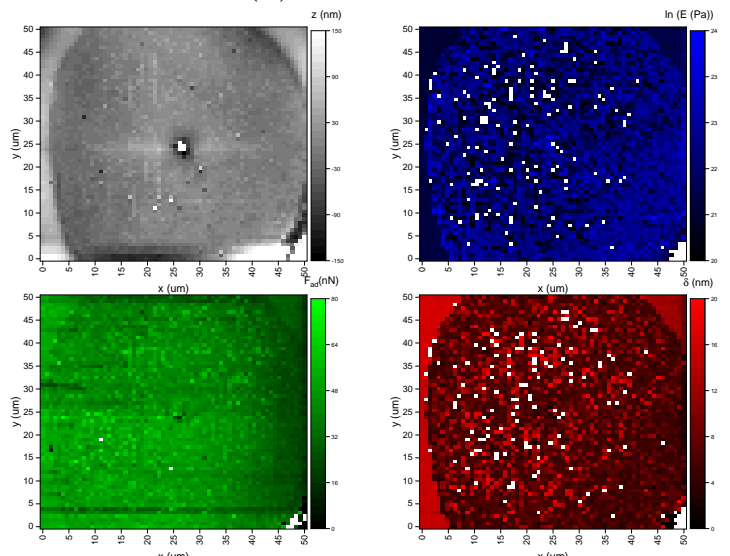

(f) Amostra V6.
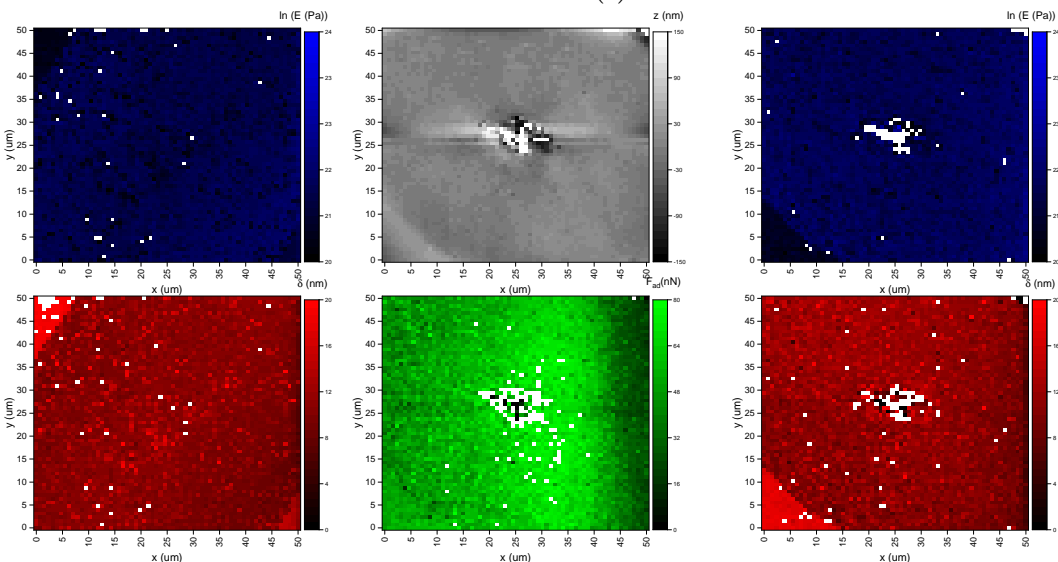

(g) Amostra V7.
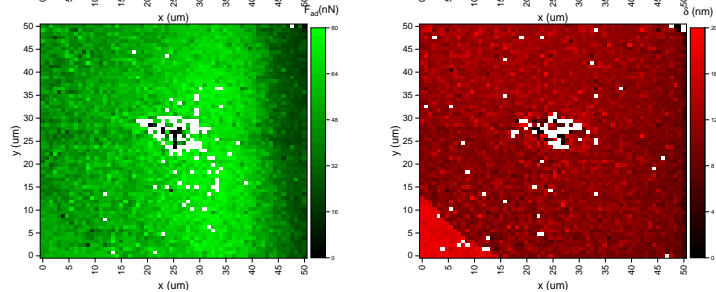

(h) Amostra V8.

Figura 3.2 - Fibras pertencentes ao grupo virgem. 

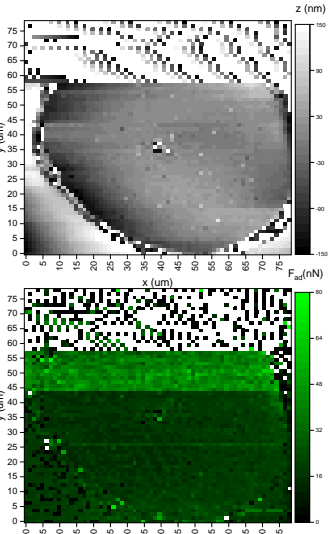

(a) Amostra C1.
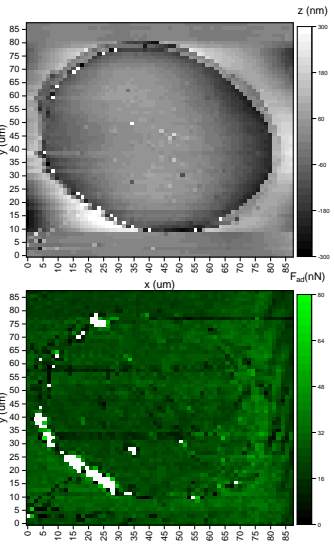

(c) Amostra C3.
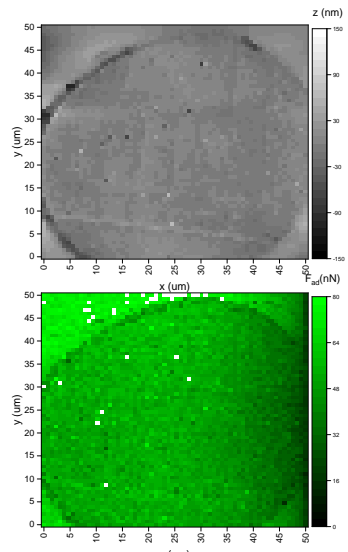

(e) Amostra C5.

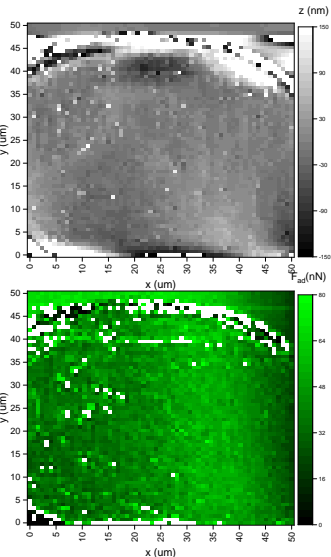

(g) Amostra C7.
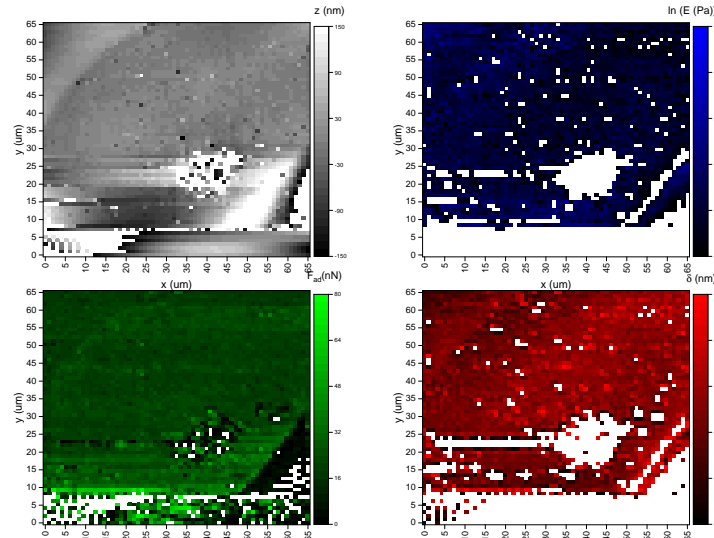

(b) Amostra C2.
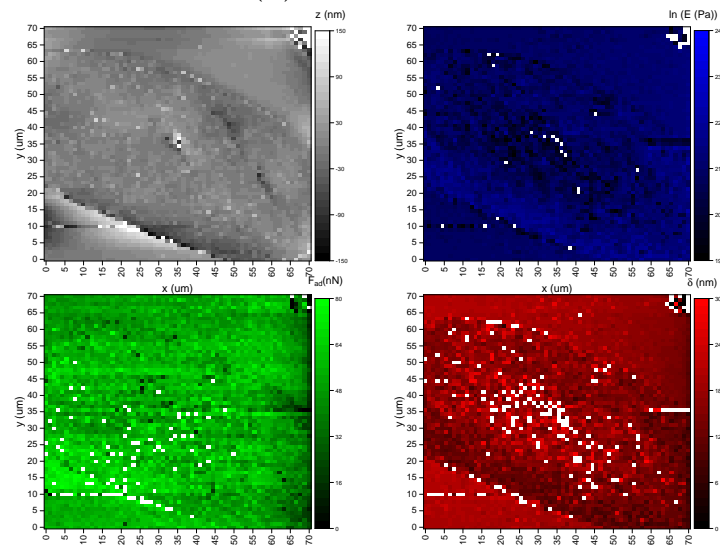

(d) Amostra C4.
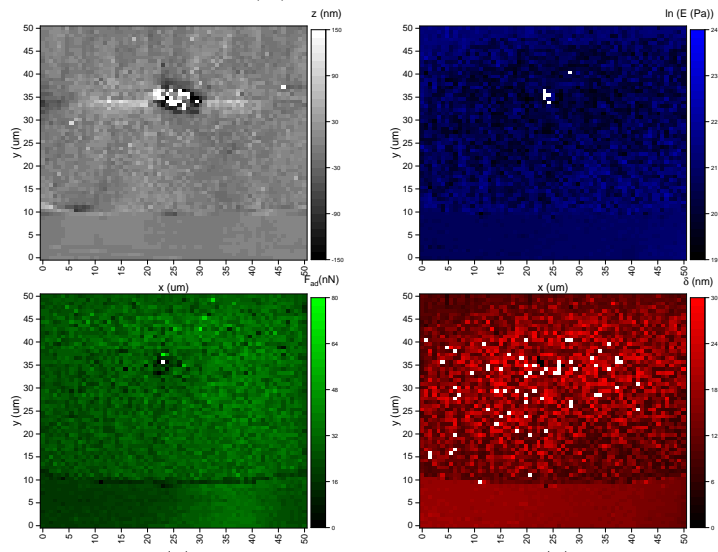

(f) Amostra C6.
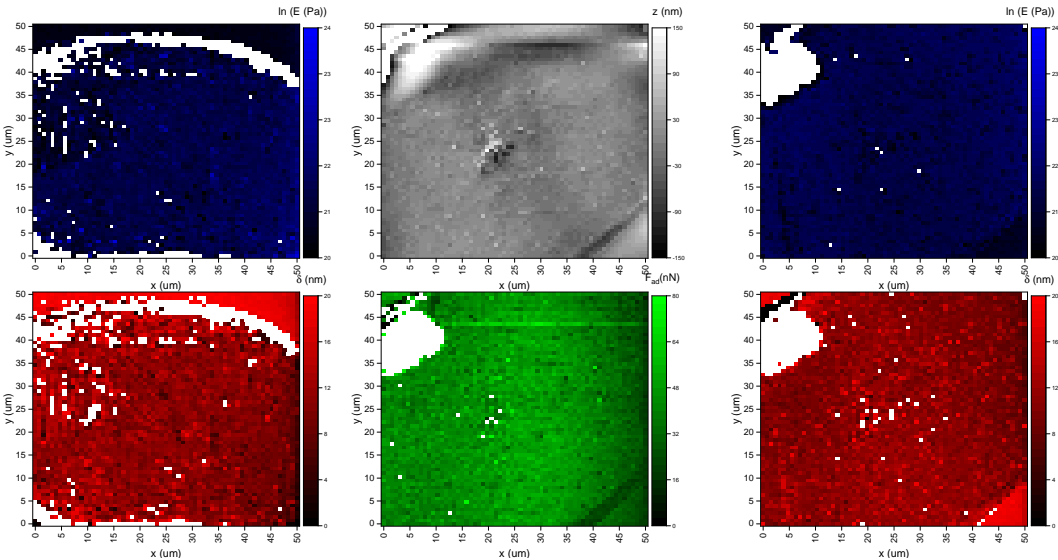

(h) Amostra C8.

Figura 3.3 - Fibras pertencentes ao grupo controle. 

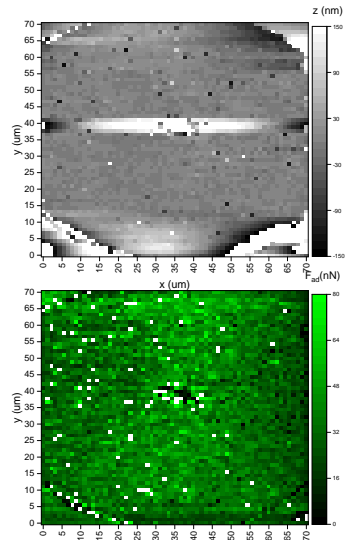

(a) Amostra P1.
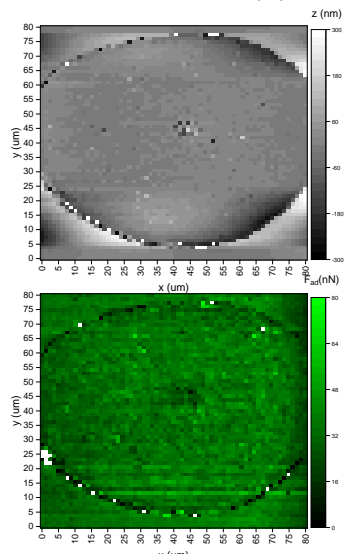

(c) Amostra P3.
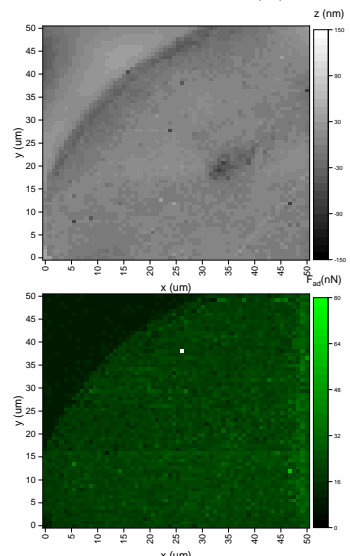

(e) Amostra P5.

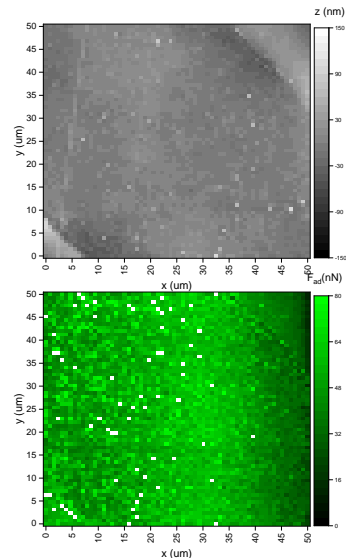

(g) Amostra P7.
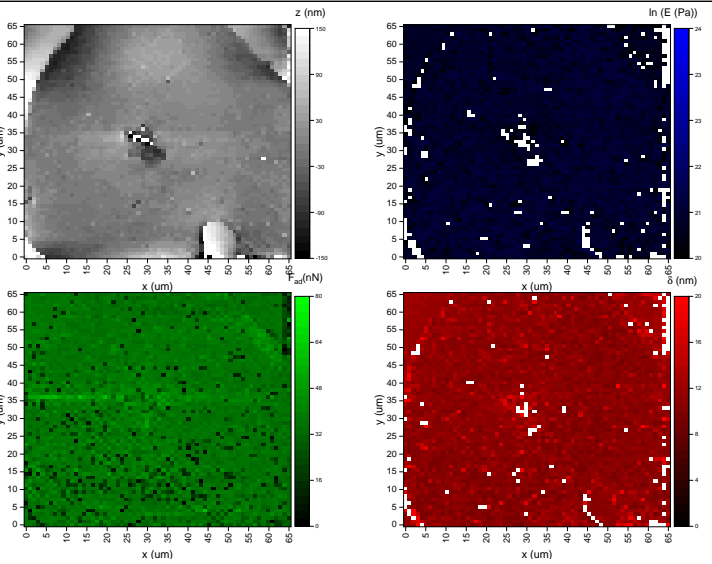

(b) Amostra P2.
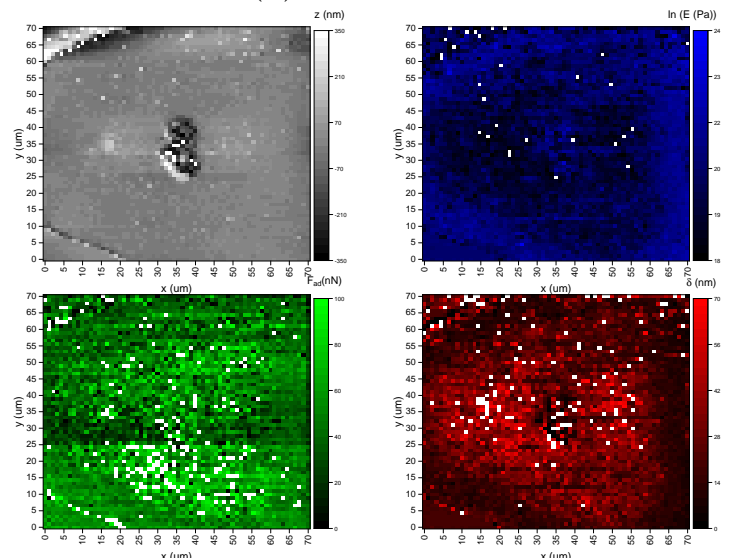

(d) Amostra P4.
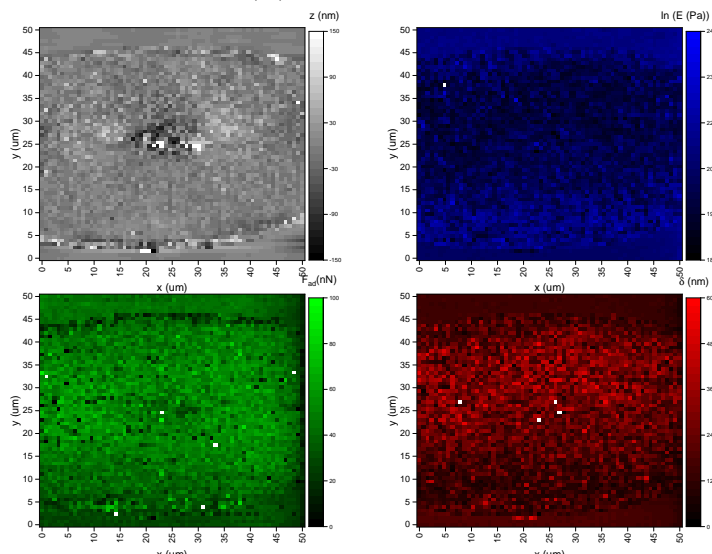

(f) Amostra P6.

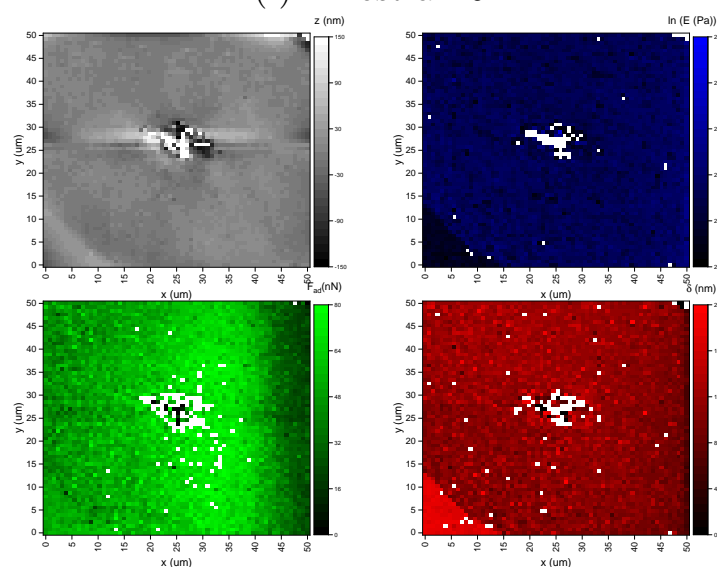

(h) Amostra P8.

Figura 3.4 - Fibras pertencentes ao grupo placebo. 

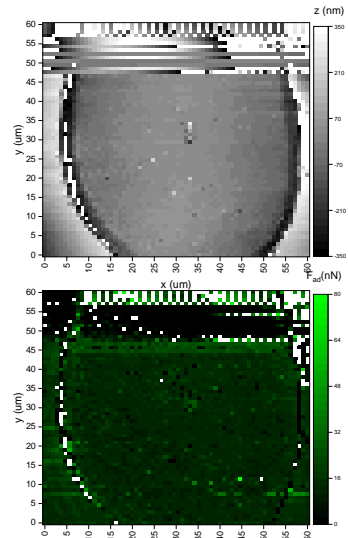

(a) Amostra A1.
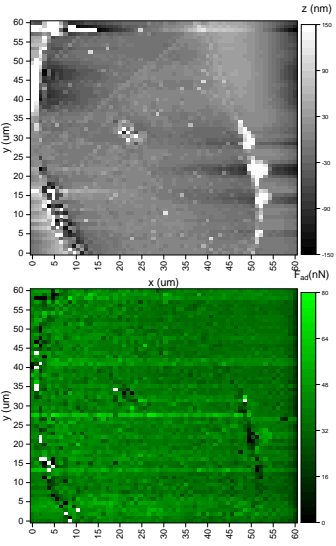

(c) Amostra A3.
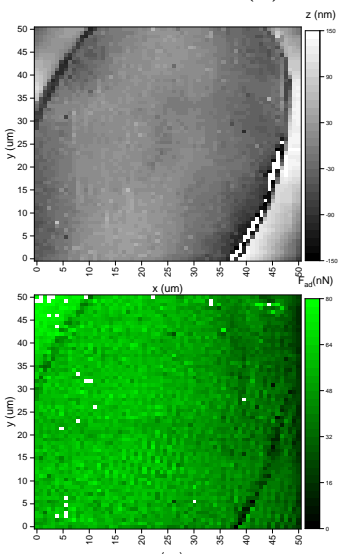

(e) Amostra A5.

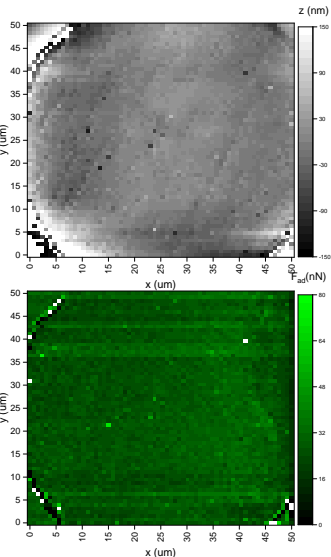

(g) Amostra A7.
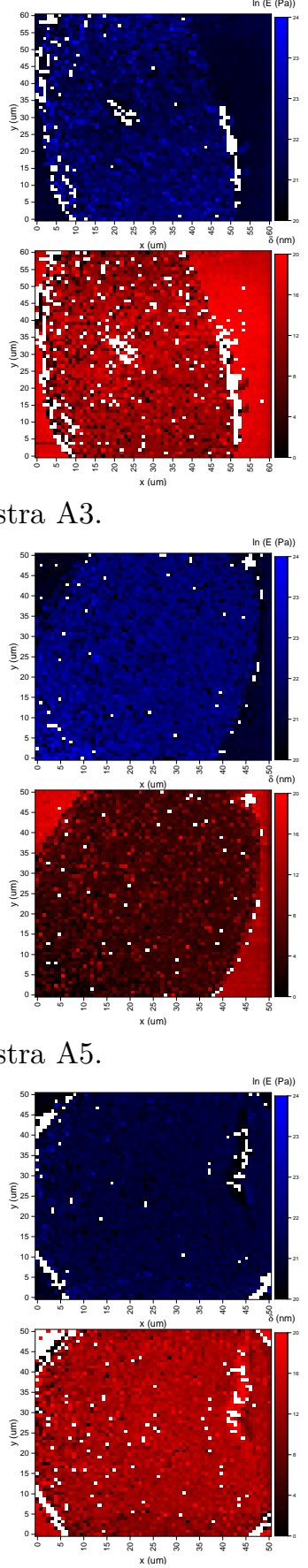

Figura 3.5 - Fibras pertencentes ao grupo ativo.
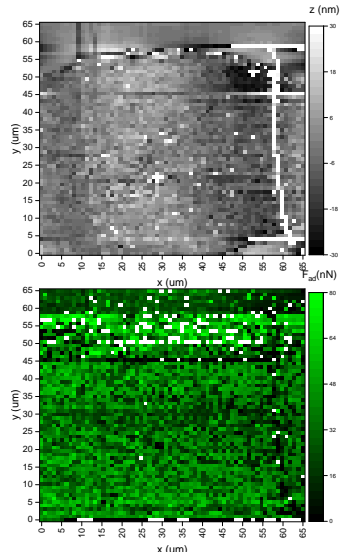

(b) Amostra A2.
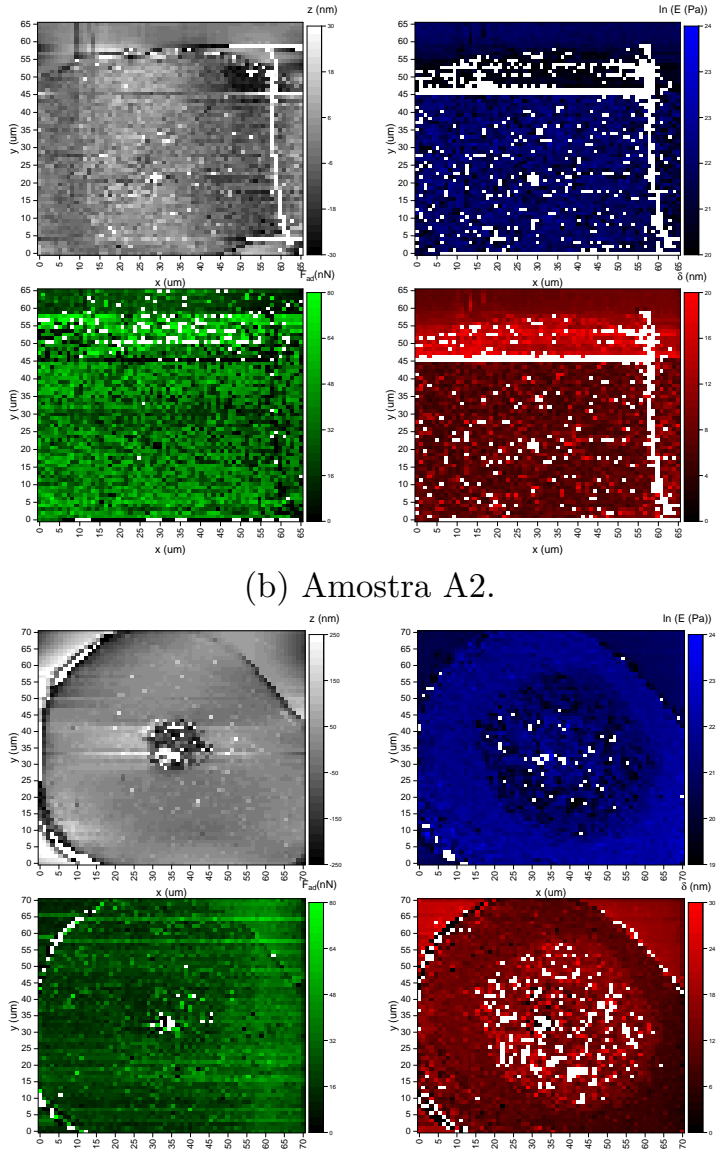

(d) Amostra A4.
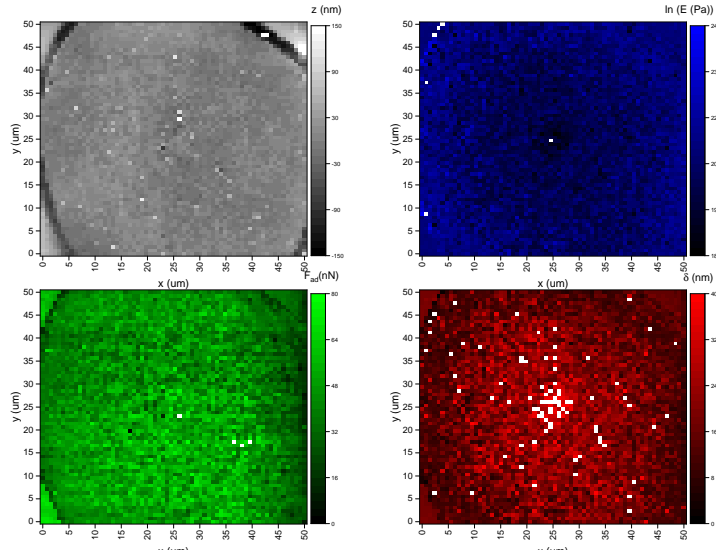

(f) Amostra A6.
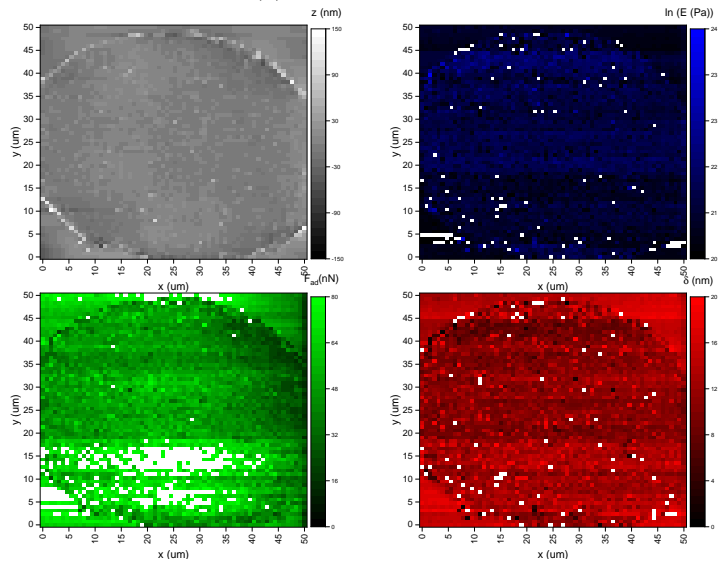

(h) Amostra A8. 
Para os valores do logaritmo natural do módulo de Young $(\ln (E))$, foi explorada a existência de tendência dos dados em relação à distância à borda da fibra, que poderia ser causada pela permeabilidade dos produtos utilizados para tratamento das fibras. Para isso, para cada ponto do mapa pertencente à região da fibra, foi determinada distância de maior proximidade da borda. Na Fig. 3.6 são apresentados exemplos de dados de $\ln (E)$ ) em função da distância à borda da fibra. Vale notar que maiores valores de distância representam pontos mais internos da fibra. Os gráficos do $\ln (E)$ em função da distância à borda, para cada fibra, obtidos para todas as amostras pertencentes aos grupos virgem, controle, placebo e ativo são apresentados, respectivamente, nas Figs. 3.7, 3.8, 3.9 e 3.10.

Na Fig. 3.11 são apresentados os valores do coeficiente de correlação de Pearson $r$ (seção A.3). para os dados do $\ln$ (módulo de Young) em função da respectiva distância à borda da fibra. É importante notar que há diferença na quantidade de dados apresentados nos gráficos. Isso é devido ao fato de ter sido considerado apenas valores provenientes de curvas com estatística $R^{2} \geq 0.95$, como citado anteriormente no início da seção.

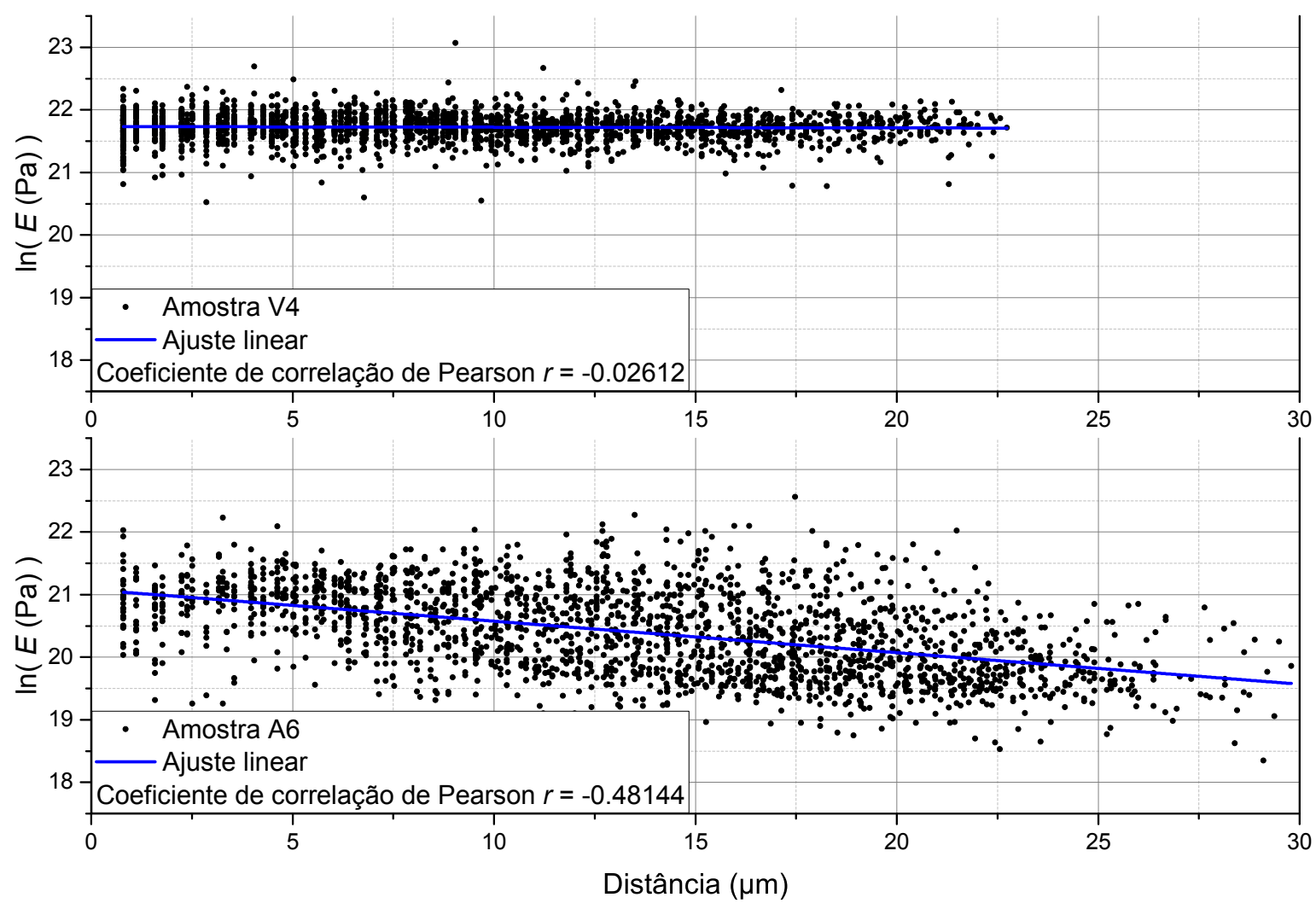

Figura 3.6 - Exemplos de gráficos de $\ln (E)$ em função da distância à borda da fibra, apresentando o coeficiente de correlação de Pearson $r$, com força de relação linear muito fraca (gráfico superior) e força de relação linear moderada (gráfico inferior).

A seguir, são apresentados os gráficos obtidos de todas as amostras pertencentes aos grupos virgem, controle, placebo e ativo, respectivamente, nas Figs. 3.7, 3.8, 3.9 e 3.10 . 

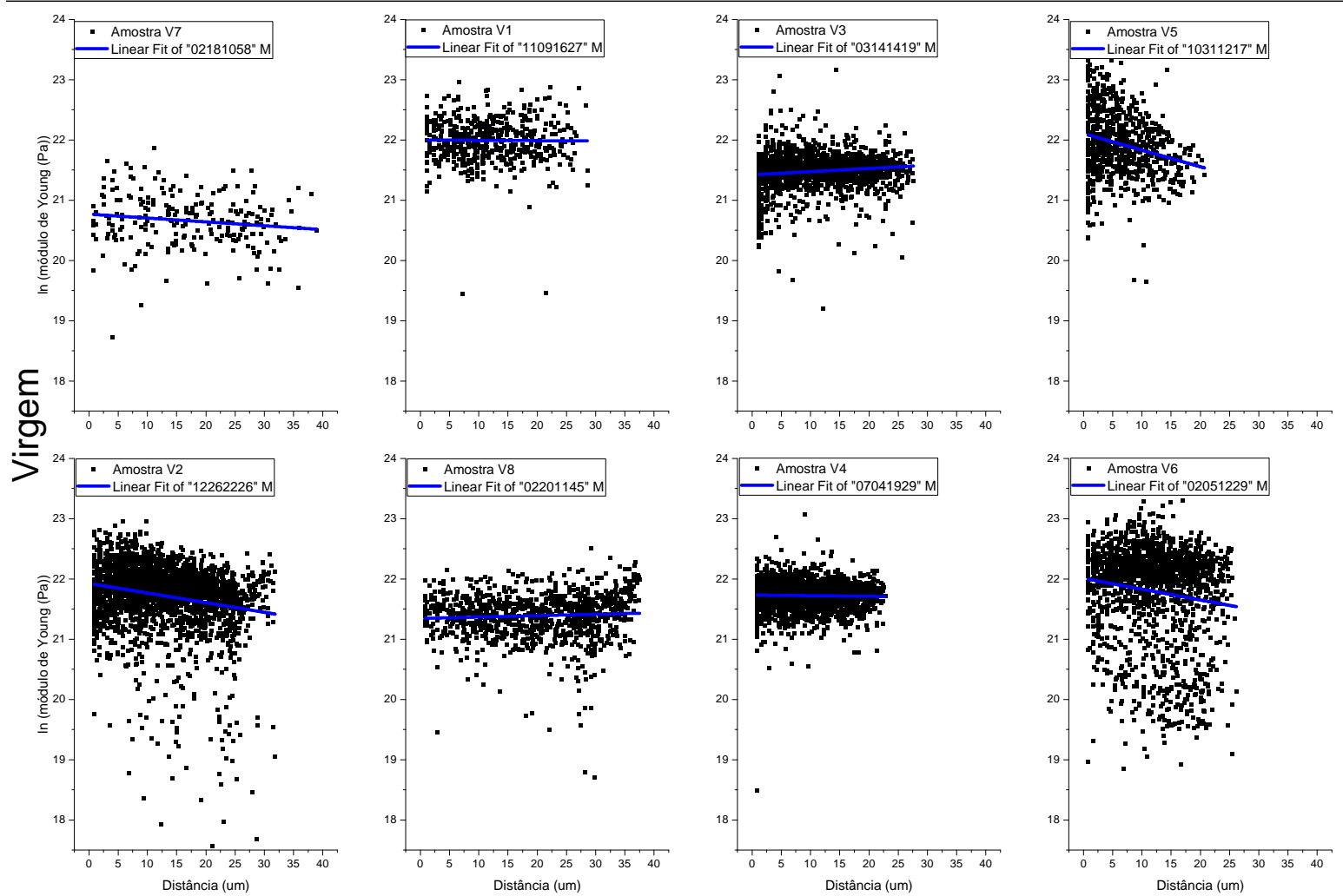

Figura 3.7 - Gráficos dos dados do logaritmo natural do módulo de Young em função da distância à borda da fibra, para os valores correspondentes às fibras pertencentes às mechas do grupo virgem.
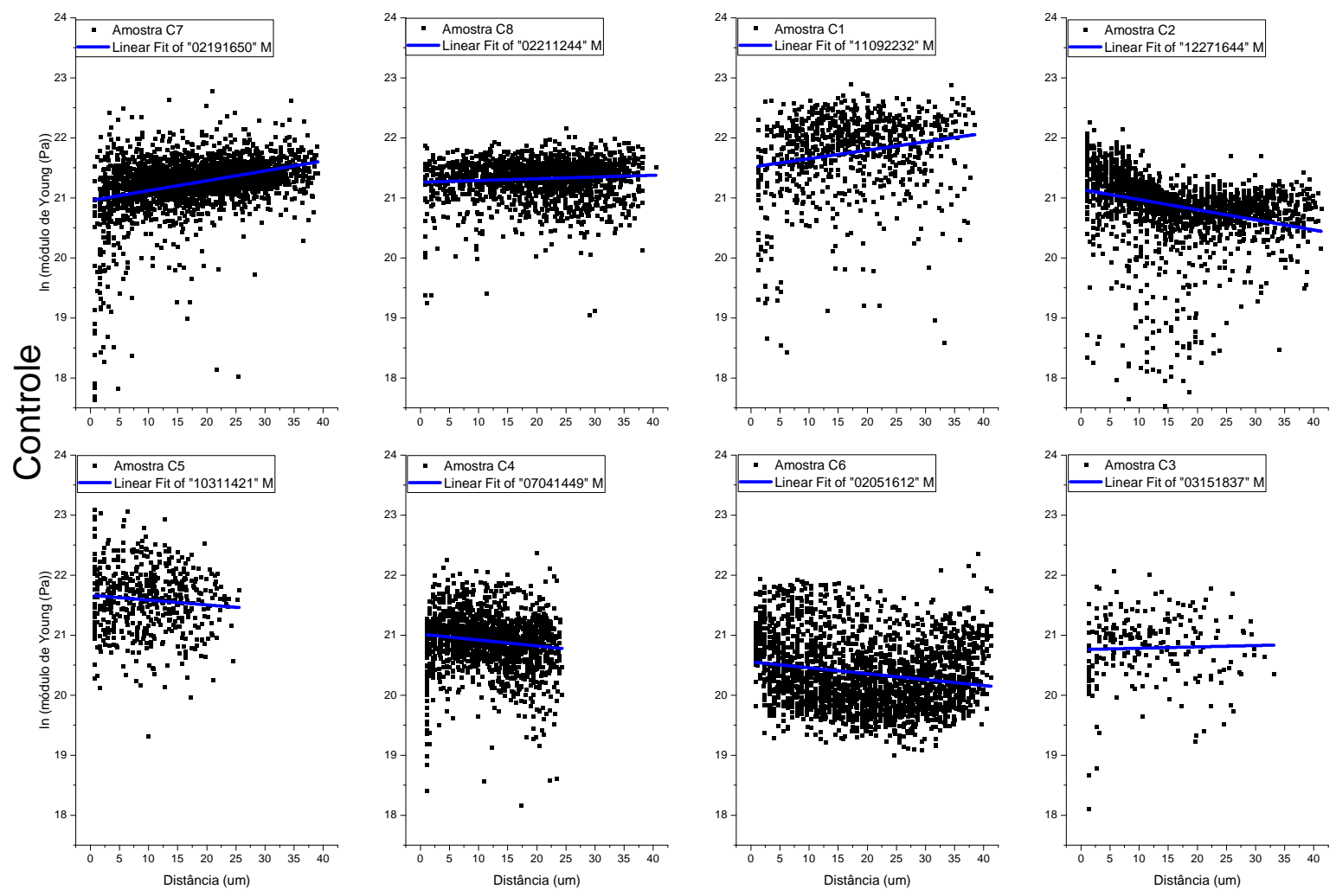

Figura 3.8 - Gráficos dos dados do logaritmo natural do módulo de Young em função da distância à borda da fibra, para os valores correspondentes às fibras pertencentes às mechas do grupo controle. 

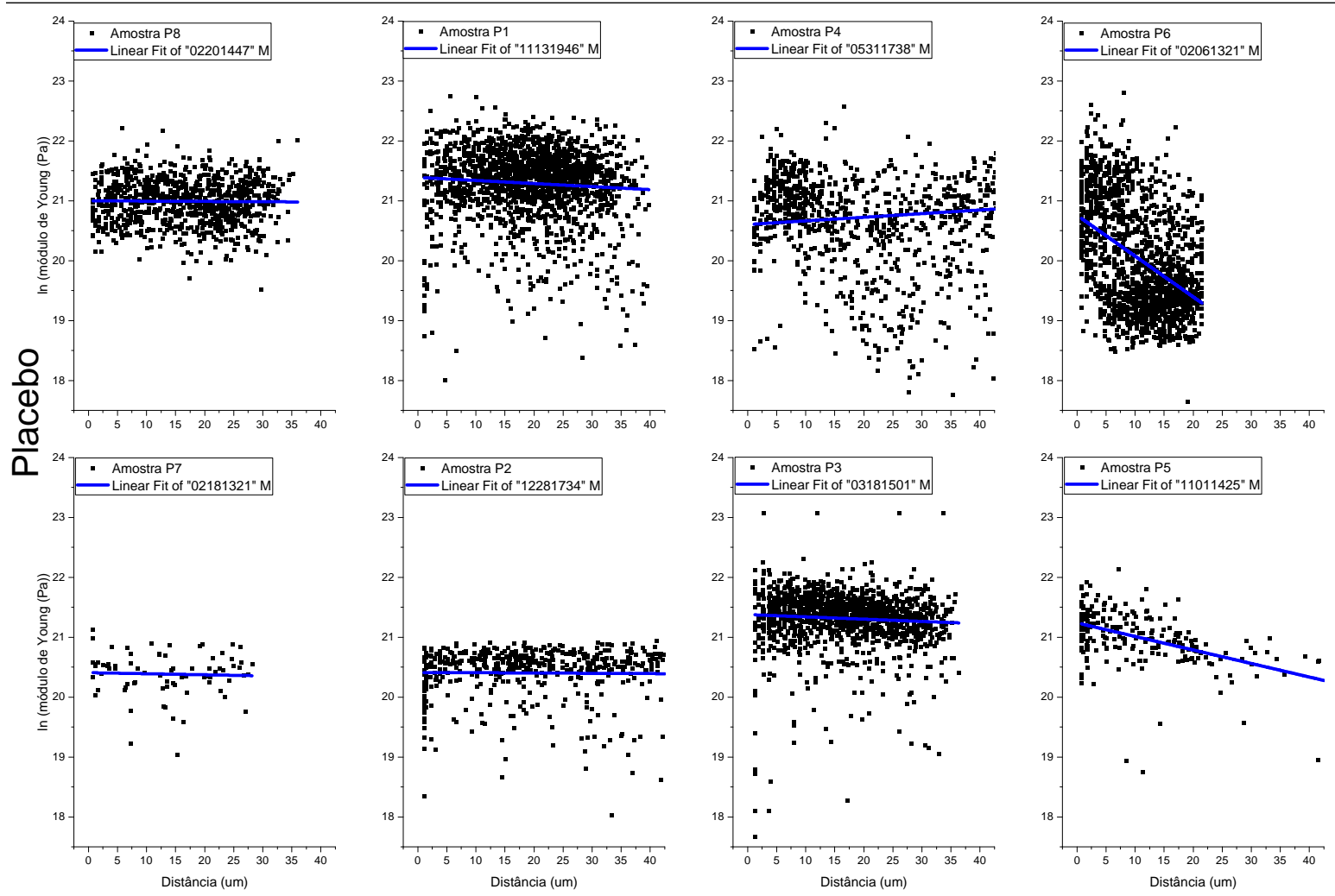

Figura 3.9 - Gráficos dos dados do logaritmo natural do módulo de Young em função da distância à borda da fibra, para os valores correspondentes às fibras pertencentes às mechas do grupo placebo.
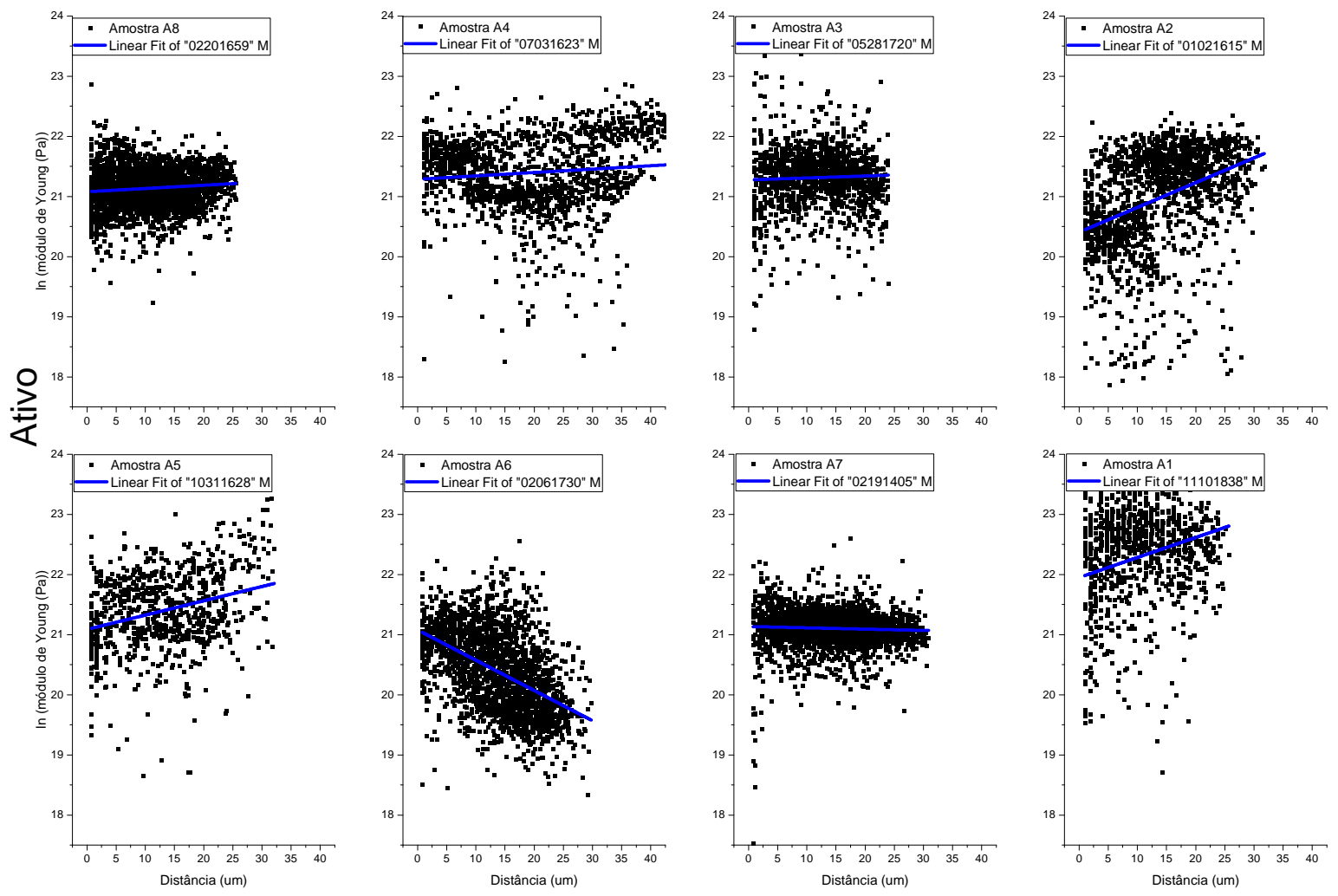

Figura 3.10 - Gráficos dos dados do logaritmo natural do módulo de Young em função da distância à borda da fibra, para os valores correspondentes às fibras pertencentes às mechas do grupo ativo. 


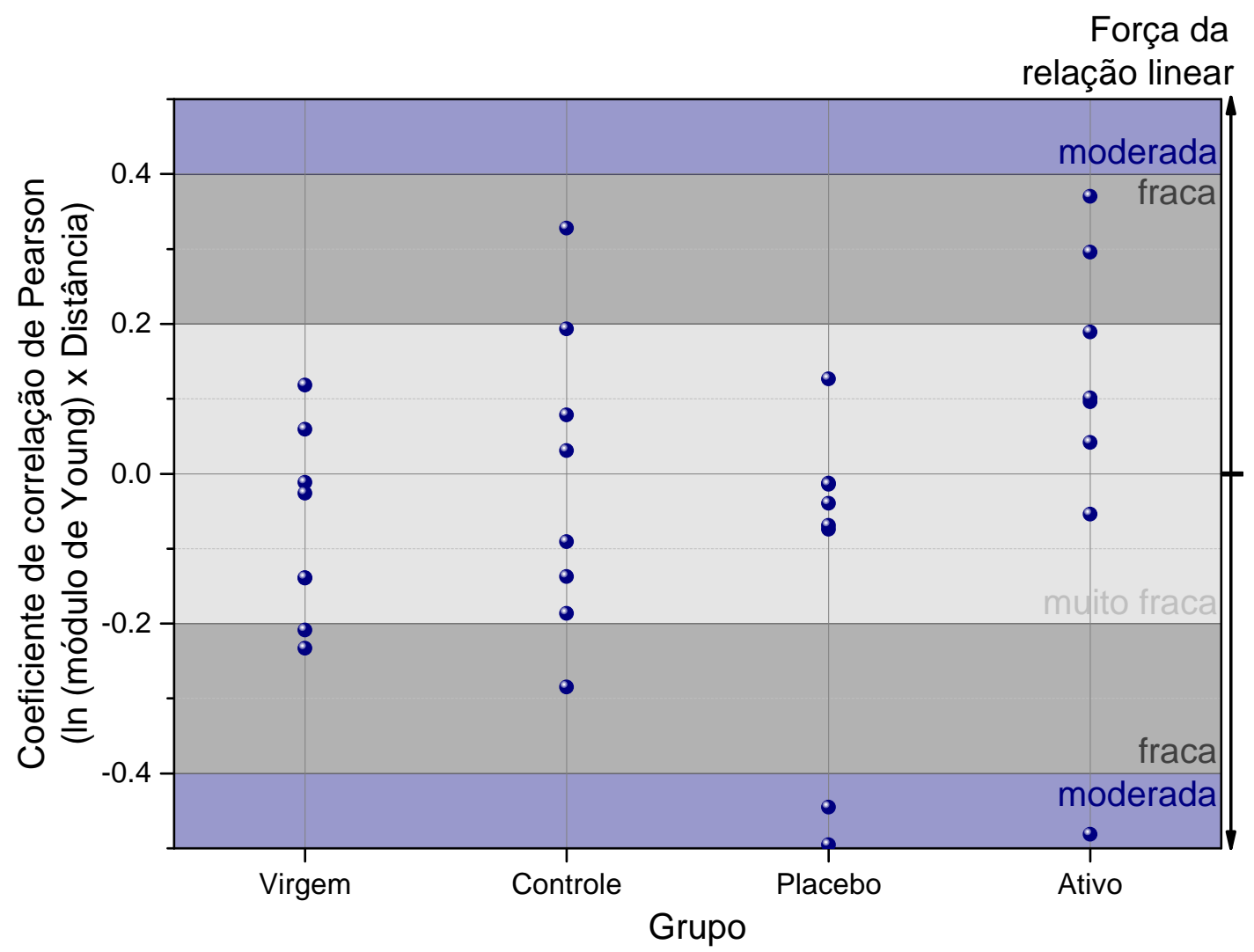

Figura 3.11 - Coeficiente de correlação de Pearson $r$ do logaritmo natural do módulo de Young com a distância à borda da fibra, apresentando nível de força de relação linear.

A partir da informação apresentada na Fig. 3.11, verifica-se que as forças de relação linear do $\ln (E)$ em função da distância à borda dos grupos virgem e controle são fracas ou muito fracas. Para as fibras do grupo virgem é um comportamento esperado, já que não é aplicado qualquer tratamento, não havendo expectativa para diferença de módulo de Young em função da distância à borda. Para o grupo controle, a relação linear para as fibras também são fracas ou muito fracas, o que sugere que o procedimento de descoloração causa efeito similar ao longo de toda a seção transversal da fibra. De 8 fibras tratadas com placebo, 6 apresentaram relação linear fraca ou muito fraca e 2 fibras (Amostras P5 e P6) apresentaram relação linear moderada negativa. Para as fibras tratadas com ativo cosmético, 7 fibras apresentaram relação linear fraca ou muito fraca e 1 fibra (Amostra A6) apresentou relação linear moderada negativa. Para as fibras que apresentaram relação linear negativa moderada, indica diferença linear de $\ln$ (módulo de Young) em função da distância à borda, apresentando valores maiores para pontos mais próximos à borda. Isto sugere que pode ter havido diferença ao longo da seção transversal devido a permeabilidade dos produtos utilizados para tratamento nestas fibras.

Para a fibra pertencente ao grupo ativo, amostra A4, pode-se observar no mapa do $\ln (E)$ uma variação radial deste parâmetro [Fig. 3.12a]. Neste mapa, foram feitos 2 exemplos de perfis [Fig. 3.12b] para visualização desta variação de $\ln (E)$ ao longo da seção 
transversal da fibra. A importância desse indício é evidenciar fortemente a permeabilidade radial do produto ao longo da seção transversal da fibra. Camargo et al., 2016 [5] apresenta um estudo de permeabilidade do ativo em questão, a partir de análise por Confocal Raman Spectroscopy [Fig. 3.13], trabalho no qual é reportado um decréscimo da presença do ativo na região a partir de $\approx 16 \mu \mathrm{m}$ de distância à borda, o qual corrobora com o resultado aqui encontrado de permeabilidade do produto, considerando que regiões de maior módulo de Young são devido a maior presença do ativo cosmético.

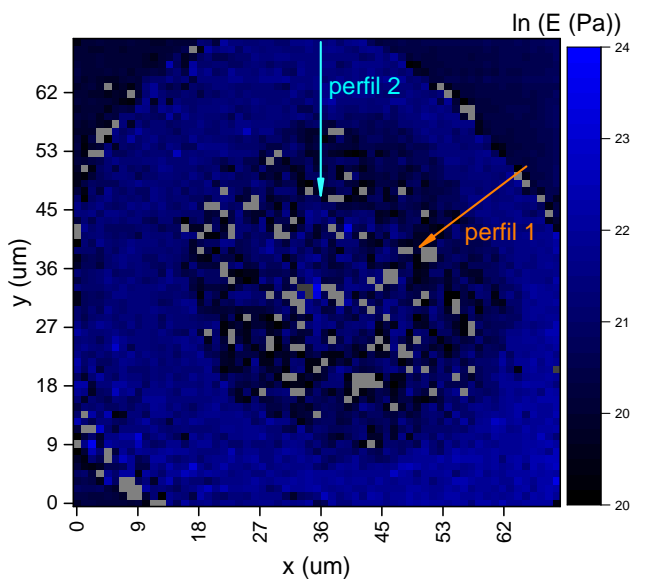

(a)

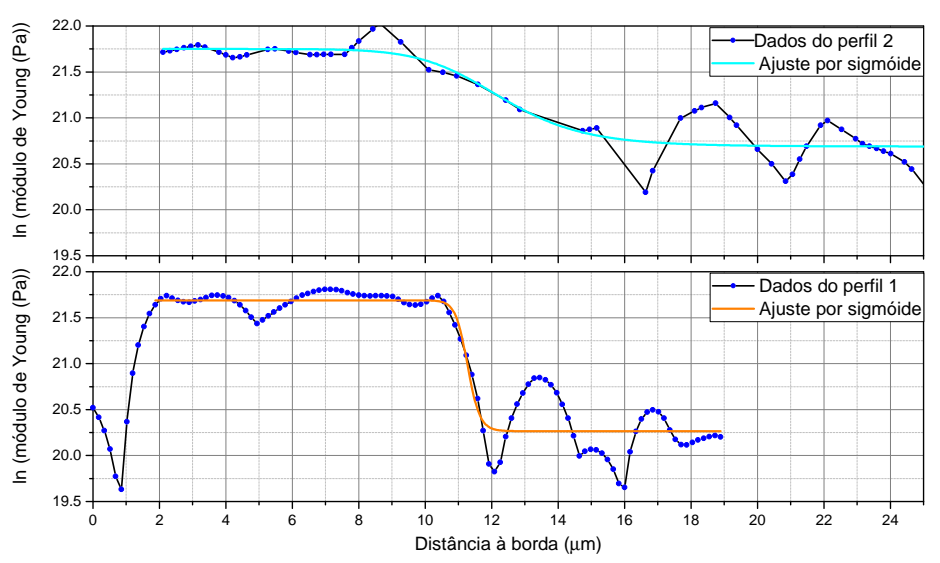

(b)

Figura 3.12 - Perfis traçados ao longo da seção transversal da fibra A4, pertencente ao grupo ativo, no mapa do $\ln (E)$ [Fig. 3.12a], mostrando relação do $\ln (E)$ em função da distância à borda, ajustados por função sigmóide [Fig. 3.12b].

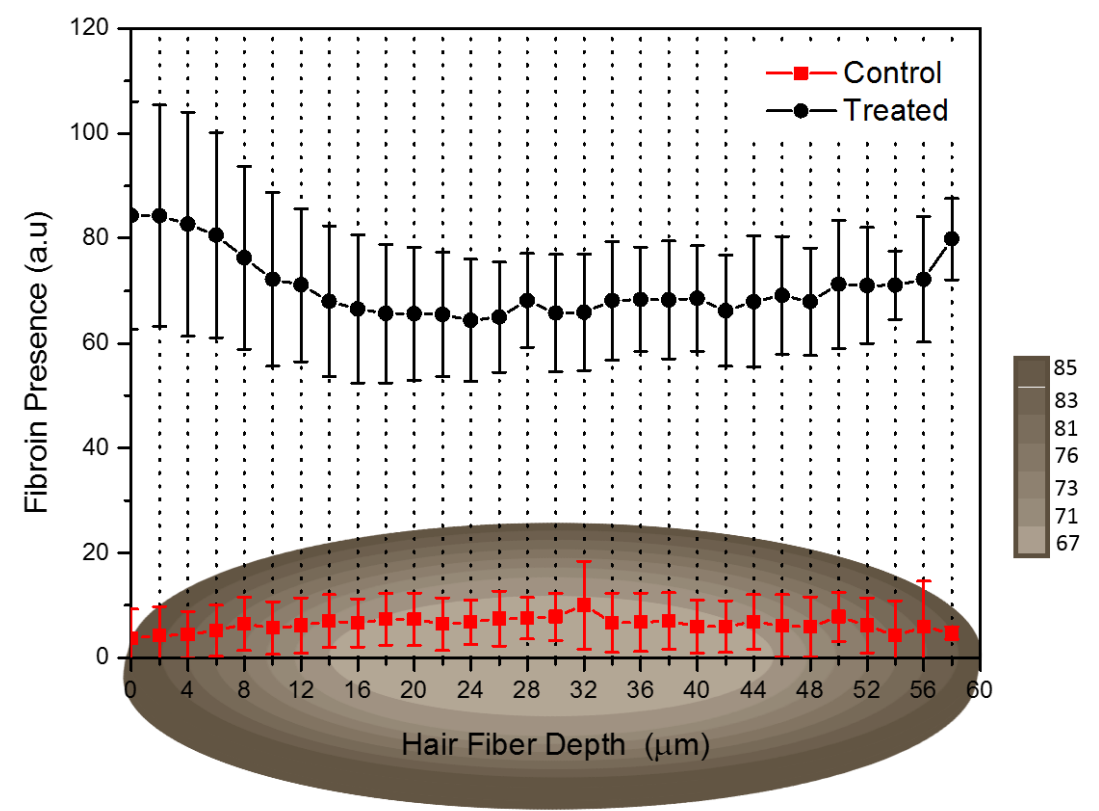

Figura 3.13 - Média das medidas do perfil de permeação em unidades arbitrárias (a.u) das fibras capilares tratadas (preto - grupo ativo) ou não (vermelho - grupo controle) com ativo cosmético composto de fibroína, em diferentes profundidades. A intensidade da distribuição espacial da fibroína é representada como cores escuras para o grupo tratado [5]. Reprodução da imagem autorizada pelos autores. 
Diferentes subestruturas presentes no córtex possuem distintos conteúdos de cistina, o que poderia resultar em propriedades mecânicas diferenciadas, como já citado anteriormente. Sabe-se que a estrutura CMC (Cell Membrane Complex) tem baixo conteúdo de cistina, o que resulta em uma menor rigidez, ou seja, um menor módulo de Young para esta subestrutura. Lembrando que para cada ponto do mapa, está associada uma curva de força, da qual pode-se extrair diversos parâmetros, como a força de adesão entre ponta e amostra e cálculo do módulo de Young, outra correlação do sistema também foi avaliada. Dessa forma, o coeficiente de correlação de Pearson $r$ foi avaliado para os dados do $\ln (E)$ em função do respectivo valor da força de adesão $F_{a d}$, para os dados na região da fibra (excluindo os dados da região da resina). Na Fig. 3.14 apresenta-se um exemplo de gráfico $\ln (E)$ em função da respectiva força de adesão $F_{a d}$. Os gráficos do $\ln (E)$ em função da $F_{a d}$, para cada fibra, obtidos para todas as amostras pertencentes aos grupos virgem, controle, placebo e ativo são apresentados, respectivamente, nas Figs. 3.15, 3.16, 3.17 e 3.18.

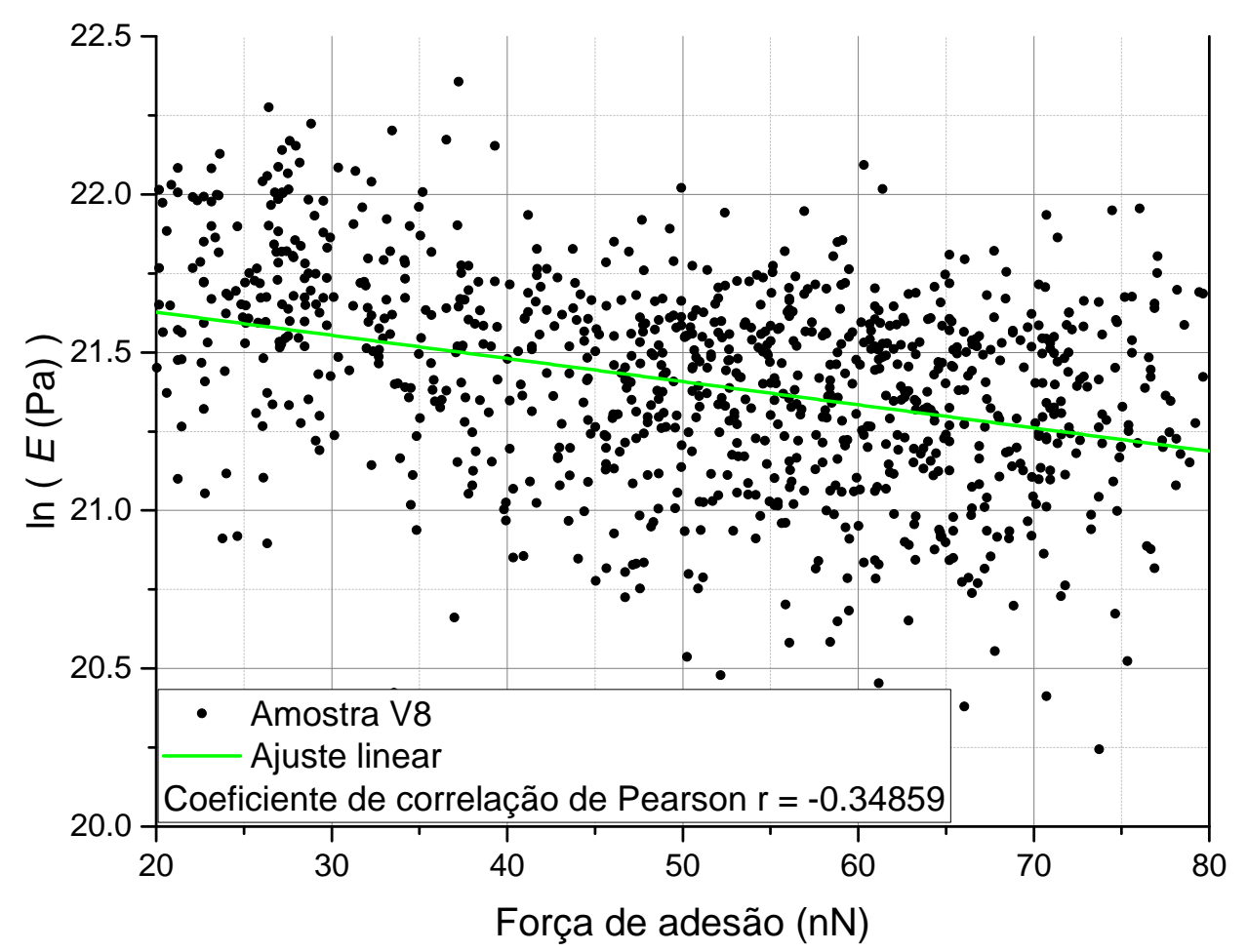

Figura 3.14 - Exemplo de gráfico de $\ln (E)$ em função da força de adesão entre ponta e amostra $F_{a d}$, apresentando o coeficiente de correlação de Pearson $r$.

A seguir, são apresentados os gráficos obtidos de todas as amostras pertencentes aos grupos virgem, controle, placebo e ativo, respectivamente, nas Figs. 3.15, 3.16, 3.17 e 3.18. Na Fig. 3.19 são apresentados os valores resultantes do coeficiente de correlação de Pearson $r$ do $\ln (E)$ com a força de adesão entre ponta e amostra. 

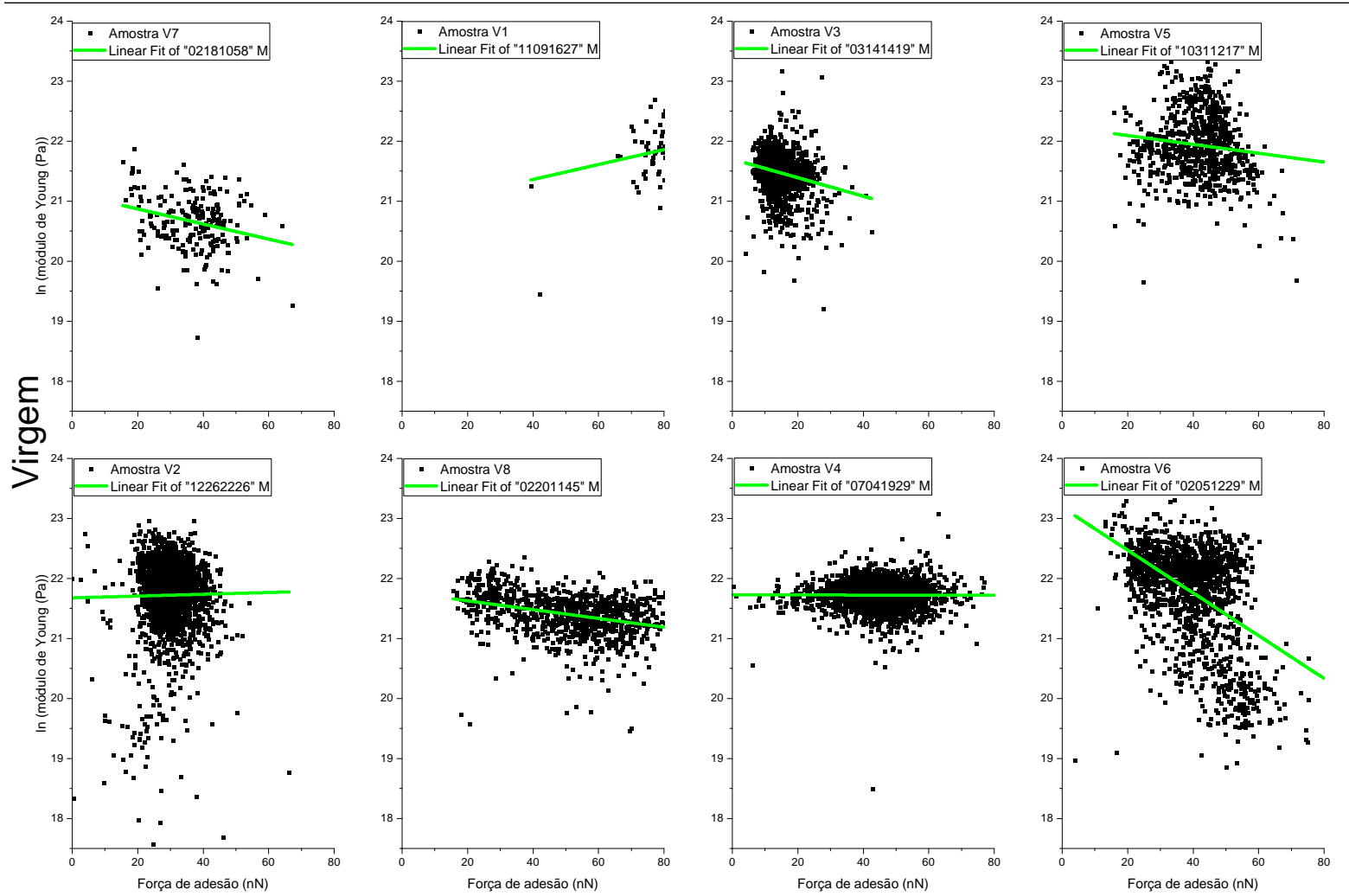

Figura 3.15 - Gráficos dos dados do logaritmo natural do módulo de Young em função da distância à borda da fibra, para os valores correspondentes às fibras pertencentes às mechas do grupo virgem.
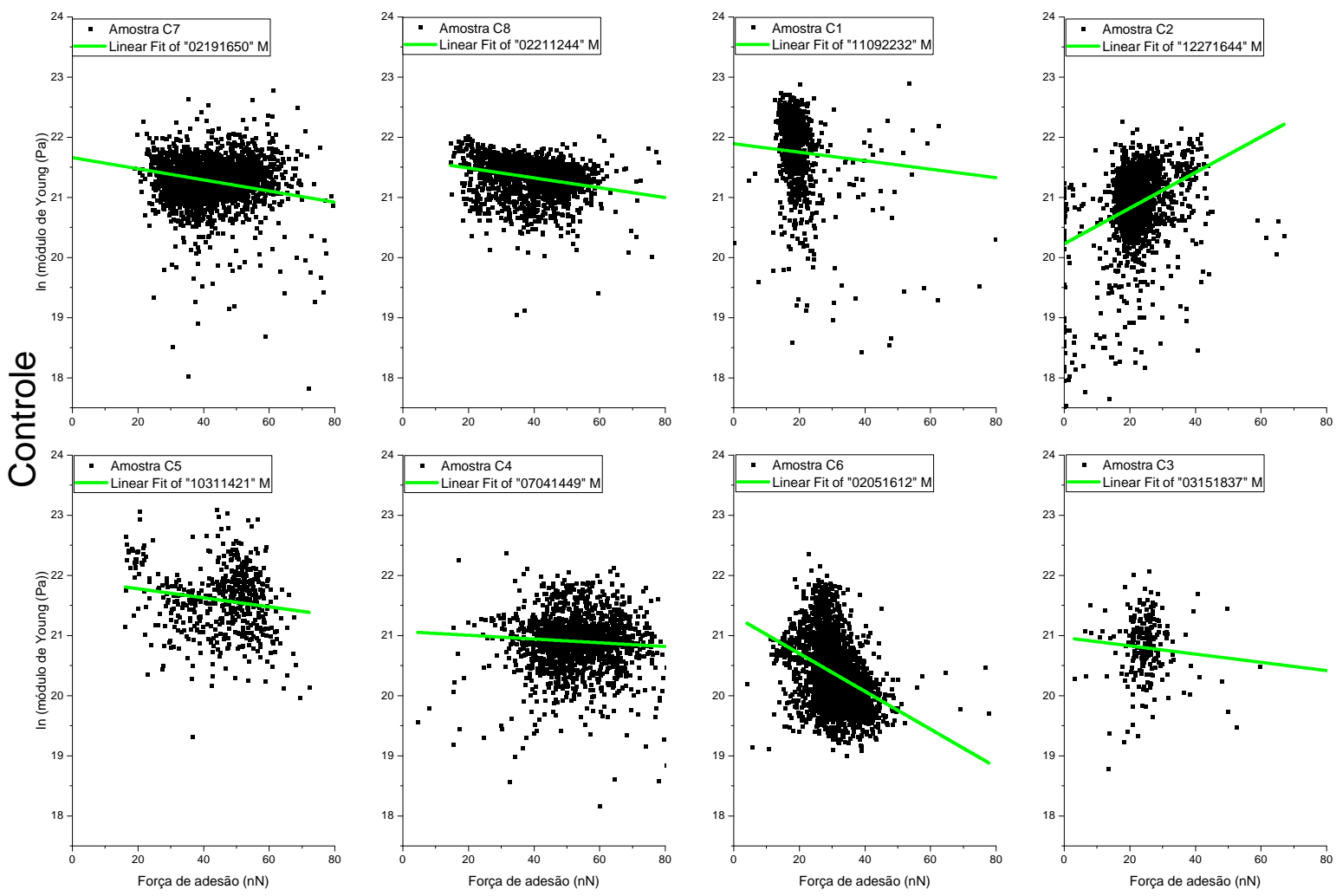

Figura 3.16 - Gráficos dos dados do logaritmo natural do módulo de Young em função da distância à borda da fibra, para os valores correspondentes às fibras pertencentes às mechas do grupo controle. 

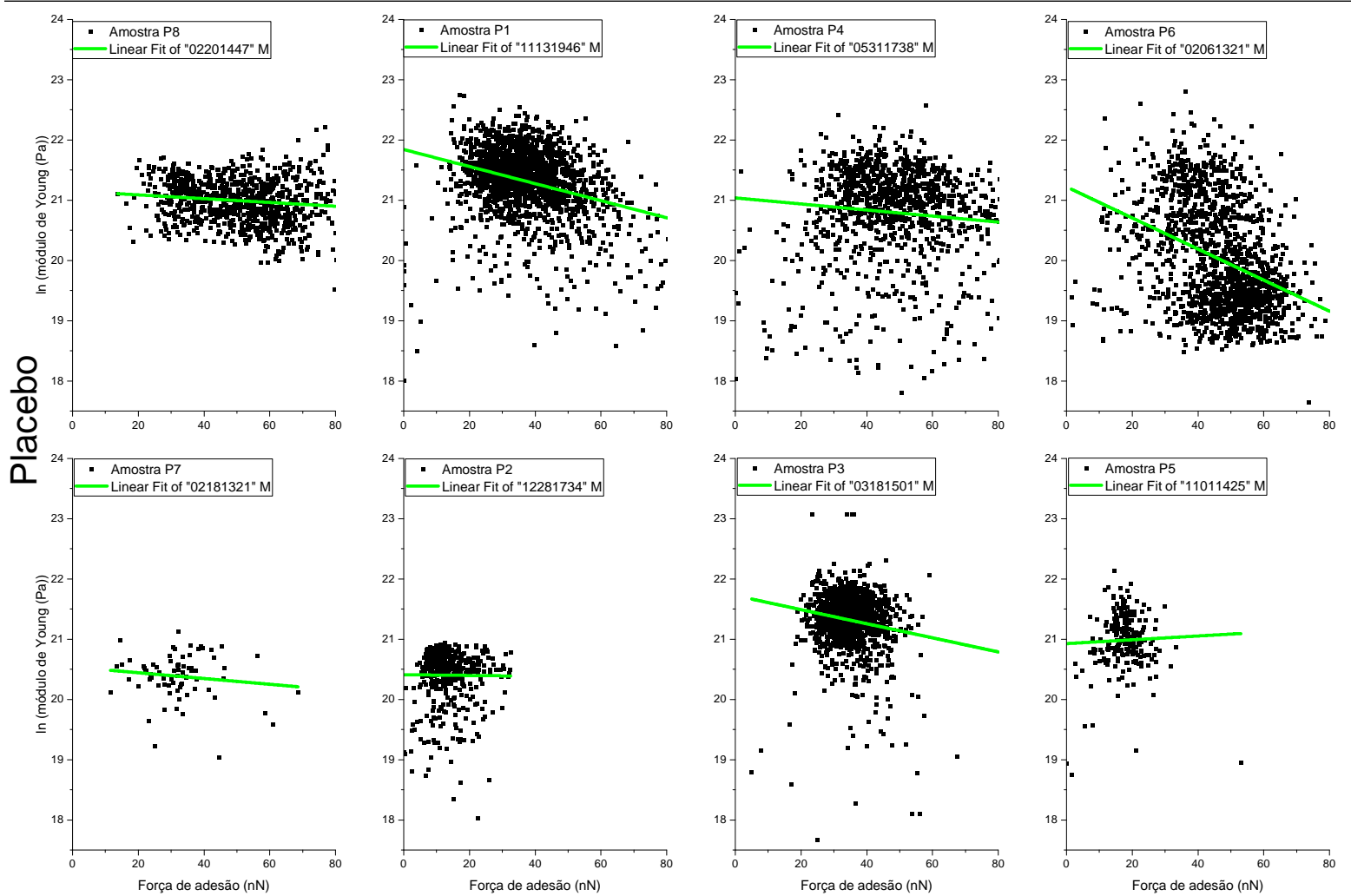

Figura 3.17 - Gráficos dos dados do logaritmo natural do módulo de Young em função da distância à borda da fibra, para os valores correspondentes às fibras pertencentes às mechas do grupo placebo.
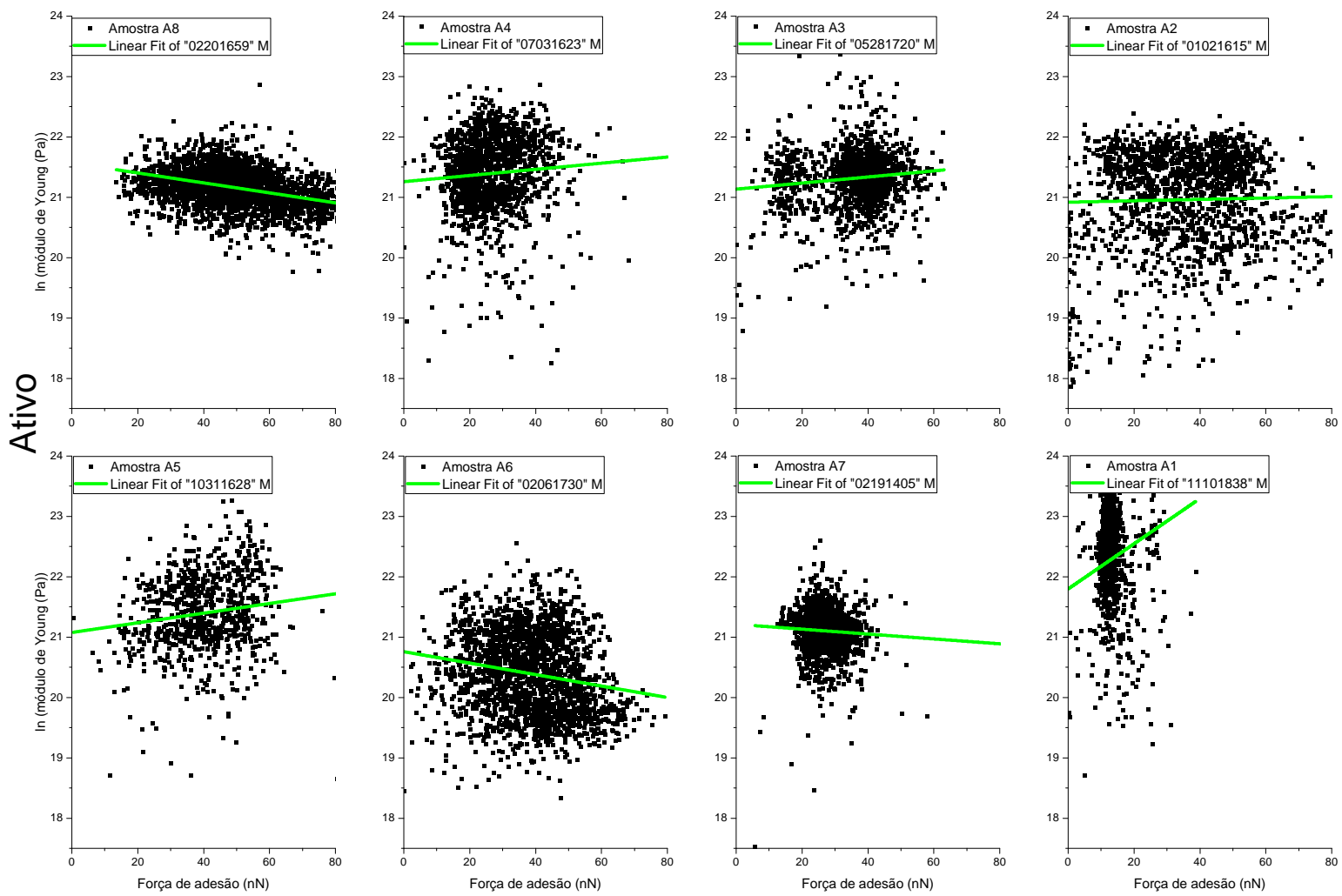

Figura 3.18 - Gráficos dos dados do logaritmo natural do módulo de Young em função da distância à borda da fibra, para os valores correspondentes às fibras pertencentes às mechas do grupo ativo. 


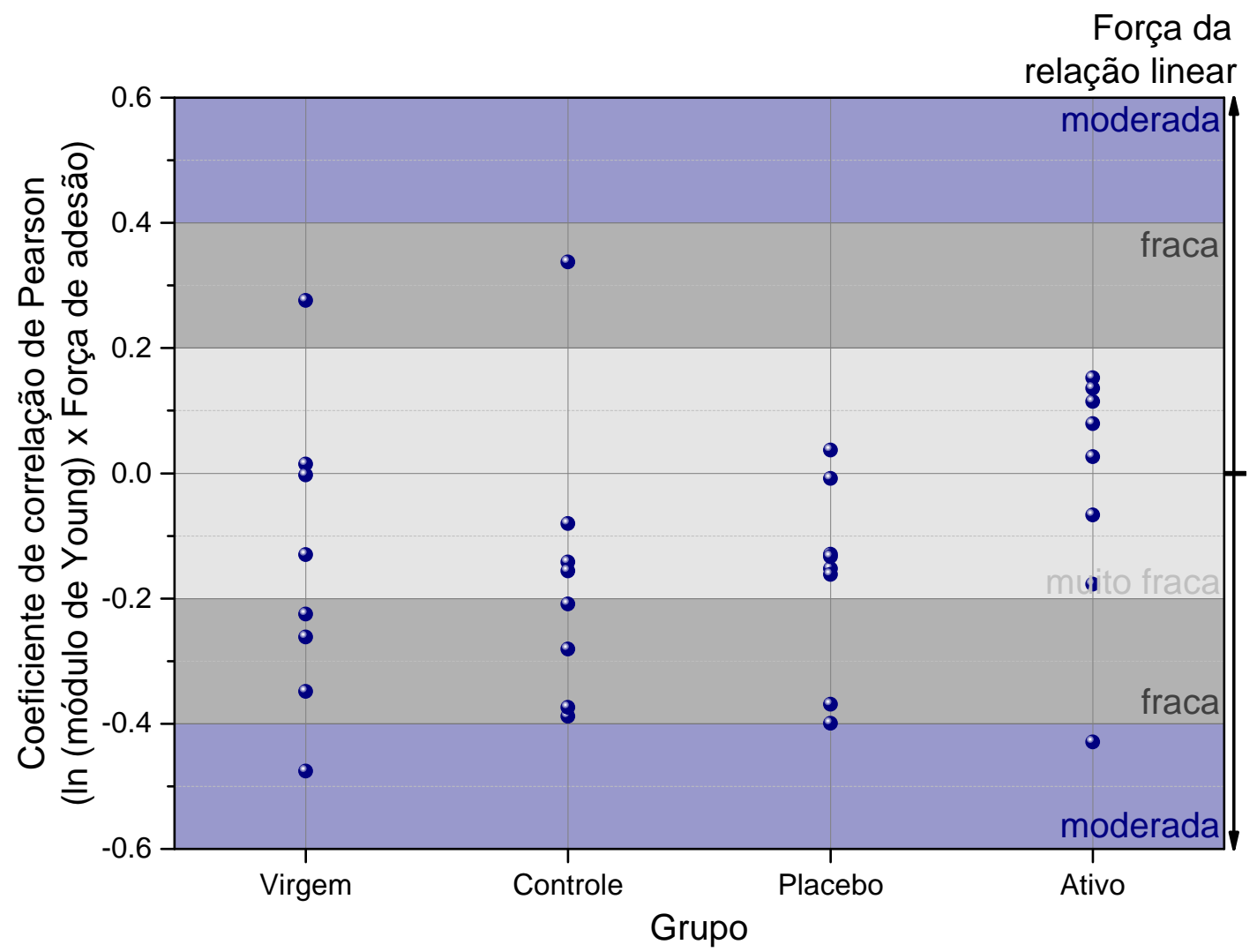

Figura 3.19 - Coeficiente de correlação de Pearson $r$ do $\ln$ (módulo de Young) com a força de adesão.

A partir da Fig. 3.19, verifica-se que os coeficientes de correlação linear são prevalentemente negativos $(\approx 72 \%)$, indicando valores maiores de módulo de Young para valores menores de força de adesão, sendo o inverso verdadeiro. A correlação pode evidenciar as propriedades mecânicas diferenciadas da subestrutura CMC, já que um de seus constituintes é material adesivo e possui baixo conteúdo de cistina, podendo explicar a prevalência de força de correlação negativa entre o $\ln (E)$ e a força de adesão entre ponta e amostra.

A prevalência de coeficientes de correlação linear negativos também pode ser explicada devido a diferença de módulo de Young entre estruturas hidrofóbicas e hidrofílicas. Quando a força de capilaridade domina as interações, superfícies mais hidrofílicas em ambientes úmidos favorecem condensação capilar e formação de filme líquido, podendo resultar em um aumento significativo da força de adesão entre superfícies [64,65]. E, assim como relatado por Kitano et al., 2009 [35], constatou-se que, em geral, as estruturas de componentes hidrofílicos possuem menor módulo de Young em comparação com estruturas de componentes hidrofóbicos de fibra capilar humana. 


\subsubsection{Dados referentes à resina}

Como os dados dependem de um procedimento sensível de calibração, conforme descrito na subseção 2.1.2, os dados da região da resina podem auxiliar na verificação da acurácia dos dados coletados, também servindo como um padrão. Sendo assim, foram realizadas análises para valores pertencentes a região da resina, agrupando-os conforme diferentes aspectos de interesse.

Na Fig. 3.20 apresentam-se as médias do módulo de Young para cada amostra na região da resina, em função do cantilever utilizado e em função do tempo após cura da resina, no qual foram coletados os respectivos dados.

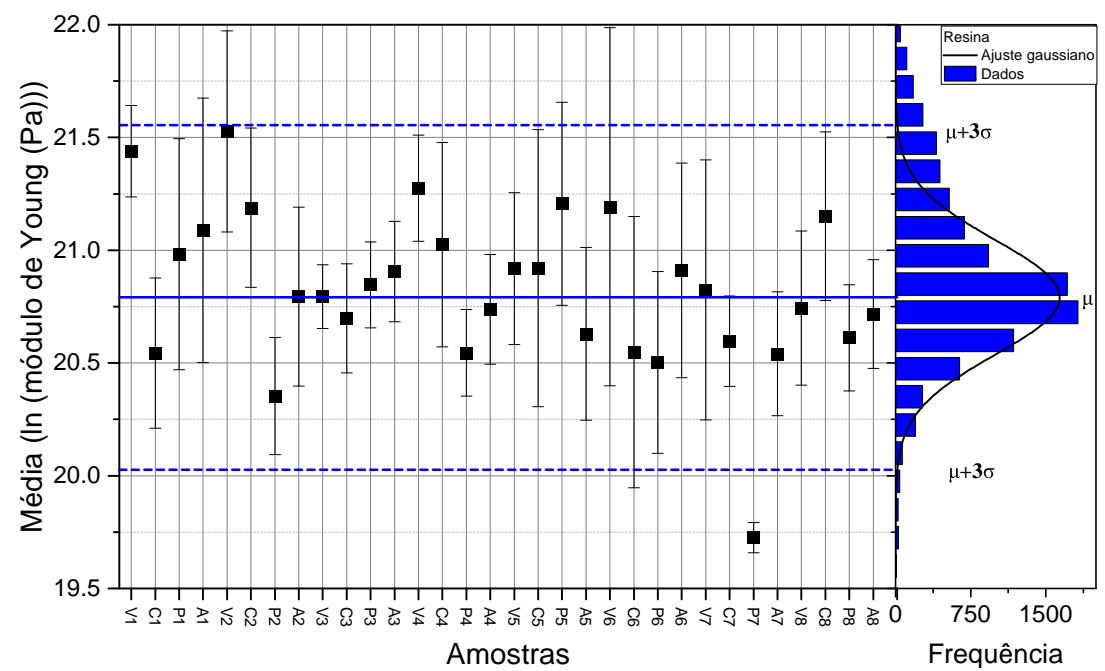

(a)

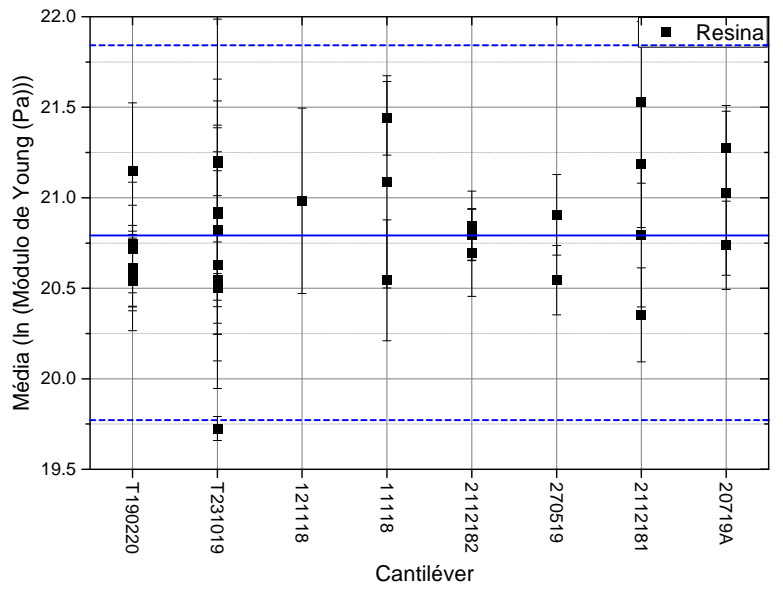

(b)

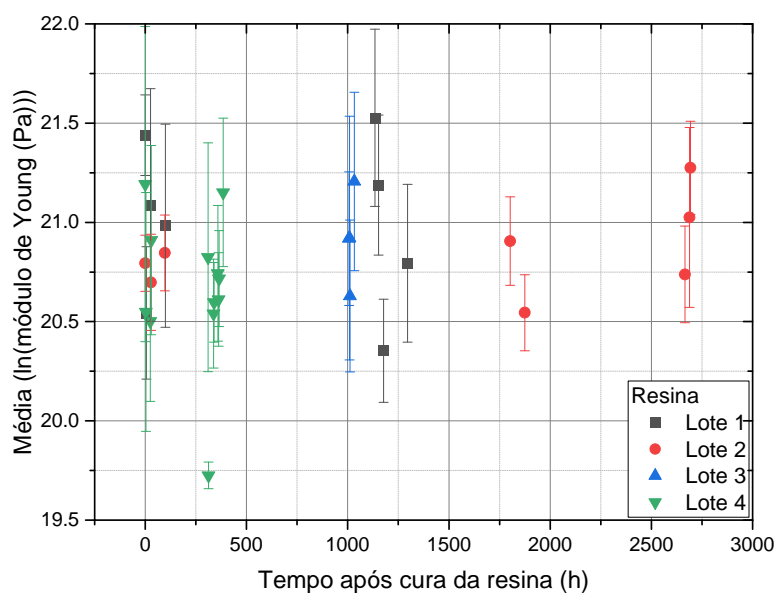

(c)

Figura 3.20 - Médias e histograma dessas médias com ajuste gaussiano do $\ln (E)$ obtido para cada amostra de resina [Fig. 3.20a], em função dos cantilevers utilizados para coleta dos dados [Fig. 3.20b] e em função do tempo transcorrido após cura da resina, no qual foi realizado a coleta do respectivo dado, agrupado por lote, de preparações realizadas em diferentes dias [Fig. 3.20c]. A linha contínua azul indica a média $(\bar{\mu})$ obtida do ajuste e as linhas tracejadas azuis indicam os limites superiores e inferiores considerando 3 desvios-padrão $(\sigma)$. 
A Fig. 3.20a mostra um panorama geral da distribuição das médias do $\ln (E)$ das amostras de resina, sem qualquer agrupamento. Na Fig. 3.20b, o agrupamento foi feito considerando o cantiléver utilizado para a coleta de dados. É de interesse considerar o agrupamento por cantilever para verificação de tendência nos dados, já que os resultados do módulo de Young dependem de dois parâmetros do cantilever: constante elástica $k_{c} \mathrm{e}$ raio da ponta $R$. Conforme observa-se, os dados não mostram tendências para qualquer cantilever, considerando os desvios-padrão da distribuição dos dados, sugerindo que os procedimentos realizados para obtenção dos parâmetros da ponta foram congruentes. Já na Fig. 3.20c, apresentam-se as médias em função do tempo transcorrido da cura da resina, no qual os dados foram coletados, agrupados por lote, de preparações realizadas em diferentes dias . Para o intervalo de tempo transcorrido para a coleta dos dados, também não foi observado qualquer tendência, o que sugere que não é perceptível mudanças no módulo de Young da resina. O agrupamento por lote também não revela qualquer tendência nos dados, sendo portanto irrelevante para a técnica, considerando os procedimentos utilizados.

Na Fig. 3.21 apresentam-se as médias do $\ln (E)$, na região da resina, em função da velocidade de avanço/retração da ponta em direção à amostra e do ramp rate (taxa na qual é coletada a curva de força completa (approach e retract)).

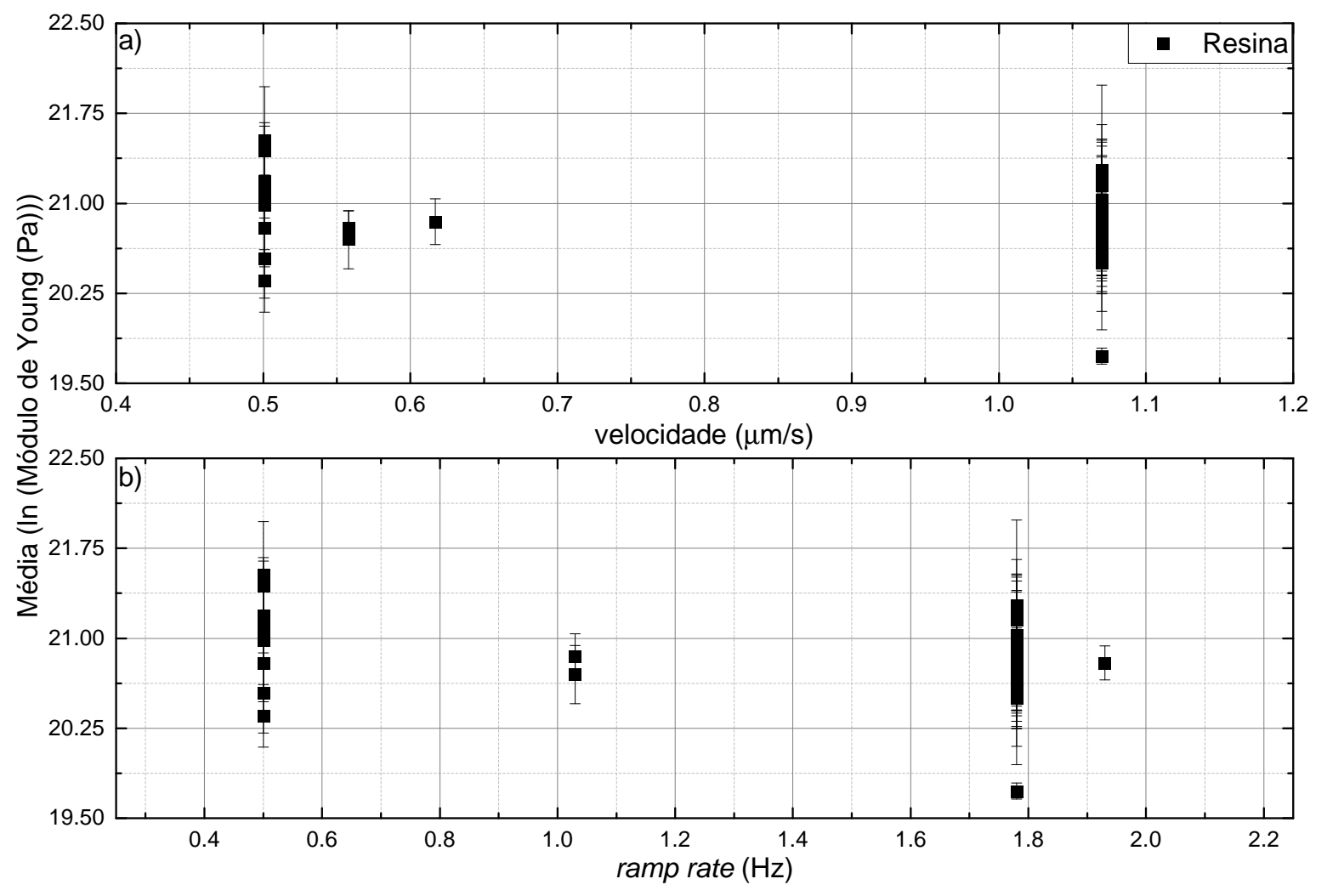

Figura 3.21 - (a) Média do $\ln (E)$ obtido para a resina, em função da velocidade de avanço/retração da ponta em direção à amostra e (b) média do $\ln (E)$ em função da taxa de coleta das curvas de força (ramp rate). 
A partir da Fig. 3.21 também não é notada nenhuma tendência em função dos parâmetros configurados para a coleta de dados, o que sugere que o módulo de Young se mostra constante no intervalo de valores utilizados de velocidade de avanço/retração da ponta em direção à amostra e também para a taxa de amostragem das curvas de força.

Sendo assim, a partir das Figs. 3.20 e 3.21, considera-se que a troca de cantilever e variação de parâmetros (dentro do intervalo de valores aqui utilizado) na obtenção dos dados, não afetam as medidas de forma significativa, quando as calibrações são devidamente realizadas, o que inclui: determinação da constante elástica do cantiléver, obtenção da constante deflection sensitivity, a cada novo posicionamento do cantiléver e medida do raio da ponta. Sendo assim, a constância das médias dos módulos de Young para a resina passou a ser uma referência para avaliação geral do cantiléver e das calibrações.

Para utilização dos dados da resina como uma referência, de forma a garantir a acurácia na comparação entre dados dos grupos de fibras, também foram avaliadas as diferentes condições ambientais na qual foram realizadas as coletas dos dados. Na Fig. 3.22 apresentam-se as médias do $\ln (E)$, para a região da resina, em função da temperatura e umidade relativa, medidas no ambiente da coleta dos dados.

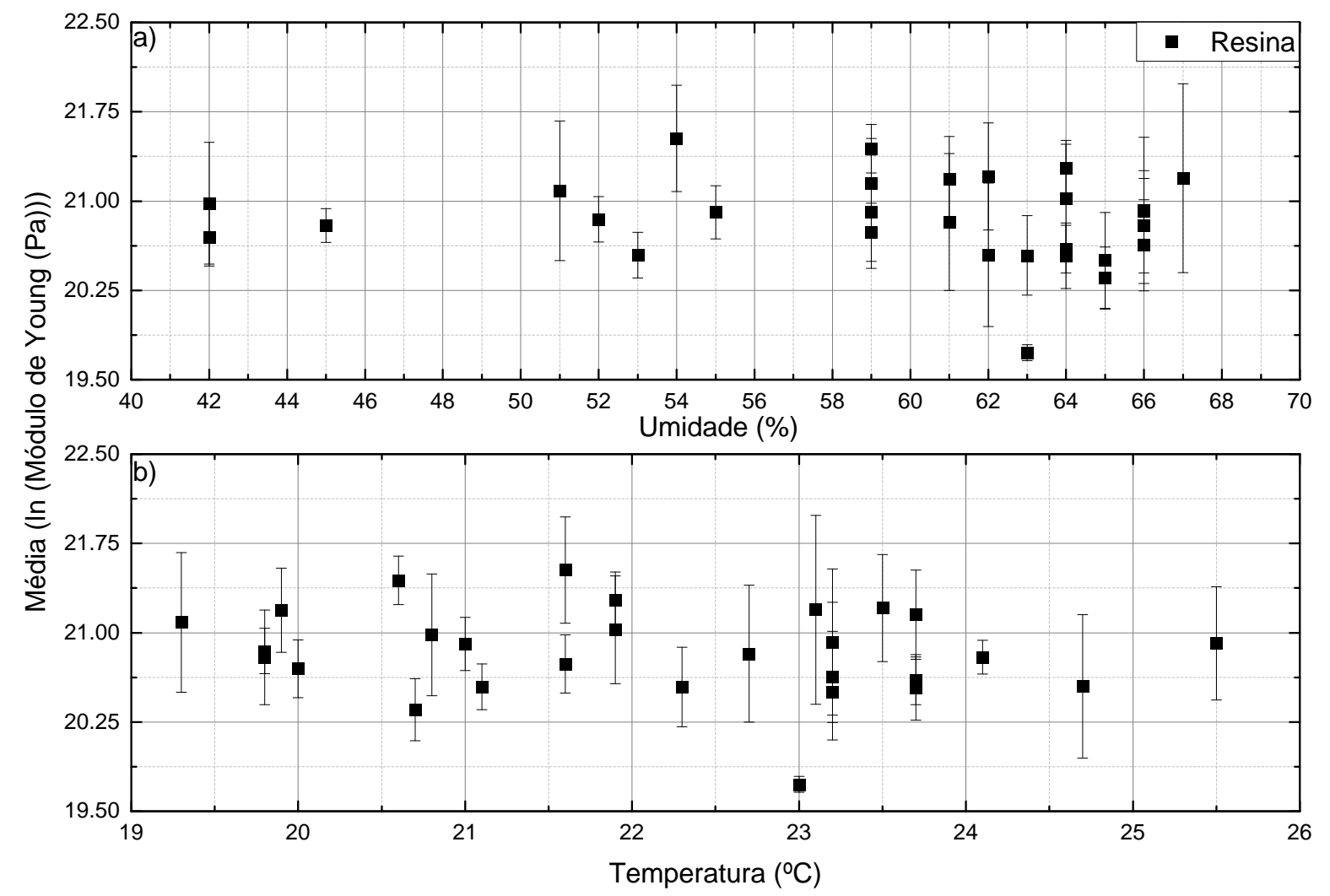

Figura 3.22 - (a) Média do $\ln (E)$ obtido para cada amostra, na região da resina, em função da umidade relativa (a) e da temperatura (b), medidas no ambiente da coleta dos dados. 
A partir da Fig. 3.22 verifica-se que os dados também sugerem constância nas condições ambientais as quais foram coletados os dados. Sendo assim, avalia-se que a utilização dos dados da resina como uma referência, coletados conjuntamente com cada fibra, mostra-se apropriada. Vale ressaltar que, esta avaliação visa garantir uma comparação coerente entre grupos das diferentes fibras.

\subsubsection{Dados referentes às fibras}

A seguir, são considerados para a análise dados provenientes das regiões do mapa pertencentes às fibras.

Na Fig. 3.23 são apresentadas as médias do $\ln ($ módulo de Young) $(\ln (E))$ para cada fibra, reunidas conforme respectivos grupos de tratamento. Cada ponto, neste caso, representa a média e seu respectivo desvio-padrão, dos valores tomados nos mapas [Figs. 3.2, 3.3, 3.4 e 3.5]. Assim, cada ponto e barra da Fig. 3.23 corresponde à média e ao desviopadrão, respectivamente, de $\ln (E)$ de uma fibra, estando os histogramas apresentados na Fig. A.1 (Apêndice A).

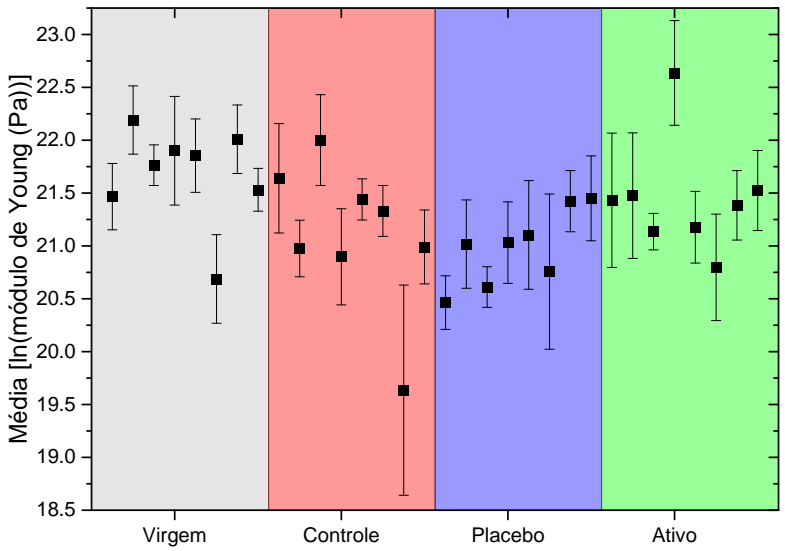

(a)

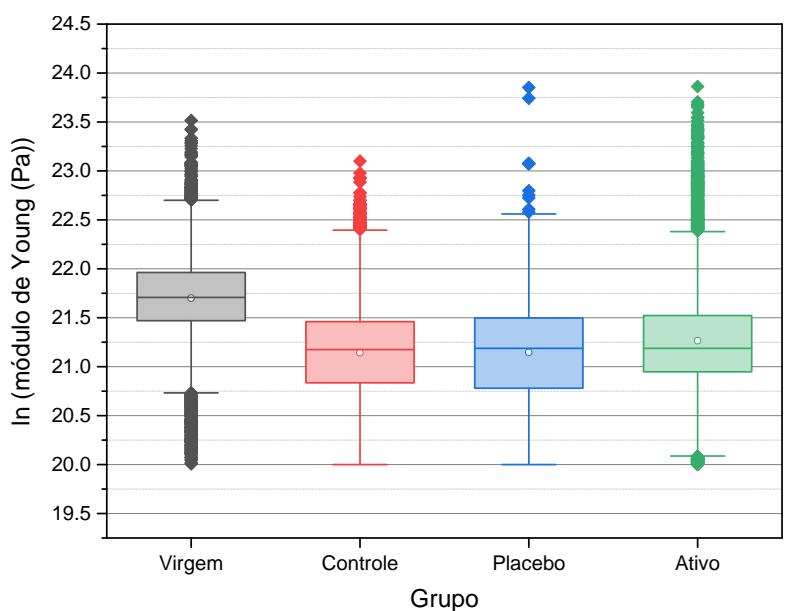

(b)

Figura 3.23 - (a) Médias do $\ln (E)$ e respectivos desvios-padrão de dados, obtidos de ajustes gaussianos, provenientes da região da fibra, reunidos conforme grupo de tratamento: virgem, controle, placebo e ativo. Cada ponto, neste caso, representa a média e seu respectivo desvio-padrão, de $\ln (E)$ tomados nos mapas, sendo cada mapa correspondente a uma fibra, apresentado na Fig. A.1 (Apêndice A). (b) Diagrama de caixa (box plot) dos dados citados, reunidos por grupo de tratamento.

Na Fig. 3.23a, a fibra que apresentou a menor média do $\ln (E)$ do grupo ativo (fibra A6) também apresentou relação linear negativa moderada para o $\ln (E)$ em função da distância à borda da fibra, como analisado na seção 3.1 (página 50). Uma baixa ou superficial penetrabilidade do produto cosmético com ativo, especificamente na fibra citada, pode ser uma possível causa do decréscimo no módulo de Young nas regiões mais internas destas fibras. A partir da Fig. 3.23b é possível verificar que todos os grupos 
apresentam distribuições aproximadamente simétricas, tendo mediana próxima à média, considerando-se adequado a aproximação a uma distribuição normal.

Na Tab. 3.1 apresentam-se as médias e seus respectivos desvios-padrão da média do $\ln (E)$, sendo a quantidade de dados, utilizados para a comparação estatística, de 6214 para cada grupo.

Tabela 3.1 - Média e respectivos desvios-padrão da média do $\ln (E)$ para cada grupo de tratamento: virgem, controle, placebo e ativo; sendo a quantidade de dados de 6214 para cada grupo.

\begin{tabular}{|c|c|}
\hline & Média $(\ln (E(P a)))$ \\
\hline \hline Virgem & $21.701 \pm 0.006$ \\
\hline Controle & $21.143 \pm 0.006$ \\
\hline Placebo & $21.144 \pm 0.006$ \\
\hline Ativo & $21.266 \pm 0.007$ \\
\hline
\end{tabular}

A partir dos dados reunidos por grupo de tratamento, foi utilizado o método paramétrico ANOVA (Analysis of Variance), empregando o teste de comparação múltipla de Tukey para a comparação das médias dos grupos [Fig. 3.24], testando a hipótese de igualdade das médias dos diferentes grupos. Para isso, foi utilizado um nível de significância $\alpha=0.05$ (5\%). Para obtenção da mesma quantidade de dados, visando proporcionar igualdade de variância para os diferentes grupos, foi utilizado método de reamostragem aleatória para avaliação da mesma quantidade de dados por grupo. A quantidade de dados por grupo foi determinada pelo grupo com menor tamanho amostral, resultando em 6214 dados para cada grupo.

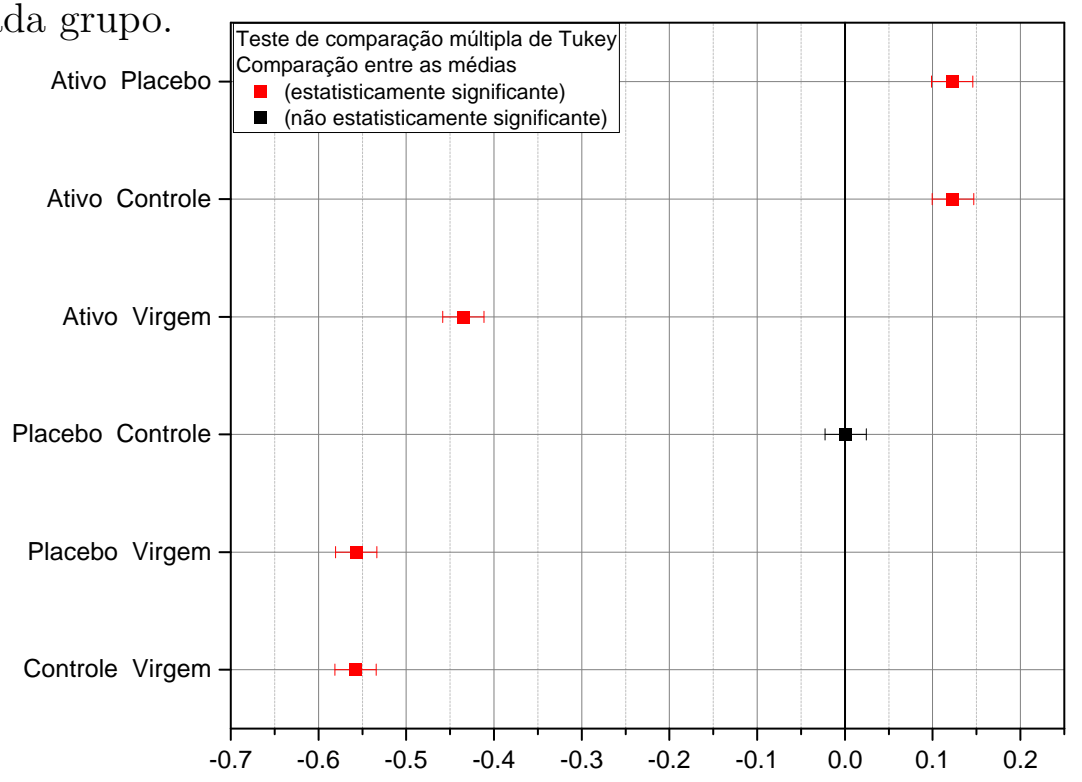

Figura 3.24 - Diferença padronizada das médias, a partir do método paramétrico ANOVA, empregando o teste de comparação múltipla de Tukey, do $\ln (E)$ dos dados da região das fibras, reunidos por grupo de tratamento. A coloração vermelha denota diferença estatisticamente significante entre o par de grupos e a coloração preta denota diferença não estatisticamente significante, considerando nível de significância $\alpha=0.05(5 \%)$. 
A partir da Tab. 3.1 e da Fig. 3.24, verifica-se decréscimo estatisticamente significante do valor médio do $\ln (E)$ das fibras danificadas quimicamente (grupo controle) em relação às fibras sem danos químicos (grupo virgem), ambas sem aplicação de produto. O decréscimo estatisticamente significante do módulo de Young das fibras danificadas quimicamente por descoloração (grupos controle, placebo e ativo) em relação às fibras não danificadas quimicamente são consistentes com dados bem estabelecidos na literatura [21], pois as fibras danificadas sofrem, principalmente, o rompimento de pontes dissulfeto, acarretando em perda de rigidez. O aumento estatisticamente significante dos valores do $\ln (E)$ das fibras do grupo ativo (danificadas quimicamente e com aplicação de produto com ativo cosmético) em relação às fibras do grupo controle e placebo, denota-se a eficácia do tratamento com a presença do ativo cosmético, melhorando o módulo de elasticidade da fibra. Quanto a não haver diferença estatisticamente significante do módulo de Young entre os grupos placebo e controle, era de se esperar, desde que não se espera atividade em um placebo.

O módulo de Young das fibras capilares também foi determinado por Tensile Tester. Na Fig. 3.25 são apresentados os valores obtidos para cada fibra, reunidos por grupo de tratamento, bem como os diagramas de caixa.

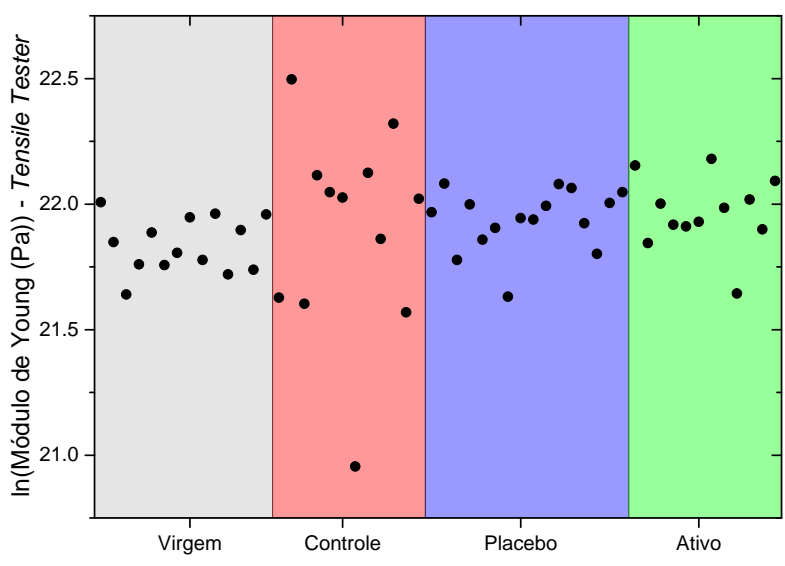

(a)

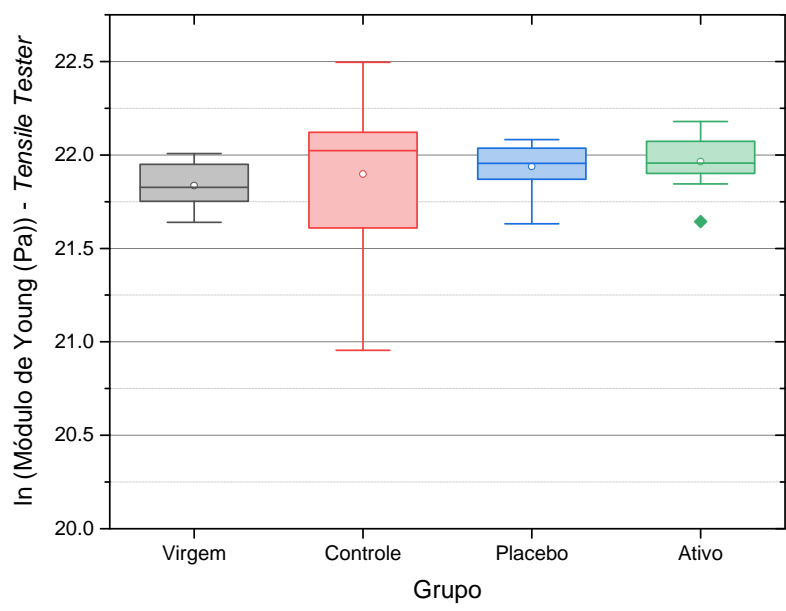

(b)

Figura 3.25 - (a) $\ln (E)$ de dados obtidos por Tensile Tester, reunidos conforme grupo de tratamento: virgem, controle, placebo e ativo. Cada ponto, neste caso, representa um valor tomado em uma medida, correspondente a uma fibra. (b) Diagrama de caixa (box plot) dos dados citados, reunidos por grupo de tratamento.

Na Tab. 3.2 apresentam-se as médias e seus respectivos desvios-padrão da média, bem como o número de dados utilizado para a comparação estatística, do $\ln$ (módulo de Young) das fibras, obtidos por Tensile Tester. 
Tabela 3.2 - Média e respectivos desvios-padrão da média do $\ln (E)$ para as fibras, obtidos por Tensile Tester, para cada grupo de tratamento: virgem, controle, placebo e ativo.

\begin{tabular}{|c|c|c|}
\hline & \# dados & Média $(\ln (E(P a)))$ \\
\hline \hline Virgem & 14 & $21.84 \pm 0.03$ \\
\hline Controle & 12 & $21.90 \pm 0.12$ \\
\hline Placebo & 16 & $21.94 \pm 0.03$ \\
\hline Ativo & 12 & $21.96 \pm 0.04$ \\
\hline
\end{tabular}

Similarmente à análise realizada para os dados obtidos por FV-AFM, foi feita comparação entre grupos dos dados obtidos por Tensile Tester, utilizando ANOVA, empregando o teste de Tukey, com $\alpha=0.05$. Na Fig. 3.26 são apresentadas as diferenças das médias do $\ln$ (módulo de Young) entre os pares de grupos.

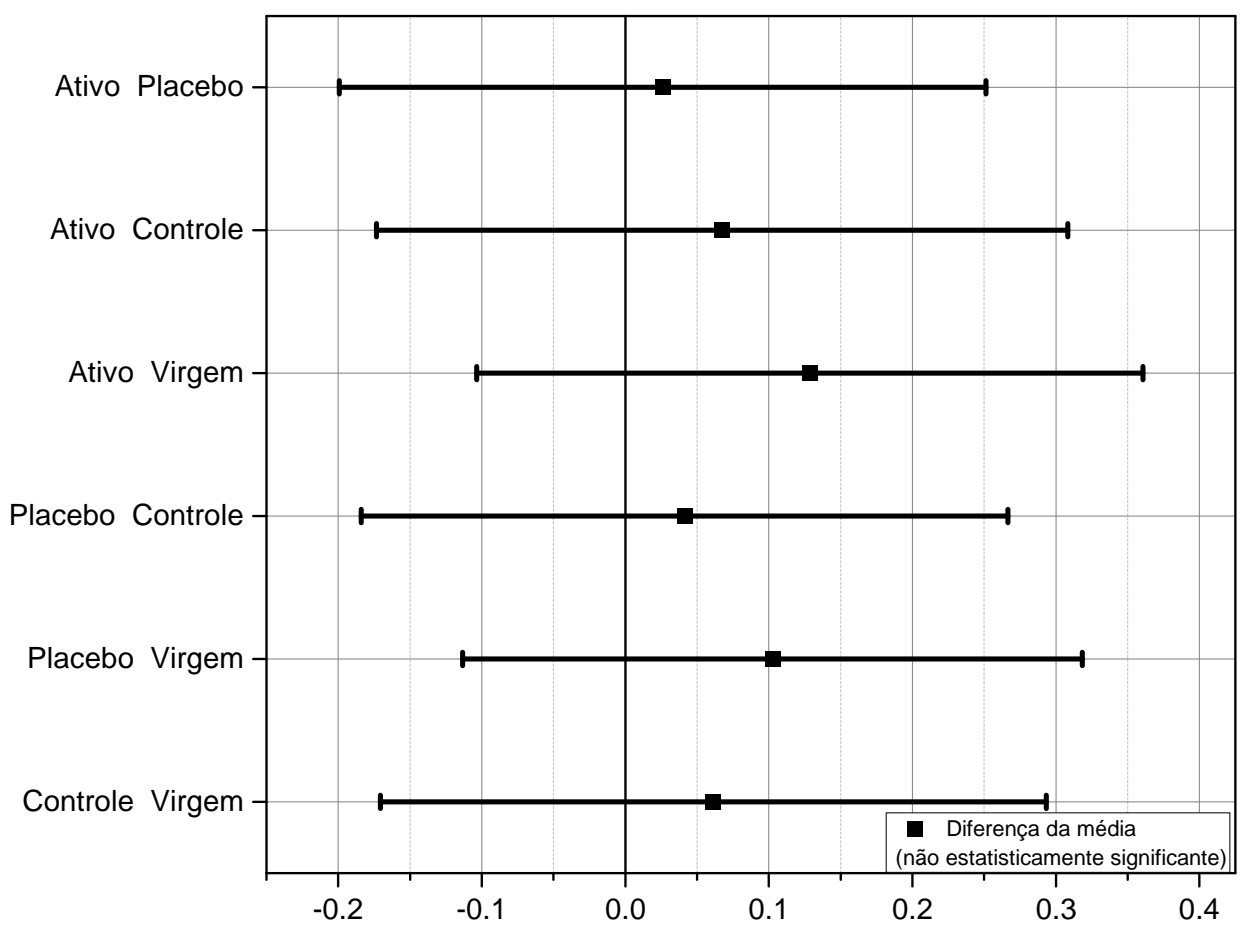

Figura 3.26 - Diferença padronizada das médias, a partir do método paramétrico ANOVA, empregando o teste de comparação múltipla de Tukey, do $\ln (E)$ dos dados das fibras, reunidos por grupo de tratamento, obtidos por Tensile Tester. A coloração preta denota diferença não estatisticamente significante, considerando nível de significância $\alpha=0.05$ (5\%).

A partir da Tab. 3.2 e da Fig. 3.26 constata-se que não há diferenças estatisticamente significantes para os dados obtidos por Tensile Tester. Portanto, verifica-se que não foi possível aferir diferenças entre os diferentes grupos de tratamento em relação ao módulo de Young, a partir de valores obtidos por Tensile Tester e, portanto, demonstrando a importância da utilização da técnica FV-AFM, na qual foram constatadas diferenças estatisticamente significantes entre os grupos de tratamento. 
Para 4 fibras por grupo, parte da fibra foi destinada para análise por FV-AFM e parte para a análise por Tensile Tester, de forma a obter os resultados para o módulo de Young $E$ das mesmas fibras para as diferentes técnicas. Na Fig. 3.27 são apresentadas as razões entre os valores obtidos pela técnica FV-AFM e Tensile Tester.

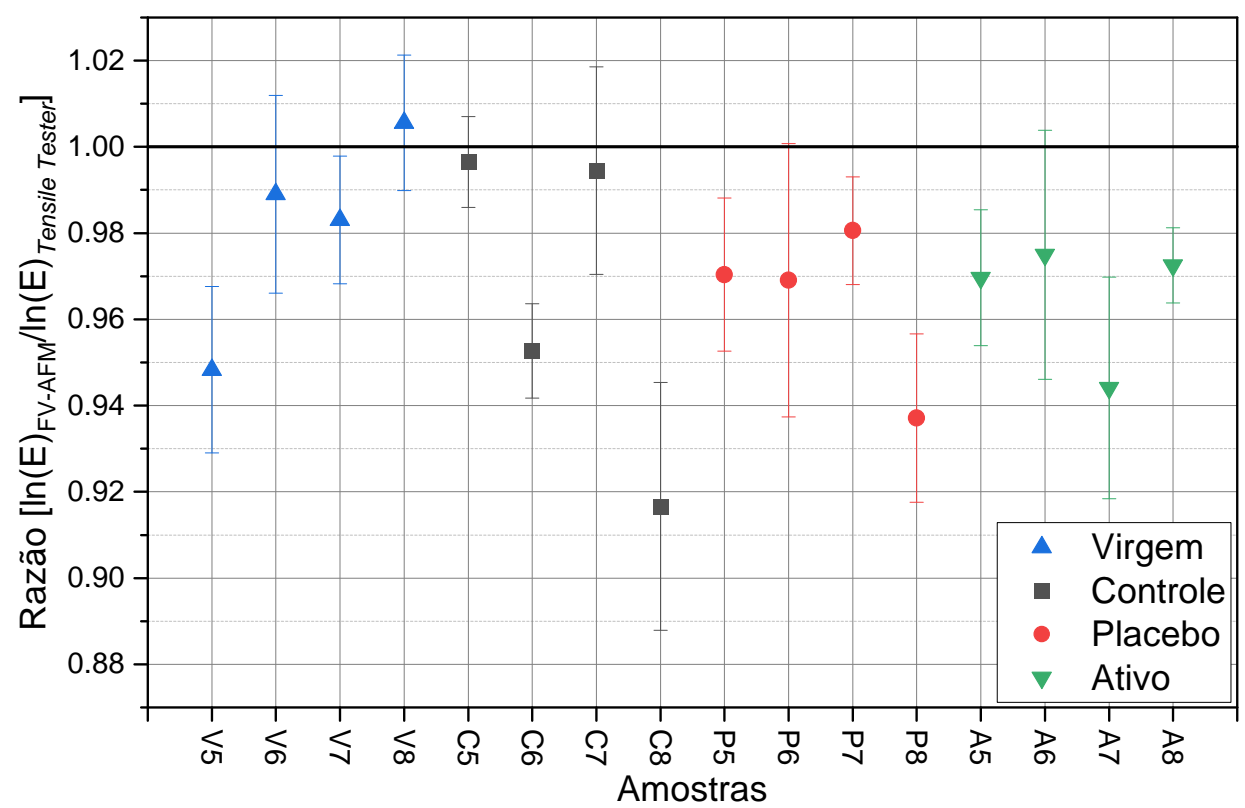

Figura 3.27 - Razão entre o $\ln ($ módulo de Young $(\mathrm{Pa})$ ) de medidas obtidas por FV-AFM e de medidas obtidas por Tensile Tester.

A partir da Fig. 3.27, verifica-se que as razões entre as medidas por FV-AFM e Tensile Tester estão entre 0.92 e 1.01, mostrando uma tendência das razões serem sistematicamente menores que 1 , o que equivale dizer que os dados medidos por FV-AFM são sistematicamente menores que os dados medidos por Tensile Tester. A maior diferença percentual entre as medidas por FV-AFM e Tensile Tester é $\approx 15 \%$, sendo que na média, a diferença é de $\approx 4 \%$, o que indica boa concordância entre os dados. Na Fig. 3.27, os dados são diferenciados por cores, às quais correspondem aos respectivos grupos de tratamento. Considerando os dados agrupados por tratamento, não foi identificado nenhuma tendência.

A seguir, assim como foi feito para o módulo de Young, são apresentados resultados obtidos para a força de adesão entre ponta e amostra. Para esta propriedade, não foi possível identificar precisamente o(s) fator(es) predominante(s) que originaram a diferença entre os grupos. No entanto, considerou-se relevante apresentar a investigação deste parâmetro, avaliando os dados conforme os parâmetros utilizados para a coleta de dados, bem como as condições ambientais.

Na Fig. 3.28 são apresentadas as médias da força de adesão entre ponta e amostra para cada fibra, reunidas conforme respectivos grupos. 


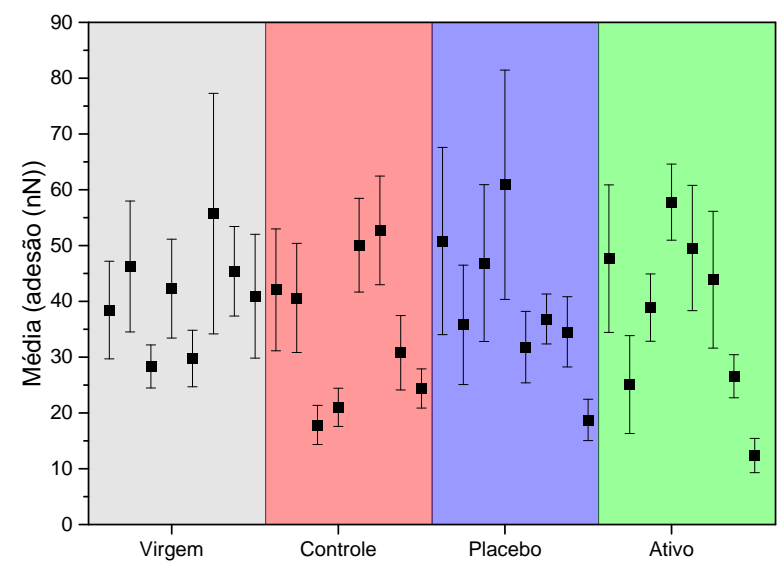

(a)

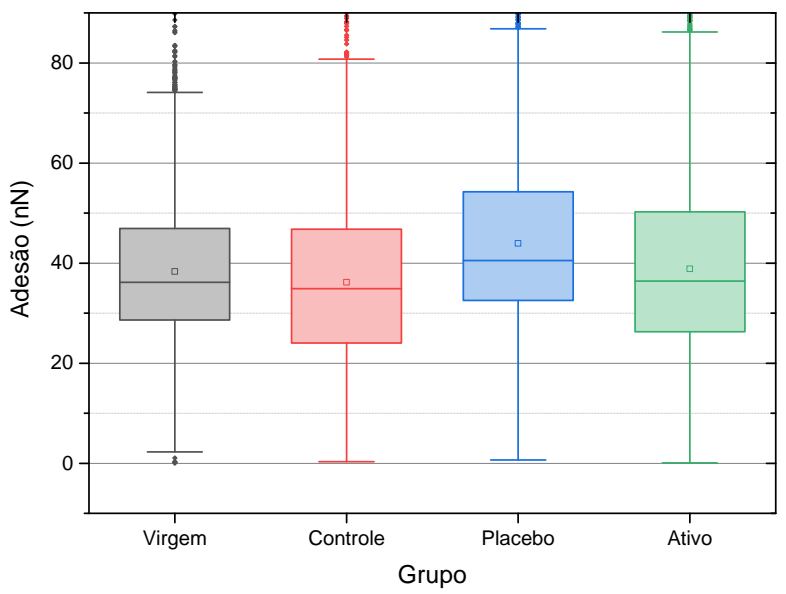

(b)

Figura 3.28 - Médias da força de adesão entre ponta e amostra de dados provenientes da região da fibra, reunidos conforme grupo de tratamento: virgem, controle, placebo e ativo. a) Média e desvio padrão obtidos do ajuste gaussiano, de histogramas apresentados na Fig. A.2 (Apêndice A). b) Diagrama de caixa (box plot) dos dados reunidos por grupo de tratamento.

Na Tab. 3.3 apresentam-se as médias e seus respectivos desvios-padrão da média da força de adesão entre ponta e amostra, sendo que o número de dados utilizados para a comparação estatística foi de 7128 para cada grupo.

Tabela 3.3 - Média e respectivos desvios-padrão da média da força de adesão entre ponta e amostra, para cada grupo de tratamento: virgem, controle, placebo e ativo; sendo a quantidade de dados de 7128 para cada grupo.

\begin{tabular}{|c|c|}
\hline & Média $F_{a d}(\mathbf{n N})$ \\
\hline \hline Virgem & $38.31 \pm 0.15$ \\
\hline Controle & $36.17 \pm 0.17$ \\
\hline Placebo & $43.92 \pm 0.19$ \\
\hline Ativo & $38.85 \pm 0.2$ \\
\hline
\end{tabular}

De forma similar à comparação feita para o $\ln$ (módulo de Young), os dados de força de adesão entre ponta e amostra foram reunidos por grupo de tratamento e utilizando o método ANOVA, empregando o teste de comparação múltipla de Tukey, foi realizada comparação das médias dos grupos [Fig. 3.29], testando a hipótese de igualdade das médias dos diferentes grupos. Para isso, foi utilizado um nível de significância $\alpha=0.05$ (5\%). Também foi utilizado o método de reamostragem aleatória para avaliação da mesma quantidade de dados por grupo, sendo a quantidade de dados por grupo determinada pelo grupo com menor tamanho amostral. 


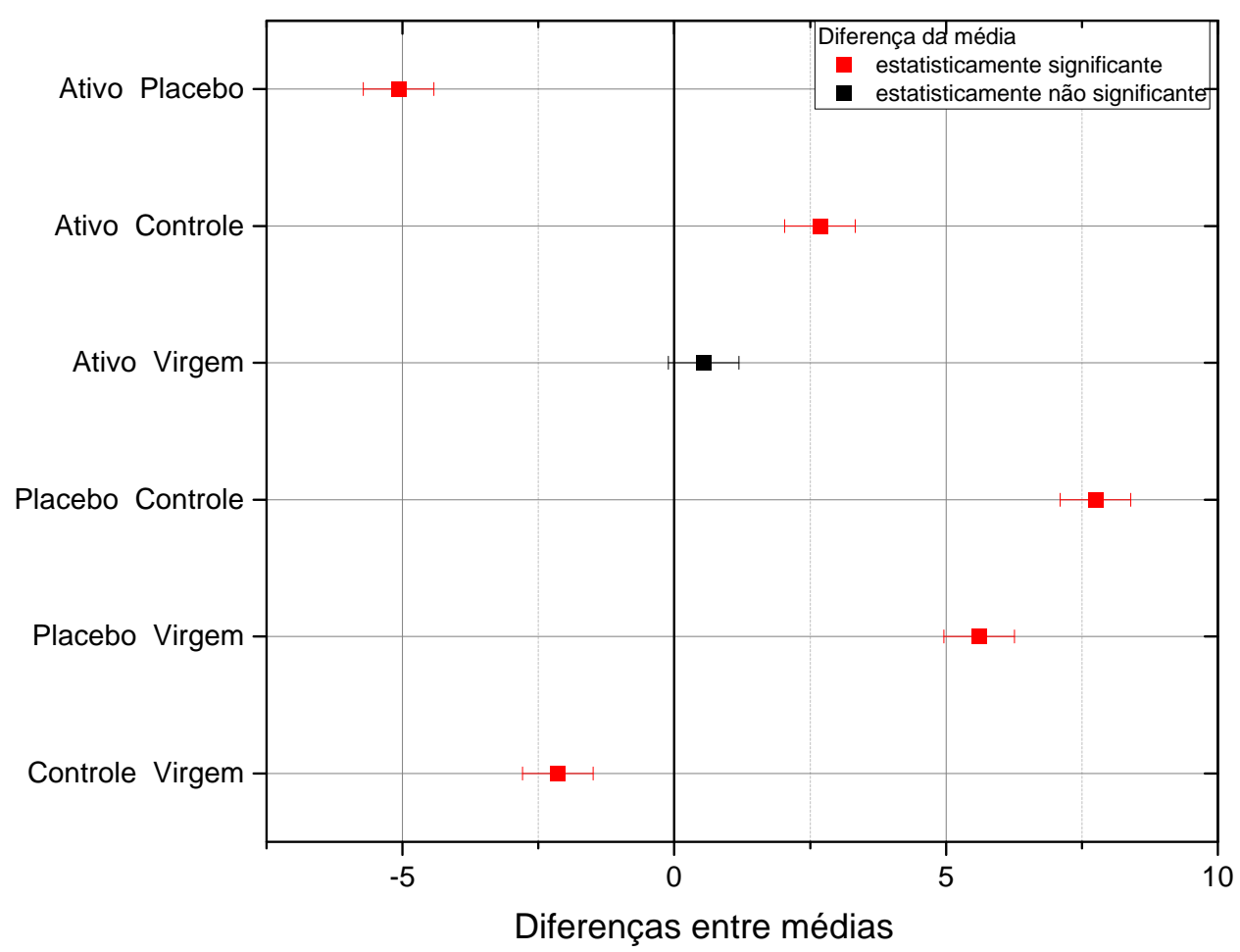

Figura 3.29 - Diferença das médias, a partir do método paramétrico ANOVA, empregando o teste de comparação múltipla de Tukey, da força de adesão entre ponta e amostra, dos dados da região das fibras, reunidos por grupo de tratamento. A coloração vermelha denota diferença estatisticamente significante entre o par de grupos, considerando nível de significância $\alpha=0.05$ (5\%).

A partir da Tab. 3.3 e da Fig. 3.29, verifica-se que a diferença das médias dos grupos virgem e ativo não é estatisticamente significante, mostrando um decréscimo para a média do grupo controle e acréscimo para o grupo placebo.

Fibras danificadas quimicamente por processo de descoloração são mais higroscópicas $[17,22]$, esperando-se uma maior força de adesão. Porém, os resultados apresentaram um decréscimo estatisticamente significante da média do grupo controle comparado ao grupo virgem, o que sugere que a diferença entre as médias da força de adesão entre esses grupos pode não estar sendo determinada pela força capilar, considerando apenas a diferença em hidrofilicidade das amostras. A força capilar depende de fatores como rugosidade, deformabilidade, tamanho e forma e natureza liofílica das superfícies, assim como o tempo necessário para formação de menisco e umidade relativa, tornando a interação complexa e interdependente [65]. Portanto, foram avaliados outros parâmetros das amostras, para investigação de possível dependência da força de adesão com os mesmos. Na Fig. 3.30 apresenta-se a força de adesão em função das condições ambientais na tomada dos dados (temperatura e umidade relativa), assim como a velocidade de avanço/retração da ponta em direção à amostra e do ramp rate para os grupos virgem, controle, placebo e ativo. 

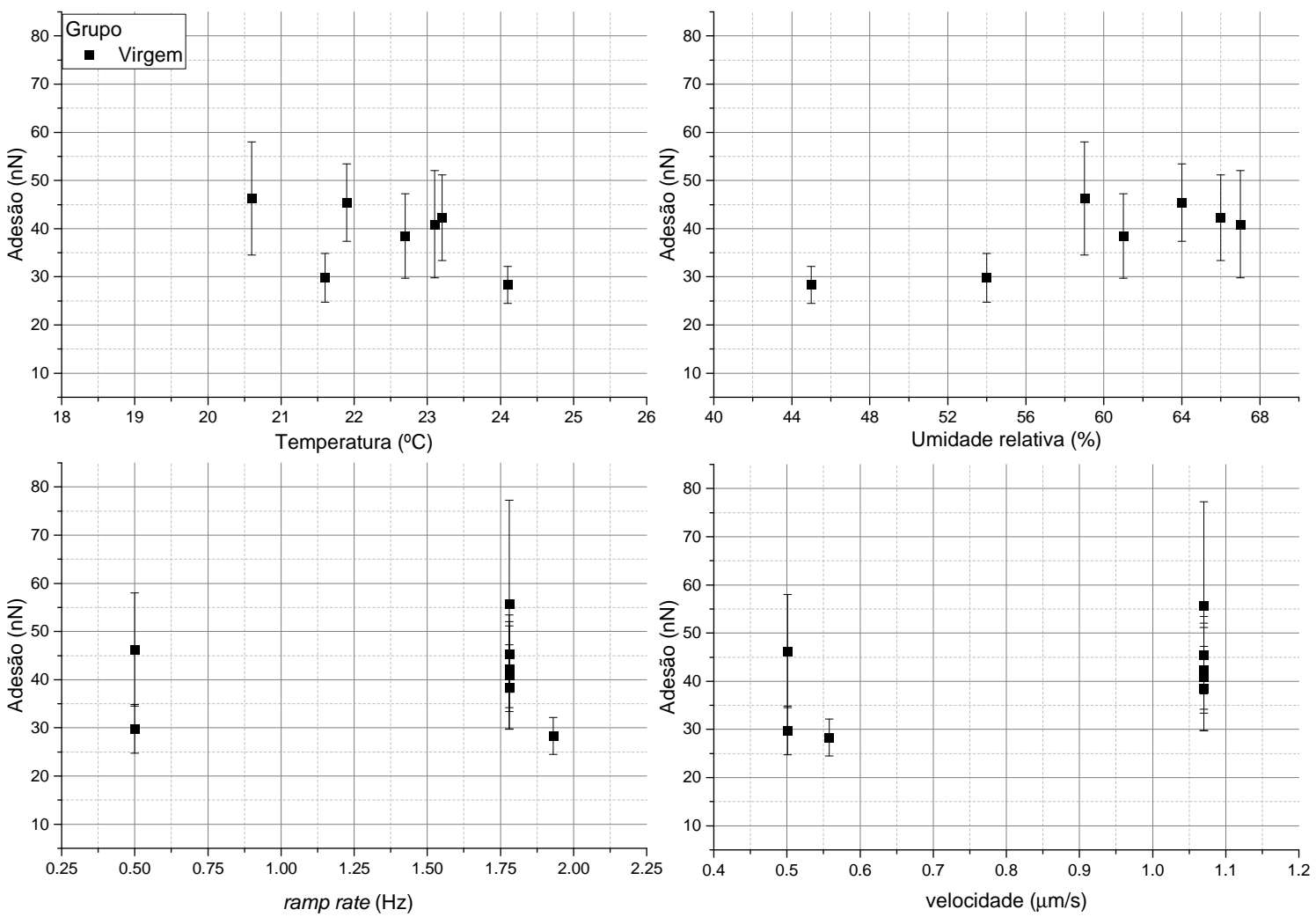

(a)
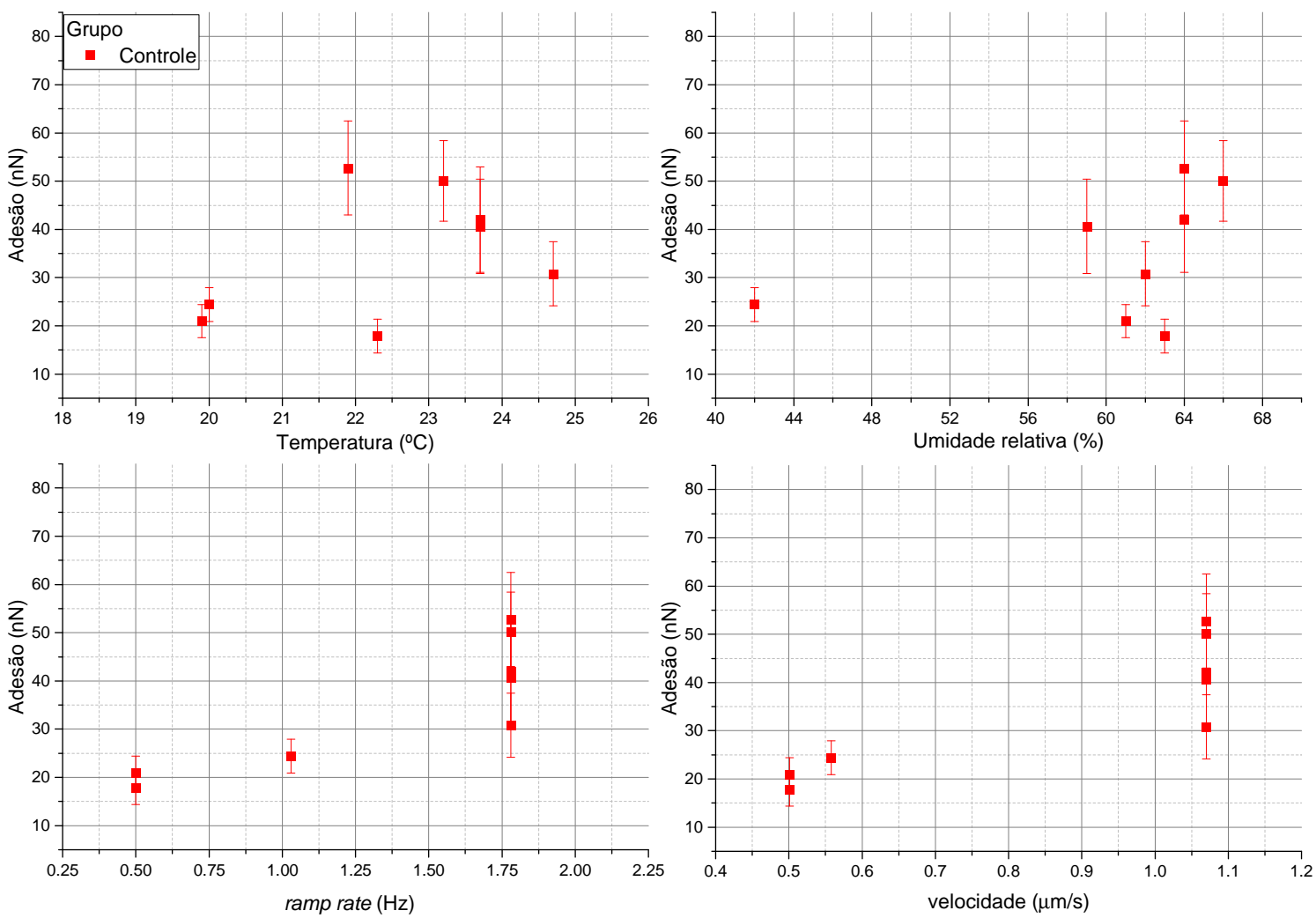

(b) 

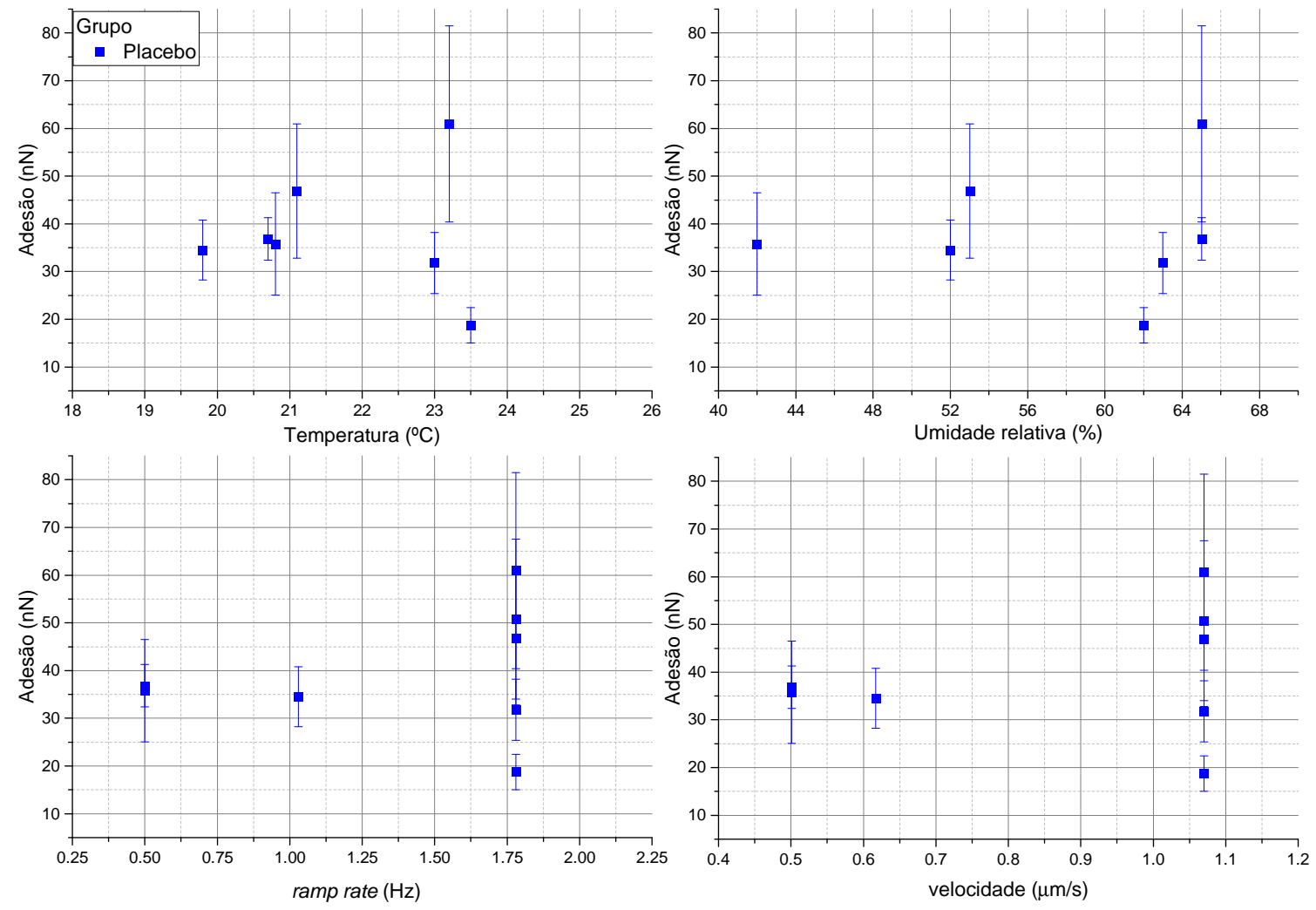

(c)
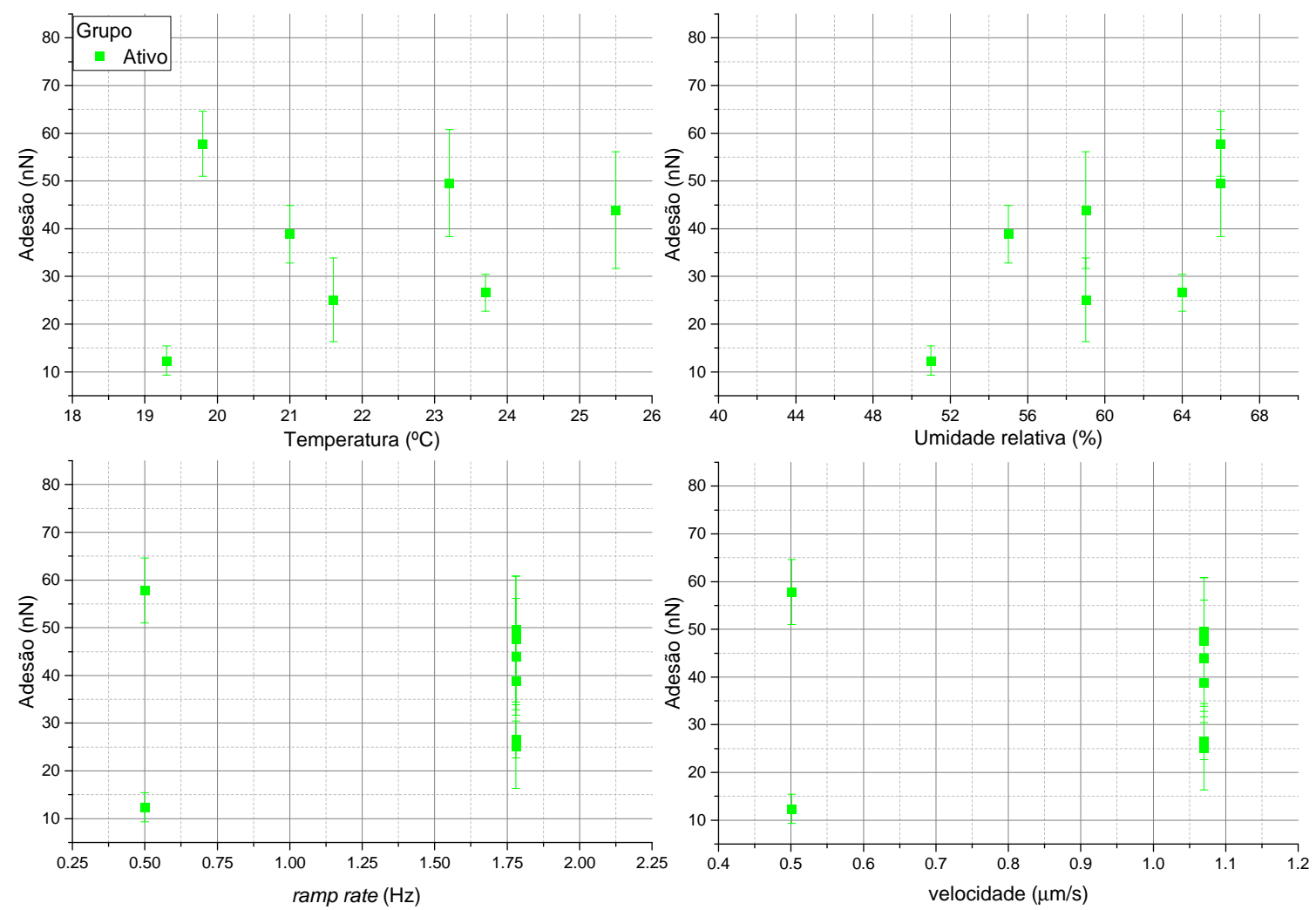

(d)

Figura 3.30 - Gráficos de força de adesão em função da temperatura, umidade relativa, velocidade de retração/avanço da ponta e ramp rate para as fibras pertencentes ao: a) grupo virgem, b) grupo controle, c) grupo placebo e d) grupo ativo. 
Avaliando os parâmetros de condições ambientais da tomada dos dados, bem como os parâmetros do scanner (velocidade e ramp rate), reunidas por grupo de tratamento, não foi verificada nenhuma tendência nos dados.

Na Fig. 3.31 são reunidos os dados de força de adesão de todas as amostras, em função da temperatura, umidade relativa, velocidade de retração/avanço da ponta e ramp rate.
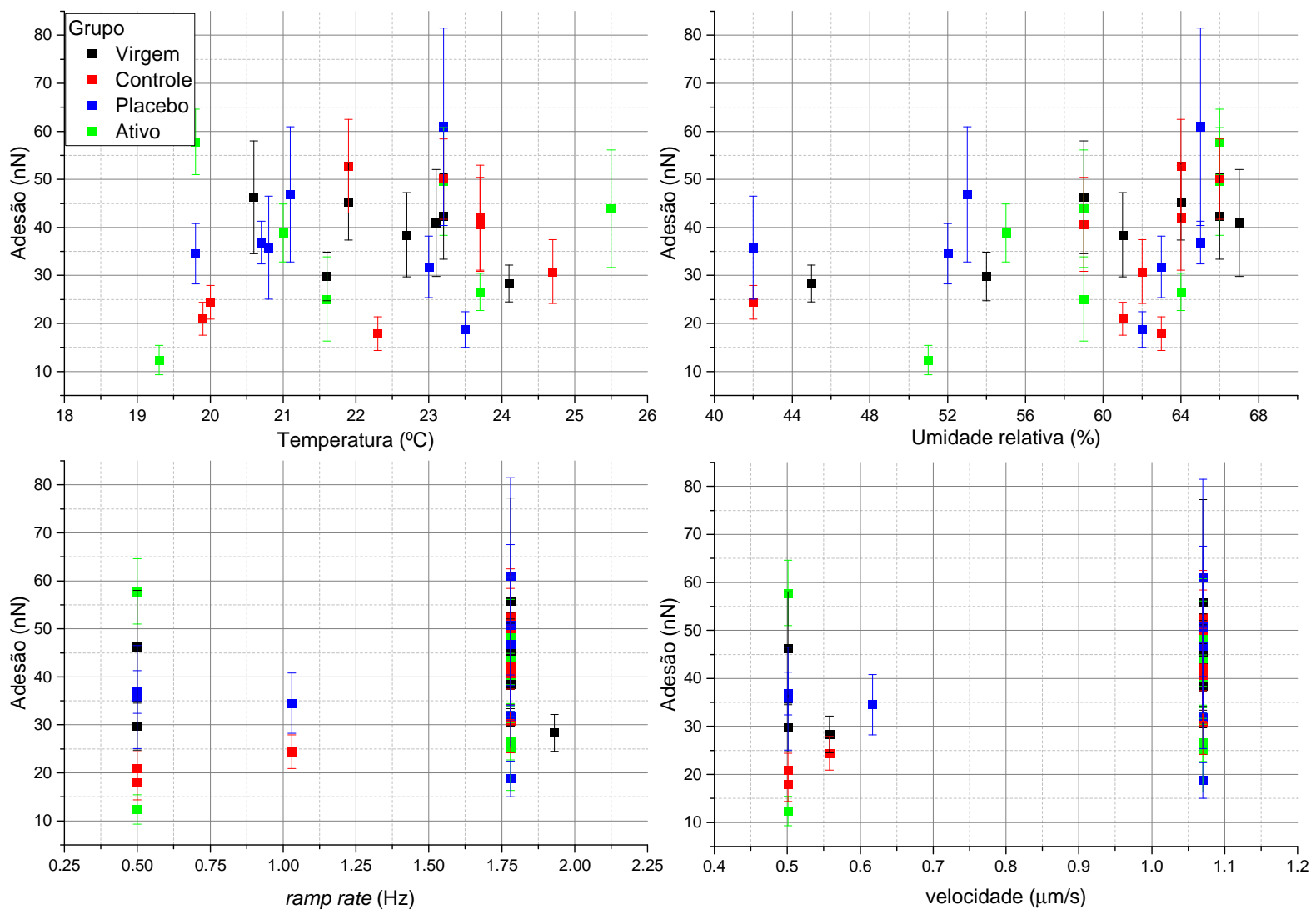

Figura 3.31 - Gráficos de força de adesão em função da temperatura, umidade relativa, velocidade de retração/avanço da ponta e ramp rate para as fibras pertencentes grupo virgem, controle, placebo e ativo, diferenciando-se por cores, conforme legenda.

Observando a Fig. 3.31, também não é notada tendência nos dados. Uma possível causa do decréscimo da força de adesão pelo grupo controle em comparação com o grupo virgem pode ser devido a degradação da estrutura CMC, que, como já discutido, possui propriedade adesiva. A degradação dessa estrutura é bastante evidente na comparação das micrografias entre esses grupos, como será discutido na seção a seguir.

Para aclaramento mais completo sobre a diferença nas médias de todos os grupos, torna-se necessário investigação adicional para elucidação do fator predominante ou dos fatores predominantes que causam as diferenças entre as médias de força de adesão entre os grupos, seja pela força capilar ou por outras forças de interação. 


\subsection{Microscopia Eletrônica de Transmissão}

No Laboratório de Filmes Finos do Instituto de Física da USP (LFF-IFUSP) foi realizada a inclusão em resina epoxy de fibras capilares sem danos químicos (grupo virgem), sem processo de fixação ou coloração prévia (realizado apenas os passos 1, 2, 3 e 7) (subseção 2.4.1). Para testar o efeito da coloração dos cortes no grid (passo 8), foi realizada a coloração das amostras com $\mathrm{C}_{12} \mathrm{H}_{10} \mathrm{O}_{14} \mathrm{~Pb}_{3}$ (citrato de chumbo) 0,2\% e parte delas, com $\mathrm{OsO}_{4}$ (tetróxido de ósmio) 1\%. Na Fig. 3.32 são apresentadas as micrografias obtidas por TEM, com magnificação original $\mathrm{M}=15.000 \mathrm{x}$, para comparação do processo de coloração (staining).

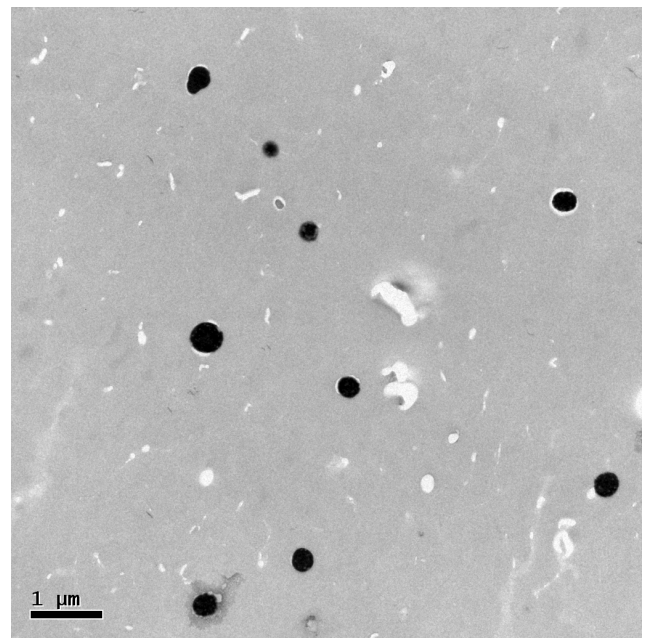

(a)

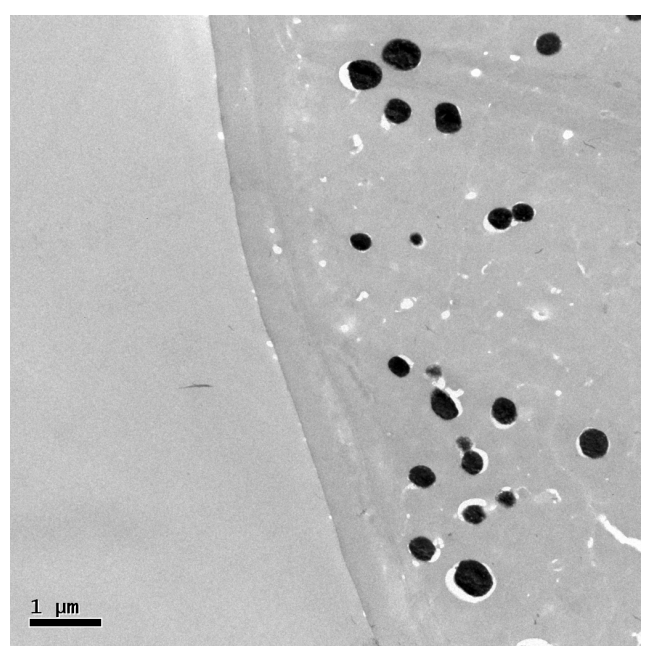

(c)

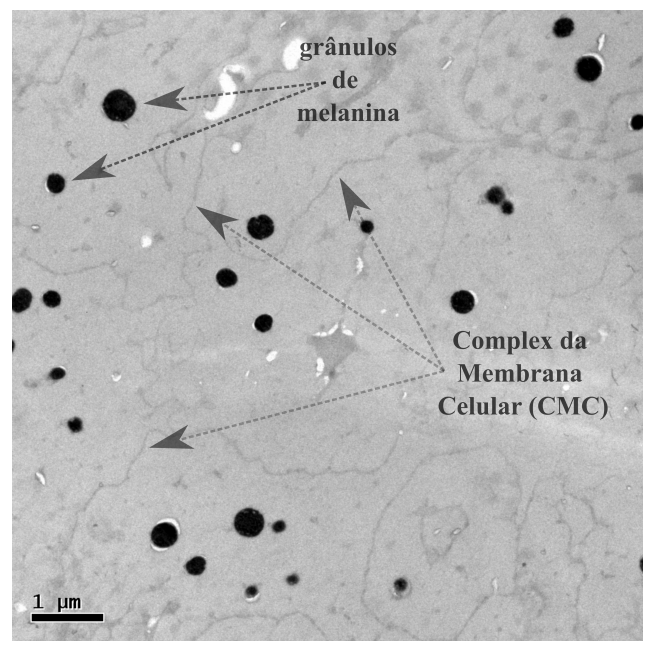

(b)

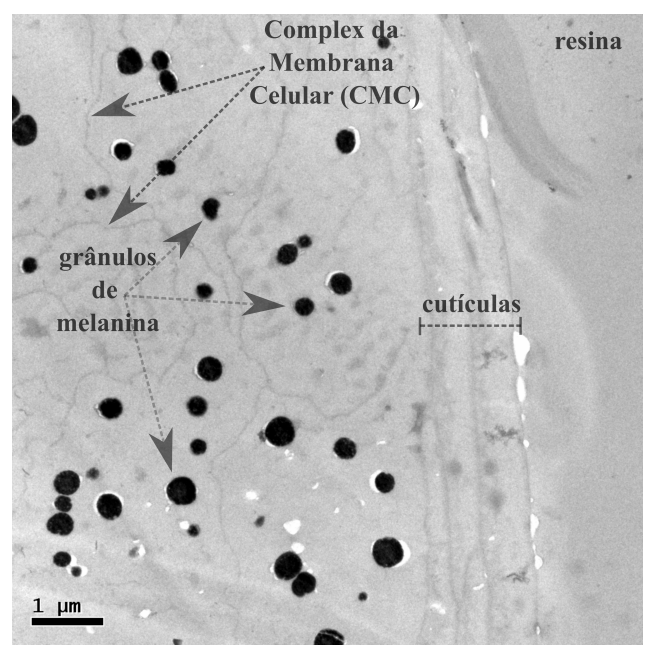

(d)

Figura 3.32 - Micrografias por TEM, de seções transversais de $80 \mathrm{~nm}$ de espessura, de fibra capilar sem danos químicos (virgem), com diferentes procedimento de coloração (staining) por: a) sem e b) com $\mathrm{OsO}_{4}$, evidenciando o córtex, ambas com coloração por $\mathrm{C}_{12} \mathrm{H}_{10} \mathrm{O}_{14} \mathrm{~Pb}_{3}$; c) sem e d) com $\mathrm{OsO}_{4}$, evidenciando também a cutícula, ambas com coloração por $\mathrm{C}_{12} \mathrm{H}_{10} \mathrm{O}_{14} \mathrm{~Pb}_{3}$. As setas apontam para os grânulos de melanina e Complexo da Membrana Celular (CMC). Magnificação original $\mathrm{M}=15.000 \mathrm{x}$. 
A partir da Fig. 3.32 verifica-se que os corantes utilizados no procedimento de staining propiciaram revelar as cutículas e os grânulos de melanina, apresentando contraste adequado para estas estruturas. Ainda a partir da Fig. 3.32 é possível verificar que a utilização do tetróxido de ósmio propiciou revelar o complexo da membrana celular (CMC), mostrado na Fig. 3.32b, quase não visível com a coloração somente por citrato de chumbo [Fig. 3.32a]. A coloração por tetróxido de ósmio também melhorou o contraste para observação das cutículas, conforme comparação entre Figs. 3.32c e 3.32d. Portanto, foi adotado o procedimento descrito na subseção 2.4.1, ou seja, adotando ambos os corantes no procedimento de staining para as amostras que são apresentadas a seguir.

A seguir, são apresentadas as imagens por TEM de seções transversais de amostras pertencentes aos grupos virgem e controle, para avaliação dos danos advindos do processo de descoloração.

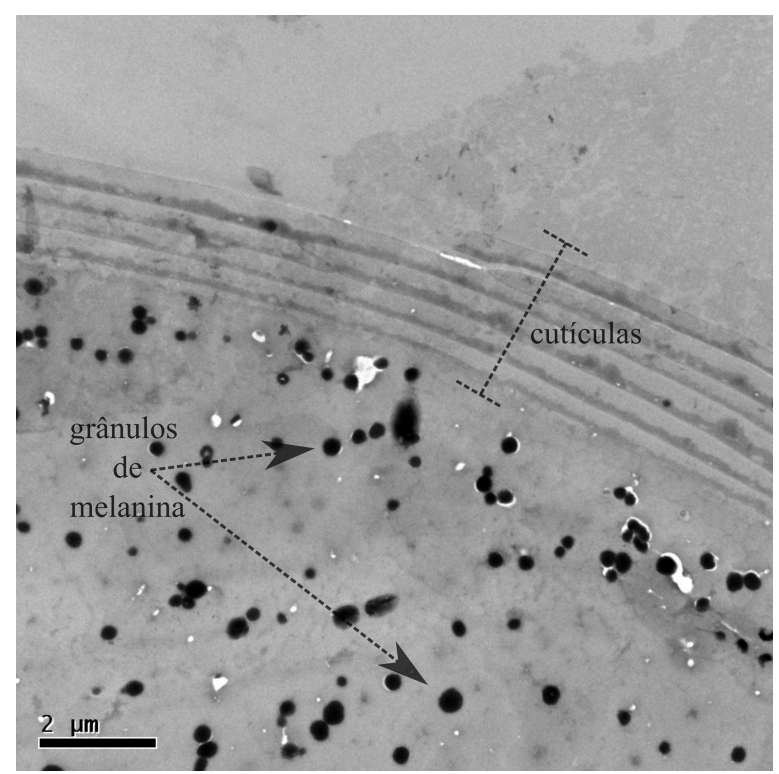

(a)

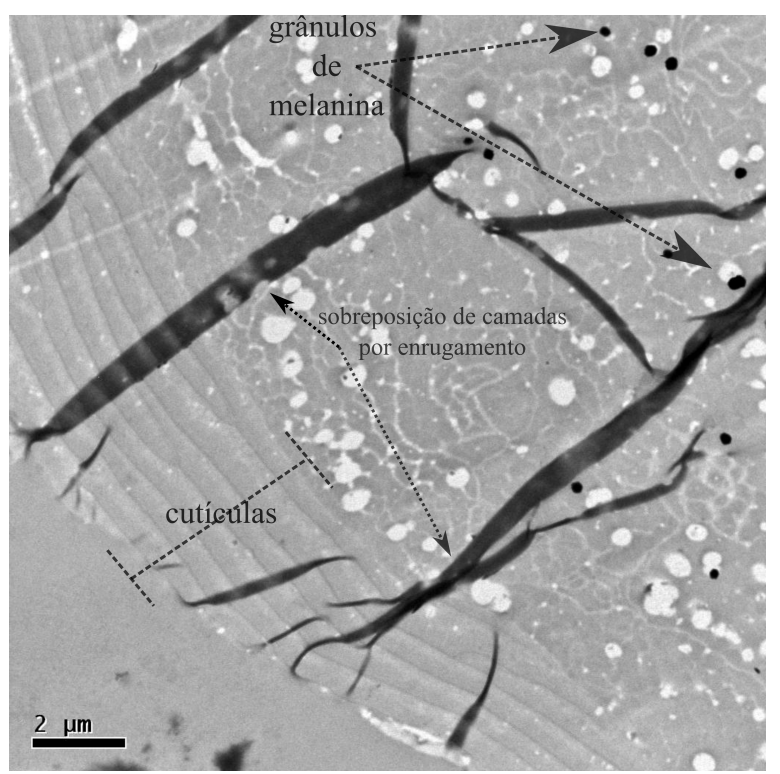

(b)

Figura 3.33 - Micrografias por TEM, de cortes transversais de $80 \mathrm{~nm}$ de espessura, de fibras capilares pertencentes ao (a) grupo virgem (sem danos químicos) e (b) controle (com danos químicos).

Embora tenha sido realizado procedimento similar para obtenção das amostras do grupo virgem e controle, constatou-se enrugamentos severos dos cortes da fibra do grupo controle, o que não ocorreu com a fibra do grupo virgem, como mostrado na Fig. 3.33. Na Fig. 3.33b são apontadas as tiras escuras, advindas da sobreposição de duas camadas, devido ao enrugamento do corte. A fragilidade da amostra do grupo controle, em razão do dano químico, evidenciado por áreas brancas na micrografia [Fig. 3.33b], pode ter propiciado a dificuldade na preparação adequada da amostra, principalmente por afetar propriedades mecânicas da mesma (conforme exposto na subseção 3.1.2). 


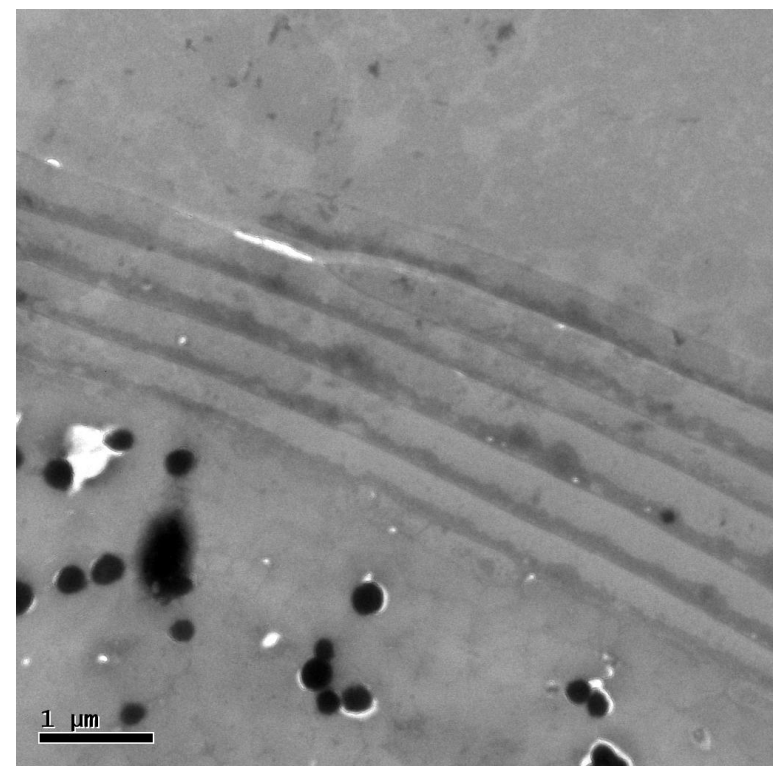

(a)

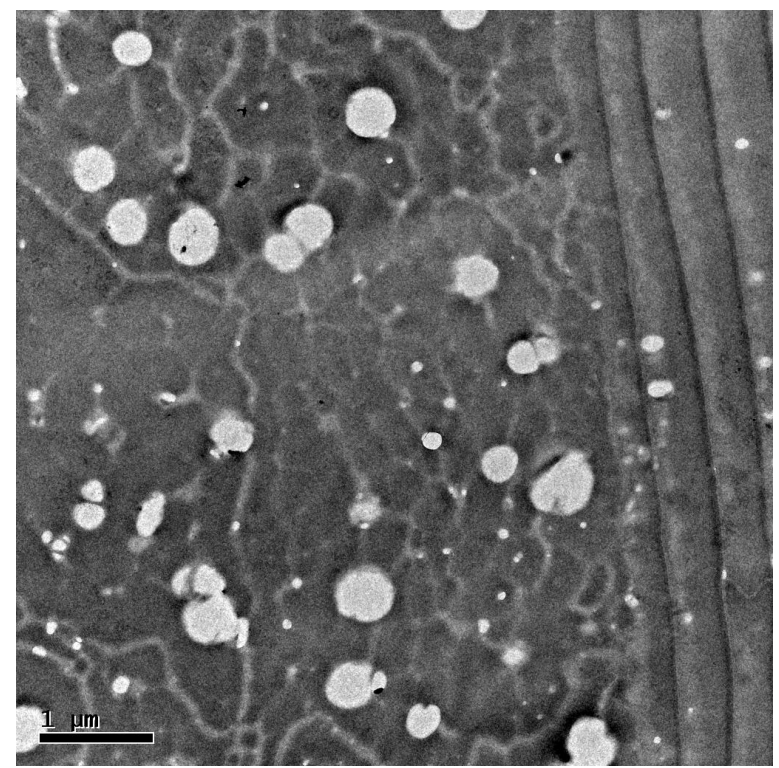

(c)

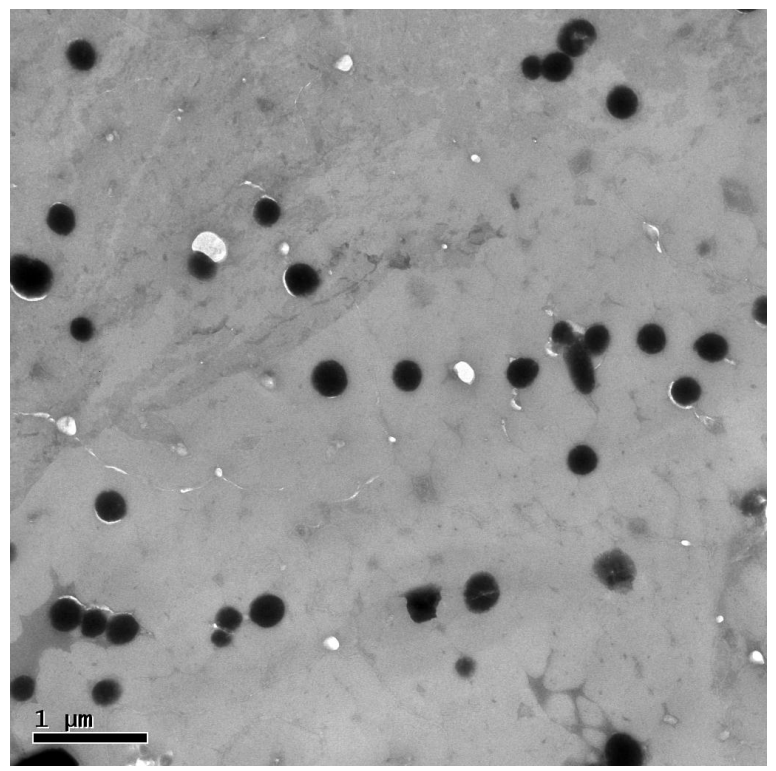

(b)

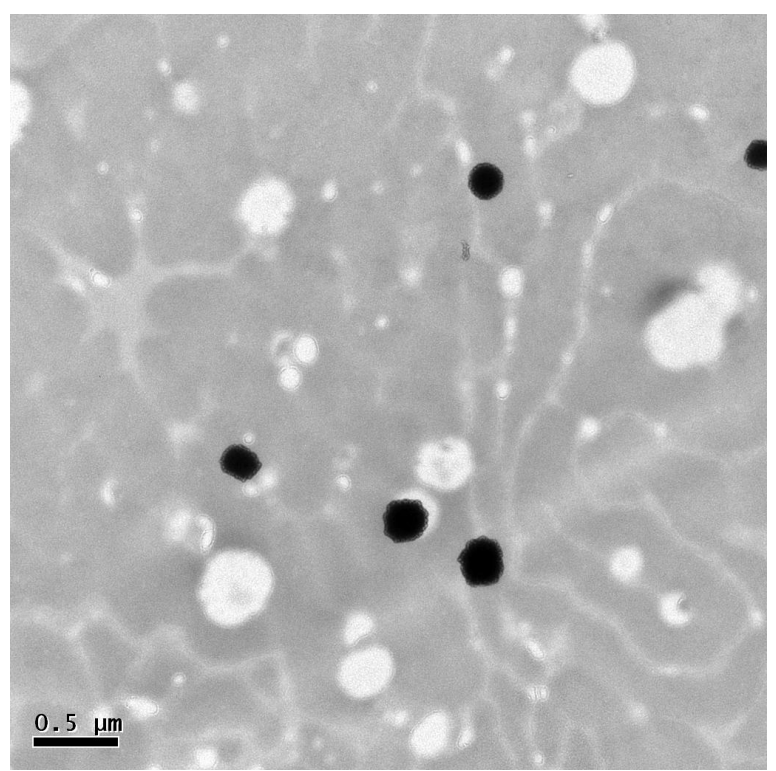

(d)

Figura 3.34 - Micrografias por TEM, de cortes transversais de $80 \mathrm{~nm}$ de espessura, de fibras capilares pertencentes aos grupos virgem [Figs. 3.34a e 3.34b] e controle [Figs. 3.34c e 3.34d], mostrando as cutículas [Figs. 3.34a e 3.34c] e evidenciando o córtex [Figs. 3.34b e 3.34d].

A partir da Fig. 3.34 observa-se que os grânulos de melanina são revelados e os corantes foram eficientes para obtenção do contraste na região cuticular. Em relação aos grânulos de melanina: para o grupo virgem, tal estrutura é visualizada como tons escuros e para o grupo controle, como tons claros, que devem ser orifícios, pois o processo de descoloração degrada os grânulos de melanina. Os orifícios são uma forma predominante de dano na cutícula e no córtex de fibras modificadas quimicamente [48,50]. O processo para a descoloração ocorre não selecionando exclusivamente os grânulos de melanina, mas 
também atua em outras subestruturas, como descrito na subseção 1.2.1. Nas Figs. 3.33 e 3.34, a partir da comparação das micrografias, também ficou evidente o dano sofrido pelo CMC. 


\section{Sumarização e conclusões}

No desenvolvimento de produtos cosméticos para fibras capilares, caracterizações macroscópicas de propriedades mecânicas possuem um papel de extrema importância. Com o intuito de compreender os danos causados por tratamentos ou agentes externos, bem como para avaliar a performance de ativos cosméticos, técnicas sofisticas têm sido utilizadas.

Este trabalho apresenta a utilização da Microscopia de Força Atômica (AFM) para a avaliação da eficácia de um ativo cosmético, na melhora das propriedades mecânicas de fibras capilares humanas. Para isso, foram caracterizadas fibras capilares humanas sem e com danos químicos (grupos virgem e controle, respectivamente), causados pelo processo de descoloração. Para as amostras danificadas quimicamente, foi aplicado o produto sem e com ativo cosmético (grupos placebo e ativo, respectivamente).

Para avaliação das fibras, foram realizadas caracterizações, principalmente, por AFM e Microscopia Eletrônica de Transmissão (TEM). Para isso, as fibras foram embebidas em resina, formando um bloco, e foram feitos cortes por ultramicrotomia, para observação de seções transversais por TEM. A superfície do bloco de resina obtido do corte, com seção transversal da fibra capilar exposta, foi utilizada para caracterização por AFM, no modo Force Volume (FV-AFM). A partir do registro de curvas de força a cada ponto da varredura, obtendo uma matriz 2D de curvas de força, associadas à imagem topográfica, obteve-se dados de força de adesão entre ponta e amostra $\left(F_{a d}\right)$, deformação máxima da amostra pela ponta e módulo de Young $(E)$. Assim, obteve-se um mapeamento multiparamétrico de propriedades mecânicas e topografia das amostras, abrangendo a seção transversal da fibra e a região circundante, preenchida pela resina, utilizada para embebimento das amostras. Os dados da resina, presentes em todos os mapeamentos, foram empregados como referência para o módulo de Young, o que garantiu uma comparação coerente entre os grupos das fibras, necessária para avaliação da eficácia do produto. Para comparação entre os dados dos grupos, avaliações estatísticas foram feitas, empregando o método paramétrico ANOVA (Analysis of Variance), considerando nível de significância $\alpha=0,5$ $(5 \%)$.

Foi encontrado que o grupo controle apresentou um decréscimo estatisticamente significante da média do logaritmo natural do módulo de Young $(\ln (E))$ em relação ao grupo virgem. Este resultado demonstra a degradação das fibras do grupo controle, causada pelo dano químico por descoloração (bleaching). Um mesmo resultado foi encontrado na análise feita por TEM, pois as micrografias de fibra do grupo controle apresentaram orifícios nas estruturas, o que são formas predominantes de dano na cutícula e no córtex 
de fibras modificadas quimicamente. Já o grupo ativo, apresentou um aumento da média do $\ln (E)$ em relação ao grupo controle e em relação ao grupo placebo, indicando que a aplicação do produto cosmético com ativo foi eficaz na melhora do módulo de Young das fibras danificadas quimicamente. Vale mencionar também que o módulo de Young foi, ainda, determinado pela técnica de caracterização macroscópica de propriedades mecânicas Tensile Tester, no qual não foi possível identificar diferenças estatisticamente significantes entre os grupos das fibras, evidenciando a vantagem da análise por FV-AFM. Também foi encontrado um decréscimo radial do $\ln (E)$ ao longo da seção transversal (iniciado na região externa (cutículas)) de fibra do grupo ativo, o que sugere uma variação radial da permeação do ativo, indicando que a melhora do módulo de Young se deve à presença do ativo. Este resultado é compatível com a análise realizada através de Confocal Raman Spectroscopy, obtido por outros autores, identificando variação radial na permeação do ativo.

Foi observado também uma queda de $\ln (E)$ com relação ao aumento da força de adesão entre ponta e amostra $F_{a d}$. Para isso, foi empregada análise do coeficiente de correlação de Pearson, na observação conjunta da força de adesão entre ponta e amostra $F_{a d}$ e de $\ln (E)$, onde foi encontrada uma prevalência de coeficientes negativos, correspondendo a um decréscimo do $\ln (E)$ para maiores $F_{a d}$. Este resultado corrobora com a presença de estruturas diferenciadas em propriedades adesivas, chamadas de Complexo da Membrana Celular (CMC: Cell Membrane Complex). As estruturas CMC possuem menores valores de módulo de Young em relação a outras estruturas das fibras devido ao seu baixo conteúdo de cistina, aminoácido que tem grande relevância nas propriedades mecânicas das fibras. Este resultado também pode ser explicado devido ao fato de estruturas compostas de componentes hidrofóbicos da fibra possuírem maior módulo de Young do que estruturas compostas por componentes hidrofílicos.

Na comparação entre grupos das médias de força de adesão entre ponta e superfície da amostra, foi observado: decréscimo estatisticamente significante da força de adesão do grupo controle em relação ao grupo virgem; aumento estatisticamente significante do grupo placebo em relação ao grupo controle e; decréscimo estatisticamente significante do grupo ativo em relação ao grupo placebo. Sabe-se que fibras danificadas quimicamente por processos de descoloração são mais hidrofílicas que fibras não danificadas, devido à perda de conteúdo lipídico e aumento de porosidade [23]. Assim, esperava-se, principalmente, aumento da força de adesão do grupo controle em relação ao grupo virgem, considerando que a força de interação dominante seria a força capilar e que a principal diferença entre as amostras são suas diferenças de hidrofilicidade. No entanto, a força capilar é dependente de diversos fatores, tornando a interação complexa. Sendo assim, constatou-se a necessidade de investigação adicional para elucidação de um ou mais fatores que seriam preponderantes para a diferença entre as médias das forças de adesão entre os grupos. 


\section{Perspectivas futuras}

\subsection{Microscopia Eletrônica de Transmissão}

Na preparação das amostras para TEM, foi observado que a maioria dos cortes ou regiões parciais dos mesmos estavam sob o suporte da malha (regiões não transparentes) do grid, o que impossibilita o imageamento. Portanto, utilizar grids com malhas (regiões vazadas) maiores recobertas com filmes ultrafinos para sustentação adequada dos cortes, seria favorável à obtenção de imagens panorâmicas. Já foi avaliado protocolo de recobrimento do grid por filme ultrafino de parlódio, que a partir de visualização por Microscopia Eletrônica de Varredura (SEM: Scanning Electron Microscopy), verificou-se que os filmes não apresentaram enrugamento e sustentaram os cortes [Fig 5.1]. A confirmação do sucesso do protocolo aplicado para a preparação das amostras teria de ser avaliado na própria observação por TEM.

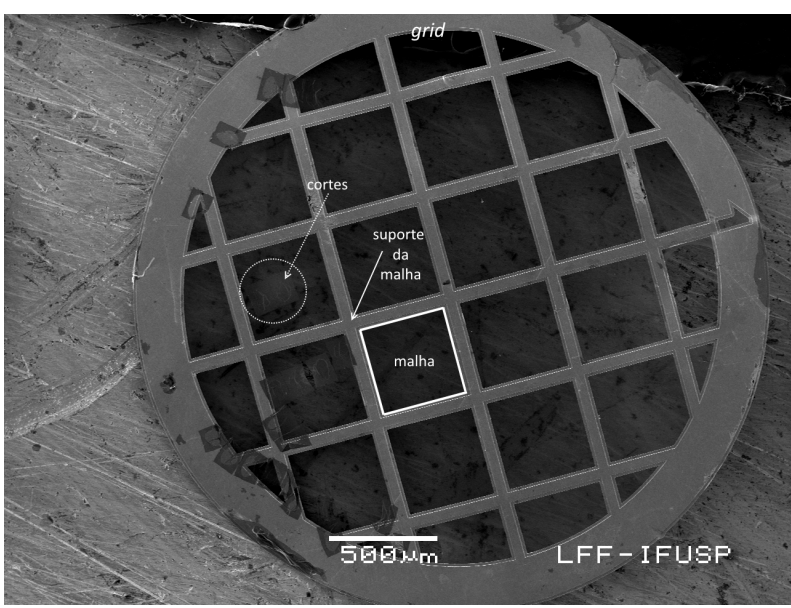

(a) Grid.

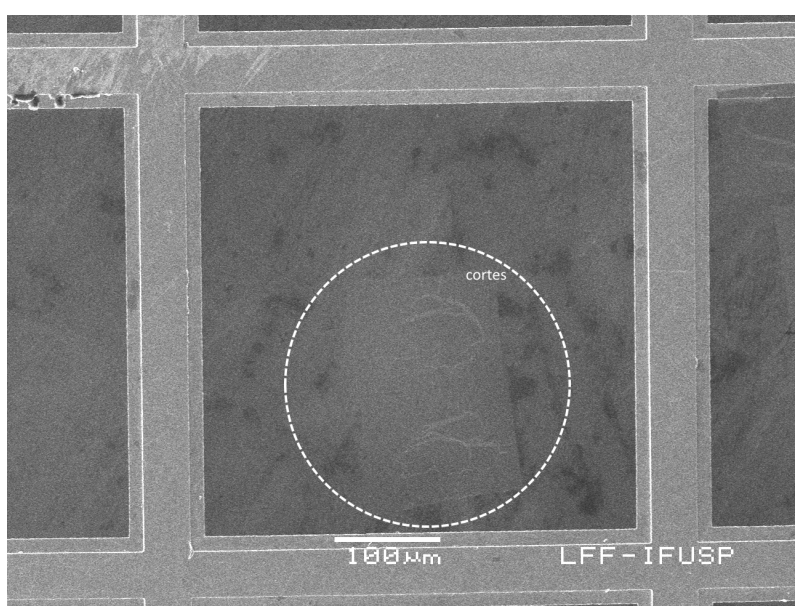

(b) Malha com filme de parlódio suportando os cortes.

Figura 5.1 - Micrografias por SEM de grid recoberto por filme de parlódio para suporte de cortes ultrafinos de seções transversais de fibras capilares humanas.

Após familiaridade com os protocolos para preparação das amostras para TEM, poderia ser realizada a completa preparação das amostras no LFF-IFUSP, inclusive a obtenção dos cortes, para posterior observação por TEM. É importante ressaltar que a preparação das amostras é fundamental para o sucesso da técnica e portanto seu domínio traria potencialidade para aplicações futuras no LFF-IFUSP.

Futuramente, os bulks provenientes dos cortes para TEM poderiam ser analisados por FV-AFM, permitindo uma correlação direta entre as imagens e mapas das propriedades mecânicas por FV-AFM e as micrografias por TEM. 


\subsection{Force Volume - AFM}

Uma abordagem interessante seria realizar o mapeamento das propriedades mecânicas com menor scan size, com intuito de distinguir diferentes subestruturas, a partir de comparação com micrografias por TEM, e identificar suas contribuições para o comportamento global da fibra em relação às propriedades mecânicas.

Pode ser relevante a análise por FV-AFM de fibras rompidas ou fibras que passaram por ensaios de fadiga. Seria interessante correlacionar a mudança nas propriedades mecânicas após transição na estrutura secundária da proteína queratina, da conformação $\alpha$-queratina $(\alpha$ - helix) para $\beta$-queratina $(\beta$ - sheet $)$, induzida por fadiga [66] ou rompimento da fibra .

Estudos sistemáticos de propriedades mecânicas utilizando AFM, identificando nanoestrututuras, seria relevante para o desenvolvimento de cosméticos. Um melhor entendimento dos danos químicos e físicos causados por agentes externos ou tratamentos elucidaria interações entre os componentes dos ativos cosméticos e subestruturas internas das fibras capilares. 


\section{Referências}

1 BHUSHAN, B.; LATORRE, C. Structural, nanomechanical, and nanotribological characterization of human hair using atomic force microscopy and nanoindentation. In: Springer Handbook of Nanotechnology. [S.l.]: Springer, 2010. p. 1055-1170. Citado 3 vezes nas páginas 6, 19 e 21 .

2 SYED, A. N. The Structure of Hair - Part 2: The Cortex. 2015. Disponível em: < http: //www.dralinsyed.com/blog/2015/4/5/the-structure-of-hair-part-the-cortex >. Citado 2 vezes nas páginas 6 e 20 .

3 CHANG, X. et al. Propulsion mechanisms and applications of multiphysics-driven micro-and nanomotors. Chinese Science Bulletin, Science China Press, v. 62, n. 2-3, p. 122-135, 2016. Citado 2 vezes nas páginas 6 e 25.

4 CAPPELLA, B.; DIETLER, G. Force-distance curves by atomic force microscopy. Surface science reports, Elsevier, v. 34, n. 1-3, p. 1-104, 1999. Citado 5 vezes nas páginas $6,25,26,28$ e 29.

5 CAMARGO, F. et al. 29th ifscc congress. In: New Technology to Obtain a Cosmetic Active with the Advantage of the Mechanical Properties of Fibroin for Hair Treatment. [S.l.: s.n.], 2016. Citado 2 vezes nas páginas 8 e 54.

6 HOUCK, M. M.; SIEGEL, J. A. Fundamentals of Forensic Science. San Diego, CA: Academic Press, 2015. Citado na página 18.

7 CUYPERS, E. et al. Consequences of decontamination procedures in forensic hair analysis using metal-assisted secondary ion mass spectrometry analysis. Analytical chemistry, ACS Publications, v. 88, n. 6, p. 3091-3097, 2016. Citado na página 18.

8 SMIJS, T.; GALLI, F.; ASTEN, A. van. Forensic potential of atomic force microscopy. Forensic Chemistry, Elsevier, v. 2, p. 93-104, 2016. Citado na página 18.

9 ABIHPEC - Associação Brasileira da Indústria de Higiene Pessoal, Perfumaria e Cosméticos. Caderno de Tendências - Higiene Pessoal, Perfumaria e Cosméticos \#2019-2020. 2018. Disponível em: <https://abihpec.org.br/publicacao/caderno-de-tendencias-2019-2020/>. Citado na página 18.

10 Research and Market. Hair Care Market - Growth, Trends, COVID-19 Impact, and Forecasts (2021 - 2026). 2021. Disponível em: <https://www.researchandmarkets.com/ reports/5119112/brazil-hair-care-market-growth-trends-and $>$. Citado na página 18.

11 Research and Market. Brazil Hair Care Market - Growth, Trends and Forecasts (2020 - 2025). 2020. Disponível em: <https://www.researchandmarkets.com/reports/5119112/ brazil-hair-care-market-growth-trends-and>. Citado na página 18.

12 Statista Inc. Size of the global hair care market from 2012 to 2025 (in billion U.S. dollars)*. 2020. Disponível em: <https://www.statista.com/statistics/254608/ global-hair-care-market-size/\#statisticContainer>. Citado na página 18. 
13 VELASCO, M. V. R. et al. Hair fiber characteristics and methods to evaluate hair physical and mechanical properties. Brazilian Journal of pharmaceutical sciences, SciELO Brasil, v. 45, n. 1, p. 153-162, 2009. Citado na página 18.

14 Momentive Performance Materials Inc. Marketing Bulletin: Silsoft* AX conditioning agent. 2012. Disponível em: < https://www.momentive.com/workarea/DownloadAsset. aspx $?$ id $=26385>$. Citado na página 18 .

15 MARCHIORETTO, S.; DOORN, S. v. Silicones Offer Multifunctional Solutions for Hair Protection. 2012. Disponível em: <https://consumer.dow.com/documents/en-us/ tech-art/27/27-13/27-1337-01-silicones-offer-multifunctional-solutions.pdf $>$. Citado na página 18.

16 HERRWERTH, S. et al. Silicone quaternium-22: New silicone technology for premium hair conditioning with additional benefits. SÖFW Journal, v. 135, n. 6, p. 11, 2009. Citado na página 18.

17 BOUILlON, C.; WILKINSON, J. The science of hair care. [S.l.]: CRC Press, 2005. Citado 3 vezes nas páginas 18, 20 e 68.

18 DIAS, M. F. R. G. Hair cosmetics: an overview. International journal of trichology, Medknow Publications, v. 7, n. 1, p. 2, 2015. Citado na página 18.

19 HALAL, J. Tricologia e a química cosmética capilar. São Paulo: Cengage Learning, 2016. Citado na página 19.

20 FEUGHELMAN, M. Mechanical properties and structure of alpha-keratin fibres: wool, human hair and related fibres. [S.1.]: UNSW press, 1997. Citado na página 19.

21 ROBBINS, C. R.; ROBBINS, C. R. Chemical and physical behavior of human hair. [S.l.]: Springer, 2012. v. 5. 50 p. Citado 3 vezes nas páginas 19, 20 e 64.

22 POPESCU, C.; HÖCKER, H. Hair - the most sophisticated biological composite material. Chemical Society Reviews, Royal Society of Chemistry, v. 36, n. 8, p. 1282-1291, 2007. Citado 2 vezes nas páginas 21 e 68.

23 LIMA, C. et al. Human hair: subtle change in the thioester groups dynamics observed by combining neutron scattering, x-ray diffraction and thermal analysis. The European Physical Journal Special Topics, Springer, v. 229, n. 17, p. 2825-2832, 2020. Citado 2 vezes nas páginas 21 e 77.

24 KREPLAK, L. et al. A new deformation model of hard $\alpha$-keratin fibers at the nanometer scale: implications for hard $\alpha$-keratin intermediate filament mechanical properties. Biophysical journal, Elsevier, v. 82, n. 4, p. 2265-2274, 2002. Citado na página 21.

25 CLOETE, E. et al. Systems approach to human hair fibers: interdependence between physical, mechanical, biochemical and geometric properties of natural healthy hair. Frontiers in physiology, Frontiers, v. 10, p. 112, 2019. Citado na página 21.

26 BINNIG, G.; QUATE, C. F.; GERBER, C. Atomic force microscope. Physical review letters, APS, v. 56, n. 9, p. 930, 1986. Citado na página 21. 
27 DUFRENEE, Y. F. et al. Imaging modes of atomic force microscopy for application in molecular and cell biology. Nature Nanotechnology, Nature Research, v. 12, n. 4, p. 295-307, 2017. Citado na página 21.

28 SWIFT, J. A.; SMITH, J. R. Atomic force microscopy of human hair. Scanning, Wiley Online Library, v. 22, n. 5, p. 310-318, 2000. Citado na página 21.

29 MAXWELL, J.; HUSON, M. Scanning probe microscopy examination of the surface properties of keratin fibres. Micron, Elsevier, v. 36, n. 2, p. 127-136, 2005. Citado na página 21.

30 BHUSHAN, B.; CHEN, N. Afm studies of environmental effects on nanomechanical properties and cellular structure of human hair. Ultramicroscopy, Elsevier, v. 106, n. 8-9, p. 755-764, 2006. Citado na página 21.

31 SESHADRI, I. P.; BHUSHAN, B. In situ tensile deformation characterization of human hair with atomic force microscopy. Acta Materialia, Elsevier, v. 56, n. 4, p. 774-781, 2008. Citado na página 21.

32 CLIFFORD, C. A. et al. Nanomechanical measurements of hair as an example of micro-fibre analysis using atomic force microscopy nanoindentation. Ultramicroscopy, Elsevier, v. 114, p. 38-45, 2012. Citado na página 21.

33 HAY, J.; PHARR, G. Instrumented indentation testing. In: ASM Handbook Mechanical Testing and Evaluation. [S.1.]: ASM International, 2000. v. 08. Citado na página 21.

34 PARBHU, A. N.; BRYSON, W. G.; LAL, R. Disulfide bonds in the outer layer of keratin fibers confer higher mechanical rigidity: correlative nano-indentation and elasticity measurement with an afm. Biochemistry, ACS Publications, v. 38, n. 36, p. 11755-11761, 1999. Citado na página 21.

35 KITANO, H. et al. Young's modulus mapping on hair cross-section by atomic force microscopy. Composite Interfaces, Taylor \& Francis, v. 16, n. 1, p. 1-12, 2009. Citado 2 vezes nas páginas 21 e 58.

36 WIESENDANGER, R. Scanning probe microscopy and spectroscopy: methods and applications. Cambridge: Cambridge University Press, 1994. Citado na página 23.

37 SALVADORI, M. C. Apostila da $1^{a}$ Aula do curso PGF5205 - Microscopia de Força Atômica e Tunelamento. São Paulo, 2013. Disponível em: <http://fap.if.usp.br/ lff/Lotus/ PGF5205/Roteiros\%20e\%20Instrucoes/Teoria/Aula_1.pdf $>$. Acesso em: 24 de agosto de 2017. Citado 2 vezes nas páginas 23 e 32.

38 Bruker Corporation. Nanoscope Software 8.15 - User Guide. Santa Barbara, CA, 2011. Disponível em: < http://www.nanophys.kth.se/nanophys/facilities/nflafm/icon/ bruker-help/Content/SoftwareGuide/NanoScope815CoverPage.htm>. Citado na página 25 .

39 RADMACHER, M. Studying the mechanics of cellular processes by atomic force microscopy. Methods in cell biology, Elsevier, v. 83, p. 347-372, 2007. Citado na página 28.

40 HERTZ, H. Ueber die berührung fester elastischer körper. Für die reine und angewandte Mathematik, v. 92, p. 156-171, 1881. Citado na página 28. 
41 SNEDDON, I. N. The relation between load and penetration in the axisymmetric boussinesq problem for a punch of arbitrary profile. International journal of engineering science, Elsevier, v. 3, n. 1, p. 47-57, 1965. Citado na página 28.

42 KONTOMARIS, S.; MALAMOU, A. Hertz model or oliver \& pharr analysis? tutorial regarding afm nanoindentation experiments on biological samples. Materials Research Express, IOP Publishing, v. 7, n. 3, p. 033001, 2020. Citado na página 28.

43 BUTT, H.-J.; CAPPELLA, B.; KAPPL, M. Force measurements with the atomic force microscope: Technique, interpretation and applications. Surface science reports, Elsevier, v. 59, n. 1-6, p. 1-152, 2005. Citado 2 vezes nas páginas 30 e 42.

44 OHLER, B. Practical advice on the determination of cantilever spring constants. Bruker Application Note\# AN94, v. 1, 2007. Citado 2 vezes nas páginas 31 e 32.

45 SADER, J. E.; CHON, J. W.; MULVANEY, P. Calibration of rectangular atomic force microscope cantilevers. Review of Scientific Instruments, AIP, v. 70, n. 10, p. 3967-3969, 1999. Citado 2 vezes nas páginas 31 e 42.

46 SADER, J. E. Atomic Force Microscope Cantilevers (Calibration method of Sader). 2017. Disponível em: <http://www.ampc.ms.unimelb.edu.au/afm/calibration.html>. Citado 3 vezes nas páginas 31, 34 e 42.

47 WILliAmS, D. B.; CARTER, C. B. Transmission Electron Microscopy: A Textbook for Materials Science. New York, NY: Springer Science + Business Media, 2009. Citado na página 35.

48 HARLAND, D. et al. Transmission electron microscopy staining methods for the cortex of human hair: a modified osmium method and comparison with other stains. Journal of microscopy, Wiley Online Library, v. 243, n. 2, p. 184-196, 2011. Citado 2 vezes nas páginas 37 e 74 .

49 AHN, H. J.; LEE, W.-S. An ultrastuctural study of hair fiber damage and restoration following treatment with permanent hair dye. International journal of dermatology, Wiley Online Library, v. 41, n. 2, p. 88-92, 2002. Citado na página 37.

50 KIM, M.-M. Effect of procyandin oligomers on oxidative hair damage. Skin Research and Technology, Wiley Online Library, v. 17, n. 1, p. 108-118, 2011. Citado 2 vezes nas páginas 37 e 74.

51 STANIĆ, V. et al. Local structure of human hair spatially resolved by sub-micron x-ray beam. Scientific reports, Nature Publishing Group, v. 5, p. 17347, 2015. Citado na página 37.

52 THIBAUT, S. et al. Human hair keratin network and curvature. International journal of dermatology, Wiley Online Library, v. 46, n. s1, p. 7-10, 2007. Citado na página 37.

53 PATRIARCHE, G. et al. Characteristics of hgs nanoparticles formed in hair by a chemical reaction. Philosophical Magazine, Taylor \& Francis, v. 93, n. 1-3, p. 137-151, 2013. Citado na página 37.

54 WAGNER, R. de C. C. et al. Electron microscopic observations of human hair medulla. Journal of microscopy, Wiley Online Library, v. 226, n. 1, p. 54-63, 2007. Citado na página 37. 
55 SATO, S. et al. Reduction and block staining of human hair shafts and insect cuticles by ammonium thioglycolate to enhance transmission electron microscopic observations. Journal of Cosmetics, Dermatological Sciences and Applications, Scientific Research Publishing, v. 3, n. 02, p. 157, 2013. Citado na página 37.

56 ORWIN, D. F.; WOODS, J. L.; RANFORD, S. L. Cortical cell types and their distribution in wool fibres. Australian journal of biological sciences, CSIRO, v. 37, n. 4, p. 237-256, 1984. Citado na página 37.

57 NELSON, W.; WOODS, J. Short technical note. Journal of Microscopy, Wiley Online Library, v. 181, n. 1, p. 88-90, 1996. Citado na página 37.

58 NEčAS, D.; KLAPETEK, P. Gwyddion: an open-source software for SPM data analysis. Central European Journal of Physics, Versita, co-published with Springer-Verlag GmbH, v. 10, p. 181-188, 2012. ISSN 1895-1082. Citado na página 41.

59 Department of Nanometrology, Czech Metrology Institute. Gwyddion - Free SPM data analysis software. 2021. Disponível em: <http://gwyddion.net/>. Citado na página 41 .

60 VUOLO, J. H. Fundamentos da Teoria de Erros. São Paulo: Edgard Blucher, 1996. Citado na página 41.

61 Bruker Corporation. Detailed Force Volume Procedure. Santa Barbara, CA, 2011. Disponível em: <http://www.nanophys.kth.se/nanophys/facilities/nfl/afm/icon/bruker-help/ Content/ForceVolume/DetailedForceVolProcedure.htm>. Citado na página 43.

62 HERMANOWICZ, P. et al. Atomicj: an open source software for analysis of force curves. Review of Scientific Instruments, AIP, v. 85, n. 6, p. 063703, 2014. Citado na página 43.

63 HU, Z. et al. Measurement of young's modulus and poisson's ratio of human hair using optical techniques. In: INTERNATIONAL SOCIETY FOR OPTICS AND PHOTONICS. Fourth International Conference on Experimental Mechanics. [S.1.], 2010. v. 7522, p. 75222Q. Citado na página 43.

64 LIU, X.; CHEN, G. S. Friction Dynamics: Principles and Applications. [S.1.]: Woodhead Publishing, 2016. Citado na página 58.

65 HARRISON, A. J.; CORTI, D. S.; BEAUDOIN, S. P. Capillary forces in nanoparticle adhesion: a review of afm methods. Particulate Science and Technology, Taylor \& Francis, v. 33, n. 5, p. 526-538, 2015. Citado 2 vezes nas páginas 58 e 68.

66 YU, Y. et al. Structure and mechanical behavior of human hair. Materials Science and Engineering: C, Elsevier, v. 73, p. 152-163, 2017. Citado na página 79.

67 ROSS, S. M. Introduction to probability and statistics for engineers and scientists. [S.l.]: Elsevier, 2004. Citado na página 95.

68 ELLIS, P. D. The essential guide to effect sizes: Statistical power, meta-analysis, and the interpretation of research results. [S.1.]: Cambridge university press, 2010. Citado na página 96. 
69 MANN, P. S. Introductory statistics. [S.1.]: John Wiley \& Sons, 2010. Citado na página 96.

70 LEVINE, D. M.; STEPHAN, D. F.; SZABAT, K. A. Statistics for managers using Microsoft Excel. [S.1.]: Pearson Education, 2008. Citado na página 96. 
Apêndices 


\section{APÊNDICE A - Histogramas}

Nas Figs. A.1, A.2 e A.3 são apresentados os histogramas de todos os dados, reunidos por grupos de tratamento das fibras, sendo cada histograma elaborado a partir de dados de uma única fibra. 

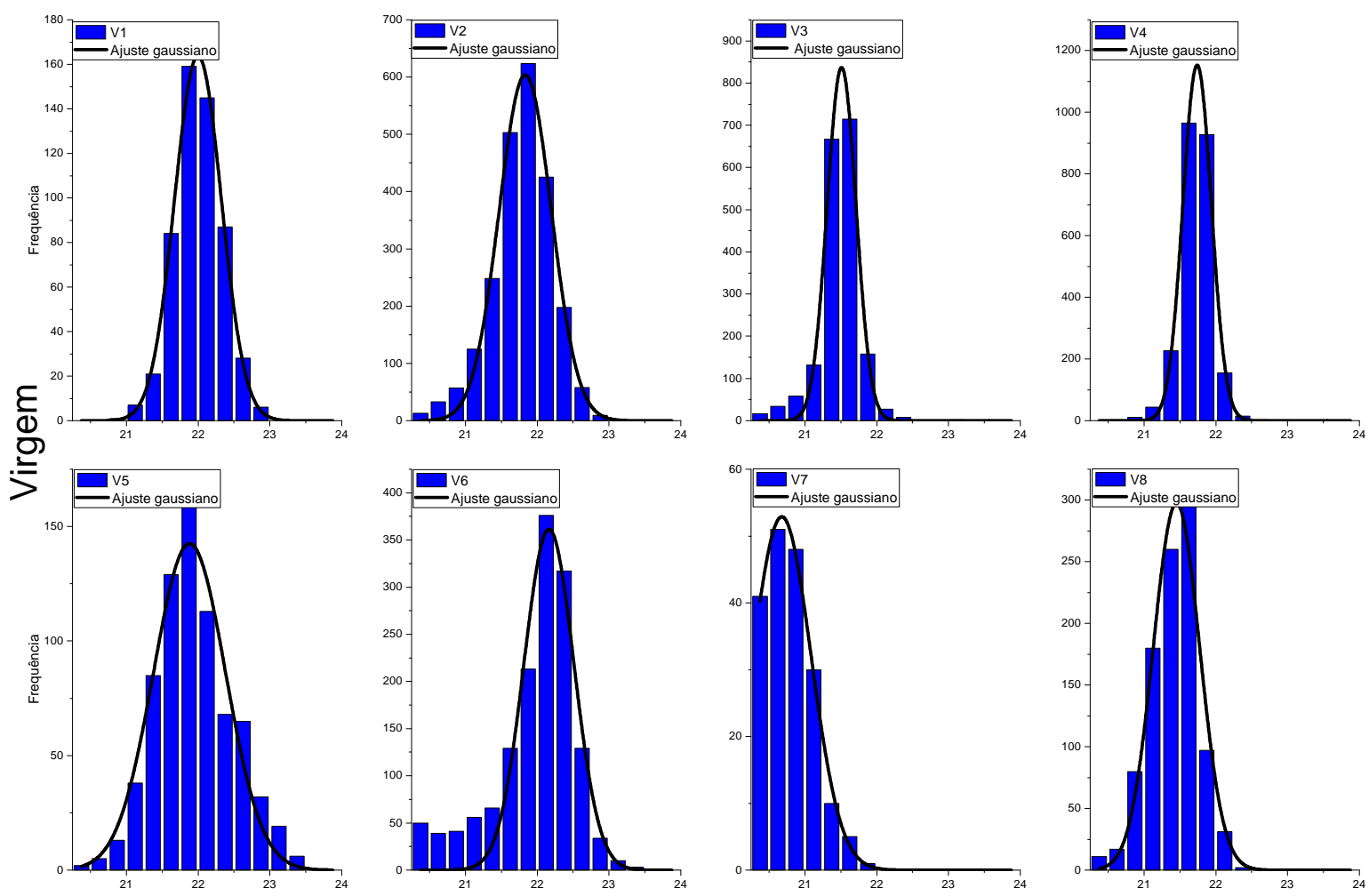

(a) Grupo: Virgem
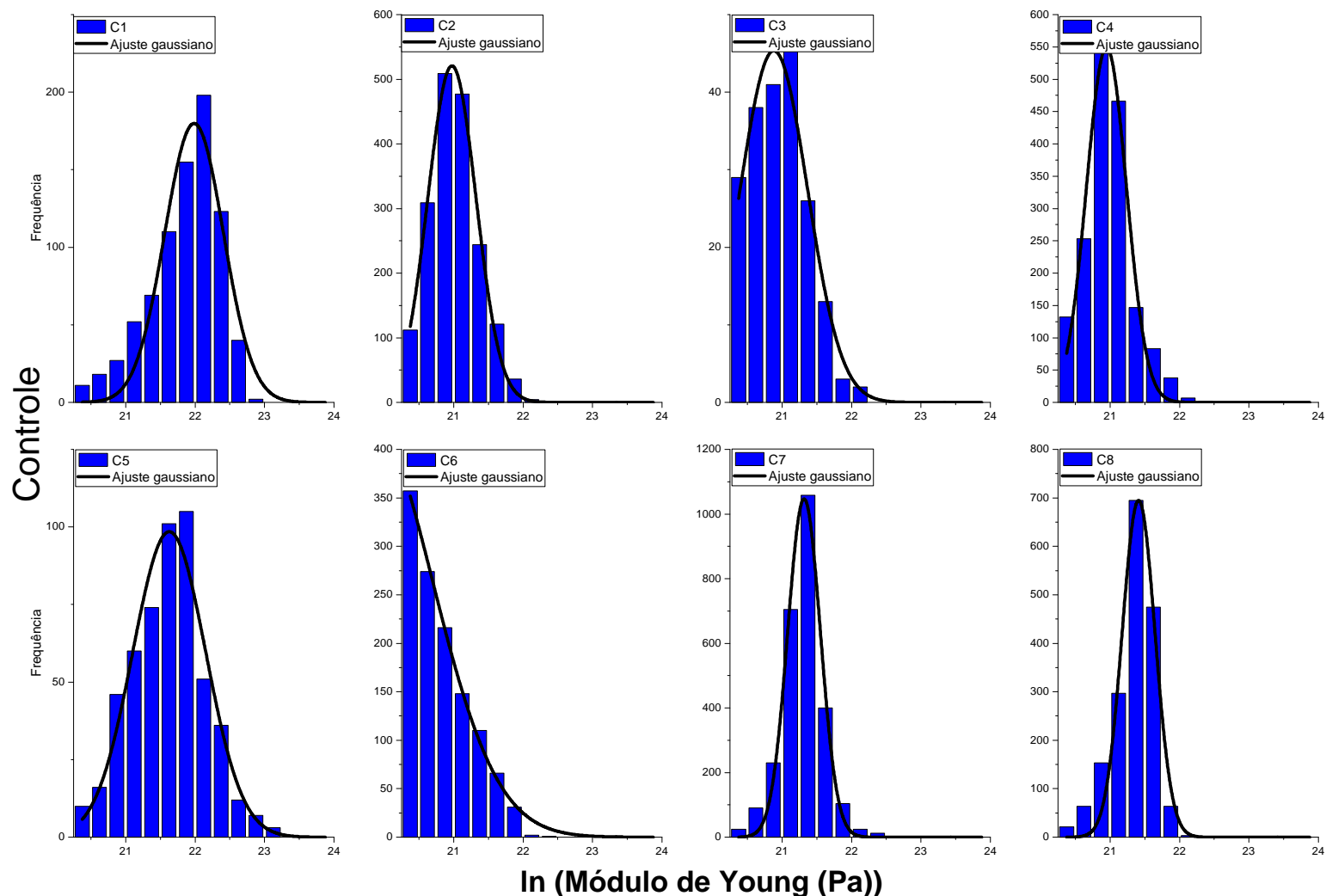

(b) Grupo: Controle 

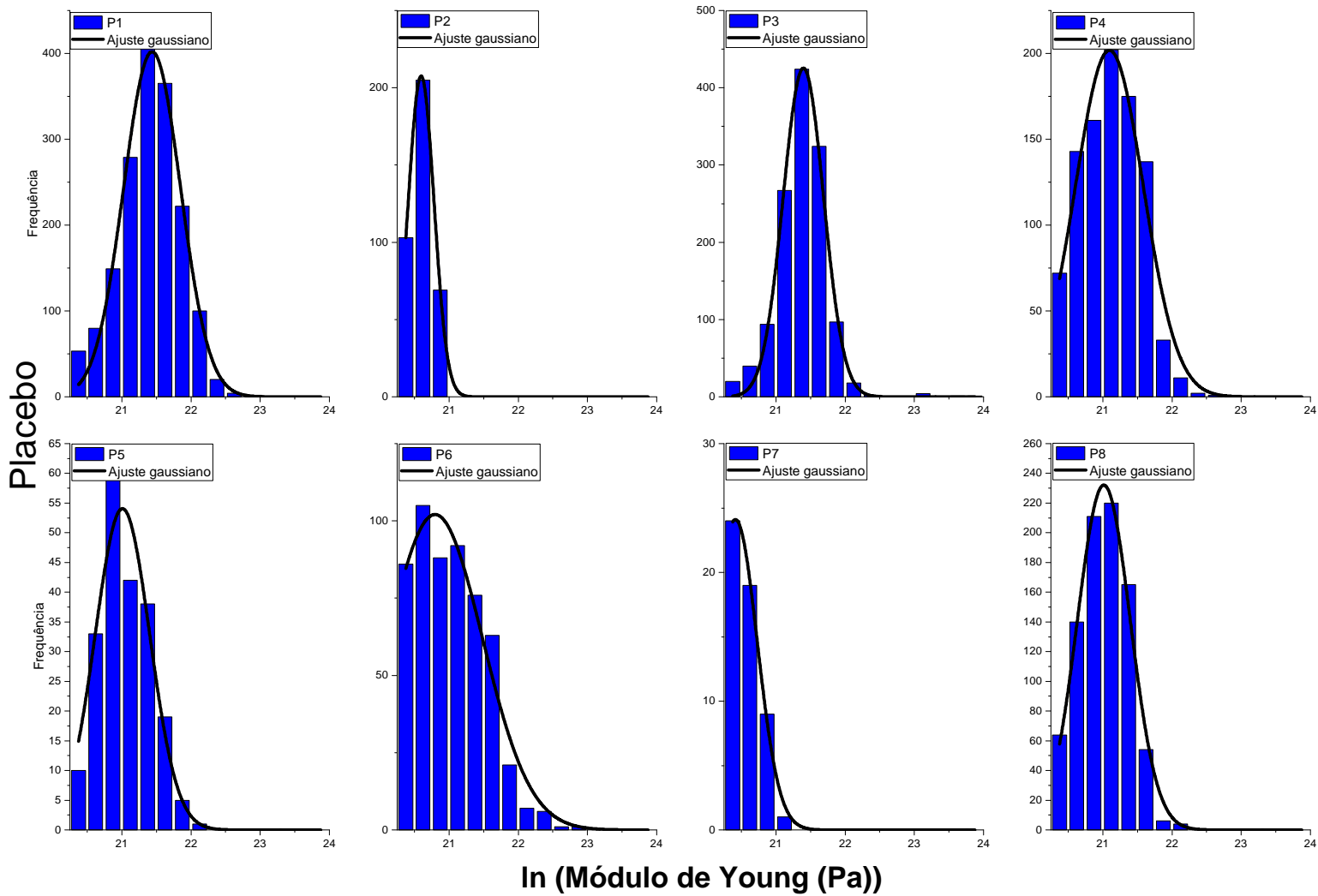

(c) Grupo: Placebo
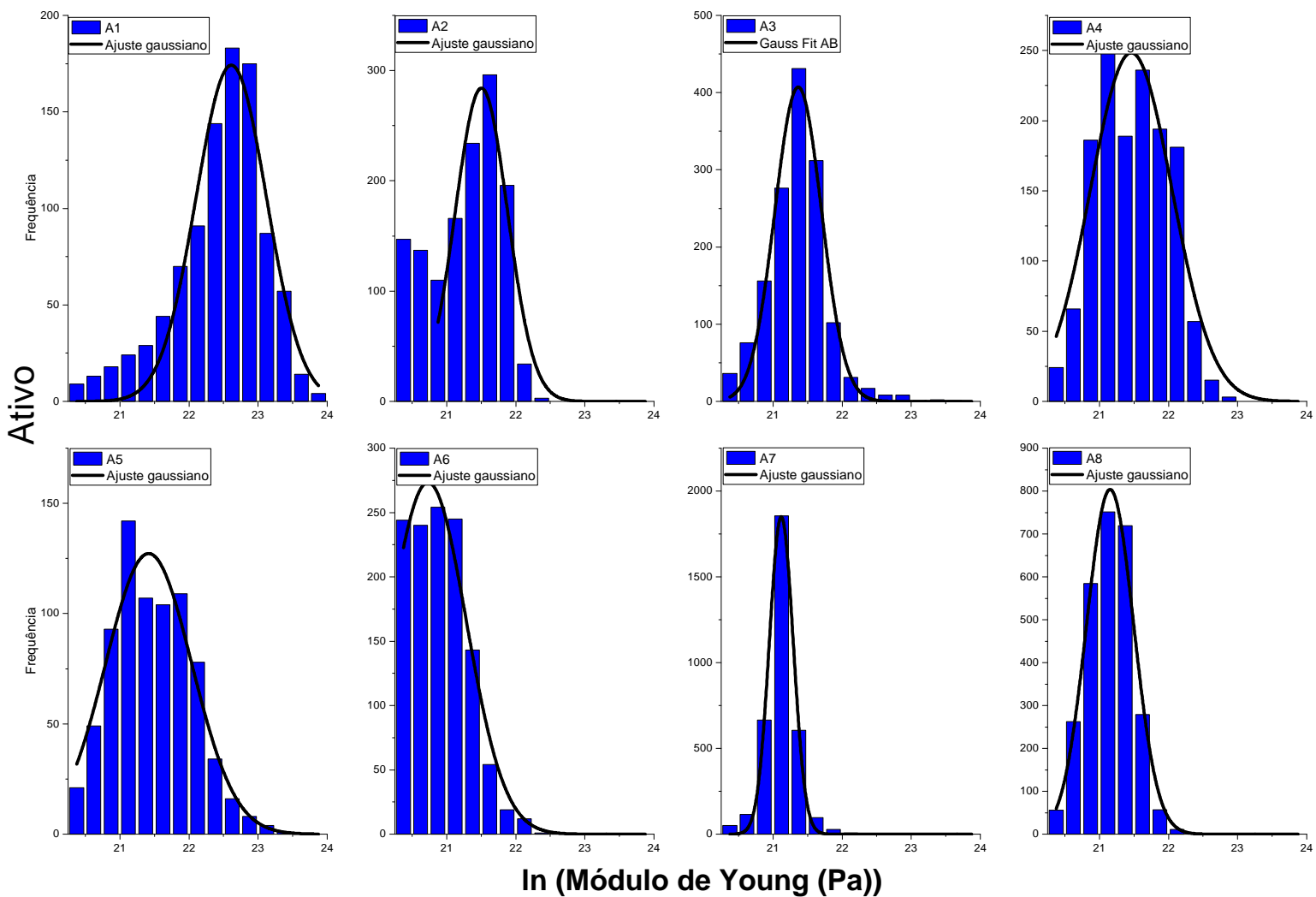

(d) Grupo: Ativo

Figura A.1 - Histogramas dos dados do logaritmo natural do módulo de Young, para os valores correspondentes às fibras pertencentes às mechas dos grupos: virgem [Fig. A.1a], controle [Fig. A.1b], placebo [Fig. A.1c] e ativo [Fig. A.1d]. 

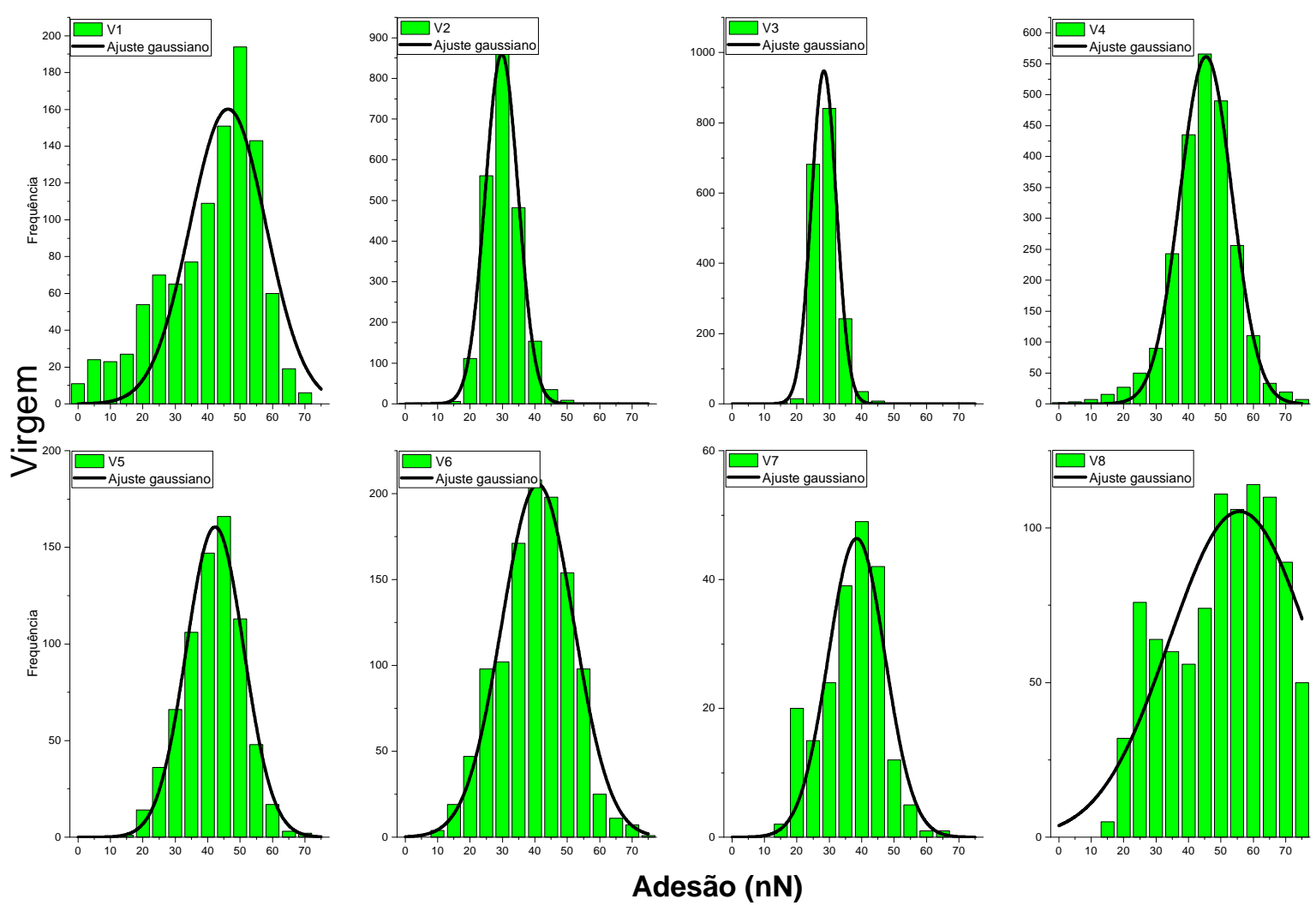

(a) Grupo: Virgem
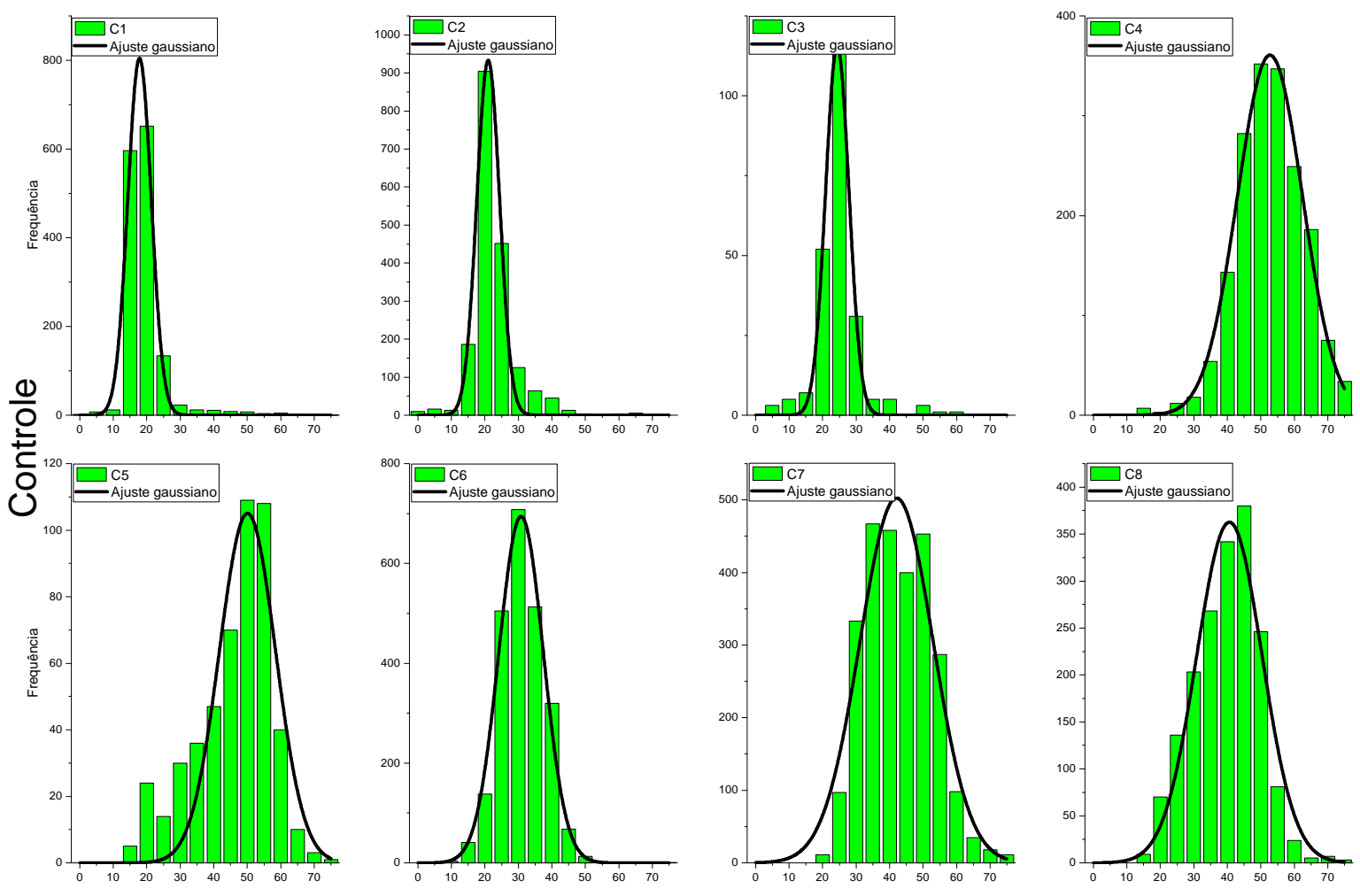

Adesão (nN)

(b) Grupo: Controle 

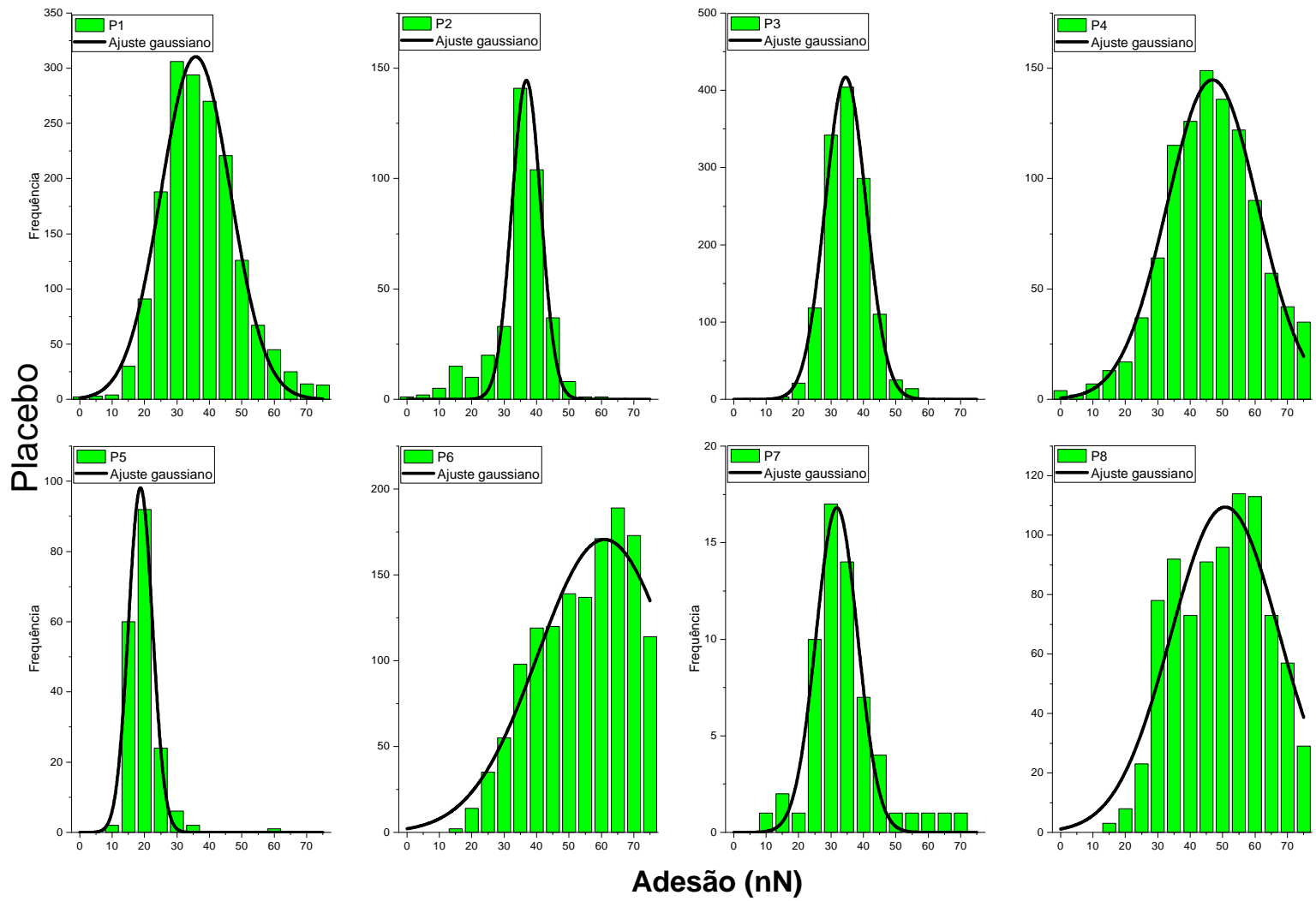

(c) Grupo: Placebo
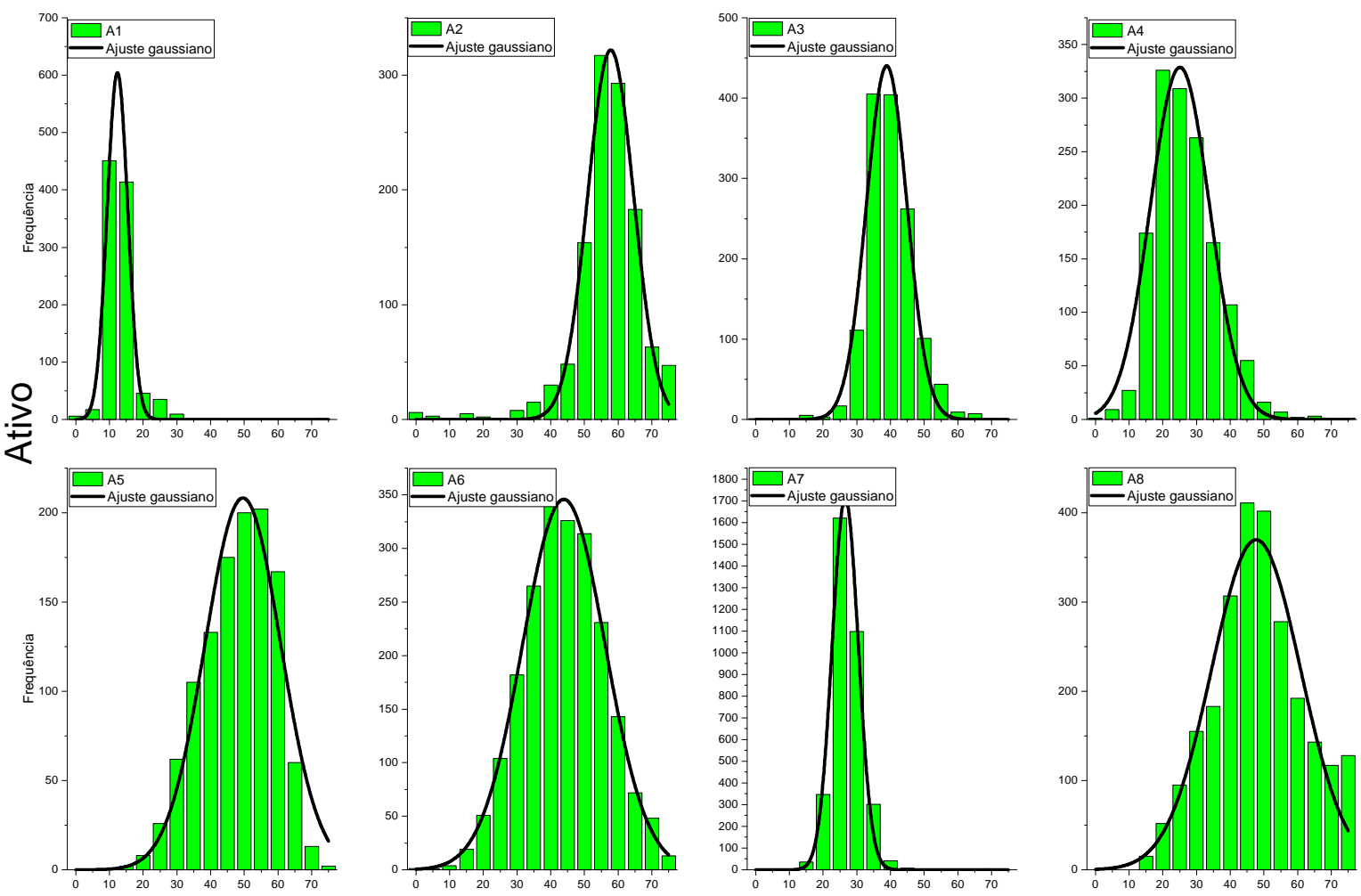

(d) Grupo: Ativo

Figura A.2 - Histogramas dos dados da adesão entre ponta e amostra, para os valores correspondentes às fibras pertencentes às mechas dos grupos: virgem [Fig. A.2a], controle [Fig. A.2b], placebo [Fig. A.2c] e ativo [Fig. A.2d]. 

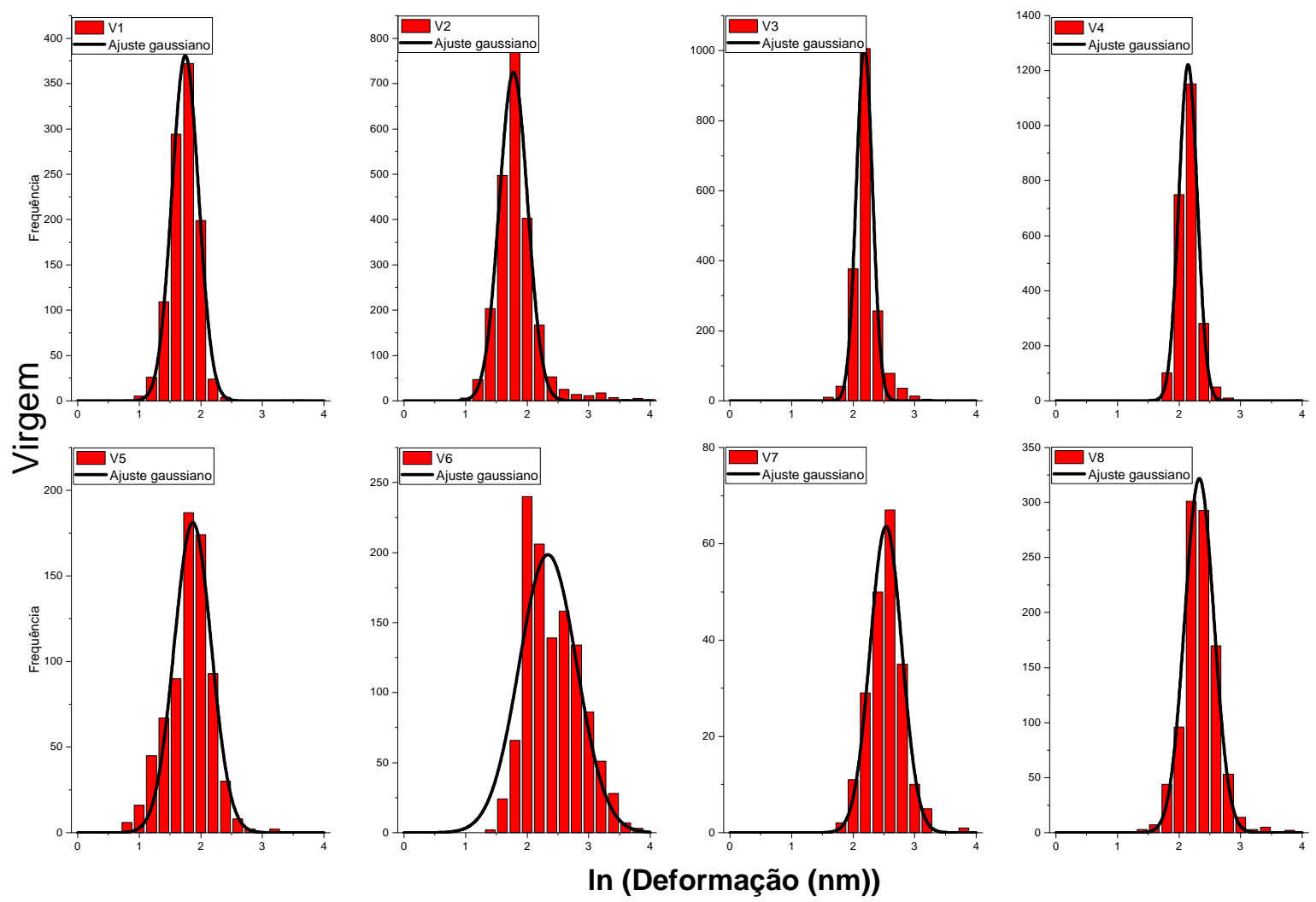

(a) Grupo: Virgem
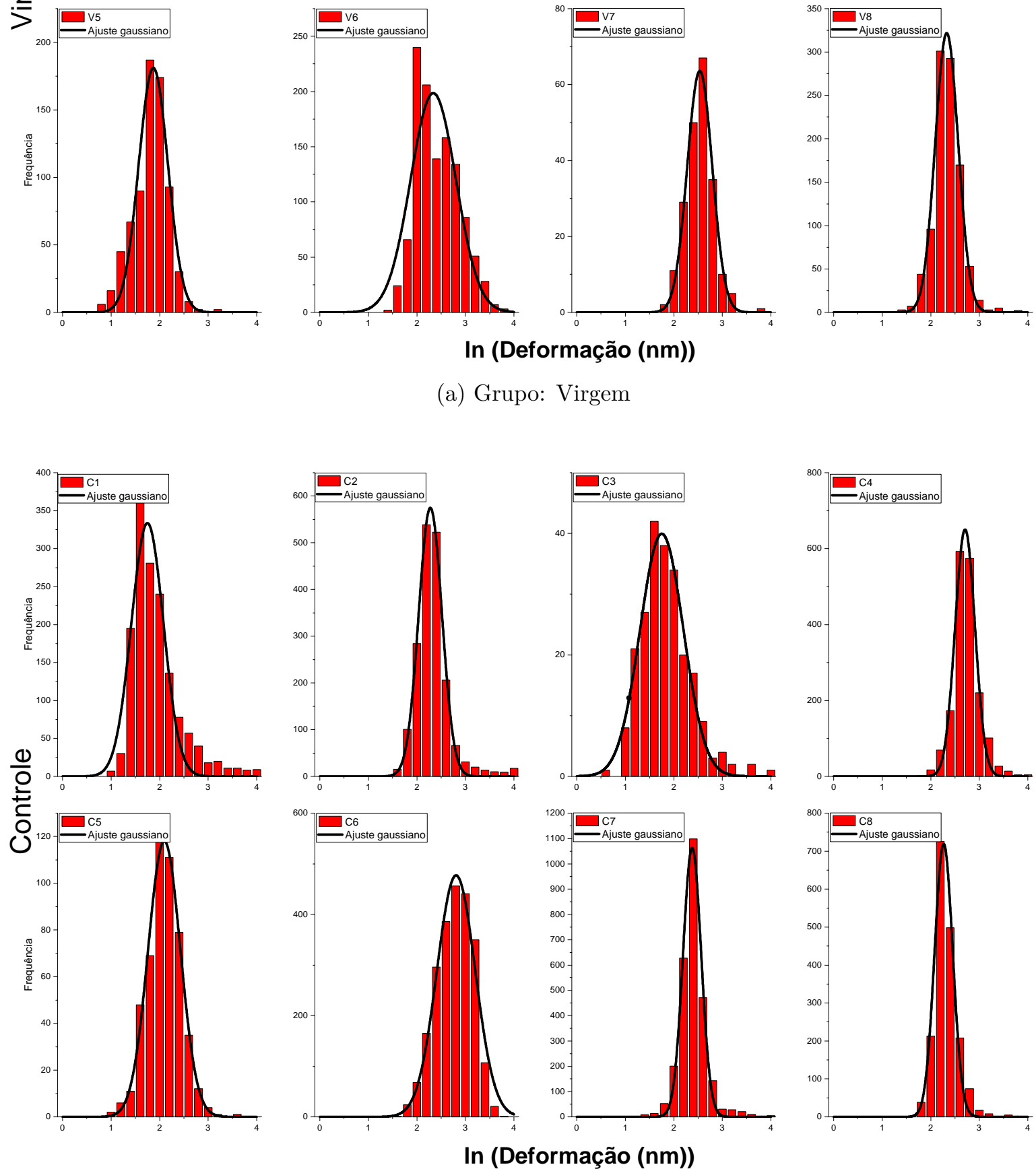

(b) Grupo: Controle

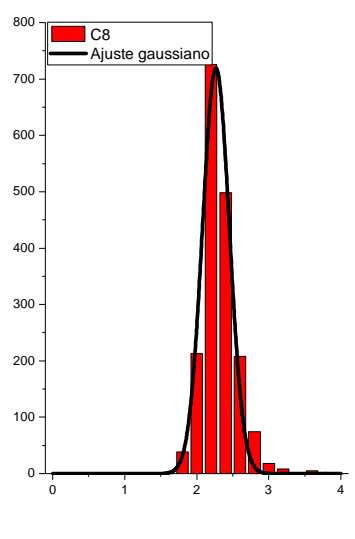



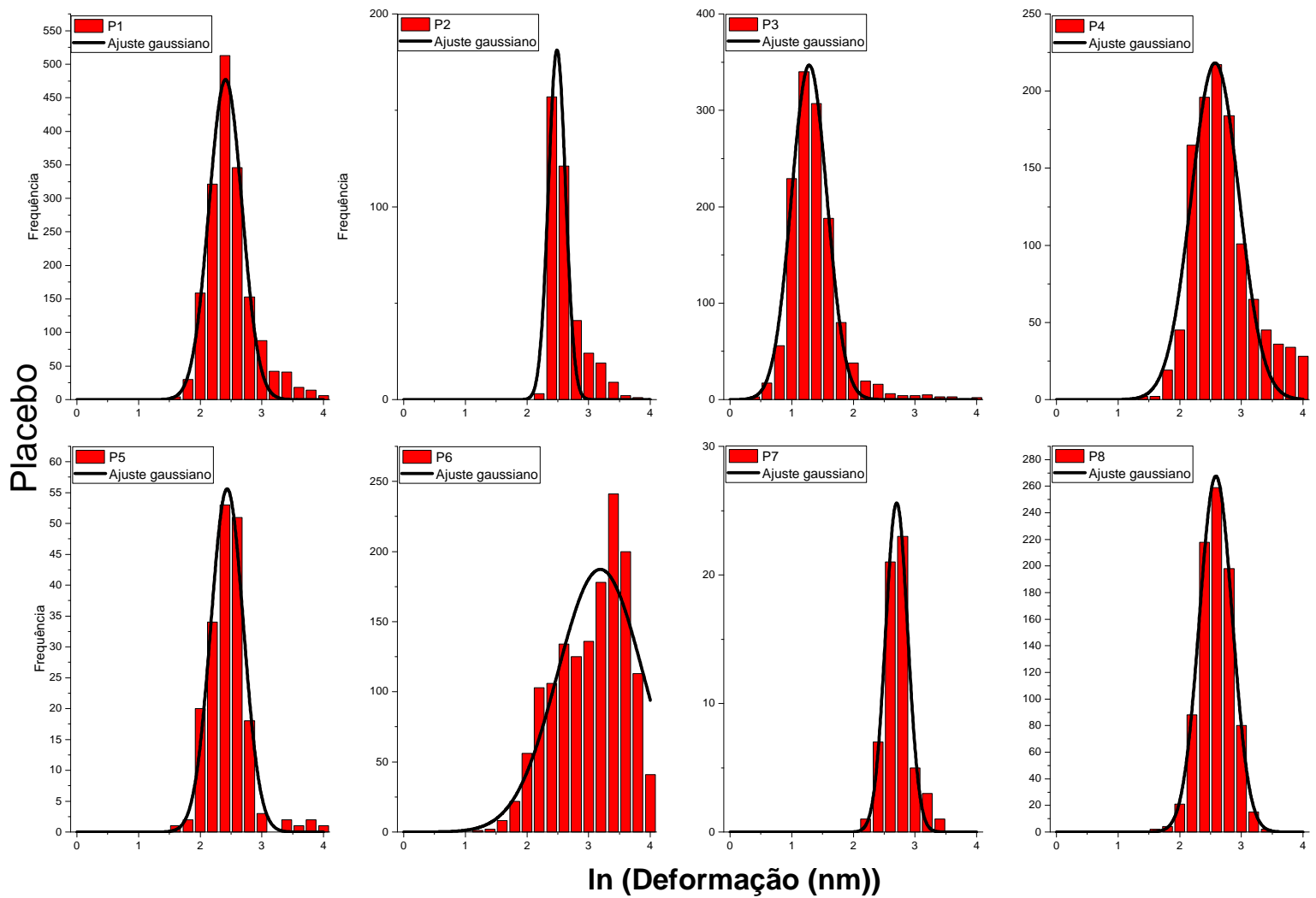

(c) Grupo: Placebo
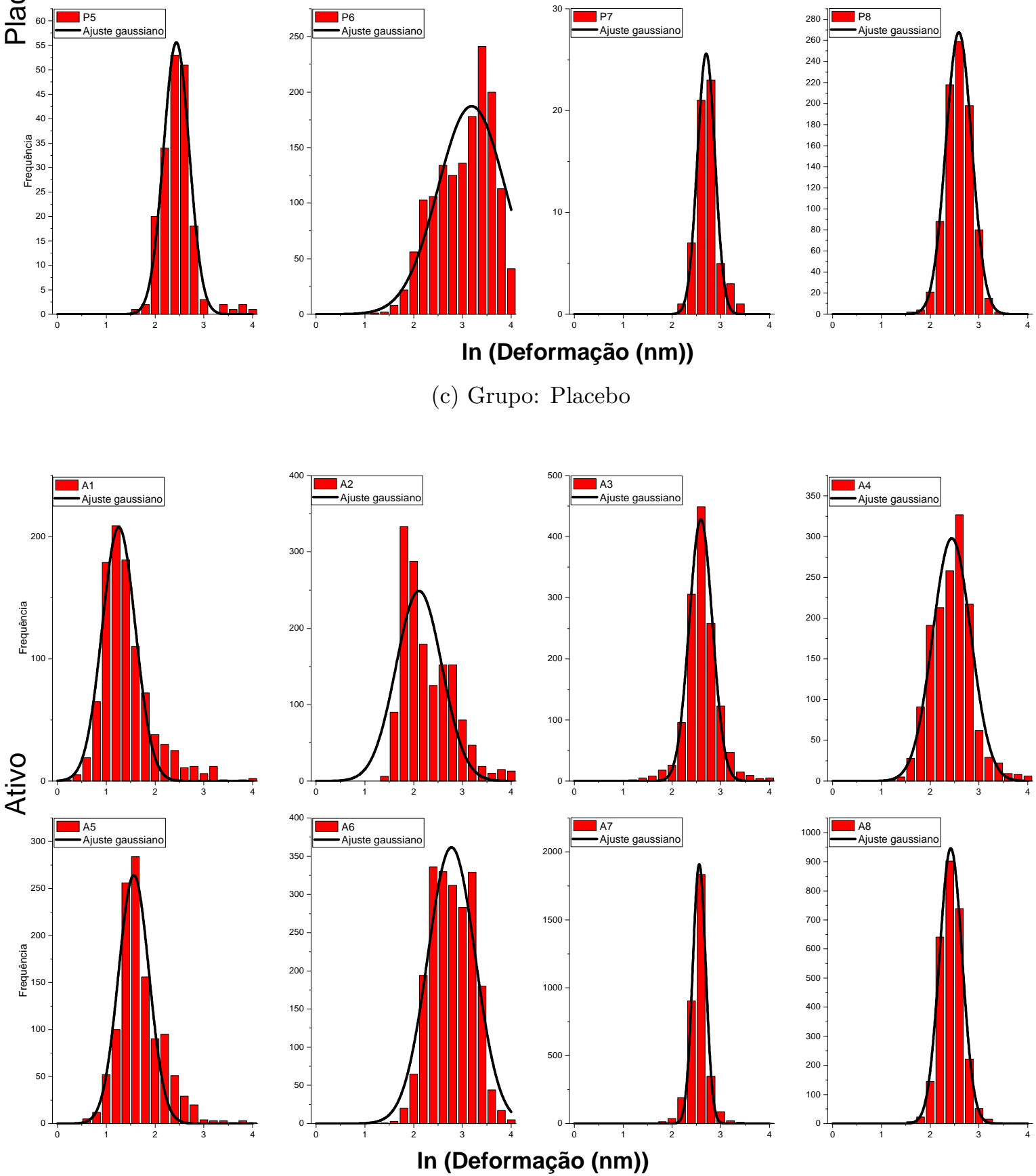

(d) Grupo: Ativo

Figura A.3 - Histogramas dos dados do logaritmo natural da deformação máxima da amostra pela indentação da ponta, para os valores correspondentes às fibras pertencentes às mechas dos grupos: virgem [Fig. A.3a], controle [Fig. A.3b], placebo [Fig. A.3c] e ativo [Fig. A.3d]. 
Anexos 


\section{ANEXO A - Métricas estatísticas}

\section{A.1 Diagrama de caixa (box plot)}

Um diagrama de caixa (box plot) [67] é uma ferramenta gráfica para representar algumas das estatísticas de um conjunto de dados. Os elementos comumente representados são indicados na Fig. A.1.

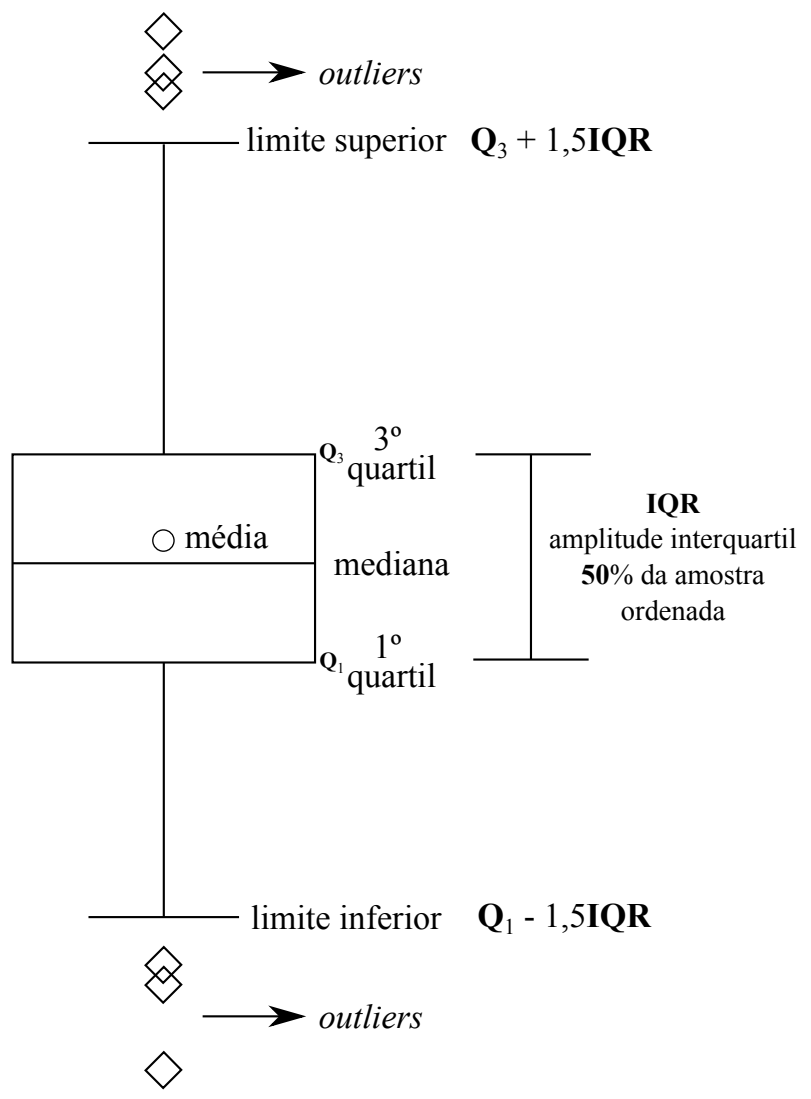

Figura A.1 - Desenho esquemático do diagrama de caixa (box plot), indicando as estatísticas representadas de um conjunto de dados.

\section{A.2 Coeficiente de determinação $R^{2}$}

O coeficiente de determinação $R^{2}$, o qual pode adotar valores entre 0 e 1 , é utilizado para avaliar a dispersão dos dados em relação a uma função específica, qualificando a regressão linear. Quanto mais próximo o $R^{2}$ estiver do valor 1, mais próximo estão os dados da função específica.

$$
R^{2}=1-\frac{\sum_{i}\left(y_{i}-f_{i}\right)^{2}}{\sum_{i}\left(y_{i}-\bar{y}\right)^{2}}
$$


onde $y_{i}$ são os valores da variável $y$ de um conjunto de dados, associados aos valores ajustados $f_{i}$, e $\bar{y}$ a média dos valores da variável $y$.

\section{A.3 Coeficiente de correlação de Pearson $r$}

O coeficiente de correlação de Pearson $r$ (Pearson product moment correlation coefficient) [68] [Eq. A.2] quantifica a força e a direção (negativa ou positiva) entre duas variáveis. O coeficiente de correlação $r$, o qual pode adotar valores entre -1 e 1, é uma medida numérica da força da relação linear entre duas variáveis de interesse. Quanto mais próximo o $|r|$ estiver do valor 1, mais forte é o grau de dependência linear. Valores positivos de $r$ representam uma dependência linear positiva e valores negativos, uma dependência linear negativa.

$$
r=\frac{\sum\left(x_{i}-\bar{x}\right)\left(y_{i}-\bar{y}\right)}{\sqrt{\sum\left(x_{i}-\bar{x}\right)^{2} \sum\left(y_{i}-\bar{y}\right)^{2}}}
$$

onde $x_{i}$ e $y_{i}$ são os valores da variável $x$ e $y$ em um conjunto de dados, respectivamente; e $\bar{x}$ e $\bar{y}$ são as médias dos valores da variável $x$ e $y$, respectivamente.

\section{A.4 Analysis of Variance (ANOVA)}

Para verificar se houve diferença estatisticamente significante entre as médias dos diferentes grupos, foi utilizado o teste paramétrico one-way ANOVA (Analysis of Variance) [69,70], adequado para a comparação de mais de dois grupos em relação à uma variável (fator), o qual é uma extensão do teste $t$, adequado para comparação entre dois grupos.

Para realização do teste, enuncia-se duas hipóteses: a principal, chamada de hipótese nula $H_{0}$, e uma hipótese alternativa $H_{1}$, que deve ser necessariamente verdadeira caso $H_{0}$ seja falsa. A metodologia do teste consiste em determinar a possibilidade de que a hipótese nula seja verdadeira, ao se considerar as informações coletadas em uma amostra. Para rejeitar $H_{0}$, é escolhido o nível de significância $\alpha$, que representa a probabilidade de rejeitar $H_{0}$ mesmo sendo verdadeira. Assim, o nível de confiança, $(1-\alpha)$, corresponde à probabilidade de que não seja rejeitada $H_{0}$ quando é efetivamente verdadeira.

Para o Teste de Hipóteses, enuncia-se:

- $H_{0}: \overline{\mu_{1}}=\overline{\mu_{2}}=\overline{\mu_{3}}=\overline{\mu_{4}} \ldots$

- $H_{1}$ : ao menos uma das médias é diferente das demais

onde $\overline{\mu_{n}}$ é a média da n-ésima amostra. 
Para avaliação das hipóteses, a variância total da população $\sigma^{2}$ é decomposta em duas variâncias: variância entre grupos e variância dentro dos grupos. A fim de determinar a rejeição ou não de $H_{0}$, é calculado o valor da estatística do teste - valor $F$ - e comparado ao valor crítico. Para testar as hipóteses, foi utilizado um valor tradicional de $\alpha=0,05$, o que significa que resultados que possuam $5 \%$, ou menos, de chance de serem obtidos, atestam a hipótese alternativa. Foi calculada a estatística do teste considerando a denominada distribuição $F$, com 2 parâmetros de graus de liberdade. No caso de rejeição de $H_{0}$, foi utilizado o método de Tukey para comparação entre pares de médias.

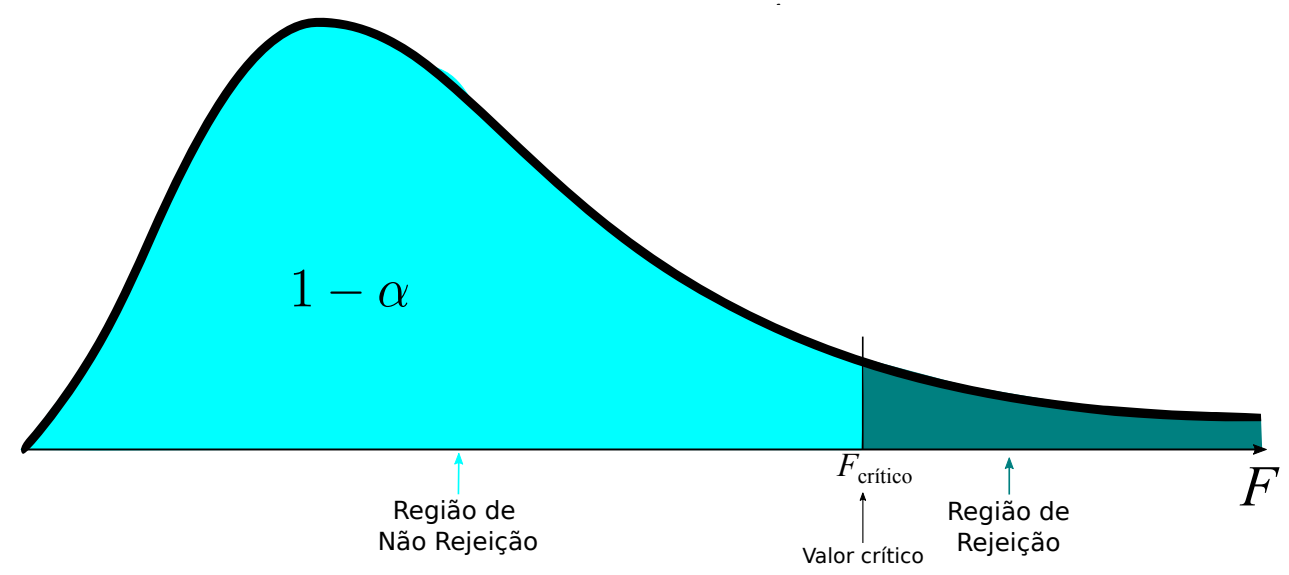

Figura A.2 - Exemplo de distribuição F. 